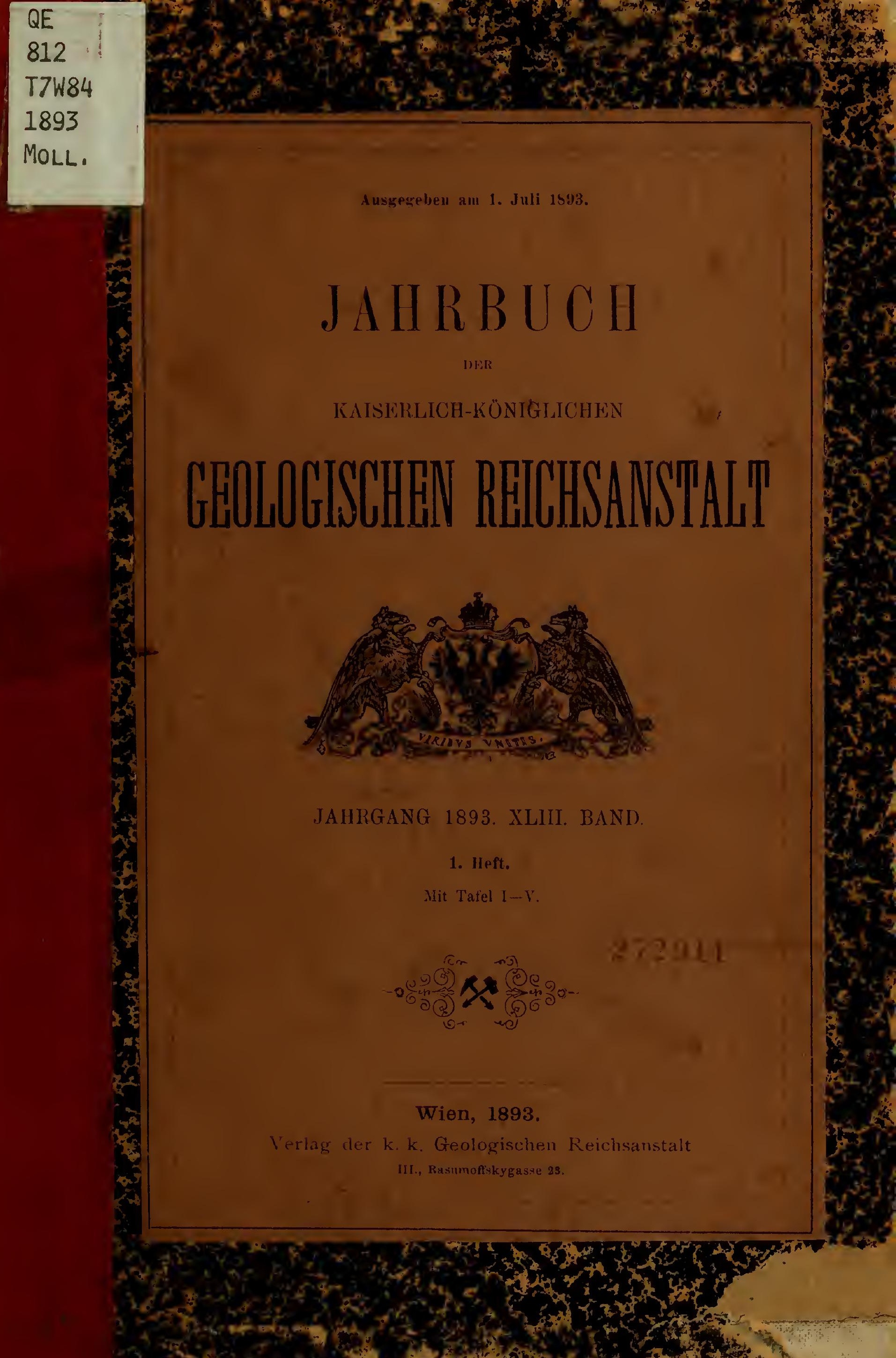




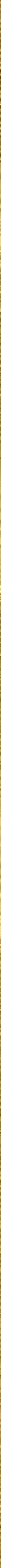








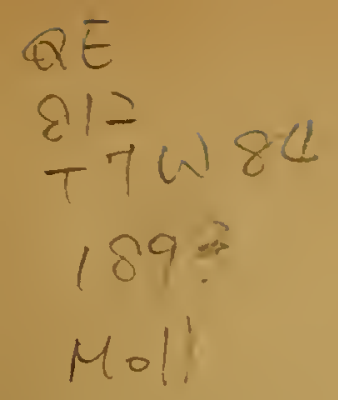

\title{
Ueber die systematische Stellung der Trigoniden und die Abstammung der Nayaden.
}

\author{
Ton S. Frh. v. Wöhrmann.
}

Mit 2 lithographirten Tafeln ( $\mathrm{Nr}$. I und II).

Das Verdienst, auf die grosse Bedeutung der Bivalvenschlösser für die Systematik anfmerksam gemacht zu haben, gebührt N e u m a y r, der 18831) auf Grund eingehender Untersuchungen die Bivalven im Gegensatz zu früheren Autoren nach ihren Schlossmerkmalen zu klassificiren suchte. Während alle übrigen Bivalven in das gegebene Schema untergebracht werden konnten, standen die Trigoniden mit ihrem eigenartigen Schlossbau vereinzelt da und wurden von Ne lm a y r nicht gerade von den Heterodonten getremnt, aber als Unterordmung aufgefasst. Steinmann hielt die von Neumayr angegebenen Unterschiede für so wichtig, dass er die Trigoniden zu einer Ordnung der "Schizodonten" erhob und sie hiermit gänzlich von den Heterodonten trennte. Diese nene Ordnung wurde vou Neumayr später ${ }^{2}$ ) angenommen und durch Hinzufuigung der Nayaden erweitert.

Erst vor Kurzem scheinen Bedenken gegen die Trennung der Trigoniden vou den Heterodonten anfgestiegen zu sein, clenn B it tu e $\mathrm{r}^{3}$ ) sucht bei Besprechung der Gattung Mactra den heterodonten Charakter des Trigonienschlosses nachzuweisen. Es dürrte daher nothwendig sein, die Trigoniden anf ihr Schloss hin zu prüifen.

Mlyophoria, Schizodus und Trigonia sind die ursprünglichen Vertreter der Familie gewesen; erst später sind einige andere Gattungen, Lyjrodesma, Remondin, Mecynodon ete., hinzugefügt worden, deren systematische Stellung zum Mindesten zweifelhaft ist. Es sollen deshalb nur diese ersten drei Gattungen hier berïcksichtigt werden.

1) Nenmayr: Zur Morphologie des Bivalvenschlosses, Sitzungsber. d. k. Akad. d. Wiss. 1883 , Bd. LXXXVIII, pag. 395.

2) Nenmayr: Ueber die Herkunft der Unioniden, Sitzungsber. d. k. Akad. d. Wiss. 1 s89, Bd. XCVIr, pag. 5.

3) Bittner: Verh. d. k. k. geol. Reichsanstalt 1892, pag. 234.

Jahrbuch d.k.k. geol. Reichsanstalt, 1993, 43. Band. 1. Heft. (S. Frh. v. Wöhrmann.) 1 


\section{Myophoria.}

Seit der Gründung dieser Gattming liat die Begrenznng derselben grosse Schwierigkeiten gemacht. Die verschiedensten Ansichten sind in dieser Frage geäussert worden. Dieselben sind meist so bekannt und so oft eingehend erörtert worden, dass es zu weit führen würde, wollte man nochmals die umfangreiche Literatur über dies Thema herbeiziehell.

Zwei Gegensätze machten sich hauptsächlich geltend, die anch in den letzten Jahren noch zum Ausdruck gekommen sind. Von einer Seite wollte man Myophoria auf die Trias beschränken, von der anderen wurde nachzuweisen gesucht, dass diese Gattung schon in älteren Ablagerungen vorkäme. Im Allgemeinen war man geneigt, die Trigoniden der Trias Myophoria, diejenigen der palaeozoischen Schichten Schizodus zu nemien, also den Gattungen geologische Grenzen zir geben. Erst vor Kurzem suchte Frechic ${ }^{1}$ ) einige Ordnung zu schaffen.

Wenu er auch mit Recht eine Anzahl devouischer Formen, deren Zugehörigkeit zu Myophoria unsicher war, oder die als Schizorlus beschrieben sind, zu der Gattung Myophoria hinzufügte, so machte er auf der anderen Seite den Fehler, mehrere Formen aus der alpinen Trias, die freilich Myophorien genamnt wurden, aber ein gänzlich abweichendes Schloss besitzen (Myophoria decussata, M. linente und M. Richthofeni), gleichfalls hierher zu rechnen und einige von ihnen sogar als Typen einzelner Gruppen zu benützen ( $M$. decussata, $M$. lineata). Dass diese Arten sich sehr weit von Myophoria entfernen und Vertreter besonderer Gattungen sind, wurde fast gleichzeitig nachgewiesen ${ }^{2}$ ).

Während Frech somit die Neigung verräth. die Gattungs-

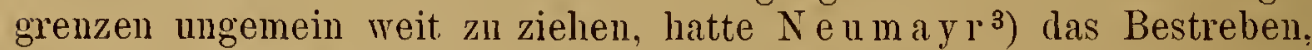
sie sehr eng zu fassen. Die devonischen Myophorien wurden von ihı, wegen ihrer meist ungetheilten Hauptzähne der linken Klappe und einer dadurch typisch-heterodonten Bezahnung, in eine neue Gattung "Kefersteinia" zusammengefasst. Feruer wurde Myophoria fissidentata aus den Raibler Schichten der Nordalpen, wegen der starken Theilung des gleichen Zahnes, dessen dadurch entstandene Kümme er für selbstständige Zähne hielt, ebenfalls von Myophoria getrennt und "Heminayas" genannt.

$\mathrm{Neumayr}$ ging bei seiner systematischen Gruppirung der Myophorien davon aus, dass sie, um zur Gattung zu gehören, einen getheilten Dreieckzahn haben und daher schizodont sein müssten.

Dies ist aber in der Regel nicht der Fall, vor allen Dingen ist das Schloss von Myophoria nicht im Neumay r'schen Sinne schizodont, soudern heterodont.

') Frech: Ueber Mecynodon und Nyophoria, Zeitschr. d. Deutsch. geol. Gesellsch. 1889, pag. 127.

2) จ. Wö h r m a n n: Jahrb. d. k. k. geol.Reichsanstalt, 1889, pag. 215, 221, 222.

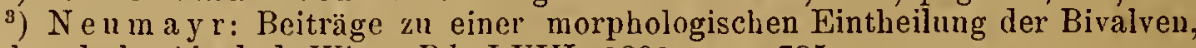
Denkschr. d. k. Akad. d. Wiss., Bd. LVIII, 1891, pag. 785. 
N e u m a y charakterisirt die schizodonte Bezalnumg in Gegensatz zur heterodonten (ladurch '), dass der $V$-förmige weit zerspaltene Mittelzahn der linken Klappe die Scharnirverbindung nach den Seiten limausdrängt und unter dem Wirbel der todte Winkel des V-Zahnes liegt. Dieser todte Winkel wird von $\mathrm{Neumayl}$ und Steinmann als Zalmgrube olne dazugehörigen Zalm aufgefasst und demgemäss in der Formel ausgedrückt.

Sehen wir uns das Schloss von Myophoric laevigate v. Alberti (Tab. I, Fig. 5, 6) darauthin an, so finden wir, dass der oberflächlich leicht getheilte Hauptzahn der linken Klappe so genau in die entsprechende Zahngrube des rechten hineinpasst, dass, gemäss der seichten Theilungsmulde auf demselben, eine leichte mediane Erhöhung sich auf dem Grunde der Zahngrube befindet. - Wir hätten also in der Zalngrube einen Zahn und zwei Zalmgruben, ebenso wie auf dem Zahn zwei Zähne und eine Zahugrube; also nach der Formel

$\frac{\text { L. } 101}{\text { R. } 010}$

Nun wird ja niemand das so auffassen. Ich liabe es nur angeführt, um zu zeigen. dass wenn man bei stärker hervortretender Spaltung die Kämme der Hauptzähne für selbstständige Zälne hält, wie Neumayr es bei Myoplorir fissidentreta gethan hat, man die entsprechenden Eindrücke in der Zahngrube ebenfalls als Zahngruben ansehen und demgemäss in der Formel ausdrücken muss.

Es ist zu verwundern, dass ein Forscher wie Neumayr von ler Ansicht ausgehen komnte, dass an einem Bivalvenschloss Zähne gebildet werden kömnten, ohne dass die mechanisch zur Einlenkung nothwendigen Zahngruben ebenfalls da wären. Es ist undenkbar und, wenn man genau genug beobachtet, bei keinem Bilvalvenschloss zu finden, dass ein zur mechanischen 'Thätigkeit gebildeter Theil ohne Funktion bliebe, was man bei einem Zahn olmé Zahngrube und einer Zahmgrube ohne Zahn doch amelımen müsste.

Tritt die Spaltung wie bei Srhizodus oder Trigonic auf die inner'e Seite des Zahms herüber, so verlässt sie die Einlenkungsfläche und kommt dann mechanisch nicht mehr in Betracht. Man kamn daher eine solche immere Theilung niemals als Zahugrube auffassen, weil dieselbe eben nur zur Stärkung des sich verbreitenden Zahnes und nicht zur Einlenkung dient. Von einem todten Winkel kann in Folge dessen nicht gesprochen werden.

Hiermit fällt der Hanptcharakter des schizodonten Schlosses in Ne umayr's Sinne weg und wir haben eine regelmässige Scharnierverbindung, die, wie wir es weiter unten in der Formel ausgedrückt findèn werden. von derjenigen "der Heterodonten nicht zu unterscheiden ist.

Wie ich vorhin angedeutet habe, ist die Theilung des Hauptzahus der linken Klappe bei den triadischen Myophorien, die doch

1) Neumayr: Zur Morphologie etc., 1. c. 1883, pag. 401. 
als Typen angenommen werden müssen, in der Intensität eine selı' verschiedene. Bei den meisten ist sie als sehr seichte Furche entwickelt, bei manchen schneidet sie tiefer ein. Dies ist aber nur individuell, denn bei fast allen Arten finden wir Uebergänge und Exemplare, die gar keine Furchıng auf der Gelenkfläche des Zahnes zeigen. Das Auftreten oder die Stärke der Furchung ist somit ebenso wenig systematisch $\mathrm{zu}$ verwerthen, wie die Kerbung der Zähne, auf die bis in die neueste Zeit, meines Erachtens, viel zu viel Gewicht gelegt worden ist. Frech macht einen Unterschied zwischen den Myophorien des Muschelkalkes, die nur ausnahmsiveise eine Kerbung aufweisen sollen und denen aus der oberen Trias, die bei genïgeuder Erhaltung ausnahmslos eine solche erkennen liessen. Ne u mayr war hingegen geneigt anzunehmen, dass die devonischen Arten ungestreifte, die triadischen vielleicht alle gestreifte Zähne hätten.

Thatsache ist, dass man bei den devonisclien Arten bisher noch nie eine Streifung beobachtet hat. Bei den triadischen tritt sie nur individuell auf und ist es eine interessante Erscheinung, dass sie bei einigen Formen mit altem Schlosstypus, wie $1 \%$. laevigate etc, nur selten bei anderen, z. B. M. Kefersteini, M. fissidentata trotz vorzüglicher Erhaltung der Schalen gar nicht zu finden ist, wälnrend solche von jüngerem Typus, wie $M$. Whateleycle, M. inflata. sie stets an allen Exemplaren zeigen.

Sobald ein solches Merkmal nur einzelnen Exemplaren eigen ist, kann dasselbe nur in letzter Linie beriicksichtigt werden, auf keinen Fall zur Trennung von Arten oder Gruppen benützt werden. Es ist noch zu bemerken, dass eine solche Kerbung nur bei Trigonia stets vorhanden ist und sonst einer nicht geringen Anzahl Bivalven zukommt, die wenig oder gar nichts mit den Trigoniden zu thum haben.

Ein besseres Kennzeichen ist die stark entwickelte Muskelleiste, die sith von der Schlossplatte um den vorderen Muskeleindruck herunterzieht. Doch lässt auch diese uns manchmal im Stich. Nicht allein, dass bei manchen dümnschaligen Exemplaren aus der Trias, z. B. von $M$. elongate und $M$. Whateleyue, diese Leiste sehr schwach entwickelt sein kamn, sondern sie ist besonders bei den meisten devonischen und permischen Formen kaum angedentet.

Ebenso wenig gute Merkmale geben, wie Frech gezeigt hat, die Einkrïmmung der Wirbel und die Entfermung der Muskeleindriìcke vom Schloss.

Es bliebe nur der Schlossapparat iibrig, der uns allerdings die sichersten Anhaltspunkte liefert, da er vom Devon bis in die Trias hinein sich kaum merklich verändert hat, allein sehr häufig', besonders bei den palaeozoischen Formen, nicht erhalten ist. Derselbe ist um so wichtiger, als man in den letzten Jahren gesehen hat, dass eine Reihe Bivalven, die man nach der Gestalt und Ornamentik der Schale für Myophorien gehalten lat und halten konnte, ihrem Schloss nach bei anderen Gattungen eingestellt werden mussten. Es ist daher olne Kenntuiss des Schlosses nicht möglich, mit Sicherheit ein Exemplar zu Myophroria zu stellen.

Da bisher auf das Schloss zu wenig Gewicht gelegt, ferner ein secundär auftretender Zahn nicht berücksichtigt worden ist, so lialte 
ich es für angebrachlit, die genaue Formel zu geben, wobei das S'hloss ron Myophoria lacviguta v. Alberti und ron Myophoria fissidentatu v. Wöh $\mathrm{rm}$. zur Grundlage genommen worden ist. (Tab. I, Fig. 1, 2, 5, 6.)

Sclloss der linken Klappe: Das Schloss besteht aus drei Zähnen. Der hintere (b) ist gewöhnlich lang und scharf vortretend, kam sich aber rerkürzen, stumpf werden oder fast ganz mit dem Hinterrand verschmelzen. Der Hauptzahn $(I)$ ist entweder stark, schwach oder gar nicht auf der Gelenkfläche getheilt. Er ist meist nach hinten gerichtet und entsendet einen schmalen leistenförmigen, je nach Umständen langen oder liurzen Fortsatz am Innenrande der Schlossplatte nach hinten, der immer in gradlinigen directen Zusammenhang mit jenem bleibt. Der Vorderzahn $(\alpha)$ ist gewöhnlich durch eine schmale Aufstülpung der Schlossplatte neben der Hauptzahngrube gebildet, kamn aber ebenso kräftig werden, wie der Hauptzahn. Vor demselben tritt zuweilen eine Zahngrube auf =

\section{L. $\left.10 \hat{1} 01(0)^{1}\right)$}

Schloss der rechten Klappe. Das Schloss besitzt in der Regel zwei Zälnne. Der hintere Zahn $\left(b^{\prime}\right)$ ist entweder lang und schmal, oder dick und kurz. Der Hauptzahn $\left(I^{\prime}\right)$ steht entweder senkrecht unter dem Wirbel oder ist nach voru gerichtet, nimmt aber immer unter dem Wirbel seinen Ursprung. Er ist an der Gelenkstlüche glatt oder getheilt. Ausser diesen beiden tritt anch zuweilen ein am Vorderrande gebildeter Vorderzahn $\left(a^{\prime}\right)$ auf, wie er bei Myoplioriu truncata Goldf sp. angedeutet ist und bei Myophoria (Schizodus) Salteri R. Ether'. und Myophoria fissidentata vorkommt. =

\section{R. $010 \hat{\overline{1}} 0(1)$}

Die Zähne beider Klappen können glatt oder gekerbt sein, doch wird keine von beiden Erscheinumgen zur Regel.

Aus der Formel geht dentlich hervor, dass wir es mit einer heterodonten Bezahnung zu thun haben. Nehmen wir die beiden Kämme des stark getheilten Hauptzahnes der linken Klappe vou Myophorin fissident ıt" mit $\mathrm{N}$ e u may fir selbstständige Zälne an, so mïssen wir, un genau zu sein, die allerdings weniger scharf hervortretenden Kämme der Hauptzähne der rechten Klappe mit in die Formel hinzuzieheu, ausserdem die diesen entsprechenden Zähnchen und Grübchen am Boden der Zahngruben mit in der Formel ausdrücken. Wir hätten demnach im Vergleich mit Ne uma y r's Formel,

1) Bei allen Formeln beniitze jch das Zeichen $\wedge$ um auszudrücken, dass der Zahn getheilt ist, das Zeichen - um den ungetheilten H a u $\mathrm{tzahn}$ in der Formel hervorzuheben und dadurch dieselbe ibersichtlicher zu gestalten. Die combinirten Zeichen deuten darauf hin, dass der Hauptzahn unassiv oder getheilt sein kanu. In Klammern gesetzte Zahlen bedenten ein nicht regelmässiges Auftreten der Zähne oder Zahngruben. 


$$
\frac{\text { L. } 1010101}{\text { R. } 0100010}
$$

folgende complicirte,

$$
\frac{\text { L. } 10[101][010] 101}{\text { R. } 01[010][101] 010}
$$

während sie einfach heissen muss:

$$
\frac{\text { L. } 10 \hat{\overline{1}} 0101}{\text { R. } 010 \hat{\overline{1}} 010}
$$

Im Hinblick auf die mechanische Bestimmung der Hauptzähne kann man deren Kämme, die stets nur secundäre Bildungen und bei derselben Art bald stärker, bald schwächer sind, sogar ganz fehlen ${ }^{1}$ ), niemals für selbstständige Zäbne ansehen. Wollte man das dennoch thun, so wïrde es, wie eben gezeigt wurde, nur die Formel compliciren und den heterodonten Charakter des Schlosses nicht beeinträchtigen. Wollten wir für $M$. fissidentata die complicirte Formel anwenden, so mïssten wir es logischerweise auch bei allen ïbrigen Myophorien thun.

Die Gattung "Heminajas"2), die uu auf den abweichenden Schlossbau begrüudet wurde, verliert demnach ihre Berechtigung und ist einzuziehen.

Ebensowenig ist die Gattung "Kefersteinia"3) anfrecht zu halten, da, wie erwähnt, der ungetheilte Hauptzahn kein charakteristisches Merkmal bietet. Wir hätten somit bei allen Myophorien eine heterodonte Bezahnung, deren kleine Unregelmässigkeiten in unserer Formel angegeben sind.

$$
\frac{\text { L. } 10 \hat{\overline{1}} 01(0)}{\text { R. } 010 \hat{\overline{1}} 0(1)}
$$

Dieselbe ermöglicht uns genaue natürliche Gattungsgrenzen zu ziehen und zugleich die Beziehungen zu verwandten Formen zu verfolgen.

Eine Gruppirung der Myoph srien nach Gestalt und Ornamentik der Schale wird immer eine recht theoretische bleiben, da wir nicht genau wissen kömmen, ob Formen, die derartig älnlich beschaffen sincl, auch wirklich in so nahem phylogenetischen Zusammenhang stehen, als es demmach den Anschein haben könnte.

$\left.{ }^{1}\right)$ v. Wöh r mann und Koken: Zeitsch. d. deutsch Geol. Gesellsch. 1892, Tal). IV, Fig. 1, 4, 5, 7 .

$\left.{ }^{2}\right)$ Ne umayer: 1892, 1. c. pag. 790

') Ebend, pag. 788. 
Zur Uebersicht dürfte es vielleicht ganz vortheilhaft sein, ähnliche Formen zusammenzustellen, und ich will kurz die Gruppen mit ihren Typen anführen, da in dieser Beziehmng Ste inmann ${ }^{1}$ ), Frech ${ }^{2}$ ) und $\mathrm{Ne} u$ m a $\mathrm{r}^{3}$ ) auseinandergehen.

Die Neumayl'sche Eintheilnng dürfte die natürlichste sein und soll sie hier bis anf Gruppe 5, die nach Einziehung der Gattung Hemingias wegfällt, beibehalten werden. Als Typen habe ich nur solche Arten gewählt, deren Schloss genau bekannt ist.

1. Laeves: Schale rundlich oder gestreckt oval. Kiel nur angedeutet, Oberfläche glatt, niemals berippt. Typus: Myophoria fissidentata r. IT ö l r m. (Raiblerschichten).

2. Corinatae: Schale rundlich dreieckig. Kriel scharf und deutlich. Oberfäche glatt; am Wirbel können Falten entstehen, die von diesen in unregelmässigen Abstïnden radial ausstrahlen, selten aber den unteren Rand erreichen. Typus: Myophoria laevigata v. Alberti (Muschelkalk), Myophoria Kefersteini Mï üster sp. (Raiblerschichten).

3. Flabllatae: Mit zahlreichen. zumeist stumpfen Radialrippen und dichten, oft scharf vortretenden concentrischen Anwachsstreifen verziert. Typus: Myophoria Whateleyae v. Buch. sp. (St. Cassian und Raiblerschichten).

4. Elegantes: Vorderseite ist bis zur Kielfurche mit concentrischen, stumpfen, regelmässig angeordneten Rippen bedeckt. Der Kiel tritt meist scharf hervor. Typus: Myophoria elegans Goldf. sp. (Muschelkalk und Lettenkohle.)

\section{Schizodus.}

Schizodus ist von Myophoria sehr schwer zu trennen. Die Zahnformel dürfte diesselbe sein wie die für Myophoria aufgestellte, doch ist bei den wenigen Exemplaren, deren Schloss bekannt ist und die sicher dieser Gattung angehören, nicht festzustellen, ob an der rechten Klappe ein Vorderzahn auftritt oder nicht. Der einzige Unterschied im Schloss dürfte nur der trigonienartig tief gespaltene Hauptzahn der linken Klappe sein.

Dass das Fehlen einer Muskelleiste, die grössere Entfernung der Muskel vom Schloss und der opistogyre Wirbel keine sicheren Merkmale sind, hat W a a g e ${ }^{4}$ ) gezeigt. Von den als Schizodus beschriebenen Formen gehören Schizorlus compressus, Sch. pinguis, deren Schlösser abgebildet wurden, sicher nicht zu Schizodus, sondern zu Myophoria, da bei ihnen die charakteristische Spaltung der Hauptzähne der linken Klappe fehlt, und sie somit gar nicht von Myoplioria unterschieden werden können. Es sind daher wahrscheinlich alle von $W$ a a g e aus dem indischen Perm beschriebenen Trigoniden zu Myophoria zu stellen. Auch sämmtliche von $\mathrm{Ha}^{5}{ }^{5}$ ) beschriebenen Formen aus dieser

1) Steinmann: Leitfaden für Palaeontologie, pag. 252.

$\left.{ }^{2}\right) \mathrm{Frech}:$ l. c. pag. 134 .

3) Neumayer: 1892, l. c. pag. 789.

4) IV a a e $n$ : Salt Range fossils, pag. 242.

5) Hall: Palaeontologie of New York, Vol. V. Lamellibranchiata II, pag. 447. 
Familie dürften obiger Gattung angelïren, doch können uns erst gut erhaltene Schlösser darüber aufklären. Eine genaue Untersuchung der verschiedenen Schizodusarten aus den palaeozoischen Schichten wird zweifellos den Erfolg haben. dass die grosse Mehrzahl derselben anderen Gattungen zugesellt werden muss. Dass die von Stoppani, Winkler und Anderen zu Schizodus gestellten Steinkerne aus dem Rhät auch nicht die geringsten Beziehungen zu dieser Gattung haben, braucht, glaube ich, nicht weiter nachgewiesen zu werden.

Es dürfte schliesslich darauf heraus kommen, dass die einzige Art, die sicher zu Schizodus gehört, Schizodus obscurus Sow. sp. aus dem Perm ist. Es ist daher sehr fraglich, ob die Gattung Schizodus unter diesen Umständen auf die Dauer aufrecht erlialten werden kamn.

\section{Trigonia.}

Unter allen Gattungen in der Familie der Trigoniden ist Trigonic in Bezug auf den Schlossapparat die beständigste. In der Ornamentik und Gestalt der Schale finden sich zuweilen Anklänge an Myoplioria, wie z. B. Trig. Lingonensis D $\mathrm{um}$. aus dem mittleren Lias und Trig. excentricu Sow. aus dem Grïnsand Englands, doch wird das Schloss niemals dardurch beeinflusst. Diese Beständigkeit zeigt, dass wir es mit einer entwicklungsgeschichtlich fertigen Gruppe zu thun haben, die sich au bestimnte äussere Berlingungen gewöhnt hat und nur dort auftritt, wo sie dieselben vorgefunden hat, während sich z. B. bei den Myophorien ein deutliches Anpassungsstreben erkemnber macht.

Bisher wareu keine älteren Trigonien als die aus dem Jura bekannt und man suchte in der oberen Trias nach Formen, welche sie mit Myophoria, von der sie sich voraussichtlicl abgezweigt haben. verbiuden sollten. Im Schlossbain weisen Myophoria Whateleyae v. Buch. sp. aus den Schichten von St. Cassian und Raibl und Myophoria inflata Em $\mathrm{mr}$ r. aus dem Rlıät die nächsten Bezielıugen auf, doch ist die Schalenormamentik bei beiden Formen eine so grundverschiedene von derjenigen der Trigonien, dass eine Abstammung letzterer von ihnen höchst unwahrscheinlich wird. Dies kann uns nicht Wunder nehmen, da Trigonia, wie wir gleich sehen werden, schon in viel älteren Schichten auftritt. Ly!riodon Gaytani, welche von Klipstein ${ }^{1}$ ) aus den Schichten von St. Cassian beschrieben, und von dem ein unpräparirtes Schloss der linken Klappe abgebildet wurde, ist, wie ich mich an einem Exemplar ans der Strassburger Sammlung, das ich durch die Liebenswürdigkeit 'von Professor B en ecke zur' Untersuchung erhielt, überzengen kounte, eine echte Trigonia, und zwar aus der Grupue der Costutue. Dies ist insofern von ungemeiner Wiclutigkeit, als wir dadurch sehen, dass sich Trigonic mit allen ihren Gattungsmerkmalen als ausgebildete form (allerdings seln selten) schon in Sedimenten. finclet, die anf den sogenamnten Muschelkalk der

1) Klipstein: Beitrige zur Geologie der östlichen Alpen, Giessen, 1843, pags. 262, Tah. XVI, Fig. $16 \mathrm{a} \mathrm{b} \mathrm{c.}$ 
Alpen abgesetzt worden sind. Dadurch wird es sehr wahrscheinlich, dass sie mit der fremdartigen Fauna. die wir dort zuerst begegnen, aus dem Südlen eingewandert ist. Wir müssten also, wemn wir Verbindungsglieder mit Myophoria finden wollen, dieselben im unteren Muschelkalke, Buntsandstein oder nsch älteren Ablagerungen in südlicher gelegenen Regionen suchen.

Wie Bittne r mit Recht nachgewiesen hat (Verh. d. k. k. geol. Reichsanstalt 1892, pag. 234), ist die Zahnformel, die Ne um a y und Steinm an n für Trigoniq angeben, falsch. Der Fehler liegt darin, dass beide Antoren die Höllung des gespaltenen Hauptzahms der linken Klappe für eine Zahngrube ansahen, die in diesem Falle morphologisch keine ist. Eine Zahngrube ohne entsprechenden Zahn kann eben in keinem Falle für eine solche angesehen werden. Bittı er zeigte durch die richtige Anwendung der Ste in mann'schen Formel

\section{L. $10 \hat{101}$ \\ R. 01010}

dlass Trigonia eine heterodonte Bezahmung hat.

Diese Formel ist auch nicht ganz genau, denn wir finden bei Trigonia pectinatı am Vorderrand der rechten Klappe einen schmalen wenig vortretenden Zahn (Tab. I, Fig. $4 a^{\prime}$ ), der bei den fossilen Arten meist nur angedeutet ist. Ihm entspricht in der linken Klappe eine ebenso schmale Zahngrube (Tab. I, Fig. 5). Wir müssen diesen Zahn berüclisichtigen. weil er bei Myophoria und Unio zuweilen ausgebildet ist und eine scwohl morphologische wie plyylogenetische Bedeutung hat. Die Formel wïrde also genau heissen

$$
\frac{\text { L. } 10 \hat{1} 01(0)}{\text { R. } 01010(1)}
$$

und dadurch mit derjenigen von Myophoria vollständig übereinstimmen.

\section{Nayadae.}

Die recenten Nayaden weisen einen solchen Formenreichthum auf und sind ihre Gattungen durch Uebergänge so eng mit einander verbunden, dass sich dem Systematiker bei einer Classification grosse Schwierigkeiten in den Weg legen. Nenerdings hat v. I he r'ing ${ }^{1}$ ), der im Gegensatz zu anderen Zoologen die Verwerthung der Identität des anatomischen Verhaltens zur Classification für ungeeignet lält, einen Versuch gemacht, die Gattungen der beiclen A d a m'schen Unterfamilien Trionidue und Mutelidue narh dem Verhalten der Larve und der Kiemen umzugruppiren. Zı ersterer Familie zählt er die Gattungen, welche sich aus einer Glochidiumlarve, zur zweiten diejenigen, die sich aus

') $\nabla$. Ihering: Separatabdruck des Zool. Anzeigers, Leipzig 1891-92, Nr. 380 und 381 . 
einer Lasidiumlarve entwickeln. Die Glochidiumlarve hat eine doppelklappige kalkige, die Lasidiumlarve eine chitinöse unpaare Schale: jene ist embryologisch die ältere, diese die jüngere Larvenform. Da nun Tnio eine Glochidiumlarve liat, Iridina, die mehrfach und auch von v. Il e ring für den ältesten Typus der Nayaden gehalten wird, aus der Lasidimmlarve entstehen soll (v. Thering folgert es nach Analogie ähnlicher in Südamerika auftretender Formen), ist es möglicl, dass aus dieser Erscheinung Schlüsse auf das Alter der beiden Gattungen gezogen werden könnten. Die Larve von Livlina ist, wie wir geselien haben, unbekannt. Sollte aber durch spätere Untersuchungen festgestellt werden, dass ihre Larve ein Lasidium wäre, so ist dadurch nicht viel gewonnen, denn $\mathrm{Ter}$ ed 0 , eine ausserordentlich rückgebil-

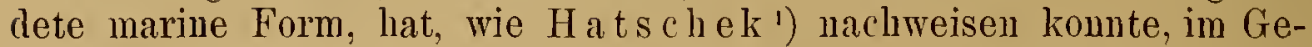
gensatz zu den übrigen Bivalven eine Larve, deren anfänglich ebenfalls nur unpaare chitinöse Schale sich erst in späteren Stadien zu einer zweiklappigen entwickelt.

Dieser Umstand wïrde eher dafür sprechen, dass man in den Muteliden v. I hering's rückgebildete Individuen zu sehen hätte. Ich glaube aber nicht, dass man auf derartige embryonale Entwicklungsstadien irgend welches Gewicht in Hinsicht anf die Altersfrage der Gattungen legen kam.

Auch wenn uns die Untersuchung des anatomischen Baues der Thiere oder das Studium ihrer embryonalen Entwicklung Auskunft ertheilen könnten, so wären die Ergebnisse von nur geringer Berleutung für die Lösung der Altersfrage, da von den fossilen Vertretern dieser Familie nu die 'Schalen bekannt sein kömen. Es kann daher nur das Schloss für uns in Betracht kommen, das sich allerdings nach den bisher gesammelten Frfahrungen zur Vergìeichung und Systematik am besten eignet.

Das Schloss der Nayaden ist Verändelungen ausgesetzt gewesen, wie wir sie in keiner anderen Familie der Bivalven antreffen. Wir finden bei ihmen alle Schlossformen vertreten, den taxodonten Typus (Iridina etc.), den heterodonten ${ }^{2}$ ) (Unio, Castalic etc.) und anodonten (Anorlonta etc.).

Da es nach den bisherigen Untersuchungen keinem Zweifel unterliegt, dass die zahnlosen Nayaden sich ans den bezahnten gebildet haben, so kommen sie als anerkannt modificirte und junge Formen bei unserer Frage nicht in Betracht.

Etwas anderes ist es bei den taxodonten und heterodonten Gattungen. Von ersteren wäre nur die recente Iridina zu berücksichtigen, da sie von den ihr ähnlichen Formen, wie Mutela exotica, Mutela dubia und Fossulı, das ausgebildetste Schloss und dadurch die auffallendsten Anklänge an die ältesten Bivalven mit taxodonter Bezahuung zeigt. Von den heterodonten Nayaden ist nur I'nio, welche

1) Hats chelk: Arbeiten des zool. Instituts in Wien, 1880, III., Heft I.

2) Dass das desmodonte Schloss anch als heterodontes betrachtet werden muss, hat Bittner bei Mactra nachgewiesen. (Verh. d. k. k. geol. Reichsanstalt 1892, pag. 232.) 
schon vom Jura an mit Sicherheit bekannt und somit anerkannt die geologiscll älteste Gattung ist, in Betracht zu ziehen.

N enma y $\mathrm{r}^{\prime}$ ) suchte zuerst das eigenthümliche Schloss von $l, i$ dina (I'leiodon) dadm'ch zu erklären. dass die schizodonten Zähne (d. h. nach Ne um ay r diejenigen Zïlne der Nayaden, die den gekerbten von Trigomic analog sind) sich verlängert und abgeflacht und ihre Kerbung anf der Schlossplatte zurïckgelassen hïtten. Er schliesst darans. dass das Schloss der Iridina nicht dem taxodonten Schloss der Nuculiden und Arciden homolog sei und bezeichnet es als pseudotaxodont.

v. I hering ${ }^{2}$ ) scheint von der Publikation Neumayr's keine Kenutniss gehabt zu haben, denn er behauptet, ohne derselben Erwillnnng zu thun, die Stammformen aller Unioniden und Muteliden müssten ein taxodontes Schloss besessen laben, weil z. B. Lividina ein solches aufweist. Er nahm im Gegensatz zu Nenmayr an, die Kerbung der Zähne von Ĺnio, Castalia etc. sei aus den Zahngruben des taxodonten Iridinenschlosses hervorgegangen.

Untersucht man das Schloss von Iridina genaner, so ist es nicht scluwer, den Beweis dafür zu funden, dass man es, wie $\mathrm{N}$ e u may annahm, mit einem obliterirten Schloss zu thun hat. Die fast senkrecht zum Rande gefurchte und ziemlich unregelmässig gezahnte massige Schlossplatte bildet nicht eine gleichmässige Ebene, sondern es ragen an derjenigen der linken Klappe bejderseits vom etwas rorderständigen Wirbel clentlich zwei stmmpfe Erbölnungen (Tab. II, Fig. 11, I,, ) hervor. zwischen denen sich eine zahngrubenartige Vertiefung befindet. Innen entsprechen an der rechten Klappe zwei Einsenkungcn, die einen stumpfen Höcker einschliessen. (Tab. II, Fig. 10, I'.)

Es kann, glanbe ich, nicht zweitelhaft sein, dass wir nach Analogie des Unionenschlosses die Rudimente der Haupt- und Vorderzälnue an der linken: des Hauptzahnes, des vorderen und hinteren Zahnes an del rechten Klappe, nebst den entsprechenden ehenfalls rückgebildeten Zahngruben hier vor uns haben. Es wäre, um anf die von The ringsche Erlklärmo zurückzukommen, viellei،ht möglich, in diesen von uns für Rudimente früherer Zähne erklürten gekerbten Erhöhmmgen der Schlossplatte im Entstehen begriffene Zühne zu erblicken; es widerspritche aber ein rlerartiges Vorgehen unseren morphologischen Erfalrungen, nachl welchen die Zähne des Heterodontenschlosses aus einzeluen Zïhnen des Taxodontenschlusses hervorgegangen sind.

Es frïgt sich mun, wie die taxodonte Bezahmung bei Iridina zu erklärell sei.

Nenm a y r nalmo. wie gesagt, an, dass dieselbe aus der übriggebliebenen Kerbung der 'obliterirten Zähne entstanden sei. Wäre er nicht so hartnïckig von einer directen Verwandtschaft zwischen Ti.igonir und Ínio ausgegangen und hätte er den Schlossapparat von Crio genauer untersucht, so hätte er gefunden, dass an demselben eine

1) Neuma yer: Ueber die Herkunft der Unioniden 1. c. pag. 15.

$\left.{ }^{2}\right)$ v. Ihering: l. c. pag. 13; Separatabdruck aus dem Nachrichtsblatt der deutschen malako-zool Gesellschaft 1892 Nr. 1 and 2. Zur Kenntniss der Gattung Cristaria, pag. ?. 
doppelte Kerbung auftritt. Dieselbe ist an besonders dickschaligen Arten, wie z. B. bei Unio gibbosus Barnes (Ohio) und Unio cuneatus B a rn es (Ohio), sehr deutlich zu sehen. Diejenige Kerbung, die fast bei allen bezahnten Nayaden an dem Haupt- und Vorderzahn der linken und am Hauptzahn der rechten Klappe auftritt, strahlt radial vom Wirbel aus und ist im subumbonalen Theil des Schlosses am schärfsten ausgeprägt. An den hinteren leistenförmigen Zähnen ist sie als schräg gegen die Richtung des Kammes lanfende Streifung zu erkennen. Diese ist bei den erwähnten dickschaligen Formen auch auf der Schlossplatte sehr deutlich vorhanden.

Im Gegensatz zu der ebenerwähnten primären lässt sich ebenfalls bei den dickschaligen Exemplaren an den hinteren Zähnen eine secundäre Kerbung beobachten. Dieselbe läuft voll der Basis senkrecht zum Kamm herauf, schneidet die primäre und überwiegt bei manchen Unioniden ganz.

Ich halte es für zweifellos, dass der taxodonte Charakter des Iridinenschlosses zum Theil aus dieser secundären Kerbung entstanden ist. Morphologisch ist es leicht zu erklären, dass die secundäre und nicht die primäre Kerbung am Hinterrande zur Zahnbildung geführt hat. Erstens musste die primäre bei einer Obliteration der hinteren Zähne zugleich mit diesen verschwinden, da sie die gleiche Richtung hatte, zweitens konnte dieselbe, auch wem sie auf diesem Theil der Schlossplatte stärker vorgetreten wäre, mmöglich zur Artikulation der Klappe verwendet werden, da sie einer Verschiebung der Schalen nicht den genügenden Widerstand entgegengesetzt hätte. Wir kennen thatsächlich unter den Bivalven mit taxodonter Bezahmung keinen einzigen Fall, in welchen bei einer gebogenen Schlossplatte die Zühne die gleiche Richtung mit derselben inne hätten. Nur bei geraden, d. h. quer zum Wirbel gerichteten Schlossplatten finden wir Längszähne, die gewöhnlich erst an den beiden Enden derselben typisch entwickelt sind. Diese secumdäre Kerbung am Hinterrand hat sich fraglos mit der primären im subumbonalen Theil vereinigt und das taxodonte Schloss hervorgebracht.

Interessant wäre es zu erfahren, welche äussere Bedingumgen diesen Atavismus herbeigeführt haben, und kömuten vielleicht genaue Beobachtungen der Lebensweise und Oertlichkeit uns einen Fingerzeig geben, vorausgesetzt, dass dieser Atavismus nicht früher ausgebildet und dam beibehalten wride. Jedenfalls gehört Tridinc zu den interessantesten Bivalven und wäre den Zoologen ein dankbares Untersuchungsobject.

Aus diesen Erörterungen geht hervor, dass Iridina, ebenso wie die anderen mit ähnlichen taxorlonten Schlössern versehenen Muteliden eine junge atavistische For'n ist und somit nicht als Urtypus der Nayaden betrachtet werden kann.

Dies Ergebniss stelit anch mit den geologischen Thatsachen im Einklang, da man bisher nie Nayaden mit taxodonter Bezahnung fossil mit Sicherheit nachgewiesen hat.

Es bleibt somit Unio als älteste Gattung der recenten Nayaden ïbrig.

Ans diesem Grunde und weil bei den übrigen heterodonten Formen die Bezalmung meist. sehr modificirt ist, wollen wir das 
Unionenschloss, und zwar das am regelmässigsten ausgebildete, vou Unio rectus La m. (T'ab. I, Fig. 7, 8), zur Aufstellung der Zahuformel und zur Erörterumg der verwandtschaftlichen Beziehung zu anderen Bivalyen unseren Betrachtungen zu Grunde legen.

Ias Schloss der linken Klappe besteht ans zwei hinteren leistenförmigen Zähmen $(b, c)$, einem zuweilen in der Mitte gespaltenen (Unis vertus Lam.) Hauptzahn ( $I$ ) und einem Vorderen Zahn ( $($ ) $=$

\section{L. $1010 \hat{\overline{1}} 01(0)$}

I)as del rechten aus einem langen leistenförmigen hinteren Zahn $\left(6^{\circ}\right)$, einem Mittelzaln (Tab. II, Fig. $8 c^{\prime}$ ), dem Hauptzahn ( $\left.I^{\prime}\right)$, anf dem zuweilen die ursprüngliche Spaltung erkeunbar ist, und einem vorderen Zahn $\left(\iota^{\prime}\right)=$

\section{R. $01010 \hat{\overline{1}} 0(1)$}

Aus der Formel ist ersichtlich, dass wir es bei Unio und somit bei den anderen Familiengliedern ebensowenig wie bei den Trigoniden mit einer "schizodonten" Bezahmmg zu thm laben, sonder"n dass dieselbe typisch heterodont ist.

Del vordere Zahn der rechten K'lappe und somit die entsprechende Zalmgrube auf der anderen sind, wie bei den Trigoniden, nicht bei allen Exemplaren oder Arten ausgebildet. Nur bei einer geringen Anzahl ist der Hauptzahn der linken Klappe am Kamm getheilt.

Die übrigen Merkmale der Unionen sind theils besprochen, theils so allgemein bekaunt, dass ich hier nur noch das Auftreten von Hilfsmuskeln und die starke Perlmutterschicht im Innern der Schale hervorheben möchte. Die Corrosion der Wirbel, auf die melufach Bezug genommen wird, hat, weil sie nur bei Bivalven anftritt, die im süssen oder brackischen Wasser leben, nicht die geringste systematische Bedeutung. Wir kömnen uun nach diesen nothwendigen einleitenden Erörterungen der Frage üher die Herkunft der Nayaden näher treten.

Fünf Gattungen ron Bivalven, „Cardinia, Anoplophora, Anthrarosiu. Trigonia und Trigonodus", mit welchen Unio in verwandtschaftliche Beziehungen gebracht worden ist und vou denen die meisten geradezu für Vorfalıren der Nayaden gelıalten worden sind, kommen hier in Betracht.

\section{Cardinia.}

Cardinice ist erst im unteren Lias mit Sicherheit nachgewiesen worden. Alles was ans geologischen älteren Ablagerungen als Cardinia bestimmt oder beschrieben wurde, ist zum Mindesten unsicher, da Schlösser schlecht oder gar nicht bekannt sind. Darin ist es Cardinia wie Schizodus ergangen. Alles, was kein Schloss hatte und in Steinkern oder Schale irgendwelche Aehnlichkeit aufweisen kounte, wurde ohne weiteres einer dieser Gattungen einverleibt. 
Das Schloss (ler Cardinien ist, wie auch Neu ma y $\mathrm{r}^{1}$ ) erkannte, rückgebildet. Durch rlas Hereintreten des Ligaments sind die subumbonalen, das heisst die mechanisch am meisten ins Gewicht fallenden Zähne rudimentär geworden.

Dass diese Rudimente einem verkümmerten Heterodontenschloss angehören und somit gegen eine Verwandtschaft mit den Unionen sprechen sollen, wie Neumayr meinte, wird durch den gelieferten Nachweis des lieterodonten Charakters des Uniouensclılosses hinfällig. Gegen eine Abstammung dürfte nur die Rückbildung des Schlosses sprechen, da es kaum anzunehmen ist, dass die Gattung Unio, die mit einem normal und fertig ausgebildeten Schlossapparat auftritt und geologisch vor Cardinia unbekamt ist, aus einer in dieser Weise morlificirten Gattung hervorgegangen wäre.

Es ist schwer zu sagen, mit welchen Formen Cardinia in Verbindung zu bringen wäre. Es ist möglich, ja sogar wahrscheinlich, dass sie sich von Trigonodus abgezweigt hatte, wofïr die am stärksten ausgebildeten hinteren Zähne, die Grestalt der Scliale und sonstige Nerkmale sprechen dürften, doch lässt sich dies mit Sicherheit nicht feststellen. Immerhin scheint es mir zweckmässig, sie vor der Hand neben Trigonodus zu stellen, eine Gattmo, zu der sie, wie gesagt, doch die meisten Bezielnungen hat und die, wie wir später sehen werden, mit den Nayaden vereinigt werden soll.

\section{Anoplophora.}

Aroplophora kann lier noch weniger in Betracht kommen. Die von mir untersuchten kleinen Formen, wie Anoploplor Miinstevi W i s s m. von St. Cassian. Heiligkreuz ete. und Anoplophorre recte Gü m b el sp. (letztere ist mit Schloss im Jahlb. der R.-A. 1889, Tab. IX., Fig. 7-9 abgebildet) aus den Raibler Schichten Nordtirols und Bayerns zeigen an gnten Exemplaren je einen langen schmalen Zahn am Hinterrand jeder Klappe und eine leichte Verdickung der Schlossplatte unter dem Wirbel, die bei der recliten Klappe am stärlksten entwickelt ist.

Bei g'ossen Formen, wie zum Beispiel (ler von $\mathrm{Stur}^{2}$ ) als Myoconcha grandis erwälnuten Aroplophora lettica Queust. aus den Rablerschichten ron Lunz, ron denen trefflich erhaltene Exemplare sich in der Reichsanstalt in Wien befinden, erkennt man die Schlossverhältnisse noch rleutlicher. Besonders stark, natürlich im Verhältnisse zu' Grösse der Schale, sind bei rlenselben die subumbonalen Zähne entwickelt. An der linken Krlappe befindet sich ein breiter, dicker, vom Rande der Schlossplatte gebildeter, an der rechten ein unterhalb derselben vorspringender löffelförmiger Zahı, der den ersten nach unten umfasst. Es ist ein Schloss, das zu unregelmässig ist, ım in einer Formel ansgedrückt zu werden. Da die vorderen Muskeleindrücke sehr hoch herauf und nach vor's in die Spitze der Schale

i) Neumayr: Ueber die Herkunft etc. 1. c. pay. 23.

2) Stur: Geologie der Steiermark 1871, pag. 248. 
hereingerïrlit. ansserden tief eingesenkt und durch eine kräftige Muskelleiste gestiitzt sind, so ist die Aelnlichkeit mit Myoconcha allerdings eine sehr grosse. Man kam duophophor aber in Anbetracht der Gestalt und wegen der bei grossen Formen stark rortretenden Zähne nicht mit Myoconchr verwechseln. Immerhin sind die Bezielnumen zwischen Myoconcha und Aroplophora, gleiches Schloss (bei ersterer ein subumbonaler Zahn, aber nie so kräftig wie bei dieser). gleiche Muskeleindrüclie, so innige, dass gar nicht daran zu zweifeln ist, dass beide in eine Familic gehören. Anoplophor wäre demgemäss ron den Cardiniiden zu tremen und zu den Prasiniden zu stellen.

\section{Anthracosia.}

Erst kürzlich ist eine Monographie über die "Antlıracosien" aus dem Perm liusslands von Amalizky') erschienen. Diese Arbeit ist insofern wichtig, als der Verfasser nachzuweisen sucht, dass die ron ihm behandelte Grupe in naher verwandtschaftlicher Beziehung zu den Nayaden stände und als deren Vorläufer anzusehen wäre. Schon frïher hat Amalizky ${ }^{2}$ ) anf Grund seiner Untersuchungen der in Rede stehenden Biralven sich veranlasst gesehen, gegen die ron Neumayr vertretenen Abstammung der Nayaden von Trigonia Stellung zu nelimen.

Amalizky's neue Familie der "Anthracosidae" umfasst eine Reihe ron Formen, deren Schlösser für heterodont, taxodont und zahnlos gehalten werden. Zn den taxodonten stellt er die nenen Gattungen Palaeomutela und Oligodon; zu den heterodonten solche Formen. welche er für Anthracosia und C'arbonicola hielt; zu den Zahnlosen bei Najarlites D aws o u untergebrachte Bivalven. Die Zahulosen sollen sich sowohl aus den Taxodonten wie ans den Heterodonten entwickelt haben. Nach A malizky wäre also hier eine analoge Formenreihe wie bei den Nayaden zur Entwicklung gekommen. Dies ist mit der Hauptgrund, weshalb Amalizky seine "Anthracosien" für die Vorfahren der Unioniden erklärt.

Dass eine solche Formenreihe im angegebenen Unfange nicht vorhanden ist, sondern vom Verfasser bis zu einem gewissen Grade kiumstlich geschaffen wurde. fermer die beschriebenen Bivalven keine Anthracosien sind und auch nicht die geringsten Beziehungen zu den Nayaden aufweisen kömmen, soll in den folgenden Zeilen gezeigt werden.

Wie Amalizky selbst hervorhebt und es aus den Albbildungen hervorgeht, sind die einzelnen Gattungen durch Uebergänge eng miteinander verbunden. Alle Exemplare, die abgebildet wurden, zeigen eine so gleiche oder analoge Gestalt und Ornamentik der Schale, so dass, hätte man ausschliesslich nach derselben zu be-

1) Amalizky: Ueber die Anthracosien der Permformation Russlands. Palaeontographica 1892. Bd. XXXIX.

2) Amalizky: 'Zur Frage der Abstammung der Uninnilen. Sitzungsber. d. biol. Abth. d. Waischamer naturhistorisch. Gesellsch. 17. Jän. 1891. 
stimmen, nur wenige Arten-aus dem ganzen Material ausgeschieden werden könnten.

Die meistens gut erhaltenen Schlossapparate haben A malizky verleitet, eine grosse Anzahl Arten und sogar mehrere Gattungen anfzustellen. Eine Gattung (Palaeopleiodon), die el früher (l. c. 91) publicirte, scheint wieder zurückgezogen worden zu sein, da sie in der erwälnten Monographie nicht genamnt ist.

Wie bereits angeführt, unterscheidet $\mathrm{A}$ in a $\mathrm{l}$ i z $\mathrm{k}$ y drei verschiedene Bezahnungsformen.

Von denselben ist der heterodonte Typus der anffallendste. Betrachtet man die Schlosspräparate derjenigen Exemplare, die zu Anthracosia und Carbonicola gestellt wurden, so ist auf den ersten Blick ersichtlich, dass von einer heterodonten Bezahmmng im $\mathrm{Ne} \mathrm{u}$ may r'schen Sinne nicht die Rede sein kann. Die Zähne sind ganz unregelmässig ausgebildet und lassen nur eine zum Schlossrande senkrechte Richtung erkennen, wälrend bei den Heterodonten die Zähne radial am Wirbel angeordnet sind. Ferner sind sie auf der ganz unregelnässigen Schlossplatte ohne irgend eine sonst erkemubare Ordnung anfgesetzt. Gewöhnlich treten einer oder mehrere ron diesen Zähnen aus rein mechanischen Gründen im subumbonalen Theil stärker hervor, als die übrigen, es würde aber keinem objectiven Beobachter einfallen, dieselben für die regelmässig gestellten mul gestalteten Cardinalzähne der Heterodonten anzusprechen.

Unter den Taxodonten zeigt Palaeomutela das regelmässigste Schloss. Dasselbe errinnert auffallend an ein Nuculidenschloss, mit dem Unterschiede, dass auf der unter dem Wirbel verengerten Schlossplatte sich keine Ligainentgrube vorfindet und die Zähnchen nicht allein öfters eine willkürliche Richtung einschlagen, sondern auch mehrfach getheilt sind. Bei Oligodon ist die Schlossplatte unter und hinter. dem Wirbel zusammengezogen, breit, aber kurz, die Zähne daher stärker ausgebildet als bei der vorigen Gattung.

Von den "Nayaditen" kann abgesehen werden, da sie keinerlei Schlossmerkmale besitzen.

Palaeomutela, die, wie wir gesehen haben und auch aus den Abbildumgen ersichtlich ist, das regelmässigste und somit nornalste Schloss besitzt, ist im Gegensatze zu Amalizky's Auffassung als Grundform zu betrachten.

Sehen wir uns von dem Gesichtspunlite die Abbildungen auf den Tafeln all, so finden wir, dass das Tab. XXI, Fig. 3 gezeichnete Schloss von Palacomutela subovalis Amal. ein fast rein taxodontes Schloss besitzt, während dasselbe der gleichen Art, Fig. 4 und 5, ganz unregelmässig ist. Bei Pal. irvegularis, Fig. 26, ist der Schlossrand unter dem Wirbel schon sehr stark erweitert mnd die Bezahnmmg kräftiger geworlen. Oligodon Kingi var. tuberculodentata A m a l. (Tab. XXII, Fig. 21 ") hat noch kräftigere Zälne, ist aber genau genommen von Pulceomutela nicht zn trennen. Bei den übrigen Exemplaren von Oligodon zieht sich die Schlossplatte immer mehr unter dem Wirbel zusammen, einzelne Zihne treten stärker hervor, bis schliesslich ein Schlossapparat entsteht, der bei Anthrecosic Venjuliorri A mal. (Tab. XXII, Fig. 1, 2) und Anthracosia Löwinsoni A mal. (Tab. XX, Fig, 7) zn sehen ist. Die Schlösser von 
Carbonicola Toiliziuna d e Ry kholt (Tab. XIX, Fig. 91) und Carbonicoln substeyncephalum A mal. (eliend. Fig. 14') sind schon, nach der Zeichnumg zu urtheilen, schlecht crhalten und trotzdem sehr verschieden, während dasjenige von C'arbonicola suboulis Amal. Fig. 7" den Charakter von Palaeomutela, in der Vergrösserung $7^{\circ}$ aber einen Theil seiner Zälnne verloren liat.

Wemn man sieht, dass die Schlösser von Anthracosia Lömiusomi (Tab. XX, Fig. 7) und Anthr. Verijuhowi (Tab. XXII, Fig. 1, 2), die ja viel grössere Unterschiede aufweisen, als die Schlösser der einzelnen Gattungen untereinander, zu einer Art gezïllt werden, so liommt man zu der Einsicht, dass die Classificirung, die Amalizky vorgenommen hat, eine ganz künstliche sein muss.

Wie bereits elwähnt wurde, ist die Gestalt und Omamentik der Schale in meisten Fällen eine so übereinstimmende, dass, nach ihr zu urtheilen, nur einzelne der abgebildeten Formen als selbstständige Arten gelten können. Bei Untersuc' ung des Schlosses kommen wir zu dem analogen Resultat, dass nämlich dasselbe bei den einzelnen Exemplaren, mögen sie nach $A$ m alizky verschiedenen Gattungen oder Arten angehören, gleich abweichend sein kann und daher ebenso wenig für die Richtigkeit seiner umfangreichen Gliederung sprechen würde. Auffallender Weise ist Amalizky bei seinen Palaeomutelen nicht auf die eigenthümlich nuculaähnliche Beschaffenheit des Schlosses aufmerksam geworden, obgleich T s c h e ru it $z$ s ch e w eine hierhergehörige Form aus dem Perm von Kostroma als Macrodon Kingianum beschrieben und abgebildet hat und Krotow ${ }^{2}$ ), wie Amalizky selbst pag. 141 erwähnt, 1888 einige permische Exemplare vom Ural mit Vorbehalt zu Palueoneilo gestellt hatte.

Krotow hatte vollkommen Recht, als er die permischen sogenamnten Anthracosien vom Ural zu der Hall'schen Gattung Palaeoneilo aus dem Devon und Carbon Nordamerikas stellte. Bei Untersuchung der von Amalizky dem Münchener Museum geschenkten Stücke fiel mir sofort die ungemein grosse Aehnlichkeit derselben mit Palcreoneilo auf. Besonders an dem Schloss eines Exemplars von Pulacomutela, das sich anf einem Gesteinsstück mit Nayadites Oliensis $\mathrm{A} \mathrm{m}$ a l. (von ilm selbst bestimmt) zusammen vorfand, waren die Zähne so regelmässig gruppirt, dass ein Vergleich mit der amerikanischen Gattung nicht ron der Hand zu weisen war. Der einzige Unterschied ist die durchgängig legelmässige Ausbildung und Stellung der Zähne und der Schlossplatte bei letzterer, da sowohl Gestalt und Ormamentik der Schale in den Grundzügen übereinstimmen und ganz gleiche, kettenförmig aneinander gereihte, in leichtem Bogen vom vorderen Muskeleindruck $z \mathrm{um}$ Wirbel hinziehende Hilfsmuskeleindrücke auftreten. (A m alizky l. c. Tab. XXI, Fig. 38, 46, 48.)

1) Tschern itzs ch ew : Der permische Kalkstein im Gouvernement Kostroma Verh. d. k. k. min. Gesellsch. 1884. Separat. 1885, pag. 15, Tab. XV, Fig. 7.

$\left.{ }^{2}\right)$ Ich kann die Publikation von Krotow nicht anführen, weil Amalizky keine Literaturnotizen über die neueren russischen Publikationen angibt, sondern sich nur mit Namennennung begniigt, und es mir in der kurzen Zeit unmöglich war, sie zu verschaffen.

Jahrbuch d.k.k. geol. Reichsanstalt, 1893, 43. Band. 1. Heft. (S. Frh. v. Wöhrmann.) 3 
I)ie Gattung Paluconeilo tritt schon im Untersilur Böhmens anf, denn B a r' r a n d e beschreibt ') einen Palaeoneilo Hectens, aus Et. I). Es dürften aber die Nehrzahl der Tab. 270-273 als Nucule und Leda abgebildeten Formen auch zu Palaroneilo gehören. In Nordamerika geht sie von Mitteldevon bis ins Carbon hinauf. In Europa erscheint sie im Devon Frankreichs. Im Kolılenkalk Belgiens ist sie ron de Ko-

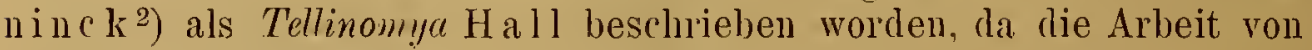
$\mathrm{Hall,}$, in der Palceonilo abgebildet worden ist, in selben Jahr erschien und diesem Autor noch nicht zugïnglich sein konnte.

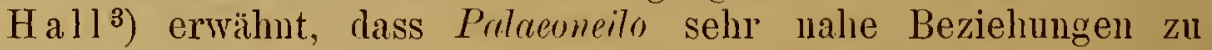
Tellinomya hätte und dass heide sich bei genauer Untersuchung als "congeneric" erweisen dürften. Jerlenfalls kam beim Vergleich der von de Kon inck (Tab. XXVI, Fig. 25-29) abgebildeten Tellinomyra. mit Hall's Abbildungen von Palceoneilo kein Zweifel sein, dass die Originalexemplare einer Gattmig angehören. Interessant ist es, dass bei den geologisch jüngsten Formen ans dem Kollenkalk Belgiens, wie z. B. bei Palreoneilo sinurtus de Rykholt die Zähne bereits nicht mehr so fein und gleichmässig sind, wie bei den amerikanischen aus dem Devon und sich am Vorderrand eine stärkere und unregelmässigere Bezalmung ansbildet. Dies ist eine Frscheinung, die 7.u A malizky's "Palaeomutela" hinleitet.

Um diesen Uebergang vom regelmässigen taxodonten Schloss zum unregelmässigen zll veranschaulichen, habe ich die Schlösser des devonischen und carbonischen Palaeoneilo und der permischen Palaeomutela neben einander abbilden lassen. (Tab. II, Fig. $3,4,5$.) Die Zusammengehörigkeit derselben ist daraus klar ersichtlich. Natürlich weist Palconutela als Brackwasserform das diffenzirteste Schloss auf. Palneomutela, hat, abgesehen vom abgebildeten, ein so variables Schloss mo eine so ständig mregelmässige Bezahnung, dass wir sie, glaube ich, als eigene Gattung betrachten kömmen. Palaemmutelı wäre demnach ein Palaeoreilo mit unregehnässiger Bezahmmg. Wir haben num bei Besprechung der Amalizky'schen Gattungen und Arten gesehen, wie verschieden die Schlösser der einzelnen Exemplare sein können, und eine contimuiliche Reihe von den regelmässigsten zu den mregelmässigsten Schlossapparaten festgestellt. Da eine Trennung in verschiedene Gattungen bei sonst ganz gleich bleibendem äusseren und immeren Charakter nur eine ganz kïnstliche sein könnte, Pclceomutela die normalste Form ist, so wäre es zweckmässig, diesen Namen für alle übrigen Formen, mit Ausnahıne derjenigen, die ein zahnloses Schloss besitzen und $z, 1$ rayalites gestellt worden sind, beizubehalten, die übrigen theils einzuriehen, theils auszumerzen.

Eine genaue Untersuchung der Original-Exemplare kömte allein über die Berechtigung und Begrenzmog dor einzehnen Amalizkyschen Arten entscheiden.

1) Barrande: System Silurien du centre de la Bohême 1881, part. I, Vol. VI, Tab, 272, IV, F'ig. 1-8. Text I, pag 127.

2) de Koniuck: Fanne du calcaire carbonifèrc de la Belgique, Tome XI. 1885, pag. 138.

s) H a 1l: geological Survey of the State of New-Iork, Palaeontologie Vol. V, part I. Lamellibranchiata II. pag. XXVII, pag. 333-349, 1885. 
Wir liatten hier eine Gruppe taxodonter Bivalven, die ursprünglich das Meer bewohnten (Silur, Devon, Kohlenkalk), dann aber in brackische Gewässer einwanderten (Perm). Durch diese veränderte Lebensweise ist das Schloss ganz analog dem der Nayaden umgebildet worden. Wie wir es weiter mnten nochmals bestïtigt finden werden, macht sich der Unterschied zwischen dem Aufenthalt im Meer und in brackischen Gewässern am Schloss rer Bivalven dahin geltend, dass die ursprïngliche Regelmässigkeit im Bau der Zähne verloren geht und ganz abnorme Bildungen Platz greifen kömmen. Unter gewissen Bedingungen geht das Schloss ganz verloren und es stellen sich zahmlose Formen ein. Daher wäre es möglich, dass sich die zngleich mit den Palaeomutelen auftretenden zalmlosen Muscheln aus jenen rückgebildet hätten. Da Palaconeilo und Paleomutelı nebst der zahnlosen For'm, für die wir den Namen Nayadites für's erste beibehalten wollen, trotzdem eine nene Bezeichnnng vielleicht richtiger wäre, un ihre Herkunft zu betonen, ausserdem CtenoIontu, Tellinomya, Nuculites, eine durch charakteristische Merkmale abgegrenzte Gruppe sind, so wäre es angezeigt, sie in eine besondere Familie der "Ctenodontiden“ zu stellen und diese als Unterfamilie der Arciden zu betrachten. Diese Familie wäre durch das äusserliche Ligament, das Fehlen einer Ligamentarea und Grube und bis anf die zahnlosen Formen. falls diese hierher gehören, durch ein Schloss gekemnzeichnet, clas mit einer ununterbrochenen Reihe regelmässiger oder corrumpirter Zähnchen besetrt ist.

Aus der systematischen Stellung der l'alaeomutelen gelıt liervor, rass sie in keinerlei verwandtschaftliche Beziehungen zu den Nayaden gebracht werden können.

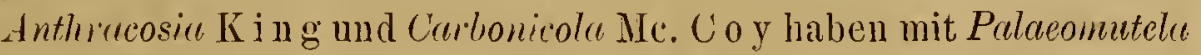
nichts zu thum. Es ist zu verwundern, dass A malizky die grosse Verschiedenheit im Schlossbau nicht erkannt hat, trotzdem dieselbe bei seinen Abbildungen anf Tafel XXXIII doch klar zum Ausdruck gekommen ist.

Bei Anthracosic. King befindet sich auf beiden Klappen unter und etwas ror dem Wirbel ein löffelförmig nach innen vorspringender Zaln. vou dem der vordere flache Theil zur Autuahme des Ligaments bestimmt und zur Befestigung desselben mit seichten Furchen verselien ist. Diese Furchen finden sich fast überall, wo der vordere Theil des Ligaments auf die Schlossplatte hineintritt, und können daher die zwischen diesen Furchen befindlichen Erhöhungen in keinem Fall für Zälne angesehen werden.

Die Schlösser von C'abonicola M c. Coy sind durchgängig fragmentarisch und äusserst mangelhaft erhalten. Beide Arten bedürfen noch einer genaneren Untersuchung. Ihre systematische Stellung bleibt bis dahin eine hörhst zweifelhafte. Mit den Unioniden dürften sie wohl kaum in Beziehung gebracht werden kömuen.

\section{Trigonia.}

In den bereits früher (itirten Arbeiten von 1889 and 1891 suchte Neumayr die Abstammung der Nayaden von Trigorio zu beweisen, 
und ging dabei von der Auffassung aus, dass Tirigoniu sowohl, wie die Mehrzahl der mit bezahnten Schlossapparaten versehenen Nayaden kein heterodontes, sondern ein schizodontes Schloss besässen. Wie nachgewiesen wurde, ist diese Anuahme eine irrige, denn sowohl die einen wie die auderen sind heterodont. Es wurde gleichfalls festgestellt, dass die Zahnformel für Trigoniu:

und fuir Unio:

$$
\frac{\text { L. } 10 \hat{101(0)}}{\text { R. } 01010(1)}
$$

lantet.

$$
\frac{\text { L. } 1010 \hat{\overline{1}} 01(0)}{\text { R. } 01010 \hat{\overline{1}} 0(1)}
$$

Aus dem Vergleich beider Formeln ist ersichtlich, dass bei Unio auf dem hinteren Theil der linken Schlossplatte ein Zahn mehr vorhanden ist, als bei Triyonia und somit beide Schlösser nicht in directen Beziehungen zu einander gebracht werden kömmen. Dieser überzählige hintere Zahm ist, wie gleich bei Besprechumg der Gattung Trigonodus gezeigt werden soll, aus dem hinteren leisteuförmigen Fortsatz des Hauptzahnes bei Myophoria entstanden, daher also nicht dem hinteren, bei der Theilung des Hauptzahnes gebildeten Kamm desselben, den Neumayr als besonderen Zahn aufgefasst liat, homolog. Der vou Ne um ayr auf Tab. I, II und III mit $a^{\prime}$ bezeichnete Hauptzahu der linken Klappe von Unio und Castalia entspricht also nicht der vorderen Lamelle des gleichen Zahns bei Trigonia pectinutu (Tab. I, Fig. 2, $a^{\prime}$ ), sondern beiden Kämmen (Fig. 2, $a^{*}, b^{\circ}$ ), die Theile eines einzigen Zahnes sind. Dass die Spaltung des Trigonienzahnes auch bei dem analogen Zaln von Unio zuweilen angedentet vorkommt, sehen wir an dem (Tab. I, Fig. 7, I) abgebildetel Exemplar von Lnio rectus L a m. Durch den Nachweis, dass der Spaltzahn von Trigonia nicht aus zwei Zähnen besteht, sonderu morphologisch nur einen Zahn darstellt, werden alle Schlüsse, die Ne um a yr in Bezug auf die Abstammung der Nayaden von den Trigonien aus der angenommenen Gleichreit der Schlösser gezogen hat, hinfällig. Man braucht nur die (l. c. Tab. I, Fig. 1, 2, 3, 4) abgebildeteu Schlösser vou Trigonia pectinata und Castalia cordata anzusehen, un das Gezwungene eines solchen Vergleiches zu erkennen.

Verwandtschaftliche Beziehungen siud sicherlich bei Unio und Trigonir vorhanden, sie siud sogar durch den Nachweis des heterodonten Charakters beider Schlösser viel iuniger, als $\mathrm{N}$ e u m a y nach seiner Theorie annehmen konnte. Denmoch reichen sie nicht aus, um eine directe Abstammung nachweisen zn könneı.

Abgesehen davon, ist es zum Mindesten höchst unwahrscheinlich, dass eine bereits in den Schichten von St. Cassian morplologisch fertige Gattung, die bis in die Jetztzeit hinein keine nemnenswerthen Schwankungen im Schlossapuarat zeigt, die Vorfahren der viel jümgeren Nayaden liefern konnte. 


\section{Trigonodus.}

Die Gattmug Trigonodus wurde von Sand be roge r anf Steinkerne aus dem Lettenkohlendolomit aufgestellt und ron Albertic zuerst beschrieben und abgebildet. Obgleich Sand berge bei der Untersuchung des Schlosses nur anf ungenügende Abdrücke von Steinkemen angewiesen war, hol er in seiner kurzen Gattungs-I)iagnose die Analogien mit dem Unionenschlosse hervor. Schon an den Abdrücken von Trigonoulus Sandbergeri v. Alb. war zu erkemmen, dass der leistenförmige Fortsatz des Hauptzahnes der linken Klappe bei den Myophorien, hier durch eine schmale seichte Zahngrube, von letzterem losgelöst und folglich als selbstständiger Zahn ausgebildet ist. Dieser und der hinterste Leistenzahn treten viel stärker hervor, als es bei Myophoric der -Fall ist. Ebenso ist der Hauptzahn der rechten Klappe vor den Wirbel gerückt und wie bei L'nio geformt, der hinterste Zahm auffallend lang und leistenförmig.

Bis ror Kurzem war die Kemntmiss dieser Gattumg nur auf Steinkerne aus der ausseralpinen Trias beschränkt.

1889 beschrieb Parona ${ }^{2}$ ) zwei Arten Tr. Balsamoi und Tr. Seriams ans den Raibler Schichten der Lombardei und bildet ihre Sclılösser ab. Ti: Balsamoi ist, wie bereits nachgewiesen wurde ${ }^{3}$ ), kein Trigonochus, sondern Myoplioria fissidentata v. Wöhrm. : dagegen scheint Tr. Seriamus, von dem allerdings nur das Schloss der rechten Klappe bekannt ist, zu Trigonorlus gerechnet werlen zu können. Das später von Tom mas aus gleichen Schichten des Friaul abgebildete linke Schloss einer Bivalve, die er zu Tr. Sandbergeri ${ }^{4}$ ) stellt, hat sich als zu Tr. rablensis Gredler (v. Wöhrm. etc l. c. pag. 185) zugehörig erwiesen.

Erst aus den Raibler Schichten des Schlossplateaus konnten gint erhaltene Exemplare von Trigonodus beschrieben und abgebildet werden $^{5}$ ). Sie gehören drei Arten $T r$ rablensis Gredler sp., $T$. costatus v. Wöh $\mathrm{r}$ m. und $T r$. minutus v. Wöh r m. an und liefern genügendes Material, um die Sandberge r'sche Definition der Gattung zu vervollständigen. Da in der oben citirten Morographie die Schlösser der drei Arten eingehend besprochen wurden, so will ich mich hier darauf beschränken, die Bezahnung in der Stein mann'schen Formel zusammen zu fassen.

Die Gattung Trigorolus ist folgendermassen zu charakterisiren:

Schale gleichklappig, länglich oval oder rundlich trapeziodal, gewölbt oder flach, vorn meist abgestutzt, nach hinten gewölnnlich

Fig. 10 .

1) v Alberti: Ueberblick über die Trias Stnttgart 1864, pag. 126, Tab. 1I,

3) Parona: Studio monographico della Fauna raibliana di Lombardia 1889, Pavia pag. 124, 125, Tab. IX, Fig. 11-17. pag. 182.

3) v. Wöhrmann und Koken: Zeitschr. d. d. geol. Gesellsch. 1892,

4) Tommasi: Rivista della Fanua raibliana del Friuli Udine 1890, pag. 47, Tab. IV., Fig. 1, 2.

5) v. Wöhlimann und Koken: l. c., pag. 184-287, Tab. VI, Fig. 1-12, Tab. VIII, Fig. 5-7. 
stark ausgezogen. Wirbel vorderständig, prosogyr. nicht stark oder kaum vorspringend. Schalenoberflä"he glatt oder mit concentrischen scharfen Rippen bederkt. Ein diagonaler Kiel vorhanden, nur angedentet oder ganz fehlend. Muskeleindrücke gewöhnlich tief eingesenkt, der vordere durch eine Leiste gestützt, doch ist diese viel schwächer ausgeprägt, wie bei den Trigoniden. und kann zuweilen fast gänzlich verschwinden. Hilfsmuskeleindrücke sind nur bei sehr günstiger Erhaltung der Schale beobachtet worden, ebenso die sehr dicke Perlmutterschicht. Eindruck der Mantelränder ohne Sinus. Ligament äusserlich oder lalb innerlich, amplidet, tritt zuweilen nach imen auf die Schlossplatte über (Tr. rablensis). Ligament-Knorpel laäutig linter dem Wirbel in einer Furche verkalkt erhalten.

Schloss der linken Klappe (Tab. I, Fig. 9, Tab. II, Fig. 1).

$$
\text { L. } 1010 \hat{i} 01(0)
$$

Der innere Leistenzahn ist zum Unterschied von. Myophoria selbststïndig und im Allgemeinen stärker ausgebildet als der hintere. Der Hauptzahn ist in der Regel getheilt, bei einzehnen Exemplaren manchmal sogar so stark, dass man die Kämme für besondere Zähne anselıen könnte, wenn nicht bei derselben Art Formen mit nur oberHächlich angedeuteter 'Theilung vorhanden wären. Ausserden kann, wie bei den 'Trigoniden und I'nio zuweilen vor' dem vordersten Zahue eine Zahngrube entstehelı.

Schloss der rechten Klappe (Tab.I, Fig. 10, Tab. II, Fig. 2).

$$
\text { R. } 01010 \hat{1} 0(1)
$$

Der Hinterrand springt gewöhnlich stark vor. Der Hinterzahn ist als starke Leiste entwickelt. Vor demselben miter dem Wirbel befindet sich noch ein nur bei gut erlaltenen Schlössern deutlich sichtbarer, schmaler, kanm hervortretender Zahn, der sich schnell nach unten herabzielit und verschwindet. Der gewöhnlich vom Wirbel weg und nach vorn gerückte Hauptzahn ist ungleich getheilt und verbindet sich wie bei linio mit dem Vorderrande. bildet.

Vom Vorderrande wird zuweilen noch ein vorderer Zahn ge-

Die Zähne sind meist glatt, doch ist hie und da eine Kerbung erkennbar, die sich von der bei den Trigoniden anftretenden durch ihre Unregelmässigkeit unterscheidet.

Triyonodus unterscheidet sich von Myophorir. und somit von den Trigoniden durch die 'Tremmug des inneren Leistenzahns vom Hauptzahn in der linken Klappe, durch die beide scheidende Zahngrube, den entsprechenden Zahn der rechten Klappe und den meist vor den Wirbel gestellten Hauptzahn der letzteren; ferner durch den in der liegel stirker vorspringenden Hinterrand. Von Lnio nur durch den regelmässig ausgebildeten und getheilten massigen Hauptzahn. 
Bei Trigonorlus lassen sich nach Analogie der Myoplıorien in Hinsicht anf die Ornamentik der Schale zwei verschiedene-Gruppen unterscheiden: 1. Corinatar, 2. Costatae.

\section{Carinatap.}

Schale glatt oder nur mit concentrischen Anwachsstreifen bedeckt. Sclıloss sehr verïnderungsfillig. Ein liel meist deutlich ausgebililet.

'Ty u us: Trigonodus rablensis Gred le r sp. (Raiblerschichten der Südalpen). $\Lambda$ n dem l. c. Tal). V1I. Fig. 5 abgebildeten Schlossfragment ist der vordere Theil dex Schlossplatte, was auf der Zeichumng leider nicht zum Ausdruck gekommen ist, mit einer Streifung versehen, die ungeführ parallel zum Rande läuft. Dieselbe diente zur Befestigung des nach imnen tretenden Ligaments.

Trigonodus cristonensis Me ek sp. Diese Art stammt aus einer Schichtenserie ron Gallinas Creck in Nen-Mexico, welche jetzt von den amerikanischen Geologen für Trias gehalten wird. Sie wurde zuerst von Ne ek') mit zwei anderen Axten $U$. gallinensis und U. Terrae inbrae. als Unio beschrieben. C o p e ${ }^{2}$ ) bildete alle drei Arten $1877 \mathrm{ab}$. Wh it e ${ }^{3}$ ) ist der Ansicht, dass I mio cristonemsis eine echte Cmio ist, dagegen die beiden anderen Arten zu schlecht erhalten seien, um eine genaue Bestimmung zu gestatten; ferner war er gencigt, die Ablagerungen, aus denen diese Bivalven stammen, eher für Jura als für Trias anzusehen.

Im vorigen Jahre bei Gelegenheit des internationalen Congresses in Washington hatte ich Gelegenheit, im National-Museum eine Anzahl zum Theil recht gut erhaltener Exemplare von I min cristonensis zn untersuchen. Beim ersten Aublick fiel mir die grosse Aehnlichkeit mit Trigonorlus rablensis vom Schlossplateau auf, und als sich ein wohlerhaltenes Schloss der linken Klappe fand, war die Stellung zu Triyonolus nicht mehr zweifelhaft. Das Schloss zeigte beide charakteristisch ausgebildeten hinteren Leistenzähne, von denen der innere in keinem directen Zusammenhang mit dem getheilten Hauptzalın steht. Das Schloss unterscheidet sich daher nicht im geringsten von dem des Tr. rablensis. Tr. cristonensis ist von letzterem durch den stark abgestutzten Vorderrand und eine meist sehr geringe Wölbung der nur mit Zuwachsstreifen verzierten Schale, wodurch sich dieselbe Tr. costatus nähert, zu trennen. Die beiden anderen Arten Umio gallinensis und Cnio Terre rubrae sind, wie White erwähnt, anf Exemplare begrumdet, deren schlechter Erhaltungszustand auch nicht eimmal eine annähernde generelle Bestimmung zulässt. Ich konnte lieines von denselben in oben erwähntem Museum finden. Nach den Abbildungen,

3) Meek: Annual report of Chief of Engineers 1875, 11, pag. 1003. Washington.

?) Cope: United States geographical Surveys West of the 100 th. Meridian IV, 1877. Part II, pag. 9, Tah XXIII, Fig. 2-5 Unio cristonensis, Fig. 6 I'nio gallinensis, fig. 7 Unio Terrae rubrae.

3) White: Non marine fossil Mollusca of North-Amerika. Annual report of the Director of the U. St. Geological Survey 1881-82, pag. 19, Tab. III, Fig. 5. 
welche Cope von den mangelhaften Schlössern gibt, ist es wahrscheinlich, dass sie zu Trvigonodus gehören, es ist sogar nicht unmöglich, dass die erwähnten Exemplare zu Trigonodus cristonensis zu stellen sind. Diese beiden Me ek'schen Arten sind also sehr zweifelhaft, und es frägt sich, ob es nicht rathsamer wäre, sie einzuziehen. An den $\mathrm{Ab}$ bildungen von $\mathrm{Cope}$ lassen sich Hilfsmuskeleindrücke neben dem vorderen Muskeleindruck erkennen; wenn solche auch nicht unwahrscheinlich sind, so kanu nach der schlechten Beschaffenheit des Schalenimnern der von mir untersuchten Exemplare nicht erwartet werden, dass so kleine Vertiefungen geselien wurden. Dass Tr. cristonensis nicht aus Jura-Ablagerungen stammt, würde schon der rein triadische Charakter dieser Bivalve beweisen, denn Trigonodus ist aus jüngeren Ablagerungen als die Trias bisher noch nicht bekannt geworden. Dass die amerikanischen Geologen nicht mehr in Zweifel über die Stellung der Schichten sind, geht daraus hervor, dass die Exemplare von Tr. cristonensis im Museum bei der Trias eingeleiht waren.

Trigonodus Sandbergeri v. Alberti (Lettenkohle).

Trigonodus Hornscliulii Berger sp. ist nach v. Alberti eine gute Art (Lettenkohle).

Trigonodus minutus v. W öli r m. (Raiblerschichten vom Schlern). Trigonodus Serianus Parou a (Raiblerschichten der Lombardei). Trigonodus problematicus Klipst. $s p$. Bei genauer Untersuchung von To m mas s's Originalexemplaren zu Myophoria fissidentata ${ }^{1}$ ), deren Abbildungen leidel ungenügend ausgefallen waren, stellte sich heraus, dass diese Formen zu Trigonodus gestellt werden müssen und nach ihrer äusseren Gestalt einer Art angehören, die von Klipstein ${ }^{2}$ ) als Unio problematicus aus den Schichten von Heiligkreuz beschinieben und abgebildet wurde. Das Schloss wal Klipstein unbekamnt. $\mathrm{H}^{\prime} \mathrm{aue \textrm {r } ^ { 3 }}$ ) bildete dasselbe spätel von Exemplaren aus den Raibler Schichten von Raibl ab und stellte sie zu Cardinia. Die Präparate beider Schlösser sind aber, nach den Abbildungen zu urtheileu (als ich 1887 die $\mathrm{Hau}$ ar'schen Originale in der geologischen Reichsanstalt durchsals, waren die Exemplare von Cartinin moblematicn nicht darunter), so ungenügend, dass man sich keilı rechtes Bild von denselben und ihrer Finlenkumg machen konnte. Dies war vielleicht der Grund, weshalb diese Art bis jetzt verschollen blieb.

Da die bisherigen Abbildungen ungenügend sind und diese Art zum Vergleich mit Unio wichtig ist, so habe ich die Originale To m masi's hier nochmals zeichnen lassen. (Tab. I, Fig. 9, 10.) Leider sind die Zähne der rechten Klappe etwas abgesägt, doch erkemnt man ihre Gestalt an den entspreclienden Zahmgruben der linken Klappe.

1) Tommasi: Rivista della Fauna raibliana del Friuli. Udine 1890. Tab III a, Fig. 5-8.

$\left.{ }^{2}\right)$ Klipste in: Beitrag zur Geologie der östlichen Alpen, pag. 265, Tab. XVII, Fig. $25 a b c$.

$\left.{ }^{3}\right)$ v. II a u r: Beiträge zur Kenntniss der Funna der Raiblerschichten. Sitzungsber. der k. Akad. d. Wissensch. Wien 1857. Bd. XXIV, pag. 543, Tah. I, Fig. 7-9. 
Schale gleichklappig, stark gewölbt, glatt, nur mit concentrischen Anwachsstreifen bedeckt. Umriss rundich dreieckig. Iorderrand abgestntzt, gerundet; Hinterand ziemlich gerade nach miten gerichtet. Dindurch. dass die Schale von einer diagonalen Linie, die sich vom Wirbel nach hinten zur unteren Ecke zieht, zum Hinterrand steil abfällt, wird ein Kiiel gebildet. Wirbel stark eingebogen, prosogyr, berühnen sich. Ligament amphidet. Muskeleindrücke sind tief eingelassen. Die Muskelmasse meist verkohlt erhalten. An der 'Tab. I, Fig. 10 abgebildeten rechten Krlappe ist über dem vorderen Muskeleindruck und vor dem hinteren ein Hilfsmuskeleindruck sichtbar. Das Imere der Schale ist mit einer dicken Perhmutterschichte versehen.

Das Schloss beider Kilppen ist wie bei lon vorher erwähnten Trigonodusarten beschatfen, doch in Anlyetracht der Grösse und Dicke der Schale viel massiger ausgebildet. I)er Hauptzalm der rechten Klappe ist seh" bedeutend nach vorn verschoben, der hintere Zahn in der Regel stumpfer als bei den anderen Arten. Bei der linken Klappe konnte an der Basis des ausserordentlich massiven Hauptzahnes eine muregelmässige Kerbung erkamnt werden, wie sie z. B. bei I wio in noch höherem Maasse ausgebildet ist. Der vordere leistenförmige Zahn ist noch nicht durch eine so scharf einschneidende Zalmgrube vom Hauptzalm losuelöst, wie bei Trigonodus reblensis. Am Vorderrand der reshten Klappe befindet sich ein rudimentärer Vorderzahn, dem eine seichte Zahngrube an der linken entspricht. Von Myophoria fissidentutu, zu welcher diese Art gerechnet wurde, unterscheidet sie sich in der Gestalt der srhale und durch das abweichende Schloss.

\section{Costatae.}

Schale recht Hach, mit scharfen, regelmässig concentrisch angeordneten Rippen verziert, Kiel nur angedentet, Wirbel wenig vorspringend. Schlossapparat sehr bestïndig: Schleril)

Typus: Tirigonorlus costatus v. Wöhrm. (Raiblerschichtell vom

Wie schon erwähnt wurle, betonte Sand berger die auffallende Uebereinstimmung im Schlosse von Trigonodus und Unio. Ne um a y " (1. '. 1889, pag. 23) hielt wegen des heterodonten Charakters von Triyonodus einen Vergleich mit den schizodonten Unionen für gänzlich ausgeschlossen. Bei der Beschreibung der Trigonodusarten vom Schlern (l. c. pag. 182, 186, 215) maclite $\mathrm{i} \cdot \mathrm{h}$ anf die grosse Aehnlichkeit derselben mit Unio aufmerksam, die besonders deutlich in einer rechten Klappe von Trigonodus rublensis (1. c. Tab. VIII, Fig. 8) zum Ausdruck kam. Vergleichen wir die Schlossformel von Unio

$$
\frac{\text { L. } 1010 \hat{\mathrm{L}} 01(0)}{\text { R. } 01010 \hat{\mathrm{i}} 0(\mathrm{l})}
$$

mit jener von Trigonodus

$$
\frac{\text { L. } 1010 \hat{101(0)}}{\text { R. } 01010 \hat{10(1)}}
$$


so ist der einzige Unterschied, fler aus denselben hervorgeht, schon durch die Zeichen hervorgehoben. Die Bezalnnung ist, wie es auch die auf Tab. I, Fig. 7-10, Tab. II, Fig. 1, 2, 8, 9 abgebildeten Schlösser von Trigonodus und. Unio varanschaulichen, vollstindig identisch. Eine Verschiedenheit macht sich nur darin geltend, dass bei Trigonodus das Schloss regelmässiger gebant, die Zälme keine so vorgerückte Kerbung zeigen mod der Hauptzahn der linken Klappe stets durch eine meln oder weniger regelmässige Furche in der Mitte getheilt ist. Fasst man ansserdem ins Ange, dass die Gestalt eine lomologe ist, im Innern der Schale Perlmutterschicht und Hilfsmuskeleindrücke auftreten, ferner das Ligament amphidet, stark entwickelt ist und zuweilen nach Innen himneintritt, so wird man sich kaum dem Eindruck entziehen. dass Trigonodus und L'mo unter allen besprochenen und bekannten Bivalven die anffallendste Uebereinstimmung zeigen. Trigonorius ist eine marine Bivalve, Lnio dagegen lebt ausschliesslich in suissen Gewïssern und kann man sie daler njcht olme weiteres vereinigen.

Nun ist aber bekannt, dass alle Süsswasserbivalven ursprünglich Meeresbewohner waren, später in Flussmündungen, Flüsse. Seen einwanderten und durch die verinderte Lebensweise zum Theil bedentenden Veränderungen in Schale, Schloss etc. unterlagen. Bei der Frage, von welchen marinen Formen sich die Nayaden abgetheilt haben kömnten, ist nach den vorliegenden Untersnchungen wohl nur Trigonodus zu nemmen.

Anffallend ist, dass man in den Raiblerschichten der Alpen Tirgonodus mur in solchen Sedimenten finclet, deren petrographische Beschaffenheit, Sande, Gerölle, Mergel, für eine Ablagerung in nächster Nähe einer Küste spricht. Dasselbe ist auch in Nordamerika bei Trigonodus cristonensis der Fall.

Es ist daher sehr wahrscheinlich, dass diese Nähe der Küste einzelne Exemplare veranlasst haben, sich in Flussmündungen anzusiedeln mod dort heimisch zu werden, wo dann die Umwandlung in Unio sich vollzog.

Diese Muthmassung wird durch das geologische Alter beider Formen bestätigt. Trigonorhs ist bisher nur im unteren lievper bekannt, rerschwindet dann in Furopa spurlos. Welchen Schicliten der emropäischen Trias die sandigen Sedimente von Gallinas Creek in Neu-Mexiko entsprechen, in denen Trigonodus cristonensis häufig vorkommt, ist noch gänzlich in Dunkel gehüllt.

Unio tritt in Europa mit allen typischen Nerkmalen ausgestattet erst in den Ablagerungen des obersten Jura, d. l. im Purbeck anf, und ist seitdem in allen Süsswassel-Ablagerungen zum Theil massenhaft verbreitet. Es ist daher anzunehmen, dass sich die Umbildung von Trigonodus in Unio in anderen Gebieten während der Jurazeit vollzogen hat und C'nio erst zugleich mit Auftreten von SüsswasserAblagerungen erschienen ist.

Interessant ist es, lass der einzige hamptsächliche Unterschied in den Schlossapparaten von Trigonodus nud Thio hauptsächlich in der corrumpirenden Wirkung der einschneidenden Kerbung besteht. Die Zähne werden bei Unin durch letztere imregelmässig, wulstig und verlieren ihre ursprïnglich genan und scharf begrenzte Gestalt. 
Bei der Umbildung des marinen Proloconeilo in die brackische Pulapomutelu fanden wir genau dieselbe Erscheinumg, nur in anderer Form. Da keine Kerbung zerstörend wirken konnte, so traten dort unregelmässige Theilungen der einzelnen Zïhnchen auf, einzehe derselben sind anf Kosten der anderen stärker ausgebildet; die meisten zeichnen sich durch eine wulstige, unregelmässige Gestalt aus, lassen aber gewölnlich noch die ursprïnglich regelmässige Anordnung erkennen. Der Charakter der Stammform bleibt also in den Grundzügen gewahrt und weist auf dieselben zurïck. Dies ist eine beachtenswerthe Thatsache. Dieselbe widerspricht der Annahme, dass man in Fidiria die recente Vertreterin der Palaeomutelen zu sehen hätte, da sie, trotz ganz analoger Bezahnung, noch die Spuren des heterodonten Schlosses auf ihrer Schlossplatte trägt.

Um die Uebersicht zu erleichtern ist es zweckmässig, zım Schluss die Ergebnisse der in dieser Arbeit nieder'gelegten Untersuchungen zusammenzufassen.

Wie el'wähnt, hatte $\mathrm{N}$ e u m a y r versucht, auf Grund des BivalvenSchlosses eine neue Systematik einzuführen. Dieselbe hat sich aber ebenso lückenhaft gezeigt, wie die frühere und somit keinen Ersatz für dieselbe geboten. Die Gruppe der Schizodonten ist wieder mit den Heterodonten vereinigt worden, da ilne Abgrenzung in Folge genauer Untersnchungen sich als zu theoretisch und somit praktisch unverwerthbar erwiesen hat. Wenn auch die Schlossmerkmale für eine allgemeine Systematik unzureichend waren, so sind sie doch zur Abgrenzung von Gattungen zuverlässiger als alle anderen. Der Charakter des Schlosses bleibt länger bewahrt als derjenige der Schale und bietet uns daher die besten Anhaltspunkte, um verwandtschaftliche Beziehungen zu verfolgen. Selbstverständlich darf man die übrigen Kennzeichen nicht ausser Acht lassen, sondern dieselben, soweit es zulässig ist, mit in Betracht ziehen.

Die Trigoniden, zu denen vor der Hand nur die Gattungen: Myophoria, Schizodns und Trigonia gerechnet werden können, verbleiben an ihrem bisherigen Platz in der Systematik.

Myophoric reicht vom Devon bis ins Rhät; Schizodus scheint nur durch eine einzige Art vertreten zu sein, und zwar im Perm. Ob diese Gattung auf die Daner beibehalten werden kam, muss durch genane Untersuchungen festgestellt werden.

Trigonic ist als fertige Fornn von den Schichten von St. Cassian an bekannt und kann daher wälnend dieses Zeitraumes keine Seitenzweige entsendet haben.

Die Nayaden behalten ebenfalls ihre frühere systematische Stellung neben den Trigoniden bei. Ihre Familie wird un die Gattung Trigonodus, als marine Stammform der Unioniden, vergrössert, die sie zu gleicher Zeit mit den Trigoniden eng verbindet, da Trigonodus sich von Myophoria abgezweigt hat.

Curdinia ist aller Wahrscheinlichkeit nach aus Trigonodus rückgebildet worden und somit ebenfalls in diese Familie anfzumehmen. Die Familie der Nayarlidcle I, am. würde also 1. aus einer marinen Gruppe: Trigonndus, Cardimia, 2. aus einer Süsswassergruppe: Unionidae, Mutelidae bestehen. 
Die Familie der Cardiniidae Zittel dürfte einzuziehen sein, da die Gattungen Trigonochs und Cardinia zu den Nayaden gekommen sind, Anoplophora bei den Prasinirla Stolick a eingereiht wurde mol die systematische Stellung von Anthracosia und Carbonicola eine äusserst zweifelhafte ist.

Die von A malizky als Anthracosien etc. beschriebenen Bivalven aus dem Perm Russlauds gehören insgesammt (vielleicht mit Ausschluss der zalmlosen Formen) (ler Gattung Palceomutela A m al. an.

Für die Gattungen Ctenodonta S alte r, Nuculites Hall, Tellinomya Ha 1l, Palaeoneilo Hall mo Palcoomutelu Amalizky ist eine neue Familie "Ctenorlontidae" begriundlet worden, die bei den Avcidne einzureilien ist.

Ctenodonta, Nuculites, Tellinomya (Devon) und Palaeoneilo (SilurKohlenkalk) sind die marinen Gattungen, wälırend Palaeomutelı (Perm) eine Brackwasserform ist.

Die generische Abgrenzung der marinen Gattungen lässt viel zu wïnschen $\ddot{z} h$ rig und ist es möglich, dass durch eine genaue Revision der Originale, z. B. Ctenodonta, Tellinomya und Palcenneilo, in eine Gattumg zusammengezogen werden müssten

Die Gattung Oligoron $\Lambda$ malizky ist einzuziehen. 


\title{
Zur Geologie der Gegend von Ostrau.
}

\author{
Von Dr. E. Tietze.
}

(Vorgetragen in der Sitzung der k. k. genl. Reichsanstalt am 20. Decemlier 1892.)

\section{Zur Frage des Vorkommens von Steinkohle in oberen Oderthal und dessen Ungebung.}

Vor Kurzem hat ein angeblicher Fund ron Steinkohle bei Wagstadt ${ }^{1}$ ) in Oesterr.-Schlesien eine gewisse Aufregung in rlen für Bergbau sich interessirenden Kreisen von Mähren und Oesterr.-Schleșien hervorgerufen. Da der betreffende Fundpunkt in einem Gebiet gelegen ist, welches nach den bisherigen Aufnahmen als der Culmgrauwacke zulgehörig erachtet wurde, so galt plötzlich Alles, was die Geologen in jenen Gegenden dieser Granwacke zngerechnet hatten, als ein zu Hoffnungen auf Kohle berechtigendes Terrain, während man andererseits, da num schon einmal die Schranken der bis nun geltenden Auffassung durchbrochen waren, sich mit dem Interesse für jene Culmgebiete nicht begnïgte und auch solehe Gegenden als möglicherweise kohlenreich betrachtete, welche bereits der karpathischen Erhebung angehören und von theils cretacischen, theils eocänen Gliedern des Karparthensandsteines eingenommen werden ${ }^{2}$ ). Diese Vorstellungen bewirkten, dass ungemein ausgedehnte Landstrecken mit Freischürfen anf Steinkohle belegt wurden.

Da nun ein grosser Theil derselben Landstrecken erst unlängst von Geologen der geologischen Reichsanstalt begangen worden war, olne dass aus den Berichten derselben ein Anlass zı so überschwenglichen Hoffnungen hervorgegangen war und da die betreffenden Geologen der mir amtlich unterstellten Section angehörten, überdies specielle, auf den Gegenstand gerichtete Anfragen an mich herantraten, so ergriff ich gerne eine mir im vergangenen Sommer sich darbietende Gelegenheit, durch persönlichen Augenschein von dem Stande der fraglichen Angelegenheit mich zu überzeugen. Von den Ergebnissen dieses Austluges erstatte ich hiermit Bericht, und wenn

1) Das Städtchen liegt in der Luftlinie etwa 23 Kilometer in südwestlicher Richtung von Ostrau entfernt.

2) In Bezug auf die letzterwähnte Eventualität hatte es allerdings schon früher nicht ganz an Sanguinikern gefehlt.

Jahrbuch der k. k. geol. Reichsanstalt, 1893, 43. Bancl, 1. Heft. (Dr. E. Tietze.) 
ich dabei zu einem, wie sich vielleicht herausstellen wird, im Ganzen wenig ermuthigenden Urtheil gelange, so glaube ich durch die Abgabe desselben nicht blos einer Pflicht zu genügen, sondern hoffe auch deı wirklich legitimen Interessen, welche sich an jene Kohlenfrage knüpfen können, durch die Offenheit meiner Meinungsäusserung nicht zu schaden, sondern zu nützen.

Eine kurze Darlegung der allgemeinen topographischen und geologischen Verhältnisse, auf welche ich später Bezug nehmen muss, sei hier meinen Auseinandersetzungen vorausgeschickt.

Die Kaiser Ferdinands-Nordbahn, unsere Hauptverbindungslinie zwischen Wien und Oderberg, folgt zwischen Prerau und Ostrau einer Tiefenlinie, welche, vom rein orographischen Standpunkte angesehen, als die Scheidelinie zwischen den in dieser Gegend nahe aneinander tretenden sudetischen und karpathischen Erhebungen gelten muss. Im Wesentlichen ist diese langgestreckte, in der Richtung von SW nach NO verlaufende Depression auch eime Grenzzone zwischen den sudetischen und den karpathischen Formationen, soweit dieselben sich an der Oberfläche bemerkbar machen. Die karpathischen Formationen, hier aus verschiedenen Gliedern des Karpathensandsteines und den diesem untergeordneten Eruptivbildungen bestehend, treten ansschliesslich auf der südöstlichen Flanke dieser Tiefenzone auf, während die nordwestliche Flanke derselben ausschliesslich von sudetischen Massen, und zwar insbesondere von den Grauwacken und Schiefern der Culmformation eingenommen wird. Doch reichen in der Gegend von Leipnik und Weisskirchen die sudetischen Massen über die bewusste Depression hinüber und nehmen, wenngleich in räumlich relativ beschränkter Weise, daselbst an der karpathischen Bergmasse theil ${ }^{1}$ ), denı südlich von den genamnten beiden Städten setzen Grauwacken und in der Gegend von Weisskirchen sogar devonische Kalke, wie sie im Bereich des mährisch-schlesischen Granwackengebietes von verschiedenen

1) Ich schliesse mich bezüglich der geograpischen Auffassung von der Bedeutung der bewussten Depression als einer Grenzlinie zwischen karpathischen und sudetischen Erhebungen vollkommen dem juingst von Camerlander in dem Jahrbuch der k. k. geol. Reichsanstalt (1890, pag. 105) vertretenen Standpunkte an und erblicke keinen Uebelstand darin, dass man die Grauwackenberge südlich von Leipnik und Weisskirchen orographisch zu den Karpathen rechnet, während sie, geologisch gesprochen, noch als sudetische Massen zu behandeln sind. Wie unsere neuere Aufnahme des fraglichen Gebietes zeigt, besitzen diese von der Hauptverbreitung der palaeozoischen Gebilde der Sudeten äusserlich abgetreunten Massen ibberdies keinen geschlossenen Rand gegen die karpathischen Gebilde, innerhalb deren sie stellenweise noch inselförmig anftreten, so dass eine auf geologische Principien zu basirende Abgrenzung der Sudeten und Ḱarjathen hier zu mancherlei Unzukömmlichkeiten führeu wiirde. Da ferner voll einigen Autoren eine Fortsetzung gewisser sudetischer Gebilde in der Tiefe unterhalb der karpathischen Erhebungen angenommen wurde (welcher Punkt später noch beriihrt werden muss), so käme man bei Festhaltung eines rein geologischen Eintheilungsprincips der Gebirge in unserem Falle dazu, ein und dieselbe Gegend für zwei verschiedene Gebirge gleichzeitig in Anspruch zu nehmen, was eine geographische Absurdität wäre. Meinen Standpunkt derartigen Fragen gegenüber, wonach für geographische Eintheilungen in erster Linie topographische Gesichtspunkte in Betracht kommen müssen, habe ich übrigens erst kürzlich gelegentlich eines Referates über Dr. Diener's Westalpen zu skizziren Gelegenheit gehabt. (Mitth. d. k. k. geogr. Ges. in Wien. 1892, pag. 147.) 
P’unkten bekamnt sind, den Rand der Depression zusammen. da sogar noch etwals östlich von Weisskinvhen tanchen deroleichen ältere (iesteine noch auf dieser Seite auf. Weiterhin indessen, zwischen AltTitschein und ()stran. stellt die bewnsste I)epression ein völliges Scheidethal zwischen Grauwacken und Karpathensandsteinen vor. Längs des sudetischen Randes liegen hier die Ortschaften Oriau, Fulnek, Wagstadt, Königsbery und Bobrownik, längs des kanllathischen die Ortschaften Alt- und Neutitschein, Braunsberg und Paskau.

Die erwälnte Tiefenzone wirl nun von zwei nach entgegengesetzter Richtung laufenden Flüssen durchzogen. Im südwestlichen Theil derselben thiesst die bei Weisskirchen ans den Karpathen kommende Beczwa, und im nordöstlichen Theile derselben Tiefenzone bewegt sich die etwas unterhalb des Stältchens Odrau aus den sudetischen Graumackenhiigeln hervortretende Oder. Mam hat deshalb diese eigenthümliche Depression anch als die Beczwa-Oderfurche bezeichnet und könnte sie einem jener nicht allzuseltenen Längsthäler vergleichen, in welchen, wie im P'usterthal, eine Wasserscheide mitten durch das Thal hindur'hzieht. Doch muss hier einschränkend bemerkt werden, dass die Längsaxe der betreffenden Furche zwar annähernd, aber nicht ganz genau mit der herrschenden Streichungsrichtung der Gebirgsschichten der Umgebung übereinstimmt.

Jene Wasserscheide aber erlualt eine besondere Bedeutung noch dadurch, dass sie eiı Theil der grossen europäischen Wasserscheide ist, indem die Beczwa als ein Zuthuss der March dem Stromgebiet der Donau angehört. Da der bei Bölten und Pohl Hiessende Luhabach noch der Oder zustrebt, so ist die Lage der genannten Wasserscheide durch die flache Erhebung zwischen Bölten und Weisskirchen bezeichuret.

Was nun die Gebilde anlangt. die man in Bereich der BeczwaOderfurche selbst antrifft, so sind dies ganz vorwiegend diluviale Absätze, nuter denen neogene Ablagerungen theils vermuthet, theils direct nachgewiesen sind. Am nordwestlichen Ende indessen der besprochenen Furche, dort wo die Oder nach Vereinigung mit der von Troppan kommenden Oppa in das flachwellige oberschlesische Tiefland einzıtreten beginnt, sind bekannterweise auch flötzreiche carbonische Schichten in der Tiefe vorhanden, ja es treten diese rarbonischen Gesteine bei Ostrau sogar stellenweise bis an rlie Tagesoberfläche empor. genïgren.

Soviel mag behuts der allgemeinen Orientirung hier vorlüufig

Da es sich um eine Kohlenfrage liandelte, habe ich vor Beginn meiner in dem geschilderten Gebiet in Betracht kommenden Excursionen mir die zuletzt erwähnten Punkte des Auftretens der productiven Kohlenformationen zuerst angesehen, insbesondere die guten Aufschlüsse, welche am Rande des Oderthales gegenüber von Hruschau zu beobachten sind, um so auf Grund frischer Erimnerung an den etwa nöthig werdenden Vergleich zwischen den Ostrauer Gesteinen und denen des fraglichen Granwackengebiets heranzutreten. Schien ja doch stellenweise sogar die Meinmo zu bestehen, als ob dieses Gebiet, das schon von allen früheren Antoren seit Beyrich's 
grundlegender Arbeit über die Entwicklung des Flötzgebirges in Schlesien für älter als die thötzführenden Schichten des Kohlengebirges gehalten worden war, von letzterem als gar so nicht wesentlich verschieden aufzufassen sei!

Ich habe dam jenes Granwackengebiet, dessen Fortsetzung mir schon von verschiedenen anderen Theilen Mährens und Schlesiens bekannt war', an melıreren dem Oderthal näler' gelegenen Punkten besucht und mich dabei, wie nicht anders zu erwarten war, davon überzengt, dass die betreffenden Gesteine im Grossen mnd Ganzen nicht so schwer von den Gesteinen der Ostraner Kohlenformation zu unterscheiden sind, wenngleich die letzteren gerade in der Nähe der Grauwacke derselben manchmal etwas ähnlicl werden, wodurch denn auch, wie später besprochen werden wird, einige Autoren zu irrthümlichen Vorstellungen über das Verhältniss der bei Ostrau aneinander grenzenden älteren Bildungen veranlasst wurden.

Die Mittheilungen, welche ich nun auf Grund der erwähnten Excursionen zu machen in der̂ Lage bin, kömnen, abgeselıen von der zu gebenden Erörterung der im Titel dieses Anfsatzes vorangestellten Frage, übrigens anch als eine kleine Erönnzung der Localschilderung dienen, welche der kürzlich verstorbene Baron v. Camerlander in seiner umfangreichen Arbeit über die südöstlichen Ausläufer der mährisch-schlesischen Sudeten bezïglich der Gegend zwischen oder und Oppa uns hinterlassen hat. (Jahrb. d. geol. Reichsanst. 1890.) Ich benütze rleshalb rliese Gelegenlueit. nm zugleich einige nene Beobachtungen bekamt $z u$ geben. welche zwar mit der Kohlenfrage in jener Gegend nicht in jedem Fall direct im Zusammenlang stehen, welche aber doch geeignet sind, zu zeigen, dass selbst widerholte Besuche des bewussten Gebiets, auch wenn dieselben zur Constatirung nener Thatsachen: führen, doch gerarle die Anwesenheit flötzführender Schichtencomplexe rlaselbst nicht ans Licht bringen.

Selbstverstandlich habe ich insbesondere der Ungebung ron Wagstadt meine Aufmerksamkeit zugewenlet, dem dort liegt ja der Punkt, von welchem die Erregung in der zu besprechenden Angelegenheit ausging. Fine kurze Beschreibung der dortigen geologischen Verhältnisse wird also den iubrigen Erörterungen, die ich zu machen habe, vorangehen diurfen.

Das kleine Stältchen Wagstadt liegt am Wagbache, einem r/aHuss der Oder, und längt mit dem etwas unterhalb befiudlichen Dorfe Gross-Olbersdorf lïngs des genannten Baches zusammen, die Hauptmasse der die Stadt bildenden Gebüude zieht sich indessen an der nördlich vom Wagbache sich erhebenden Berglehne hinauf zu beiden Seiten der volı hier nach Troppan führenden Kaiserstrasse und ist in ilrem westlichen Theile mit den Hänsern des Dorfes Radnitz unmittelbar verbunden.

Südlich von Waystarlt anf der anderen Seite des Baches liegt zunächst an der nach Fulnek führenden Strasse das kleine Dorf' Wipplarsdorf und etwas entferuter, auf der Höhe des GrauwackenPlateaus das Dorf Bielan.

Fchte mur inzweifellafte Culmgramwarke bildet hier ubberall das Grundgebirge, welches insbesondere durch einen grossen Stein- 
bruch westlich Wipplarsdorf gut aufgeschlossen ist. Es ist die Simdsteinfacies der Grauwacke. die in diesem Steimbuch auftritt, die dam auch an dem sogenannten Galgenberg rorkommt und sich ron di narh der zwischen Bielan und Brawin gelegenen Höhe zieht. wo etwa am halben Wege zwischen den letzuenamnten ()rten in einem kleinen Wäldchen Namens (Obleska, in der Umgebung des die Höhe ron 407 Meter angebenden I'unktes der Generalstabkarte kleinere verlassene Steinhrüche sich befinclen. Süclöstlich aber von diesem Punkte erblickt man noch vor der Fulneker Strasse die Spuren der Schiefer. in deren Bereich das Dorf Bielau gehört und die sich in keiner Weise ron don anderwiuts mit der Culugrauwacke rerbundenen Schieferm nuterscheiden. Spuren derselben Schiefer sah ich auch nördling von Bielan an dem Wege, der von der dortigen Ziegelei nalch einem neben der Fulneker Chanssée stehenden líreuze fülnt. Im Uebrigen zeigt allerdings der gegen den Waghach gekehrte $\mathrm{Ab}$ lıang der Bielauer Höhe keine besseren Anfschlüsse der alten Gesteine, da. wie das schon bei der genamnten Ziegelei der Fall ist, diluviale Lelme inshesondere längs der von Bielan abwärts und östlich Wipplarsolorf volbeiführenden sanften Terrainfurche das ätere Terrain verdecken, nu dimn in der Näle der Thalsohle längs des ganzen Sürlwestgehänges les Wagbaches eine mächtigere Ablagerung zu bilden. Welche ron ()lhersolorf bis A]tstarlt oberhall, Wagstarlt reicht und die raselhst durch Lehmgruben melufach anfoeschlossen ist.

Anf rer Höhe von Bielan selhst wird aber der Schiefer durch eine andere Mblagerung rerleckt, die bei Weitem interessanter ist als jencr I.thm. Man sieht hier (zum Theil durch Gruben anfgedeckt) dicht beim Iorfe einen märhtigen, etwas glimmerigen losen Sand, in dem sich seln feste (puarzitische Sandsteinplatten ansscheiden oder anch bisweilen nur plattenartige Knanern von quarzitischem Sandstein, so dass hierbei die Grenze zwischen Concretionen und Schichten nicht immer leicht zu bestimmen ist. Dio Lagerumg dieses Gebildes ist horizontal. Fossilien wurden darin nicht gefunden.

Dieses Vorkommen wrile ron Camerlander bei seiner im Uebrigen, wie man anerkennen darf, mit grossem Fleiss beschriebenen, wemn auch kartographisch nicht durchwegs glïcklich dargestellten Anfinalnme übersehen. Fs stimmt aber vielfach überein mit den lockern fossilarmen Sandsteinen und losen Sanden, welche dieser Autor (vergl. z. B. l. e. pag. 195) bei Fulnek und an anderen Punkten ILährens in Bereich der Grauwacken entrleckt mol mit Recht dem Neogen zugezahlt hat. Hier hei Bielau ist zudem die Verbindung der losen Sande mit den Quarziten seln dentlich, welche Camerland e $r$ anderwärts in Mähren (1. r. pag. 200) meist nur in Form ron losen Blöcken auffand, was ilm mit Reclit Veranlassung gab (l. c. pag. 203) zum Vergleich an gewisse, seinerzeit von mir geschilderte Terhältnisse Galiziens anzmknüpfen, wo ähnliche Quarzitblöcke sich als Reste einer zerstörten tertiüren Decke erwiesen haben, wie das später Ulılig bestïtigte. Die Aufschlüsse bei Bielau sind also bezüglich der mrsprünglichen l'rovenienz der hewussten Quarzitblöcke II ̈̈hrens direct beweiskräftig, dem selbst hei Daskabat, oder Hoskowitz wo C'amerlander solche Blörke in direrter Verbindung mit 
Sanden antfand (1. c. pag. 275 und 202), konnten Uebergänge derselben in ausgesprochen schichtförmige Bildungen wie bei Bielan nicht nachgewiesen werden.

Ganz ähnliche Sande, wie die von Bielan, spielen nun auch bei Wagstadt selbst eine nicht unbedentende Rolle, wo sie aller(ings weniger leicht anfzufinden sind und wohl deshalb von $\mathrm{C}$ a me r l a nde $\mathrm{l}^{\circ}$ ebenfalls nicht bemerkt wurden. Im süıöstlichen Theile der Stadt treten dort an der Berglehne zwar noch die Schiefer der Grauwacke hervor. aber in oberen Theile der Stadt herrschen namentlich auf der ganzen östlichen Flanke die neogenen Sande, welche auch noch etwas östlich der Stadt im Süden der nach Königsberg führenden Chaussée vorkommen (nördlich von dem auf der Generalstalıskarte angegebenen alten Bräuhause) und die sich andrerseits auch noch im Westen der zm Troppauer Chaussée führenden Strasse nachweisen lassen. Sie sind innerhalb der Stadt hauptsächlich durch Brumengrabumgen ${ }^{1}$ ) und Fundamentirungsarbeiten von Gebänden constatirt worden. Eine Sandgrube aber, die dicht neben der genamnten Strasse, allerdings imerhalb eines eingefriedeten Rammes gelegen war, konnte ich sogar direct besuchen. Bei dem im oberen Theil der Stadt yelegenen Friedliof wird der Sand übrigens von Lehm bedeckt, was vielleicht Veranlassung gegeben hat, das ganze Gebiet der Stadt in den Bereich diluvialen Lelums fallend aufzufassen, wie dies Cam ellander bei seiner Aufnalme gethan hat, da ja übrigens ancl an einigen anderen Punkten an diesen Gehänge Spuren solchen Lehms zu finden sind, wie z. B. bei Radnitz. wo der tertiäre Sand nicht mehr vorkommt und unter dem Lehın bei verschiedenen Brumengrabungen direct Granwackenschiefer ermittelt worden sind.

Gleich oberhalb der Stadt stehen diese Schiefer ebenfalls an. Sie sind neben der Troppaner Strasse und an dem dortigen Windmühlenberge an rerschiedenen Punkten aufgeschlossen, bei einem Streichen in Stunde 2 und bei nordwestlichem, zum Theil sehr steilem Einfallen.

An einer bereits ziemlich hoch gelegenen Stelle der Strasse, jedoch noch vor den auf der Hölıe stehenden Windmühlen überschreitet man die Schichtenköpfe ron Granwarkensandsteinbänken, die ebenfalls nordwestlich fallen, aber mit etwas geändertem Streichen in Stunde 3. Etwas weiter aufwärts traf ich auf den Ackerfeldern, welche den Windmühlenberg bedecken, Spuren von Schotter, welchen ich nach Analogie mit ähmlichen Vorkommmissen in Mähren für neogen anzusprechen geneigt bin. Geht man num aus dieser Gegend in das

1) Die etwas ergiehigeren Brumnen des erhöhten Stadtgebiets von Wagstadt wie insbesondere der sogenannte Gemeindebrumen gehören dem Bereich jener Sandablagerung an, welche anf liese Teise fiir die betreffende Gemeinde eine hesondere Wichtigkeit besitzt. Doch reichen die von jenen Brunnen gelieferten Wassermengen im Hinblick auf gewisse von der Geneindevertretung geplante Einrichtungen nicht melı ganz aus und scheint man entschlossen, fur das gesteigerte Wasserbedurfniss in anderer Weise Abhilfe $\mathrm{zn}$ schaffen. Ich erwähne das hier nur im Voribergehen, da gewisse vorläufige Studien, die ich im Interesse der Wasserversorgung von Wagstadt anzustcllen Gelegenheit hatte, mit dem Zweck meiner diesmaligen Wittheilung nicht in unmittelbarer Verbindung stehen. 
nordöstlich von Wagstadt befindliche Gamlichthal, so trifft man in der Schlucht, welche in dieses Thal bein Kreuz vor der Murzkemiihle mïndet, im Gebüsch versteckte, durch einen Wasserriss herrorgerufene Aufschlïsse ron Grauwackensandsteinen, welche mit den Sandsteinbäuken an der Strasse in Verbindung stehen dürften, wie es andererseits wahrscheinlich ist, dass die früher genamnten Sandsteine der Obleska als Fortsetzung dieses Zuges gelten können. Geht man indessen von dem Windmüllenberge suidwestlich hinab ins Thal des Wrabaches, so gelangt man an eine im Volksmunde als Steingraben bekamute Schlucht (es ist das die erste Schlucht westlich von Radnitz) wo Grauwackenschiefer südöstlich fallen, die erste Andeutung einer Umkehrung der bisher beobachteten Fallrichtungen.

Ein Stück hinter den Windmühlen befindet sich an der Strasse die sogenamite Amma-Kiapelle, in deren Nähe bereits wieder Scliefer anstehen und von lier aus (genaner von einem südlich der Kapelle befindlichen Kreuz ans) gelangt man anf einem Feldwege in die Schlucht von Pateysky, in deren oberem Theil sich eine kleine Häusergruppe dieses Namens befindet. Was in dieser Schlncht entblösst ist, ist fast durchyängig Srhiefer von echtem Culmcharakter. Nur an wenigen Stellen auf dem östlichen Gehänge werden anch wenig mächtige Lagen ron Graurackensandstein beobachtet. Hier aber befindet sich der Ort, wo der Anfangs erwähnte Fund von Steinkohle gemacht worden sein soll.

Etwa $i$ bis 8 Minuten unterhalb der genannten Häusergruppe erreicht man einen Punkt, an welchem zuerst ein Schacht abgetenft und sodann gebolurt wurde, bei welcher Gelegenheit angeblich ein ungeführ 3 Meter mäclitiges Flötz ron Steinkohle angetroffen wurde. Merkwürdigerweise aber traf ich den Schacht bereits zum Theil versehiittet und alle Haldenproducte aus seiner Umgebung fast bis anf die letzte Spur weggeräunt. Durch Erkundigungen erfuhr ich, dass folgende Anhaltspunkte bei der Inangriffnahme der betreffenden Arbeit in Betracht gekommen waren. Einmal sollen auf den benachbarten Aeckern brembare dunkle Gesteinsstücke, die man für Kohle hielt, gefunden worden sein. Ausserdem aber hatte Jemand bei einer Grabung nächst einem der Häuser von Pateyski vermoderte "vegetabilische Reste" entrleckt. wobei dam der Betreffende voraussetzte, dass in dieser Gegend nach der Tiefe zu eine "reifere" Tíohle anzutreffen sein möchte.

Das Letztere erwähne ich nur als Curiosum. Was aber jene brembaren Gesteinsstücke anlangt, so brancht man an deren Auffindung nicht zu zweifeln, hat aber deshalb auch noch nicht nöthig darin Beweise für die Existenz von Steinkohle in dieser Gegend zu erblicken. Ich sellust habe vor einigen Jahren bei Ptin (zwischen Plumenau und Konitz mitten im echtesten Grauwackengebiet anfgelassene Schmrbaue anf liohle gesehell, welche sich ganz zweifellos nur nit einem schwarzen, hituminösen und deshalb bis auf einen gewissen Grad brembaren Schiefer befasst hatten, wie el eben 'in der mährisch-schlesischen Granwacke bisweilen vorkommt, und wie el vermuthlich anch bei der später noch näher zu bespreclienden Localität Bölten schon im Jahre 1803 und dann nochmals im Jahre 1853 zu falschen Hoffnungen rerleitete. Hat ja doch auch schou Oeyn- 
h a us e n in seiner geognostischen Beschueibung Oberschlesiens (Essen 1822, pag. 66) von "fruchtlosen Versuchen anf Steinkohle" berichtet. zu denen ein "dunkelgefärbter Thonschiefer" in der Grauwacke bei Löbnik und in der Gegend von Leobschütz Veranlassung gab. Gewisse Irrthümer kelnen also, wie man sieht, mit einer gewissen Regelmässigkeit wieder.

Jedenfalls ist in unserem Falle das Zuwerfen des besagten Schachtes und das Wegräumen der Haldenproducte. sowie des Bohrschmandes ein Vorgang, der für den unbefangen an die Saclıe Herantretenden die Ueberzengung ron der Anwesenheit von Steinkohle an dieser Stelle nicht erleichtert. Ia man am Platze der Grabung nicht in die Lage versetzt wird, zu beurtheilen, was dem eigentlich bei dem betreffenden Experiment für Steinkohle gehalten worden sei und wie das Nebengestein dieser angeblichen Kohle ausgesehen hat, so bleibt man ausschliesslich auf das Vertranen zu den bei jenem Versuch zunächst Betheiligten angewiesen, und zwar nicht etwa blos auf das Vertranen in deren nicht anzuzweifelnde bona fides, sondern auch auf das Vertrauen in das Urtheil und die lienntuisse derselben. Da nun, wie ich glanbe, die betreffenden Unternehmer nicht den Anspruch erheben, als Fachmämıer zu gelten, so entfällt für ilıren liente der fachmämischen Controle entrïckten Versuch anch jede zwingende Beweiskraft. Mit anderen Worten, wo wir keine Kohle an Ort und Stelle sehen, branchen wir auch nicht an Kohle zu glauben, zum Mindesten nicht an ein besonders mächtiges und dabei von unreinen Beimengungen freies Flötz.

Was wir sehen ist nur, dass wir uns bei Wagstadt und speciell in der Pateyski-Schlucht inmitten der Culmgrauwacke befinden, von der man aus Frfalurung weiss, dass sie kein Ort der Kohlenführung ist. l)iese Erfalırung aber. die bisher noch von allen Beobachtern anelkannt wurde (vergl. z. B. Stur's Cnlmflora, pag. 102 und $103^{1}$ ). ist

1) Stur spricht hier ausdrïcklich von dem "gänzlichen Mangel von Kohlenflötzen" in der fraglichen Formation. Allerdings ist in den ursprünglich mit dem Namen Culm belegten Schichten von Devonshire das Auftreten etlicher unbedeutender Flötze bekamnt geworden von einer schlechten Kohle, die dort Culm genannt wird und der Formation sogar ihren Namen gab, allein nach Stur's neuesten Untersuchungen (Jahrb. geol. Reiclısanst 1889, pag. 8 11. 16) gehören gerade diese kohlenführenden, als Upper. ('ulm masures bezeichneten Bildungen gar nicht mehr dem Culm, sondern den Schatzlarer Schichtẻn an und mïssen (1. c. pag. 16) für jünger als der Millstonegrit gehalten werden. (Vergl. auch Stur's Monographie der Culmflora pag. 172 )

Gleichviel ẗbrigens, wie sich das in Wirklichkeit verhält, so hat doch gerade in der untercarbonischen Grauwacke Mitteleuropas sich hisher noch nirgends ein eigentlicher Kohlenlergban entwickelt Nicht einmal bei Landshut in PrenssischNiederschlesien dïrfte dies der Fall gewesen sein, wo nach den mir im Augenblick zngänglichen Daten jedenfalls noch mit etwas grösserem Erfolge als in anderen Culmbezirken nach Kohle gesucht wurde. Man fand dort (vergl. Gii rich, Erläuterungen zu der gcologischen Uebersichtskarte von Schlesien, Breslau, 1890, pag. 58) an verschiedenen Stellen anthracitische, "we nig mächtige" (höchstens 1 Meter starke), iiberdies durch Zwischenmittel von Braudschiefern, in hohe in Grade verunreinigte Flötze"; dass man indessen mit solchen Erfunden dem Abbau der obercarbonisclsen Flötze der jener Gegend benachbarten Reviere vou Waldenburg und Neurode keine gofïluliche Concurrenz machen kanu, liegt wohl auf der Haud. 
gerade für Mähren unt Oesterreichisch-Schlesien nicht gering anzuschlagen, denn seit vielen Jahren ist jenc Grauwake allenthalben durch Steinbriche für Schottergewimmmg oder durch Srhieferbrïche, stellenweise sogar durch Erzberghane aufoeschlossen, so dass die liohle. die in derselben vorkäme, lüngst entdeckt sein wiurde, wenn einer solchen liohle irgendwelche allgemeinere Bedeutumg zukommen sollte. Dazu kommt, dass diese Crrauwacke ja nicht zu den horizontal geschichteten, sondern $2 n$ den mamigfach gestörten Gehilden gehört und dass in Folge dessen die versihiedenston Abtheilungen derselben an die Oberfläche treten und Gelegenheit zu ihrer burehforschumg geboten haben.

Ein kleines, rein lokales Kohlenvorkommen könnte ja allerdings den bisherigen Nachforschungen entgangen sein, und die Möglichkeit, dass ein solches eimmal irgendwo gefunden wird, soll nicht absolut hestritten werlen. Tielleicht ist sogar in der Pateyskischlucht nicht Alles hlos Brandschiefer gewesen. Principielle theoretische Bedenken dagegen hraucht man im Hinhlick auf die Flötzchen hei Laudshut (siehe rorige Seite die Anmerkmug) nicht zu erheben. aber mit der Auffindung einzelner unbedentender Schmitze wie sie dort. oder wie sie etwa manchmal im Karpathensandstein ${ }^{1}$ ) vorkommen. ist der Industrie nicht gedient. Hier bei Wagstadt handelt es sich aber um ein Flötz von angeblich 3 Meter Stärke, von dem man also auch eine ziemlich respectable Ansdehnung in der Breite voraussetzen sollte und das wäle eine derartig nene Erscheinmo für die mährischschlesische Grauwacke, dass man zu deren Eimreihumg unter umsere Erfahrumgen stärkere Beweise braucht, als sie uns zur Zeit durch die erwälnte Grabung und Bohrung zugänglich gemacht werden.

Was es endlich mit den Kohlenstuickchen für eine Bewandtuiss hat, welche man ja als von der fraghichen Stelle stammend zu sehen bekommt, bin ich nicht in der Lage zu beurtheilen. Jedenfalls soll ja doch in der Tiefe, in welcher das fragliche Flötz gefunden wurde, nicht mehr gegraben, sondern gebohrt worden sein und in diesem Falle würde man von diesem Flötz in der Hamptsache keine wirklichen Stiicke, sondern wohl nur zerkleinerten Bohrschmand zu erhalten in der Lage gewesen scin, abgesehen höchstens von einigen Brocken. welche der Bohrer als Nachfall aus dem Bohrloch mit heranfgebracht haben kömnte. Ton einer Kernbonrung oder dergleichen halse ich wenigstens bei dieser Gelegenheit niclits gelıört.

Anf keinen Fall können die beschriebenen Verhältnisse bei Wagstadt zu solchen Hoftumugen berechtigen. wie sie Seitens mancher líreise für weite Gebiete auf Grund jenes augeblichen Fundes noch vor Kurzem gehegt wurden. Wenn nämlich in der Pateyskischlıcht sogar mehr zweifellose Kohle aufgedeckt gewesen wäre, als ich vermuthe, so wäre das noch immer kein ansreichender Beweggrund, mn

1) Der I.etztere, den ja iiberdies die allerïltesten Beohachter in Mähren und den angrenzenden Gebieten mit der Granwacke \%u verwechseln geneigt waren, stellt nïmlich hezüglich der liohlenfrage ein völliges, auf gewissen fraciellen Aehnlichkeiten beruhendes Aualogon zu dieser vor. 
für ganze Quadratmeilen Landes das Schurfrecht zu erstreben, lerliglich auf die Thatsache hin, dass dort Granwacken rerbreitet sincl.

Ich habe übrigens nicht versäumt, auch andere Punkte des Grauwackengebietes in der Nïhe des Oderthales zu besuchen, wie die Gegend der unteren Oppa zwischen Hultschin (in Preussisch-Schlesien) und Dielhau, damn die Gegenden von Fulnek und Odrau.

Nördlich von Dielhau befindet sich nahe der nach Troppun führenden Eisenbahn, noch etwas östlich vor der auf der Generalstabskarte angebenen Fischerei, ein grosser Bruch in nordwestlich fallendem Grauwackensandstein von grossentheils selır massiger Beschaffenheit. Auch hier sollen Spuren von Steinkohle vorgekommen sein, und wurde mir sogar ein angeblich von hier stammendes Stückchen Kohle gezeigt. Im besten Falle kann dasselbe nur einem sehr dümen Schmitz angehört haben. Ich vermochte in dem Steinbruch selbst nicht mehr das Geringste dieser Art aufzufinden und ebensowenig gelang dies einem bewähnten Grubenbeamten aus Ostran, der die Güte gehabt hatte, mich hieher zu begleiten. Von einer Fortsetzung der productiven Kohlenformation hieher, kamn schon gar keine Rede sein. Kann man doch überdies daran erimnern, dass nicht allzuweit von diesem Punkte und sogar noch näher an Ostrau bei Bobrownik südlich von Hultschin ein Leitfossil des umproductiven Culm, die Posidonom!y" Becheri schon seit F. Römer's Untersuchumgen bekannt ist.

Meine Begehumgen des Gebiets von Fulnek und Odrau führten zu keinem ginstigeren Resultat, wenn man das nach dem Standpunkte derjenigen beurtheilen will, welche dieses Gebiet mit Freischürfen auf Kohle belegt hatten. Doch komnte ich hier die Constatirung einiger Einzelheiten vornelımen, welche Camerlan der auf der von ihm verfertigten Karte nicht zum Auschruck gebracht hatte.

Als ich von Zauchtl über Klötten nach Fulnek ging, fand ich den neogenen Tegel, den die Aufnahme des Gemmanten an einigen Stellen in dem langgestreckten Dorfe Zauchtl angiht, auch noch weiter aufwärts verbreitet, da ich denselben ganz unzweifelhaft auch unter dem dortigen Maierhofe und noch ein Stiick weiter nordwestwärts beobachten konnte, an einer Stelle, wo C a m e rland e r's Karte dilnvialen Schotter verzeichnete.

Steigt man nun von hier nach Klötten hinauf, so trifft man sofort auf Grauwacke, deren Sandsteine noch vor dem Dorfe in mehreren Steinbrüchen gewonnen werden. Doch bildet in diesen Brüchen der Grauwackenschiefer die Hauptmasse, während die Sandsteine nur als Einlagerungen auftreten und auch beim Dorfe selbst kommt mehrfach der Schiefer zum Vorschein, dessen Farbe ich deshalb hier auf der Karte den Vorzug geben würde. Dies ist der Punkt, von welchem bereits Makowsky und Rzelı ak gelegentlich ihrer Darstellung der geologischen Verhältnisse von Brümn (Verh. d. naturh. Vereins in Brünı, 1884, pag. 6t) das Vorkommen mariner Culm- bezüglich Kohlenkalkfossilien (Crinoiden und Brachiopoden) anführten, worauf dann auch Camerlander (1. c. pag. 154) zu sprechen kam. Von Kohlen aber ist hier natürlich keine Spur zu sehen.

Am Wege von Klötten uach Stachenwall (in der Richtung gegen den sogenamten Viehwegried ${ }^{z}$ u) kommt anfü̈nghch der Schiefer eben- 
falls an cinigen Stellen zum Vorschein. l)as ältore Gebirge wird hier aber an einigen l'unliten ron umeinen Thonen bedeckt, die man nur für lieste ron Tertiär halten kann. während es nnaufgeklärt hleilst. was es mit den Schottern für ein Bewandtniss hat. welche Cam e r land e r hier einzeichnete. Sollten dergleichen hier thatsächlich rorliommen. Was ich aber trotz eifrigen Nachsurbens nicht feststellen komte, so dürften es ülnigens neogene und nicht diluviale Schotter sein. da diluviale Schotter, wie sie der genaunte Antor lier vermuthet. auf diesen Höhen schwellich vorauszusetzen sind.

Cam erlander selbst hat überdies bereits tertiäre Bildunen in der Gegend zwischen kiötten, Stachenwald und Fulnek aufgefunden. und zwar in Gestalt von Sanden (vergl. 1. c. prag. 195). Ich selbst kam diesen Funden einen nenen hinzufügen, dem ich sah solche lose, horizontal geschichtete Sande, die ein Seitenstïck zu den Salnden ron Wagstart bilden. im Walde zwischen Stachenwald und Jastersdorf etwas nordwestlich von dem auf der Generalstabskarte mit 373 Meter Höhe angegehenen P’unkte. Lbgesehen von solchen Sanden und Terwittermgslehmen kommen hier nirgends Bildumgen ror, die jünger als der Culnschiefer sind, den man zwischen dem Viehwegried und Fulnek an einigen Stellen trifft und der anch am Waierhof Fulnek sehr dentlich ansteht, bis er am Schlossberge von Fulnek dem Granwackensandstein Platz macht. In Hirschenwald oder Hirschberg aber (südöstlich ron Fulnek an der Strasse nach Nentitschein, bezüglich nach Stachenwald) kommen wieder S(hiefer vor. in welchen. wie sich ans einigen in der Wiener Universitätssammlung anfbewahrten Stücken ergibt, ausser merkwürdigen Concretionen auch Goniatiten zu finden sind, die, soweit ihr Erhaltungszustand überhaupt eine Bestimmung zulässt, in die Terwandtschaft des G. crenistrio gehören diurften.

Ich will mich indessen mit solchen Einzelleiten, die mit der uns beschäftigeuden Hauptfrage theilweise nur in losem Zusammenhange stehen, nieht weiter abgeben. dagegen will ich einen Umstand hervorheben, auf den zwar scion Cam e r a n d er (l. c. pag. 120 u. pag. 121) treffend hingewiesen hat, der aber erst durch die Frage nach der Gestalt und Fortsetzmug des Ostraner Kohlenbeckens seine praktische Berleutung erhält. Während nämlich für die weiter nach XW liegenden Culmgebiete südöstliches Schichtenfallen die Regel ist. stellt sich für dic Randzone der Culngrauwarke gegen die BeczwaOrlerdepression zu das entgegengesetzte nordwestliche Fallen ein, wie ich das thatsärhlich für die ganze Gegend zwischen Dielhan, Wagstadt. Fulnek und Odran bestätigen kann. Die Schichten der Granwacke kehren der Oderfurche, wie sie zwischen Heinzendorf, Zau'htl, Stauding und Ostrau sich hinzielıt. ihre abgerissenen Schichtenköpfe zu, deren correspondirendes Gegenstück nicht wahrgenommen werden kamn. Es ist hier und längs der die Oderfurche fortsetzenden Beczwafurche, wie $\mathrm{C}$ a m e rland er sich ausdriickt, nur mehr der nordwestliche .Flügel einer grossen Anticlinale erhalten, der östlinhe fehlt. Man mag darum nicht fehlgěhen, wemn man die Beczwa-Oderfurche einem Längsbruche vergleicht, an dem für einen Theil ilı́s Ver- 
laufes (an der (Gler) der östliche Rand dieser äussersten sudetischen Schichtenserie alogesunken ist".

Nun gilt allerdings für das productive Kohlengebirge von Ostrau die Beobachtung. dass im Wesentlichen (d. h. abgeselien von den lokalen Umbiegungen der Ränder secundärer Faltungen) das Hauptstreichen der Flötze in NO-SW dem Streiche n der Culmgrauwacke parallel verlänft ${ }^{1}$, aber anders verhält es sich mit dem Ei nf all e n der Schichtell. Man betraclite nur die Karte des Ostran-Karwiner Revieres, welche Jirinsky in der Tafelbeilage seiner muten citirten scliönen Monographie (Taf. I) mitgetheilt hat und man wird finclen, dass allen westlich von Ostrau in der Richtung gegen den Culmrand zu gelegenen Flötzen (Rothschild, Juliana, Bmno, Franziska, Günther, Arlolf u. s. w.) ein mngefähr östliches Fallen zugeschrieben wirr. Dieses Fallen ist aber der in der Randzone des Culm herrschenden Fallichtung entgegengesetzt ${ }^{2}$ ) mol dieser wirhtige Umstand scheint bei den bisherigen geologischen Nittheilungen über das Ostraner Becken keine angemessene Berücksichtigung gefunclen zu haben.

Sagt ja doch Jicinsky (1. c. pag. 9), dass die Wellen des Culmgebirges "mit der wellen- mol sattelförmigen Ablagerung des gleich daran stossenden Theiles des Kohlengebirges bei einem gl eir hen Haupteinfallen von NW narch SO parallel" seien und daher auch "ein und dieselbe Ursache mol Zeit der Entstehmng" besässen. Hier" wird also offenbar das jenseits des mehr orler weniger schmalen cumrandes allerdings allgemeiner herrschende Südostfallen der Granwacke als die normale Fallriclitmo dieser Bildung angesehen, mit der diese letztere unter das productive Carbon mntertauchend gedarlit wird. Es ist mir indessen wahrscheinlich. dass .Ticinsky, bei dessen Monograplie der Schwerpunkt in cler bergtechnischen Darstellmg liegt, sich in diesem Falle hauptsächlich anf die Aensserungen einiger mderer, speriell g'eologischer Fachmänner verlassen hat.

Stur, der bekanntlich die productive Kohlenformation von Ostran als oberen Culm ausgilut, kommt wenigstens wiederholt auf die angebliche Concordanz seiner Ostraner Schichten mit der Cuhngranwacke zu sprechen. In seiner Besclneibung der Culmflora des mährisch-schlesischen Dachschiefers (Abhandl. der geol. Reichsanstalt 8. Bd., Wien 1875-1877, pag. Xl der Finleitumg) wirk anf einer Seite zweimal hervorgehoben, dass die Dachschiefer des Cuhm mor die Ostraver Schichten eine „unminterbrochene Schichtenfolge" bilden. Auf Seite 102 derselben Abhandlung heisst es ebenfalls. dass die hetreffenden Bildungen zu einander" "oncordant" gelagert seien, was

1) Bezïglich des Streichens der Schichten des Ostraner Kohlengebirges vergleiche z. B. Jicins'ky's Monographie des Ostrau-Karwiner Steinkohlenrevieres, Teschen 1885, pag. 15.

2) Selust dort, wo die Cnlmgranwacke gegen die Nachbarsehaft des productiven liohlengebirges hin an gewissen Stellen eine flachere Lagerung aufweist, ist immer noch eine gewisse Neigung gegen Westen zn bemerken ma Cam ellander hol schon bei einer friberen Gelegenheit (Verhandl. d. k. k. geol. Reichsanstalt 1887, pag. 269) hervor, dass anch dort, wo innerhalb der flacheren Partien der hewusstèn Randzone plötzlich stärkcre Störungen eintreten, dieselben „hei stets westlichem Verflachen" stattfinden. 
dann eine Seite später speriell für den Cum von Bobrownik bei Hultschin eincrseits und die "altesten kollenführenden Schichten" von Petřkowitz des (Ostraner Beckens andererseits hchamptet wirl. Auf diese angebliche Concordanz bei Bobrownik verweist $S t u r$ damm nochmals in seiner Monographie der Ostraner Schichten (derselb. Bil., pag. 430) und indem er sodann behauptet, dass diese Schichten und der schon in äleren Sinne sogenamnte Culm , in einander übergehen ", benützt er diese Voraussetzmg als einen Hauptbeweis für die Zngehöligkeit der Ostraner Sehichten zum Culm.

Man wäre num wohl berechitigt gewesen zu elwarten, dass eine so folgenschwere Voranssetzmng etwas eingehender als durch die blossen wiederholten Behanptungen ron jener Concordanz, nämlich durch Schildermeg von thatsächlichen Lagerungsverhältuissen begründet worlen wäre, doch wird eine solche Begrüudung in allen auf diesen Fall bezüglichen Schriften St ur's rergeblich gesucht. Tiehmehr scheint es. dass dieser Antor sich hierbei vornehmlich auf die Angaben anderer allerdings sehr hervorragender Autoren verlassen hat, die vor: ihm eine der seinigen gleichwerthige Behauptung bezilglich jener Con'ordanz antgestellt hatten, allerdings zumeist wohl ohne dieser Veinumg eine besondele Tragweite beizumessen.

Zunüclsst war es F. Römer, der in seiner Geologie von Oberschlesien (Breslaı 1870, pac. 49) davon spuach, dass an clem ndurch die Opja mo die Orler gelnildeten Winkel in der Umgebung von Hultschin" der Culm roncordant von clem flötzfïhrenden Gebirge berleckt werde. Diese Meinung wird freilich dmroh die von demselben Antor lecrusgegehene geologische Karte ron Oberschlesien (Blatt Nr. I1, Loslau) wenig unterstützt, dem anf dieser Karte erscheinen die dem Granwackengebirge nächstgelegenen der an (ler 'Tagesoberflïche sichtbaren Partien des productiven Kohlengebirges, wie der Königsber' und der Dubiček bei Hoschialkowitz noch durch eine etwil 400-500 Meter breite, von Dihnvinm berlerkte Zone von jener ilteren Formation getrennt. Fine un mittelbare Berühnung der beirlen angeblich gleichförmig gelagerten Bildungen. wie man sie nach (ler Darstellung einiger Schriftsteller hier zu sehen fast erwarten kömnte. ist demnach nicht $z u$ beobachten. und so laandelte es sich für Roemel wohl anch nur mn die Mittheilung eines gewissen allgemeinen Eindrucks, den die Verhältnisse an jener Landecke hervorriefen. Freilich scheinen anch Andere einen solchen Eindruck gewonnen zu haben, demn die Angabe Römer's deckt sich wieder mit einem noch älteren Auspruch Beyrich's (Karsten's Archiv, 18. Bd. 1844, pag. 37), der ebentalls die Stelle, an der Landecke südöstlich von Hultschin" als eine Berülnungsstelle beider Formationen hervorhob und die Worte linzufügte: „In vollkommen gleichförmiger Lagerung gehen beide Formationen dort so ganz ineinander ïber, dass wie Her'r v. Carnall sich ausdrückt, das Vorkommen des Kohleustoffs, d h. das Erseheineu ron Steinkohlenflötzen das einzige Anhalten zur Bestimnung der Grenze beider Gebilde al)gibt". "Bezüglich rler gleichförmigen Lagerung aber verweist Beyrich ganz besonders in einer Anmerkung auf die speciellere Beschreibung derselben Gegend durch v. Carnall im Jahre 1832. 
Dem gegenüber ist es nun interessant, zunächst in diesem Aufsatze Carnall's selbst (Karsten's Archiv, 4. Bd. 1832) den Ursprung aller jener Aussagen anfzusuchen. Nachdem der letztgenamte Autor (l. c. pag. 311) davon geredet, dass bei Bobrownik das Steinkollengebirge an die Grauwacke grenze. bemerkt er, dass dort mamnigfache Störungen der Lagerung vorkommen und dass auch die Flötze dasellost gestört seien, nicht blos die Granwacke. "Fs dürfte daher", fährt er (pag 312) fort, „keinem Zweifel unterliegen. dass diese Steinkohlengebirgsmasse in gleicher Art wie das Grauwackengebirge nach dem Absatze mannigfaltige, gewaltsame Umänderungen der Schichtenlage erlitten hat".

Damit ist nun doch nur gesagt, dass beide Gebirgs-Abtheilungen nicht mehr in regehmässiger Lagerung sich befinden, aber aus dem Umstande, dass zwei gestörte Schichtencomplexe an einander grenzen, folgt noch nicht, dass sie concordant seien. Die Redewendung "in gleicher Art" in dem oben citirten Satze bezieht sich auch nicht nothwendig auf eine Schichtenconcordanz, sondern wohl nur anf den Begriff der gestörten Lagerung im Allgemeinen. Wer daran noch zweifeln wollte, wird durch den unmittelbar an jenen Satz anschliessenden Satz eines Besseren belehrt. v. Carnall schreibt: „Dadurch (durch jene Störungen nämlich) ging natürlich (!) das Gepräge der Anflagerung der jüngeren Bänke auf die älteren verloren, und indem hier aufdiesen sonst gewolnten Leitfaden Verzicht $z$ u leisten ist, bleibt nur das Verhiltniss der inneren Eigenschaften der beidlerlei Gebilde zu prüfen übrig". Und num kommt die Behauptung, dass Granwacke und Kohlensandstein zwar „in den Extremen leicht unterscheidbar" seien. aber dass die Gesteine der beiden Formationen sich manchmal und gerade speciell in der betreffenden Gegend bei Petrkowitz (das ist in der Nähe von Bobrownik bei Hultschin) sich "bis zur Verwechshung ähnlich sehen", so dass das Vorkommen der Kohle der "einzige" Anhaltspunkt zur Tremmung dieser Formationen abgebe. Es ist also klar. dass v. Ca r'n all nur anf petrographische Aehnhichkeiten seinen Gedlanken ron dem Uebergange jener Gebilde in einander gegründet hat, dass er aber den Berveis für die concordante Lagerung derselben ausdrïcklich und mit Bewusstsein schuldig geblieben ist und dass demzufolge die suäteren Autoren nur auf Grund eines Missverständnisses die Ansicht von einer solchen Lagerumg von Carnall übernommen, bezüghich soclam weiter verptlanzt haben.

Auch aus der Darstellung O e ynliaus en's (Geognostische Beschreibung ron Oberschlesien, Essen 1822), von der Beyrich bemerkt, dass sie eine der v. Carnall'schen ähnliche Schildermg der betreffenden Verhültnisse gebe. geht die helıuptete Concordanz keineswegs hervor. O e yn ha $u$ s en elwähnt zwar (l. c. pag. 65), dass in mährisch-schlesischen Grauwackengebirge die allgemeine Senkung der Schichten gegen das Thal der Oder und Beczwa zn gerichtet sei, aber er fügt doch nmmittelbar hinzu. dass im Einzelnen mannigfache Abweichungen vorkommen und in dieser Hinsicht verweist er unter Anderem speciell anf die Gegend ron Hultschin und Wagstadt. Es scheint also, dass ihm das veränderte Einfallen daselbst 
nicht ganz verborgen gehlieben ist, wem er anch diesem Umstande weiter keinen besonderen Werth beilegte. "Unter den verschiedenen P'unkten". sagt el freilich ferner (l. c. pag. 133), „an welchen der Kohlensandstein frei his zu Tage ausgeht, liegt die Gegend von Hultschin rem Uebergangsgehinge am nächsten, mol der Kollensandstein hat noch seln viel ron dem Charakter desselben beibehalten ", eine Achnlichkeit, die er dam später (1. c. pag. 140) nochmals betont. Was aber der genannte Autor weiterhin (l. c. pag. 141) über die Lagerung der Ostraner Flötze sagt, lässt trotzclem keineswegs in präriser Weise erkemen, dass er diese Lagerung für eine mit der Grauwacke concordante zu halten veranlasst war. Er "vermuthet" nur (l. c. pag. 143), was ja in Allgemeinen aich trotz cler factisch bestehenden Discordanz lichtig ist, dass die Flötze dieser Gegend "parallel der Grenzlinie" mit der Grauwacke verlaufen, doch würde es, meint er, der Amahme verschiedener Mulden und Sättel bedürfen, um das rerschiedenartige Einfallen dieser Flötze zu erklïren. Wem er ansserdem (l. c. pag. 139) die "verminderte Mächtigkeit und lettige Beschaffenheit der Hultschiner "Flötze" eine auffallende Erscheinung nemnt, die dort "am Ausgehenden" des Steinkohlengebirges bemerkt werden kömne, so verräth er danit deutlich. dass ihm Thatsachen bekannt waren, welche nicht eben anf eine so concordante Schichtenfolge hindeuteten, als i 1 auf Grund gewisser petrographischer Wahrnehmungen vielleicht für wahrscheinlich gehalten haben mag.

Geht man num bei der Verfolgung des Ursprungs der Sage von jener Corcordanz noch weiter in die Vergangenheit zurück und stöbert man solche Arbeiten durch, auf welche sich seinerseits O e ynh ansen beruft, so gelangt man bei Leopold v. Buch an, der in seinen geognostischen Beobachtungen auf Reisen ( $1 \mathrm{Bd}$., Berlin 1802, pag. 81) die rlort nicht näher motivirte Behamptung anfstellt", dass "gegen Troppau hinab" (womit hier die Gegend von Troppan bis Hultschin und Ostrau gemeint ist) "das Uebergangsgebirge ummerklich aber völlig in das Steinkohlengebirge übergehe", welche Ansicht ihn damn auch veranlasste (l. c. pag. 100 und 101) der Hoffinung auf Kohlenfunde in jener Gegend in einem viel weiteren Unfange Ausdruck zu geben. als wir das liente für berechtigt halten. So zieht sich also in jeweilig etwas veränderter Form der, wie man sieht, ursprünglich auf ungenügende Beobachtungen und nur auf gewisse petrographische Aehnlichkeiten zweier Gebilde gegrünctete Glaube yon deren concordanter Lagerung schon durch 90 Jahre fort, ohne dass demselben bis heute direct widersprochen worden wäre, und es wird deshalb durchaus entschuldbar, dass in neuester Zeit anch Suess, der sich ja cloch im Wesentlichen auf die Literatur stützen musste, diese Concordanz für eine ausgemachte Sache hielt (Antlitz der Erde, I. Bil., pag. 248).

Kanm man sich da wundern, wemn namentlich Laien zu der Vorstellung hinneigen. in der Culmgrauwacke könne schliesslich ebensogut Kohle gefunden werden. als in dem Oberrarbon und wenn sie in ihren Schlüssen noch einen Schritt weiter gehen als die genanten Fachmämner, ron denen freilich (a)gerechnet die aus ältester Zeit 
stammende Verlautbarung Bucli's) anch nicht einer die Verantwortung für Kohlenschïrfe in der Granwacke ubernommen haben würde? Man darf ja gewiss nicht vergessen, dass den genannten Geologen, denen wir sämmtlich für bedentsame Anfklärungen in dem fraglichen Gebiet zu Dank rerpflichtet sind, ihrer Zeit wichtigere Zwecke vorschwebten, als die genanere Feststellung des Lagernngsverhältnisses an der oberen Grauwackengrenze; indessen später haben sich nun einmal die in dieser Richtumg gemachten Aussprinche zı einer Art vou Glaubensartikel rerdichtet, auf welchem weitere Schlüsse aufzubauen von Gelehrten und Laien für zulässig erachtet wurde, und bei dieser Sachlage komte man wohl nicht umhin mit einiger Krritik an die betreffenden Mittheilungen heranzutreten.

Wir haben jedenfalls bei genauer Durchsicht dieser Literatur gesehen, dass die Beweise für jenen Glanben nirgends direct gefühnt. wurden und wir haben ansserdem kennen gelernt, dass die Srlichten des flötzführenden Kohlengebirges mit ganz entgegengesetztem Einfallen an die noriwestlich fallenden Massen des Granwarkenrandes angelagert sind, wie dem anch Jicinsky, der in mancher Hinsicht den Aussagen seiner Vorgänger nur umviliig zu folgen scheint, den franwackemrand bei Hultschin und im Oderthale direct als Ablagerungsgrenze des produrtiven Carbon bezeichnet, was mit der Vorstellung von einer coucordanten Anfeinanderfolge der betreffenden Schichtencomplexe nicht eben harmonirt, wohl aber mit der alten Beobachtung O eynhansen's von dem Auskeilen der Flötze gegen jenen Rand hin in guten Einklang zu bringen ist.

Indem nummeln die evidente Discordanz zwischen der Culmgrauwacke und dem Ostraner Kohlengebirge betont werden darf, gelangen unsere Anschamungen üher das betreffende Gebiet überdies in eine bemerkenswerthe Uebereinstimmung mit den $\Lambda$ nsichten, welche über analoge und hier zun̈̈chst zum Vergleiche heranzuziehente Gebiete ausgesprochen werden mussten.

Das Ostraner Kohlengebirge bildet ja bekanntlich nur einen Theil des grossen oberschlesischen Beckens, dessen Umrandung wir zwar nicht überall genau kennen, von dem wir aber wenigstens dort. wo es westlich von Krakan anf galizisches Gebiet übergleift, wissen. dass es an eine Partie palaeozoischer Kalke anstösst. l)ort tritt ja insbesondere auch der bekannte Kohlenkalk der Gegend von Krzeszowice auf, der im Wesentlichen als ein zeitliches Aequivalent der mährischschlesischen Culngranwacke betrachtet werden kann, und zil diesem Kohlenkalke verhält sich das dortige Steiukohlengebirge ebenfalls discordant, wie ich das schon in meiner Monographie der Gegend von Krakan (Jahrb. d. geol. R.-A. 1887, pag. 817 [395 (ler Abliandlung]) vermuthete und wie das seither ziemlich zweifellos geworden ist, seitdem man das klippenförmige Verhalten gewisser, frïher mit dem Karniowicer Kalk Ro e m e r's verbundenen Kohlenkalkpartien erkannt hat, welche dort inmitten permotriadischer Ablagerungen anftreten.

Auch für das benachbarte niederschlesische hohlenbecken gilt Aehnliches. Schon im Jahre 1869 konnte ich gelegentlich einer Peschreibung der devonischen Schichten von Fbersdorf in der Grafschaft Glatz' (Dissertation, breslan 1869. pag. 7, 13, 15, vergl. die durch 
einen palaeoutologischen 'Theil erweiterte Arheit unter demselben 'Titel. Cassel 1870. pag. 4, 8, 10 in der Zeits(hr. Palaeontographica) auf das discorilante Vorhalten des kohlengebirges von Neurode gegen die dortigen Culmgrauwacken hinweisen. und kürzlich lat gelegentlich ller prenssischen geologischen Landesaufuahmen Dathe diese Beobachtung in erweitertem Unfange bestitigt mur bereits durch eine Reihe von Publicationen ') zu erhïrten gesucht. Der Fifer Dathe's erklärt sich, wem man erwägt, dass anch für dieses Gebiet ältere Autoren von einer Concordanz zwischen Culn und Obercarbon gesprochen hatten, wie aus Just us Roth's Erläuterungen zu der geognostischen Karte ron Niederschlesien (Berlin 1867, pag. 323) ersichtlich werlen mag ${ }^{2}$ ). Interessant ist übrigens, dass selbst $\mathrm{St}$ ur schon vor lïngerer Zeit (Terhandl. geol. R.-A. 1874, pag. 207) die Lagerung seiner später mit den Ostrauer Schichten identificirten Waldenburger Schichten gegen den nierlerschlesischen Culm als discorlant bezeichnet hat.

Meine diesmaligen Mitheilungen über die Ostrauer Gegend bilden also nur eine ganz naturgemässe Frgänzıng von Thatsachen, die fïr solche Gebiete bereits gelten, bei welchen man von vornherein eine Uebereinstimmung gewisser Verhältnisse mit denen unseres mährisch-schlesischen liohlemrevieres als sehr wahrschemlich voraussetzen darf.

Vielleicht fehlt es auch anderwärts nicht ganz an Analogien zu diesen Verhïlnissen. Als $\mathrm{D}$ a $\mathrm{lm}$ e r vor einigen Jahren über den Culm von Wildenfels in Sachsen schrieb (Zeitschr. deutsch. geol. Ges. 1884, pag. 379) kam er nicht allein zu der Ueberzeugung, dass die bekamnten Flötze ron Haimichen-Fhersdorf jünger als dieser Culm seien, sondern auch dass sich in der Zeit zwischen der Ablagerung der beiden rergliohenen Bildungen gewaltige Störmgen geltend gemacht haben. Bei den Ansichten. die seit $\mathrm{N}$ a $u$ m a $n$ n theilweise noch über das angeblich unter'arbonische Alter der letztgenannten Kolnlemmulde herrschen. brancht man freilich diesen Fall nicht als ein Beispiel fiur die ras Unter- und Obercarbon zuweilen tremnende Discordanz aufzufassen, da aber nach Stur die Flötze von Hainichen und Ostran gleichalterig sind, so wäre wenigstens im Sime seiner Parallelisirmmen der von D al m e r geführte Nachweis beachitenswerth.

Dazu kommt noch, mud hierauf hat ja beispielsweise anch F. Roemer (Lethaea palaeozoica, pag. 66) aufmerksam gemacht, dass in manchen Gegenden Deutschlands, wie in Nassan und im Harz,

1) Ueber die Discordanz zwischen Culm und Obercarbon bei Salzbrum, Zeitschr. d. deutsch. geol. Ges. 1890, 42. Bd., Heft I, pag. 174; ferner Zeitschr. d. deutsch. geol. Ges. 1891, pag. 277-282; ferner zur Frage der Discortanz zwischen Culm ind Waldenhurger Schichten im Waldenburger Becken, dieselbe Zeitschr. 1892, pag. 351-358 und endlich Geologische Beschreibung der Umgebung: von Salzbrumn, in den Abhandl. der kgl. preuss. geol. Landesanstalt, Heft 13, Berlin 1892, pag. 131.

2) Dennoch hat $\mathrm{Roth}$ selhst hereits Thatsachen angefiihrt, welche der behaupteten gleichförmigen Iagerung in jenem Gehiete sehr wenig entsprechen, wie das klippenförmige Aufragen des aus Culm bestehenden Neuhäuser Schlossherges aus dem Inohlengebirge von Waldenburg (1. c. pag. 326). 
das Auftreten der echten Culmschichten ein völlig selbstständiges ist. indem sicl dort entweder überhaupt kein productives Carbon an dieselben anlehnt, oder doch nur in ganz untergeordneter und obendrein unabhängiger WVeise ${ }^{1}$ ) rlaneben zum Vorschein kommt. Das gilt bekanntlich auch für das Untercarbon in Irland, wälnrend andererseits das Obercarbon (allerdings nicht überall mit seinen ältesten Gliedern) sich stellenweise in Gebieten findet, in welchen Culm oder Kohlenkalk fehlen. Mag dann immerhin für einige carbonische Entwickelungen noch die Meinung Geltung haben, dass zwischen Unter- und Obercarbon keine Lagerungsverschiedenlıeit bestehe, wie wir das beispielsweise für das westliche Deutschland bei L epsius lesen (Geologie voll Deutschland, I. Theil, Stuttgart $1887-92$, pag. 113) ${ }^{2}$ ), so zeigt die erwälnnte theilweise Selbstständigkeit des Auftretens der beiden Formationsabtheilungen doch wenigstens clas Eine, dass wir mit der Anuahme einer Discordanz zwischen dem Culm und den Ostrauer Schichten an das geologische Publicum keine ungewöhnliche $\mathrm{Zu-}$ muthung stellen ${ }^{3}$ ). Diese Zumuthung ist umso geringer, als speciell in Mähren und Schlesien die Culmgrauwacken in ihren Verbreitungserscheinungen viel inniger mit den älteren palaeozoischen Bildungen verknüpft sind, als mit den kohlenführenden Absätzen.

Der Umstand, dass die flötzführende Ablagerung von Ostrau vol in gewissem Sime ähnlichen Störungen betroffen worden ist, wie die benachbarte Grauwacke, dass z. B. trotz des an der oberflächlichen Formationsgrenze nicht übereinstimmenden Einfallens ein ähnliches Streichen der Flötze auf ähnliche Druckwirkungen hinweist, braucht in keiner Weise als der bewussten Discordanz widersprechend aufgefasst zu werden. Dieser Umstand beweist nur, dass solche Druckwirkungen sich daselbst in verschiedenen Zeitabständen wiederholt haben, und es ist von diesem Standpunkte aus vielleicht nicht uninteressant darauf hinzuweisen, dass sogar der Bruchrand der Grauwacke, an den sich dort das Kohlengebirge angelagert hat, in der Tektonik des letzteren seine Analogie findet.

Wenigstens scheint es, dass die geradezu Flexuren ähnlichen Knickungen, mit welchen gewisse westlicher gelegene Flötze des Ostrauer Revieres gegen Osten zu absinken ${ }^{4}$ ), eine ähnliche Tendenz der Erdrindenbewegung andeuten wie jener Bruchrand. Aber das

') „Die jüngere Steinkohlenformation, welche am Südrande des Harzes bei Rothenhiitte, Ilfeld und Nenstadt, am Nordrande bei Maisdorf vorhanden ist", schreibt $\mathrm{N}$ a umann in seinem Lehrbuch der Geognosie (2. Bd., Leipig 1862, pag. 547) „scheint in ihrer Lagerung ganz unabhängig von der älteren Formation zu sein.

2) Das Fehlen der untercarbonischen Ablagerungen „am ganzen Siid- und Westrande des niederrheinischen Schiefergebirges " (ibidem pag. 125) erweckt ïhrigens einige Bedenken gegen diese Vorstellung.

3) Vergl, auch N a um ann's Lehrbuch, II. Bd., pag. 83.1 unten.

4) Vergl. z. B. anf Taf. 3, Fig. 2 der Jicinsky'schen Monographie des Ostraı- Karwiner Steinkolenreviers, Teschen 1885, die Stellıng der Flötze Francisca und Gisela beim Albertschacht und die Stellung der tieferen Flötze Minerva, Olga, Pauline, Regina von dort gegen Hruschan zn oder anch bei demselben Autor den westlichen Theil des Profils Fig. 2 anf Taf. XVII der ïsterr. Zeitschr. für Berg- und Hiitten wesen 1880. 
Alles sind Erscheinungen, welche sich auch ohne die Annahme einer Coucordauz des Kohlengebirges mit seiner Unterlage sehr wohl verstehen lassen.

Wähend man num, wie schon gesagt, bei jener alten Annalıme, zumal im Hiublicke darauf, dass Stur seine Ostraner Schichten ja noch direct zum Culm gerechuet hatte, sehr leicht auf den Finfall grerathen konnte, es bestehe bei dem vorausgesetzten Mangel einer scharfen Grenze zwischen Culmgranwacke und sogenanntem Hötzfülne (lem Culm die Wahrscheinlichlieit einer stellenweisen Flötzfülı'ung anch für jene Culmgranwacke, kam nach dem oben Mitgetheilten diese Hoffinung wohl als beseitigt betrachtet werden. Weniger als je wird es heute eine Berechtigung haben in jener Richtung kostspielige Versuche anzustellen.

Die Frage bleibt nur noch. ob und wie nach anderen Richtungen lin eine Fortsetzung der koh]enführenden Bildungen von Ostrau zu erwarten sei, abgesehen von dem ohnehin bereits seit langer Zeit erkannten Zusammenhange dieser Bildungen mit dem oberschlesischen Beckell.

Zunächst kommt da, machdem die sudetische Seite des Ostraner Revieres abgethan ist, die karpathische Unrandung dieses Revieres in Discussion, nach welcher Seite ja ebenfalls die dugen der Schürfer gerichtet waren, wie denn bereits schon vor dem neuesten Schurffieber auf dieser Seite bei Braunsberg eine Unternehmung auf Steinkohle zu arbeiten begomnen hatte. ganz abgesehen von einigen analogen Versuchen. welche etwas entferuter von Ostrau theils vor Kurzem, theils vor längerer Zeit gemacht worden waren.

Bezïglich dieser Specialfrage ist bekannt, dass die Ansicliten einiger hervorragender Geologen wie Stur und Suess eine ziemlich ausgedelunte Terbreitung des productiven Carbons inmerhalb des ron den karparthischen Flyschbildungen Mïhrens, Schlesiens und Westgaliziens eingenommenen Areals voraussetzen und dass diesen Ansichten zufolge die Grenze des oberschlesisch-mährischen Kohlenbeckens unter Lmständen erst meilenweit jenseits des karpathischen Randes zu suchen wäre.

Hierbei kann ich mich indessen kưz fassen, da $i c h$ bereits in früheren Publicationen Gelegenheit gefunden habe, zu jenen Ansichten Stellung zu nehmen, eimmal in meiner Monographie der Gegend von Krakau (Jahrb. d. k. k. geol. Reichtanst. 1887, pag. 404-411 der Abhandlung) und sodam in meinen Beiträgen zur Geologie von Galizien (Jahrb. d. k. k. geol. Reichsanst. 1891, pag. 28 etc.), in welchem letzteren Falle ich aurh speciell der in Mälnen. z. B. bei Hustopetsch versuchten Ausbeutung der im Flysch verstreuten Trünmer des Kohlengebirges gerlachte.

Ieine in den citirten Ausfülnmugen näher begriundete Meinung lässt sich in wenigen Worten dalin präcisiren, dass das productive Carbon des oberschlesischen Beckens und seiner Annexe sich zwall ursprünglich eine gewisse Strerke weit in die Gegend der hentigen Karpathen hinein fortgesetzt habe, dass jedoch theilweise zur Zeit der Flyschbildung, theilweise auch schon früher eine Zerstörung jener Carbonschichten des Karpathenbereichs stattgefunden habe, welcher 
Zerstörung eine Störung der ursprünglichen Lagerung derselben Schichten rorangegangen sei und die Wege geebnet habe. Dies wurde geschlossen anf Grund der Verhältnisse jemes ron mir schon vielbesprochenen alten Gebirgswalles, dessen letzte Aufrichtming gegen das Ende der Jurazeit erfolgt sein muss und anf dessen einstiges Vorhandensein nicht allein rerschiedene noch im Bereiche der karpathischen Sandsteinzone aufragende ältere Gesteinsklippen. sondern aurh die eigentlümlichen Trümmer hinclenten, rlie man als exotische Blöcke bezeichnet hat. Es komnte darauf hingewiesen werden. dass unter diesen exotischen Blöcken nicht allein jurassische mud altkrystallinische Gesteine vertreten sind. welche allerdings ren Hanptantheil derselben ausmachen und stellenweise sogar an jener Kilippenbildmug sich betheiligen. sondern anch carbonische Gesteine (ob)schon in beschränkter räumlicher Verbreitung ${ }^{1}$. Man durfte rann hervorheben, dass zu diesen letzteren auch der schon erwähnte enorme Blork von Steinkohlengebirge gehört, ans welchem bei Hustopetsch laut einer Angabe Stur's 26.000 Centner Kolnle gewomen wurden. Es wnrle dabei noch ansdrïclilich ron mir bemerkt. dass gerade in dem lokalen Vorkommen solcher Kohlenblöcke der beste Beweis rlafür gegeben sei, dass von einer muestörten und zusammenhängenden Fortsetzung des Steinkohlengebirges unter die hentigen Karpathen linab nicht gesprochen werden diirfe. während andererseits die stellenweise (namentlich in den Focängebieten) ganz rorwaltende Betheiligung altkrystallinischer Felsarten an jenen Blockanläufungen nur damit zu erklären sei. dass an solchen Orten die den Flysch absetzenden Gewisser die Alotragung jenes alten Gesteinswalles bereits so weit vorgeschritten fanden. dass sie das ïleste Grumdgebirge angreifen konnten, von dem also die Hauptmasse aller jüngeren, somit anch der eventuell vorhanden gewesenen carbonischen Ablagermugen bereits entfernt war ${ }^{2}$ ).

1) Es wäre sicherlich ein grosser Irrthum, wollte man alle die Kohlenstiicke und Stïckchen, welche, obschon nicht allzuoft, in verschiedenen Theilen der karpathischen Sandsteinzone gefunden werden, als Trimmer der Carbontormation deuten. Man darf nicht vergessen, dass in dieser Zone bisweilen den betreffenden Flyschschichten selhst angehörige Schmitze und kleine Linsen von Kohle vorkommen und dass nach erfolgter Zerstörung derartiger Gesteinspartien das daunus gebildete Trümmerwerk auch Fohlenstiicke enthalten kann. Dass ferner lie Qualität der ihrer Quantität nach allerdings unabbauwürdigen Flyschkohlen hisweilen eine sehr gute, der der alten Steinkohle nahekommende werden kam, liabe ich an der cretacischen Kohle von Swiatniki gezeigt (Jahrb) l. k. k. geol. Reichsanst. 1887, pag. 697).

$\left.{ }^{2}\right)$ Ich betonte urspringliclı (Jahrb 1887 pag. 402 meiner Kŕrakaner Nonographie) namentlich den Umstand, dass in der älteren Altheilung der Karpathensandsteme die altkrystallinischen Geschiebe und Blöcke seltener seien als in der jüngeren, weil zur Zeit diescr jüngeren Abtheilung die Abtragnng der vorcretacischen, in das Flyschmeer aufragenden Gesteimmassen schon grössere Fortschritte gemacht lraben musste. Einen ganz ähnlichen Gedanken hat, wie ich selie, obschon in einer etwas anderen Verbindung $\mathrm{V}$ a cek bezïglich Jer Glarner Alpen zum Ausdrucke gebracht, indem er das Fehlen gewisser iilterer Gemengtheile in den dortigen Miocänconglomeraten im Gegensatz zn dem Auftreten dieser Gemengtheile in späteren quartären Geröllbildungen durch das Verdecktsein des letreffenden Grundgebirges zur Miocänzeit exklärt, welcher Umstand erst durch die fortschreitende Denudation beholsen wurde (Jahrb. 1884, pag. 240). 
Tnter dicsen Lmständen elshicu es (nenigstens im Ilinblick anf berghaluliche Interessen) beinahe müssig noch die Fage zu discutiven. ob dem dic einstige Ausdehmmg les fraglichen Kohlenbeckens einschliesslich semer karpathischen Fortsetzung wirklich gegen So0 geographische (puadratmeilen hetragen habe. wie Stu g glaulen zu machen suchte. Doch komte ich nicht umhin anch gegen diese übertriehene Lmmahme noch besondere Berlenken zu erheben. Nag nämlich immerhin das Kohlengehirge einst stellenweise über den rorerwilnten Wall hinauscereicht haben. da wir ja ausnahmsweise auch noch südlich ron dem supponirten Terlauf desselben hei Jablunkan urössere Stïcke ron Steinkohle im Karpathensandstein kemen. so liefert uns doch das völlige Fehlen von Steinkohlenflötzen anf der Nordflanke der Tatra. so wie des in seinem Kieln aus älteren Massen bestehenden Neutragebirges und der granitischen Magura bei Tarin den besten Berreis. dass unser Kohlenbecken sich schon urspringlich nicht allzuweit in das lıeutige karpathische Gebiet hineinerstreckt haben kann. dem sonst müsste es gleich andern älteren Sedimentärbildungen daselbst zum Vorschein kommen. Eine ehemalige Fortsetzung jemes Carbons bis ins Zempliner Comitat hinein, wie sie Stur im Auge hatte (Abhandl. d. k. k. geol. Reichsanst., 8 Bd., 1877, pag. 318) war demmach in keiner Weise anzunebmen ${ }^{1}$ ).

Alle diese Erwägungen zusammengenommen mussten mich schliesslich zu dem Ausspruch bestimmen (Jahrb. d. k. k. geol. Reichsanst. 1891. pag. 33), , dass rom praktischen Standpunlit aus besondere Hoftum gen auf die productive Kohlenformation, die unter den Karpathen rollanden sein soll, nicht zu setzen sind".

So sind dem auch thatsïchlich die anf solche Hoftumugen hin unternommenen Tersuche bisher erfolglos gewesen. Weder hat ein in nenerer Zeit abgeteuftes Bohrloch am Karpathemande bei Batzdorf unweit Bielitz etwas anderes als Karpathensandstein durchstossen, noch hat der Bergbau ron Bramsberg südlich Ostrau (östliche Seite des Oderthals) bisher einen Tortheil getragen, noch

1) In friiherer Zeit hatten bekanntlich Hochstetter (1865) und Casten dy k (1873) das Vorliommen des galizischen Erdöls von liohlenflötzen algeleitet, dic unter dem Farpathensandstein liegen sollten, und hatte der erstere auf Grund dieser Voraussetzung auf eine ungeheure Ausdehnung der hei Ostrau und in Oberschlesien abgebauten Steinkohlenformation geschlossen, ähnlich wie später Stur, der von dem Vorkommen der erwälınten Kohlenllöcke und ron einen Funde obercarbonischer Pflauzen in eivem vertalkten Schiefer bei Zemplin ausging. Die Hoch stetter'sclie Ansicht ist heute, nachdem die von mir iilrigens seit jeher (vergl. Jahrl). d. k. k. geol. Reichsanst. 1579, pag. 245-303) rertretene Anschaung von dem vorwiegend animalischen Ursprunge des Erdöls inshesondere seit Engle r's Untersuchung allgemeine Geltung erlangt hat, als physilkalisch haltlos zn betrachten. Vom geologischen Standpunkte aus machte ich indessen schon im Jahre 1879 (1. c. pag. 3no) darauf aufmerksam, dass allenthalben, wo iu den östlicheren Theilen Galiziens oder seiner Umgebung mäcarbonische Bildungen zu Tage treten (ausser den obengenannten nordungarischen Gebirgen nämlicls noch in der Bukowina, an Dniestr. sowie schliesslich auch im Sandomirgebirge) das prodnctive Carbon fehle. Dass die (iiberdies nicht mit Kohlenflötzen verbundenen) Schiefer vou Zemplin, welche bei ihrer Lage sïdöstlich der 'Tatra nur einer von dem Ostraner Revier gänzlich ge. trennten Ablagerung angehöreń kömnen, dagegen nicht in's Gewicht ílleir, wurte dann im Jahre 1891 (l. c.) von mir erörtert. 
endlich lat der grosse exotisclue Carbonblock von Hustopetsch die Kosten des mit ihm unternommenen, wissenschaftlich allerdings höchst interessanten Experimentes hereingebracht. Es ist deshalb nicht ganz verständlich, dass Stur noch neuerdings (vergl. dessen Aufsatz ïber die Tiefbohrung bei Batzdorf. Jahrb. d. k. k. geol. Reichsanst. 1891) die Aufsuchumg der "Fortsetzung des ()straner Culmcarbons" in den Karpathen befürwortet und sogar von der Auffindung neuer aus dieser Formation bestehender grösserer exotischer Blöcke oder Blockklippen sich Vortheile verspricht. Ganz lokal mag sich vielleicht in den randlichsten 'Theilen der karpathischen Flyschzone noch eine orler rlie andere etwas zusammenliüngendere Partie jenes Carbons unter ller jüngeren Bedeckung erhalten laben, es fehlt aber an Anhaltspunkten zu bestimmen, wo dies sein könnte: ebenso mögen, obwohl sicher nicht allzuhüutig, Blockklippen wach Art und in der Grösse der von Hustopetsch aus demselben Material sich stellenweise im Flysch eingebettet furlen, (sollen ja doch, wie $\mathrm{Hol}$ e negger seinerzeit berichtete, die Blöcke bei Jablunkan von den dortigen Schmieden verwerthet worden sein), aber die Kosten bergmämnischer Arbeiten werden, namentlich wemn solche Blöcke erst auf das Gerathewoln] hin aufgesucht werden müssen, selbst durch die Förderung von 26.000 Centnem, wie sie bei Hustopetsch gelang, nicht entfernt gedeckt werden.

Ich habe deshalb gelegentlich meines Aufenthaltes in der Ostrauer Gegend einen Ausflug in ras Karpathensandsteingebiet, von Neutitschein, wo ebenfalls das ganze Terrain durch die Kohlenschürfer mit Ansprüchen belegt worden war, nur zu dem Zwecke unternommen, un zu sehen, ob hier etwa aussergewöhnliche, unserer Kenntniss bisher verborgen gebliebene Verlültnisse obwalten. Da aber derartige unerwartete Anzeichen vou Steinkohlenformation hier nicht zu bemerken waren, so habe ich keine Veranlassung gefunden. meine Auffassung, wie sie soeben wieder urïcisirt wurde, zu indern.

Da wir nummehr die beiden Umrandungen des Oderthales oberhalb Ostrau, einerseits die aus Granwacke bestehende sudetische. andererseits die aus Flysch bestehende karpathische als zu Hoffinungen auf Steinkolıle nicht einladend erkemnen durften, so bleibt uns bezüglich der Besprechung solcher Hoffumngen mur mehr das Oderthal selbst zu betrachten übrig. Genauer gesagt handelt es sich lier allerdings nicht blos un den relatir schmalen ebenen Streifen. der von den Alluvionen des Elusses eingenommen wird, sondern um den ganzen stellenweise gegen 10 Kiloneter breiten, seitlich vom Flusse flach hügeligen Landstrich, welcher zwischen den höher ansteigenden Thalwänden gelegen ist, wie sie eben durch die Grenzen der Grauwacke und des Karpathensandsteins auf unseren Karten näher bezeichnet werden.

Dieses Gebiet schliesst sich jedenfalls in seinem ganzen Habitus an die Gegend an, in welcher hei Ostrau die Steinkohle abgebaut wird. Es stellt direct, zurächst orographisch gesprochen. die Fortsetzung dieser Gegend dar und es zeigt, abgesehen von dem Zurïcktreten der bei Ostrau selbst nocll stellenweise, aber keineswegs üherall auftauchenden Gesteinskuppen des moductiven Carbons, eine ähuliche 
geologische beschaftenheit seiner Obertäche. innerhalb welcher Dihviahbildmugen dominiren, während unter densolhen an einigen l'unkten munächst neogenc Gesteine hervortreten.

Da hamlelt es sich mun um die Frage, ob ansser solchen allgemeinen Erwägungen bestimmte thatsächliche Anhaltspunkte für die Forterstreckmog des Carbon unter der bezeichneten jüngeren Decke vorliegen mul um die weitere Frage, wie weit man eventuell diese Forterstreckmm sich zu denken habe.

Yor Allem kommen lier die directen Versuche in Betracht, welche bereits zmr Ermittehmg dieses Verhaltens gemacht worden sind.

Ein solcher Versuch wurde bei Schönbrum unternommen, einem etwal 7 Kilometer von Mährisch-Ostran entfernten, unweit vom Znsammentusse von Oder mol Opja gelegenen Dorfe. in dessen Nähe sich bekimntlich die Bahn nach Troppan von der Hamptlinie der Nordbahn abzweigt. Nach rem Berichte .Jicinsky's (Monographie res (Istran-Karwiner Steinkohlemreviel's Teschen 1885, pag. 428) traten hier sogar einige schwache liohlenanshisse zu Tage, welche die Nachwrabme reranlassten. Fin Schacht von 120 Meter Tiefe wurde hier abgetent und es wurden dabei 8 Flötze entreckt, ron denen das tiefste in 118 lleter Tiefe, 52 Centimeter stark war. Das mächtigste Flötz war das vierte mit 62 Centimeter Dicke. Die Kohle war von hohen Brenuwerth, aber man gewamn "dur'h aufgefindene Versteinerungen" (vermuthlich PHanzen) „zugleich die Ueberzengmng, dass man sich mit diesem Schachte nahe den Hötzleeren Cuhnschichten befindet" unıl eine Bohrung, die man zur weiteren Verfolgmmg der Anfschlïsse unter der Schachtsohle noch bis zu 210 Meter Tiefe brachte, blieb wanz ohne weiteres Resnltat. Ji c insky ist jedoch der Meinung, dass man von hiej aus in der Richtung gegen Nendorf zu, das ist etwas näher an Ostrau ,jedenfalls die Flötze der 8. Gruppe" der Ustraner Flötze antreffen werde.

Der hetreffende Versuchspunkt befindet sich, mm das näher $z$. bezeichnen, etwas südwestlich von den westlichsten Hänsem von Schönbrum in der Nähe einer flachen, auf der Generalstabskarte markirten Terraineinsenkung, ziemlich genan östlich vou dem auf (lerselben Karte angegebenen, die Höhe von 256 Metern darstellenden Höhenpunkte Es ist hente von den Haldemproducten an dieser Stelle nicht mehr viel zu sehen, ıla der Schacht eingeebnet und überackert wurde. Doch sah ich noch etliche Grauwackenstücke hier mmerliegen, was beweisen kïnnte, dass das tiefste Flötz schon ganz in der Nähe des eigentlichen Culm befindlich ist, wie dem auch ol i c insky sagt, das hier schon die Schichten von Bobrownik erreicht $7 n$ seien scheinen. Ein Stück zweifellos devonischen Kalkes, welches ich hier ansserdem noch fand, überraschte mich indessen seln. deun sollte dieses Stück nicht dur'h Yensehenhand bei irgend einem Znfall hierher gelangt sein, so kömnte man fast auf die Vermuthung kommen. dass hier in der Tiefe der Culm von einer der devonischen Klippen zum Theil nuterbrochen wird, welche auch anderwïrts innerhalb der Culmgranwacken Mïhrens anftanchen.

Ungefähn 1 1/2 Kilometer nördlixh von dem Schönbrumer Schachte soll nördlich vom Maierhofe von I'oruba ebenfalls eimmal anf Kohle 
gegraben worden sein. Näheres darïber kounte ich nicht in Erfahrumg bringen. Es rerdient übrigens hervorgehoben zu werden, dass es sich hier um einen Punkt handelt, der noch näler gegen den Rand der: ïber dem Oderthal aufragenden Grauwackenerhebmgen zu gelegen ist als Schönbrum. Das Steinkohlengebirge würdle also ïber die Streichumgshinie der Schönbrunuer Flötze hinaus sich forterstrecken.

Der. Umstand, dass bei Schönbrum in jedem Falle die allertiefsten Lagen des productiven Carbons erschürft wurden, köunte zu der Vermuthumg führen. dass noch weiter von Ostran entferut auf die Anwesenheit von Kohlen nicht meln zu rechuen sei. Dieser Vermuthung stehen indessen die früher exwähnten Funde grosser exotischer Carbonblöcke von Chorin bei Hustopetsch entgegen, welche in einer etwa 45 Kilometer südwestlich vou Ostrau entferuten Gegend noch die ehemalige Ausdelnumg des productiven Carbous bekmuden. Da ferner die Hustopetscher, bezüglich Choriner Kohlen nach der Bestimmung Stur's den Schatzlarer Schichten, das heisst also einer Abtheilung angehören, welche jünger als die Ostraner Flötze ist, so scheint das Kohlengebirge anch noch in den westlichen Theilen seiner Ansbreitung in einer gewissen Vollständigkeit sich entwickelt zu laben.

Diese Entwicklung ist num eiue solche gewesen, dass analog dem Verhältuisse, welches zwischen den Flötzen ron Ostran und den dem Karpathemand benachbarten Schatzlarer Schichten von Karwin besteht, näher dem alten Grauwackenufer der carbonischen Sedimente mehr die älteren, entferuter daron mehr die jüngeren Complexe des productiven Gebirges zum Absatz gelangt sind. Bei Schömbrum, welches direct westlich ron Ostrau liegt. ist es also mur die Nähe des Grauwackemrandes, welche die Entwicklung der dortigen Flötze einschränkt, wozı noch kommen kanu, dass gerade dort vielleicht sogar eine Kuppe älterer Gesteine in das Gebiet des productiven Carbons aufragt. Aber die urspriungliche Grenze des letzteren wach anderen Seiten hin, insbesondere wach südwestlicher Richtung. wird durch die tiefe geologische Stellung der Srhönbrumer Flötze noch uicht bezeichnet.

Es bleibt uns vielmehr ein meilenlanger Streifen längs des Oderthales bis nördlich von Hustopetsch über Zauchtl hinaus ïbrig. längs welchem wir das Kohlengebirge als ursprïnglich abgelagert annehmen diurfen und wo wir anch nicht. wie es bei Hustopetsch selbst der Fall gewesen ist. eine \%ertrümmerung des Carbons speciell durch die Vorgänge bei der Flyschablagermug voraussetzen dürfell, so weit wir uns auf die noch ansserhalb der Flyschgrenze gelegenen Gebietstheile beschränkeu.

Freilich kommt hier noch ein anderer Umstand speciell für praktische Interessen in Betracht.

Die Vorgänge bei der Flyschablagerung waren es nämlich nicht allein. unter welchen dex ursprüngliche Zusammenhang der besprochenen Flötzgebilde gelitten hat. Seit lange ist es vielmehr bekannt, lass die Gewässer der Miocinzeit ebenfalls. wenn auch nur partielle Zerstörungen des Ostraner Kohlengehirges hervolgerufen habeu und dass die Neogenschichten der sogenannten Ostraner "Anflagermug völlige Canäle und Gräben in jenem Kohlengebirge ausfüllen, durch welche 
der Zusammenhang der einzelnen Fötzpartien nuterbrochen wird. Fs ist dies eine der grössten Unamehmlichkeiten für den Ostraner Bergbat.

Nun aher ist auch fïn dic weitere Fortsetzmus des oderthales oherhalb Ostraus die Anwesenheit neogener Massen ganz zweifellos. Davon, dass solche bei Zanchtl zum Vorscheine kommen. wurle schon oben gesprochen und dass Miocänschichten bei Blattendorf zwischen dem Luhabach und der Oder auftreten, hat die Aufualme Cam elsl and e r's gezeigt. Blattendorf liegt genau nördlich von Hustopets'll mo in der directen Fortsetzmo der Oder-Inepression ron ZanchtlOstrau. während allerdings der Oderftuss selhst zwischen Blattendorf und Mankendorf bereits eine andere Richtung besitzt, insofern el lier ron dem Städtchen Odran her ans dem Grauwackengebirge heranstritt senkrecht zu der Iiichtung, welche er dann in dem zu der breiten Oder-Be("zwa-1)epression gehörigen Gebiet zwischen Zamehtl unı Ostrau einschlägt. Blattendorf aber liegt in der Oder-BerzarNiedlerung. un die es sich eben hier handelt.

In welcher Weise sich num die bewnssten Neogenschichiten dem nach meiner Ueberzeugung zwischen Blattendorff, Zanchtl mol Osiran zweifellos rorhandenen Carbon anfiagern, ist bezïglich aller Einzelheiten mu durch bergmämnische Arbeiten zu ermitteln möglich. Es ist jedoch mit Sicherheit anzunehmen, dass daselbst ganz ähnliche partielle Zerstörmgen des Untergundes stattgefunden haben, wie bei ()strau selbst. Deshalb wird es Sache des Zufalis sein, ob man, sei es (lurch eine Bohrmog, sei es durch einen S('hacht ${ }^{1}$ ) die Unterlage (les Tertiärgebirges frïher oder spüiter antrifft, ob man eine relativ ‘ümne Auflagermug durchstösst, oder ob man nit seiner Arbeit das Unglück hat sich über der jüngeren Ausfüllung einer grossen Vertiefung zu bewegen.

Auch wird man in dem bezeichneten Landstriche nur ant die tieferen Flötze des Carbons zu rechnen haben. da ja eben die nrspriungliche Ablagerung der Schatzlarer Schichten, wie schon angedentet wurrle, erst in grösserer Entfermung vom Grauwackemrande sich vollzogen liat.

Illes in Allem wird es also anch hier eine Gluckssache sein, ob man banwürdige Lager muter Verlällnissen antrifft, welche den Ibbar nicht allzu thener gestalten, aber es wird wenigstens nicht mincipiell anssichtslos sein, Tersuche zu machen. Weder wird man sich. wie in ren Granwackengebieten immer meln von der Möghichkeit Kohle zu finden entfernen, je tiefer man grïbt, noch wird man, wie in dem Bereich des Karpathensandsteins dem blindesten aller 7ufälle preisgegeben sein, wem man in einem überaus gestörten Gebirge nach Rudimenten einer im Lanfe der Zeiten hart mitgenommenen Ablagerung sucht, um vielleicht in günstigen Falle einen grossen Carbonblock autzuschiurfen.

IVenn nan nämlich anch sagen mag. so gut wie man in dem keineswegs mehr intacten Ostraner Kohlengebirge mit Vortheil Abbau

$\left.{ }^{1}\right)$ In jedem Falle wird man dieses 'Terrain zunächst besser durch Bourungen als durch Versuchsschächte untersuchen. 
treibt, so gut liönue man ja auch in den zerstörten Kohlengebirge des karpathischen Bereichs sich an die eventuell vorhandenen schönen Reste halten, und wenn man umgekehrt ein auf diese Reste abzielendes Begimnen für anssichtslos halte, so diüfe man aluch in Bereiche der Neogenformation des Oderthales nichts suchen, so darf doch nicht übersehen werden, dass die Zerstörung des Carbons in heiden Fällen eine dem Grade nach wesentlich verschieden ist. Bis auf den Granit herunter sind eben die Auswaschungen im Ostrauer Carbon nicht gediehen, wie das angenscheinlich so vielfach im Bereiche der Flyschzone der Fall ist. Auf diesen graduellen Unterschier kommt es aber fïr die Praxis an, und es ist hier nebenbei bemerkt niclit minteressant zu sehen, wie eine ursprünglich anscheinend rein theoretisch wichtige Untersuchung, wie es die Forschungen über exotische Blöcke waren, dazu bestimmt sein kann, der Praxis Dienste zu leisten.

So hat denn auch Jicinsky, dieser ausgezeichnete Kenner des Ostraner Revieres (vergl. Oesterr. Zeitschr. für Berg- und Hüttenwesen. Wien 1877, pag. 281) sich nicht absolut ablehnend gegen Schurfversuche in der Gegend "zwischen Schönbrumn und Weisskirchen" (das ist in der Oder-I)repression mud deren theilweiser Verlängerung gegen die Be('zwafurche zu) ansgesprochen. Er meinte zwar, dass das Kolılengebirge dieser Gegend "jedenfalls sch tief gelegen" sei mud dass deshalb vorderhand nicht auf dasselbe leflectirt werden dürfte. Demnoch hat er einen Erfolg bei einer dirauf gerichten Unternehmumg als „immerhin in Bereiche der Möglichkeit liegend" erklärt.

Es entzieht sich der Aufgabe dieser lientigen Besprechung üher den 7eitpunkt zu reden, in welchem es angezeigt sein wird, sich fuir die fragliche Gegend näher zu interessiren. Ob dieser Zeitpunkt friiher oder später eintritt, hängt, ja zum Theile von verschierlenen Zufälligkeiten ab. Woll aber scheint es mir für den Fall. dass jener Zeitpunkt ïberhaupt koinmt, angemessen, noch etliche Worte der Frage zu widmen, bis wie weit im Bereiche der Oder-Beczwa-Depression man dem bei Nachforschungen nach Kohle in südwestlicher Richtung gelıen könne.

Wir wollen dabei zunächst in Erimerumg bringen, was über derartige directe Nachforschungen in dem fraglichen Gebiete bereits in cler Literatur vorliegt, bezüglich was für Ansichten andere Autoren auf Grund der in der Nachbarschaft desselben Gebietes gemachten Versuche geäussert haben, wenn gleich die betreffenden Angaben sehr spärlich sind.

Jicinsky hat in del soeben citirten Mittheilumg (1. c. 1877, pag. 281) nur ganz im Allgeneinen über gewisse Schurfversuche bei Weisskirchen und Hustopetsch sich geäussert, indem er hinzufüigte, dass die Kollenpartien, die man dort antraf, nur Trïmmern des Kohlengebirges angehört haben können, da die Schärhte und Bohrlöcher, die man dort niederbrachte, unter den Kohlen bald wieder jüngeres Gebirge anfulnen. Das wäre also das Verhalten der exotischen Blörke. Es ist wohl als sicher anzunehmen, lass der Autor hier nur solche Schufversuche in Auge hatte, welche in Bereiche der Flyschzone statt hatten, wie rlas für die Grabungen bei Hustopetsclı bereits 
elwähnt wurde und wie das anch für die Localitait Weisskirchen gelten muss, da südlich von Weisskirchen die Karpathensandsteine sich an das dortige ältere Gebirge anlehnen. Vermuthlich ist im letzeren Falle die etwas spüter nochmals zu erwïhnende südöstlich von Weisskirchen liegende Ortschaft Keltsch gemeint. wo thatsächlich anf Kohle gegraben wurle. Deunufolge kommt eigentlich die Jicinsky'sche Angabe grade für das nmmittelbar zur Discussion stehende Thema nicht wohl in Betracht und ich erwähne diese Angabe hier nur, weil Andere geneigt sein könnten, eine Bezielıug derselben auf dieses Thema herauszufinden. Die Darstellung Jicinsky's, der' nur von 'Tegel mul Letten spricht. in welchem die Kiohlenblöcke bei Hustopetsch mal Weisskirchen angeblich lagern, kömnte nümlich leicht auf neogene Gebilde bezogen werden, wie sie in der Oderfurche rorauszusetzen sind, während es sich in den betreffenclen Fällen, sof'ern unsere Anfuahmen richtig sind, doch nur un lettige Gebilde des Karpathens!ndsteins handeln kamn oder höchstens um solche neogene Gebilde, welche bereits den Karpathensandstein als Unterlage haben, also ausserhall) der Zone liegen, ubber die wir uns zn orientiren wïnschen.

Sicher liegt aber in dieser Zone ein Punkt. über welchen d'Elvert in seimem Aufsatz "über' den Kohlenbau in Mähren und Schlesien" uns berichtet hat (vergl. 4. Heft der Mittl. der" k. k. mährisch-schlesischen Gesellsch. des Ackerbanes, der Natur- nud Landeskiunde, Brünn, 1851, pag. 37). Der Genannte schreibt, dass in Jahre 1803 bei Pölten in damaligen Prerauer Kreise Versuche zur Auffindung von Kohle gemacht, aber aufgegeben wurlen, nachdem jede Hoftimug auf einen lohnenden Erfolg geschwunden war. Dieses Pölten ist das Dorf Bölten der hentigen Schreibweise, welches 5 Kilometer nordöstlich von Weisskirchen ganz in der Nïhe der Wasserscheide zwischen Oder md Beczwa gelegen ist.

Bald nach jener Mittheilung d'Elvert's veröffentlichte in der (inzwischen dem Format und Titel nach etwas ungestalteten) Fortsetzung derselben Zeitschrift (Mitth. der k. k. mährisch-schlesischen Gesellsch. zur Beförderung des Ackerbaues, der Natur- und Landeskunde, Brünn, 1854, pag. 107) der Ingenieur $\mathrm{B}$ ӥ h l e r einen kurzen Artikel über das wahrscheinliche Vorkommen von Steinkohle zwischen Weisskirchen, Holleschau, Kremsier mo Prerau, und glaubte derselbe damit eine Fortsetzung des Ostraner Kohlengobirges längs des Beczwathales bis über Prerau hinaus beweisen zu könmen ${ }^{1}$ \%.

Er ging dabei freilich ron theilweise nach unserem heutigen Standpunkte ganz unzulässigen Voraussetzungen ans, wie er demm z. B. bei Tlumetschan, welches im Bereich der Zone des Karpathensandsteins liegt, an die Anwesenheit des in ganz Mähren fehlenden Zechsteins glanbte, den man nur zu durchstossen branche, um anf Kohle zu kommen. Sodann gedenkt er eines Kohlenfundes bei dem soeben schon genamten Orte Keltsch, wo man zuerst bei einer Brumnengrabung anf Kohle stiess und ansserdem spricht el daron,

1) Die Citate dieses und des vorgenannten Aufsatzes bei C amerlander (1. c. pag. 207) siud nicht ganz genau und wird in densellien z. B. der B ia h le r'sche Artikel als ans dem Jahre 1853 stammend, angeführt. 
dlass bei Holleschan südlich von Leipnik, welcher Pmukt ähnlich wie Kieltsch hereits in oder doch nahe dem Bereich des Karpathensandsteins liegt, gelegentlich der Abteufung eines Versuchsschachtes Kohle getroffen worden sei. In clem letzteren Falle wissen wir aber hente durch 'T a usch (vergl. Cam e rlande r l. c. pag. 205), dass es sich um miocine Braunkohle geliandelt hat, deren Vorkommen von dem der gesuchten Steinkohle ganz mabhängig ist.

Was dann die Loalität Preran anlangt, wo $B$ üh le le ebenfalls Steinkohle vermuthete, so gestand el sellst $7 u$, in mehreren Bohrlöchern, die er daselbst bis zn 45 Kklafter Tenfe niederbrachte. nur jüngeres Tertiärgebirge angetroffen und daher einen directen Beweis für seine Ansicht nicht hergestellt zu haben.

Ansser den jetzt genamnten Punkten el'wälnt $B$ ï h l e r indessen anch das bereits von d'Elvert genamnte Bölten, wo nach seiner Mittheilung „durch Grabung eines Brumens in geringer 'Tiefe ein obgleich schwaches, aber gute Kohle lıatendes Flötz aufgedeckt" worden sei.

Nacht aher die etwas allzn sangninische Art, in der der genannte Ingenieur trotz des Nangels an greifbaren Resultaten seine Hypothese mitheilte. schon an mud für sich den Leser etwas stutzig. so wird man durch eine unmittelbar hinter B ïhle r's Artikel abgedruckte, angenscheinlich von ziemlich knndiger Hand herrührende Entgegnung ${ }^{1}$ ) noch mehr zur Vorsicht bestimmt. In dieser Entgegnung heisst es nicht allein (l. c. pag. 109) ganz richtig. man müsse abwarten, ob denn die angeblichen Kohlenspuren bei Keltsch und Holleschan thatsächlich durch ihre Beschaffenheit anf echte Steinkohle. linweisen, sondern es wird anch speciell bezinglich der vermeintlichen Kolıle von Bölten (l. c. pag. 108) die Vermuthnng geäussert, dass schwarze, bituminöse Schiefer, wie sie "von Laien nicht selten für Steinkohle angesehen" welden, daselbst zn einer Täuschung Veranlassung gegeben haben.

Da nun diese Finwände meines Wissens olne Erwiderung geblieben sind, eine weitere Bestätigung der $B$ ïlıle r'schen Angaben auch nicht erfolgte, so wird man wohl gut thm, das Vorkommen von Kónle bei Bölten zum mindesten für unsicher zu halten und anzınehmen, dass die vorher erwähnte Mittheilung d'Elvert's üher missglückte Schürfe an dieser Lokalität uns bezüglich des seln fraglichen Werthes der daselbst zu erwartenden Flötze immer noch besser orientire als $B$ ühle r's Vermuthungen.

Das Resultat mnser Umschan über die älteren hier in Frage kommenden Mittheilungen ist also ein karges und obendrein ziemlich entmuthigendes gewesen. Doch hat sich heransgestellt, dass speciell nm einer oder höchstens zwei der genamnten l’mkte, nämlich Bölten

1) Dieselhe ist mit a. l. unterzcichnet und Camerlander hat woll deshalh geglaulut, dass sie von dem seinerzeit $n \mathrm{~m}$ die Kenntnisse Mälırens hochverdienten A. Heinrich herrihre. Das ist möglich, obschon der Kritiker B ii hl er's sich auf eine damals schon mehr als 30 Jalıre alte Schrift Heinrich's in einer Form bezieht, welche den Anschein crweckt, als ob man es bei dem Verfasser der Notiz mit einer anderen Person zu thm habe. 
und allenfalls Preran direct imnerhalh der uns allein noch interessirenden. durch die Oder-lieczwa-Depression rorgestellten Zone gelegen sind, und man kömte deshall, sagen. es fehle an einel geeigneten Zahl ron hierher gehörigen Frnittehngen, ein solcher Mangel sei aber noch kein zwingender Beweis für die Nichtexistenz ron Kohlenlagern in dem hezeirhneten Gebiet. Für ein abschliessendes Trtheil sind ausserdem dic an jenen Punkten gewonnenen, uns überdies nu unvollkommen inherlieferten Frtahnum vielleicht noch micht eimmal im lokalsten Sime ganz anspeichend. Wir sind deshalb genöthigt in Frmangelnng coniigender directer dmhaltspmkte der uns beschäftigenden Frage now anf cinem anderen Wege heizn-。 kommen.

Es ist in der Finleitumg \%n diesem Autsat\% von der wichtigen Wasserscheide die liede gewesen. welche ruer durh die Oder-BeczwaDepression verläuft mid wir wollen sehen. ol Anhaltspnnkte voriegen. welche gestatten, dieses 'Terrainverhialtuiss mit unserer Lnter'suchum in Beziehmu zu bringen. Iniese Anfgabe wird ms wesentlich exleichtert durch den Lmstand, dass bereits $\mathrm{C}$ am er la n d e $\mathrm{r}^{\circ}$ in eingehender Weise jener Wasserscheirle seine Aufmerksamkeit gewilmet hat.

Derselbe machte wahrscheinlich, dass die betreffende Teraingestaltung seit lange gleichsim vorbereitet sei. Fr zeigte zmäichst, dass dieselhe Wasserwchcile hereits zur Diluvialzeit als Bodenschwelle hestand (1. c. pag. 309. sowie 212-218), dass das nordische lulandeis bis hierlier. alher nicht weiter reichte.

lass fermer zur Mionäinzeit in lerselhen fegend eine ranalantige

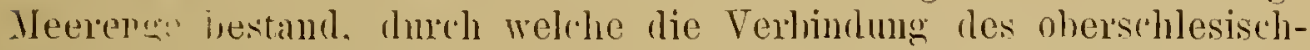
polnischen Tertiärmeeres nit der Wiener Bucht hamptsärchlich hergestellt wude. hat man seit längerer Zeit angenommen. und da derartige Meerengen die Stellen sind, an welchen sich die ron der Wasserbederliumg getrennten Landerhehungen gleirhsam die Hand reichen. so denten sie anch zugleich eine Lrt idealer Verlindmug dieser Frhehmgen an. wolche unter Umstünden einem Landrücken gleichwerthig erscheinen kam. Ian kam also vielleicht sagen. jene Wassers'heide war anch zm Mlocänzeit schon angerlentet, oder besser, sie war schon vor der miorïnen Zeit in ungefähn derselben Gegend als solche vorbereitet, wie denn überhampt alle msere neneren Beobachtnngen darauf hinweisen, dass die mit der Thalbildung zusammenhängenden lieliefverhältnisse Mährens zur jüngeren 'T'ertiün'zeit und bezüglich der ausserkalpathischen 'Theile des landes sogar schon zm1 Kreidezeit mincipiell ganz ähnliche waren wie lieute.

Baron Cam e rla n d e war sogar der Ansicht, lass an der betreffenden Stelle eine stärkere Borlenerhebmig bestand. welche von dem miocinen Meer üherwumden wurde, als es den burchgang dmoh die Berzwa-Oderfurche anshöhte (l. ‘. pag. 204-208j. Man kamn also ron diesem Standpunkt ans sagen, die Artion der mioränen Gewässer hahe hier nivellirend gewirkt. weldhe ansgleichende 'Thätigkeit dann ührigens noch huch die die Oder-Beczwa-Depression erfüllenden Serlinente dieser Gewässer gesteigert wnrde. Uebrigens

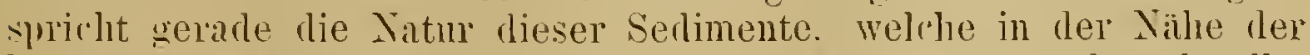
bewnsten Wasserscheide anftreten, für das Alter dieser Bodenschwelle, 
an deren Flanke wir nämlich (vergl. Camerlan d e r lag. 207), "die groben Sandsteine von Blattendorf besitzen; die hier besonders seichte Stelle des Miocänmeeres konnte Tegel und mürbe Sandsteine nicht absetzen".

Wir müssen da indessen einen Schritt weiter gehen und uns fragen, ob die bewusste Bodenschwelle, cleren Constanz wir für die jüngeren Periorlen kennen gelernt haben, nicht auch schon in viel früheren Zeiten eine Rolle gespielt hat und ob ihr für die Begrenzung rles productiven Carbon eine gewisse Bedeutung zukommt. Nicht als ob dainit gesagt sein sollte, dass etwa schon zur Carbonzeit ge- rade hier auch schon eine wichtigere Wasserscheide bestanden habe, es handelt sich vielmehr nur um die Ermittlung, ob die genannte Bodenschwelle durch eine bestimmte Beschaffenheit des Untergrundes an dieser Stelle bedingt wird und ob diese Beschaffenheit nicht mit der Ablagerungsgrenze der Kolılenformation des Ostraner Reviers in einiger Beziehung steht.

Zunächst muss da nochmals an die bereits in der Einleitung erwähnte Thatsache erimnert werrlen, dass die Oderfurche gerade dort, wo sie beginnt in die-Beczwafurche überzugehen, nicht mehr beiderseits dieselben Erscheinungen anfweist, wie zwischen Zanchtl und Ostrau, wo sie einerseits von Culmgranwacke, audrerseits von Flyschbildungen überragt wird. Gerade in der Gegend zwischen Bölten und Weisskirchen, sowie darüber hinaus bis jenseits Leipnik wird ja, wie schon gesagt, die Beczwa-Oder-Depression beiderseits von sudetischen Gesteinen begrenzt. Das südöstliche Ufer dieser Depression wircl von Weisskirchen angefangen bis in die Gegend von Metzlawitz und Pawlowitz hin voll denselben Culngrauwacken gebildet, wie sie das nordwestliche Ufer längs der ganzen Furche zusammensetzen, und speciell bei Weisskirchen treten südlich, östlich und nordöstlich von dieser Stadt noch zahlreiche Kuppen devonischen Kalkes hervor, welche Dr. v. Tausch erst kürzlicli beschrieben hat. (Jahrbuch der k. k. geol. Reichs-Anst. 1889, pag. 405.)

Dass dieser Kalk in seiner Verbreitung der Grauwacke gegenäber (trotz der Discordanz beider Bildungen) nicht völlig selbstständig ist, geht daraus hervor, dass noch östlich von demselben durch die Aufnahmen von Tausch das Auftanchen einzelner Culmpartien verzeichnet werden konnte, wie nördlich von Hleis und sogar zwischen Kunzendorf und Pohl südöstlich von Bölten. Der Devonkalk tritt also, wenn man sich die jüngeren Berleckungen wegdenkt, in dieser Gegend gleichsam klippenartig ans der Grauwacke hervor, mit welcher er aber zu einem gemeinsamen Gebirgsganzen ähnlich wie anderwärts in Mähreu verschmolzen ist.

Nan wird nun bei Betrachtung einer geologischen liarte dieses Gebietes ganz naturgemäss zu der Vorstellung kommen, dass die dem productiven Carbon vorausgïngigen Gebilde rlaselbst sich jedenfalls über die bewusste $W$ asserscheide hinaus ausgebreitet haben, dass erst durch spätere Ereignisse die Partie zwischen Weisskirchen und Leipnik von der Hauptmasse des Grauwackengebiets oberflächlich abgetrennt wurde, und dass unter der Tagesoberfliche noch der alte Zulsammenhang besteht, sofern nicht die vor und nach dem Eintritt des 
miocïnen Meeres in dem Beczwacanal stattgehabten Auswaschungen jenen Zusammenhang stellenweise aufgehohen und vielleicht sogar schon die Unterlage dieses alten Gebirges angegriffen haben.

Sei dem wie ilnm wolle, bei einer Reconstruction des hente durch die Beczwafurche unterbrochenen Grauwackengebirges gelangt man dazn, eine von Odran nach Süden über Bölten und Pohl gehende Linie als ideale Begrenzmng dies alten Massivs anzunehmen, und wenn man unter dieser Linie anch keineswegs die u'sprünghiche Ablagerungsgrenze der Grauwacke sich vorzustellen brancht, so darf man dagegen in ihr wohl die ursprïngliche Ablagerungsgrenze des productiven Carbons erblicken.

Eine scheinbare Schwierigkeit bleibt bei dieser Vorstellung noch zu überwinden. Es wurde vorhin gesagt, dass man im Sinne $\mathrm{C}$ a m e rl and e r's den Nordwestrand der Oder-Beczwafurche als einen Bruchland anzmelmen habe, und dass das Absinken der betreffenden Massen ror Beginn des Absatzes der Ostrauer Schichten stattgefunden habe. In diesem Falle würde freilich consequenter Weise nicht blos längs der Oder, sondern auch längs der Beczwa eine (gerade dort einer Grahenversenkung sehr ähnliche) Tiefenzone entstanden sein, welche den Absätzen der jüngeren Carbonzeit Raum zum Eindringen liess. Indessen frägt es sich dloch sehr, ob das $\mathrm{Ab}$ sinken längs des erwälnnten Bruches überall ein gleichmässiges oder ein graduell rerschiedenes war. Es genügte jedenfalls, wenn in der Gegend der oft erwähnten Wasserscheide jenes Absinken ein minder intensives war, um der Ausbreitung der Absätze des productiven Carbons nach dieser Seite hin eine Schranke zu setzen.

Diese Eventualität einer graduellen Verschiedenheit der betreffenden Störung wird aber von $\mathrm{C}$ amerlander, der sich mit der heute uns vorliegenden Kohlenfrage gar nicht beschäftigte und daher ganz unbefangen davon die Verhältnisse jenes Bruches beurtheilte, durchans für wahrscheinlich gehalten. Er betont ausdrücklich (l. c. pag. 208), dass „eine längs der Bruchlinie erhalten gebliebene Culmpartie" wahrscheinlicherweise den Anlass zur späteren Bildung der bewussten Wasserscheide an jener Stelle gegeben habe, sowie er in Einklang damit geneigt ist, der früher erörteten Meinung zu folgen, wonach die vermeintliche Kohle, die man einst bei Bölten zu graben versuchte, nichts als bituminöser Culmschiefer war.

Nit dieser Vorstellungsweise stimmt schliesslich vielleicht auch der. Unstand überein, dass gerade südlich von jener Wasser'scheide die devonischen Kalke von Weisskirchen sichtbar werden, das heisst, dass diese Kalke gerade hier in das Niveau der Terrainoberflache gelangen, wälnend sie ringsum unter der Culmdecke verborgen bleiben. Es hängt das freilich wohl theilweise damit zusammen, dass eben zwischen Weisskirchen und Leipnik der schon einigemal erwähnte miocäne Caual seine engste Stelle gehabt hat und dass dadurch bedingte stärkere Strömungen stellenweise in dieser Region sehr abradirend gewirkt haben; es ist aber andrerseits auch zu berücksichtigen, dass eben weil in derselben Region ein erhöhter Buckel bestand, die Kraft der Gewisser an geeigneten Punkten leichter bis zum Untergrumde der Culmgrauwacke sich durcharbeiten und 
diese Basis blosslegen konnte, dem letztere war dam in einer der Wirkung des Wassers zugänglicheren Höhenlage, als wenn die jenen Buckel und dessen näcliste Umgebung zusammensetzenden Gesteine gleich den übrigen l'artien der Beczwa-Oder-Depression in grössere Tiefen abgesunken gewesen wären. Wem num jene abradirende Wirkmng genan an einer Stelle eintrat. wo die bewnsste Canalverengerung in rler Gegend des hentigen Weisskirchen sich nach Osten zu erweitern anfing; so kamn dies leicht mit der Ammahme in Uebereinstimmung gebracht werden, dass jener Buckel, den die Gewässer allmälig zu überschreiten und zu übel'winden lıatten, dieselben zum theilweisen Ausweichen nach einer der Uferseiten nöthigte. Bei dieser Gelegenheit komnte der üher den Kalken gelegen gewesenen Culmderke arg mitgespielt werden, wobei ich keineswegs überselıen will, dass auch die nachmiocäne Erosion (besonders für die an der Beczwa sürllich von Weisskirchen gelegenen Localitäten) ihren $\Lambda_{11-}$ theil an der Blosslegung dler Kalke besitzen muss.

Es ist indessen ron vornherein wahrscheinlich, dass üherhaupt längs der ganzen zum Theil beiderseits von sudetischen Gesteinen begleiteten Tiefenzone Weisskirchen-Prerau gerade der Frosion. sei es rlurch einen vormiocänen Fluss. sei es durch marine Strömungen. welche rie Absätrie der Miocänzeit einleiteten, eine wesentliche Bedeutung für die (nachträglich fortgefülıte) Ausarbeitung der betreffenden Furche zukommt. Daher rühnt es wohl auch, dass etwas westlich von Leipnik noch jnmitten dieser Furche bei Radwanitz, Buk und Sobischek ähnlich wie bei Weisskirchen devonische Kalke entblösst worden sind.

Ich gebe ohne Teiteres zu, dass die hier zuletzt gemachten Ansführungen viel Hypothetisches an sich haben, aber man sieht wenigstens, dass der Cam erlande r'schen Ansicht von der sehr alter Fxistenz einer Terrainschwelle an dem Orte der hentigen Wasserscheide von Bölten sich die verschiedenen Erscheinmgen in der fraglichen Gegend ganz gut unterordnen lassen, und da es vorläutig schwer scin diufte, diese Ansicht durch eine bessere zu ersetzen, so wird es nicht schaden, wemn auch die Praxis mit derselhen rechnet.

In jedem Falle lässt sich sagen, dass, gleichviel ob man jene Annahme für begründet hält oder nicht und gleichviel. welchen Vorgängen man eventuell die Fntblössung des Devon im Bereiche der Beczwa-Depression zuschreibt. gerade das Zutagetreten dieser älteren Gesteine schon für sich allein eine Abmahnnng für Kohlenschürfer bedeutet. Die Kohlen sind entweder. wie ich das für walnscheinlich halte, hier nie abgesetzt worden oder sie sind spuiter weggewaschen worden, was für den Praktiker auf dasselhe liuauskommt.

Mit einem Worte, es erscheint bei dem hentigen Stande unserer Kenntnisse als ein geladezu umbedachtes Unternelnmen, wenn man jenseits der Böltener Wassers'heide nach einer Fortsetzung rles Ostraner Kohlengebirges sucht. I)as Be('zwathal, westlich von Weisskirchen, ist in dieser Hinsicht in keiner Weise als ein zu Hoffnungen amregendes Gebiet aufzufassen, und nur das Oderthal bis in die Nähe der bewussten Wasserscheide ist unter flen früher hereits erwähnten Einschränkmoen als ein Terrain zu bezeichnen, in dessen Tiefen möglicherweise Steinkohle rerborwen liegt. 
Aber anch hier wiol es nicht rithlich seim, mit etwaigen Versuchen zu nahe an jene Wasserscheide heranzugehen. da man mach den rorangehenden Voranssetzungen sich rlort nicllt allein zu nahe rem ursprünglichen Ausgehen der möglicherweise vorhanden gewesenen Flötze befundet, sondern auch mit der Wahrscheinlichkeit rerhnen muss, dass in der Nühe der alten Bodenschwelle am Ausgang der bewussten Camalverengerma Zerstörungen des vormiocänen Gebirges in grösserem Massstabe stattgefunden haben. Ueber die Linie l'etersdorf-Jassnik bei solchen Versuchen viel linausmochen, mag also nicht empfohlen werden.

Die Anschanumg. welche ich mir hiermit erlault hahe über die Auspicien der Nachforschung auf Steinkohle in der Tmgebung des oberen Oderthales anseinanderzusetzen, stimmt. wie man sieht, mit den ühertriebenen Hoffinmgen. welche der Schmrfversuch von Wagstadt hat aufleben lassen. sehr wenig ïberein. Immerhin mag es als eine Art 'Trost hinsichtlich iler rorangegangenen Discussion betrachtet werden, dass wenigstens fü̈r den zwischen Schönbrum und .Jassnik gelegenen Landstreifen. das ist für die nähere Umgebmg der Ortschaften Wischkowitz. Polanka. Stiebnig, Stauding. Botenwald, Petrowitz. Seitendorf und Zanchti narh menschlichem Ermessen die Möglichkeit besteht. auf Kohlen zn schürfen, ohne damit sich ansserhall, ler dmrch die Erfalımg mu die Wissenschaft gezogenen Grenzen zul begeben.

\section{IJ. Die Ostraner Schichten gehijen nicht zum Culm.}

Anhangsweise will ich jetzt noch eimmal speriell einer Frage gedenken, welche bereits im Terlanf der rorangegangenen Anseinandersetzung gestreift werden musste mu welche. obschon sie mit der Frage nach dei eventuellen Fortsetzmg des Ostran-Kíariner Kohlengebirges nach bisher manfgeschlossenen Regionen hin nicht gerade mmittelbar zusammenfällt, denn doch zu dem vorher besprochenen Gegenstande in einer gewissen Beziehmug steht. Es handelt sich, kurz gesagt, um die Aunahme Stur's. dass die Ostraner Schichten mitsammt ihren reichen Flötzen nicht mehr der stratigraphischen $\mathrm{Ab}$ theilung des productiven Carbons, sondern noch dem Culm zuznrechmen seien.

Ich sage absichtlich, dass diese Ammahne nicht grade ummittelbar auf die Untersuchumg del dem Ostraner Revier möglicherweise zukommenden Ausdehnung sich bezieht, denn mittelbar ist dies doch vielleicht in gewissem Grade der Fall, insofern man viel leichter dazu kommen wird, auch in dem eigentlichen Culm nach Kohlen zu suchen, wem man diesen Culm mit den Ostraner Schichten sich imnig rerlumden denlit. als wenn man eine schälfere Trennung zwischen beiden Gebilden zugestelit.

Wemn jeh mu in dem Folgenden der bewnssten Annalime entgegentrete, so liegt mir uichts ferner als eine Schmälerung des Verdienstes, welches sich Stur dur'll seine Monographie der Ostraner Schichten erworben hat. Dieses Verlienst beruht unbestritten auf aler grossen Menge feiner phytopalaeontologischer Beobaclitungen, welche 
in dieser wie in allen ähnlichen Arbeiten desselben Verfassers niedergelegt wurden, und es heruht ferner anf der Constatimng der floristischen Differenzen, durch welche die einzelnen Flötzzüge der betreffenden Schichtgruppe sich auszeichnen und welche deshalb zur leichteren Wiedererkennmig bestimmter Flötze sehr wesentlich beitragen kömmen. Diese Arbeit wird also nicht allein dem Gelehrten wichtig, sie wird auch dem Praktiker nützlich sein kömnen. Hier aber handelt es sich unter aller Anerkennung jeues Verdienstes um die Besplechung einer theoretischen Vorstellung, zu deren Begründung alle jene Beobachtungen und Constatirungen, wie wir sehen werden, nicht ausreichen und welche eine etwas schärfere Pritfung verlangt, weil sie im Gegensatze zu traditionell gewordenen Auffassungen steht.

Die betreffende Ammahme, welche Stur in der genannten Monographie entwickelt hat, basirt im Wesentlichen anf zwei Arten von Beweggrunden. Eimmal ging der Autor von der vermeintlichen Concordanz der Grauwacke und der Ostraner Schichten aus, und zweitens schienen ihm die organischen Einschlüsse eine engere Verkniipfung der Ostrauer Schichten mit der Grauwacke als mit den zulnächst folgenden Schatzlarer Schichten herzustellen, mit welchen letzteren im Sime Stur's das Obercarbon beginnt.

Das erstgenannte Motiv hätte aber, selbst wemn die Concordanz der Grauwacke nit den Ostrauer Schichten bewiesen wäre, logischerweise als unverwendbar erkannt werden sollen, insoferne die Schatzlarer Schichten gegen Karwin zu anerkanntermassen ebenfalls völlig concordant anf den Ostrauer Schichten aufruhen. Wenn es sich also blos um Lageruugverhältnisse handeh würde, dann liätten unter den Voraussetzungen, von denen St $n r^{*}$ ausging, die Schatzlarer Schichten ebenfalls zum Culm gezogen werden kömmen, anstatt dass hier mitten durch die flötzfülnenden Absätze ein tremnender Schnitt gemacht wurde.

Nun aber konnte in der obigen Darlegung gezeigt werden, dass diese Voraussetzungen bezïglich der Concordanz zwischen Granwacke und Ostrauer Schichten durchans mrichtig waren, dass in Gegentheil eine ausgesprochene Discordanz zwischen der Culmgranwacke und den Ostrauer Schichten besteht. Jener tremende Schmitt zwischen zwei Formationsabtheilungen einerseits und die Vereinigung der tieferen hier in Betracht kommenden Schichtencomplexe andererseits wird also von $\mathrm{St} u \mathrm{r}$ in einer Weise vorgenommen, die der Lagermug der betreftenden Schichten direct widerspricht.

Bezüglich jener vermeintlichen Concordanz zwischen Grauwacke und Ostrauer Schichten ist es ïbrigens noch von Interesse zu seheu, dass Stur dieselbe zwar für seine Beweisführung benützt, sie aber andererseits aus seiner Darstellung wieder theilweise eliminirt. Er schreibt nämlich (1. c. pag. 432 [326]) gelegentlich der Besprechung des Unterschiedes der Faunen des eigentlichen Culms und der Ostraner Schichten, dass dieser Unterschied vielleicht mit Niveanveränderungen im Zusammenhange stehe, "in Folge welcher ein Theil der damaligen rein marinen Abglagerung der Begleitgesteine des Dachschiefers ïber die Meeresoberfläche trat und der Grund des damaligen Meeres in einzelnen Theilen seichter geworden ist". - "Diese Störung (!) 
lespective Zmmahme des von den hamdpthamen bewolmbaren Terrains", so fülnt er fort. "habe in Folge der Trockenlegung wrosser Strecken einstigen Meeresgrundes anf die liora einen jeclenfalls :ünstigen Einfluss ausgeübt". "Viele Pflanzen konnten sich auf dem nenen Boden olme irgend welche Störmg ihner Lebensweise ansbreiten und fortleben. für andere Arten brachte das nene Land nene, veränderte Verhältnisse darbietende Standorte, md diese waren es. die zm minder oder mehr wesentlichen Verinderung ihrer äusseren Gestalt und imneren Organisation den ersten Anstoss geben komnten."

Sollte man nicht, nebenbei bemerkt, ans diesen letzten Worten auch den Schluss ziehen dürfen, dass dem Autor sogar vom phytopalaeontologischen Standpunkte ans die Bedentung der Formationsgrenze zwischen der Gramwacke (nebst ihren Dachschiefern) und den Ostraner Schichten wenigstens vorübergehend zum Bewusstsein gekommen ist. Doch wollen wir der Discussion der palaeontologischen Thatsachen hier nicht vorwreifen und ich erwähne deshalb lieber, dass Stur an einer anderen Stelle seines Werkes (1. (c. pag. 464 [358]) nochmals ron der "continentalen Hebmg" spricht, "die einen grossen Theil der Begleitgesteine des Dachschiefer's trocken legte". Daraus geht doch zum mindesten hervor, dass el den Gedanken von der Concordanz der Granwacke mit den Ostraner Schichten nicht so conseyuent dmrligefühnt hat, wje Suess, der spätel', auf diesen Gedauken gestützt, das jroductive Kohlengebirge als einst weiter über die Granwacke himüber verbreitet mo später von dort weggewaschen erklärte. (Antlitz d. Erde I. Theil, pag. 248, mten ${ }^{1}$.)

Wenn man nun auch im Allgemeinen zugeben muss, dass sehr leicht irgendwo der Fall eintreten kann, dass ein Theil des von einer Ablagermuy eingenommenen Gebietes von Störmgen betroffen wird, wälırend ein anderer Theil dieses Gebiets in msprünglicher Lage verharrt md von den mächstfolgenden Absätzen concordant bedeckt wird, dass also demzufolge partielle Emporlıebmgen gewisser Schichten mit einer Einengmg des betreffenden Absatzbeckens Hand in Hand gehen kömmen, ohme für die eingeengten Theile dieses Beckens die Möglichkeit einer Fortsetzmmg des Ablagerungsprocesses auszuschliessen, so hat man doch speciell bei der Drirchsicht der Sturschen Ablandlung die Empfindung; als ob hier die Ammahme ron ler bewnssten Concordanz und die Vorstellmmg von der dem Absatz der Ostrauer Schichten vorausgängigen Fmporhebung der Grauwacke ziemlich movermittelt neben einander laufen, da der Antor selbst

1) Andrerseits hat freilich der letzgenannte Autor hierbei wohl nicht geniigend berïcksichtigt, dass gerade unter der Voraussetzung einer solchen Concordanz das productive Carbon zwischen den Faltenwurf der Grauwacke hätte miissen vielfach eingepresst werden, wodurch bei späteren Abrasionsvorgängen ein Theil der eingeklemmten Partien vor der Zerstörung woh] bewahrt geblieben wäre. Warum eine solche Conservirung des Obercarbons gelegentlich der "grossen vortriadischen Abrasion $^{-}$gerade nur , in der weiten Mulde" stattfand, in der wir heute die flötzführenden Schichten finden, ist nicht recht verständlich, wenn man nicht in jedem Falle die Existenz dieser Mulde mit einem Terrainverhältniss in Verbindung bringt, welches sich vor dem Absatz der Flötze lerausgebildet hat. Damit langt man aber wieder bei der Annahme einer Discordanz zwischen den Schichten des Muldenrandes und der Muldenausfïllung an. 
eben keiner]ei Versuche macht, diese Vorstellungen in Sinne jener soeben skizzirten allgemeinen Anschanung miteinander zu versöhnen.

Ich erwähne das Alles übrigens nur um zu zeigen, dass die Begründung des tektonischen Theils der Stur schen Beweistührum keine ganz geschlossene ist, wie sie das wohl bei einer so einschneidenden Aenderung der bis dahin geltend gewesenen Ansichten über den Culm hïtte sein sollen. Die Autoren, die vor Stur von jener Concordanz bei Hultschin und Ostran gesprochen haben, sind zwar theilweise (wenigstens so weit dies F. Roemel betrifft ${ }^{1}$ ) an der Entstehung des Stu r'schen Irrthums mithetheiligt, sie liatten aber bei ihren Darstellungen viel weniger Ursache, gerade diesem Punkte eine solche Bedeutung beizulegen, wie dies derjenige unter Umständen thun wird, der diesen Punkt zum Ausgangspunkt einer nenen Theorie macht. Autors.

Soviel über den Wertlı der tektonischen Voraussetzungen des

Wenu wir num noch zu einer kurzon Discussion des palaeontologischen l'heils der betreffenden Bewcisführung schreiten, so haben wir uns daran zu erimnern, dass es sich bei der Beurtheilung des zu discutirenden Thatbestanles um zweierlei I)inge landelt: erstens um den Vergleich der Floren mehrerer Schichten "omplexe, und ans diesem Vergleich sucht Stur seine hauptsächlichsten Voranssetzungen zu gewimnen. sorlann aher auch un den Veroleich der Famen ilieser Schichtencomplexe, so weit solche Famen elien nachweishar sind. biesc'n letzteren Vergleich fülnt $\mathrm{St}$ u r ehenfalls und zwar mit anerkemenswerther, ganz muparteiischer Sorofalt durch, obschon er ihm viel weniger Handhiben zur Aufstellung seiner lehre bietet.

Dennorll sollte man meinen, das zur Begründung des Culm(harakters der Ostrauer Sohichten eine gewisse Uebereinstimmung der Famma des der Granwacke angehörigen Culmselhiefers mit der Fauma der marinen Finschaltungen in den Ostrauer Schichten erwiinschlt sein milsste.

Nun aber gibt Stur (1. c. pay. 341 [32j]) eine Liste von 21 Arten, aus welchen sich die damals hekamnte Fauna des mälnischschlesischen Dachschiefers rusammensetzte und eine Liste von 48 Arten. duroh welche die zunäclsstfolgende Fauna der marinen Finschaltungen ron Ostran charakterisint wird, mul da zeigt es sich. dass diese beiden Famen nur eine einzige Art Cyptorms rugnsum Flcme. mit Sicherlıeit gemeinsan haben. Das heisst, um mit $\mathrm{Stu}$ r's eigenen

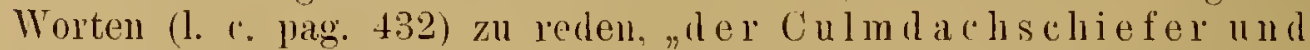
die Ostrauer Schichten bergen zwei specifisch gänzlich

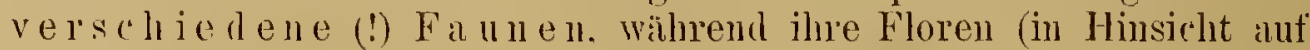
die geringe Anzahl der'Arten ${ }^{2}$ ) jerler dieser Floren) verhältnissmässig

1) Die Literatumachweise bei S tur (1. c. pag. 429 [323]) gehen iberhaupt nicht iiber das Jahr 1853 zurick, während, wic friher gezeigt wurde, gerade die anf die Lagerungsverhältnisse beziiglichen Angaben sich his zum Jalne 1802 verfolgen lassen.

") Gar so gering ist diese Artenzahl, wie sich unten ergeben wird, nun allerdings nicht, und scheint dieser Hinweis nur aus dem Bediurfniss hervor'mgehen, die thatsächliche Verschiedenheit der betreffenden Floren in gediampfterem Lichte erscheinen \% lassen. 
viele Arten mit einander gemeinsam haben, d. h. specifisch nahe velwandt sind".

Dieser Satz allein reicht aus, un zu zeigen, dass eine palaeoutologische Uebereinstimmung, welche einen engeren Verband der Ostraner Schichten mit der Culmgrauwacke begründen wïrle, nach Stur's eigenen Untersuchungen nicht besteht $\left.{ }^{1}\right)$. Del genannte Autor findet in dem angefülnten Thathestande allerdings nur eine "interessante Erscheinmo", wie sie bein Vergleiche benachbarter Formationen schon widerholt beobachtet worden sei, indem die betreffenden Floren sich langlebiger zeigten als die conrespondirenden Faunen, und er ist geneigt, jene vorhin besprochene, dem Absatz der Ostraner Schichten vorausgehende Hebung des Grauwackongebiets für den Wechsel der Fauna verantwortlich zu machen. Man kömnte aher andrerseits sagen, der erörterte Fall beweise wieder eimmal recht deutlich, dass sich die Reste fossiler Pflanzen viel weniger für die Alorenzung von Folmationsabtheilungen benützen lassen, als die Reste ron Thieren ${ }^{2}$ ). Da ferner unser allgemeines Formationsschema über'haupt, soweit dabei palaeontologische Gesichtspunkte in Betracht kommen, der Hauptsache nach auf die Aufeinanderfolge verschiedener Faumen gegründet ist, so könnte man auch noch ausserdem sagen, es sei folgerichtig, dort, wo uns genügend reiche Faunen znr Verfügung: stehen, denselben unter allen Umständen vor den gleichzeitigen Floren bei Eintheilungsversuchen den Vorzug zu geben.

Num könnte freilich auch der Umstand hervorgehoben werden, dass die Existenz der marinen Einschaltungen in den unteren Par-

1) Ein ähnliches Resultat wie beim Verglejch mit den Einschlïssen des mährischen Dachschiefer's ergiebt sich übrigens, wenn man die Ostrauer Fanna mit der Fauna des niederschlesischen Culms und seiner Kohlenkalkeinlagerungen zusammen hält. Von dieser letzteren Fanna, die viel reicher ist als die des Dachschiefers, habe ich vor längerer Zeit (Verhandl. d. k. k. geol. Reichsanst. 1870, pag. 118) unter Benützung der früheren Arbeiten Semenow's und Kunth's eine grössere Liste mitgetheilt, bei deren Durchsicht wohl ebenfalls die Abweichungen von der Fauna der marinen Einschaltungen des Ostrauer Kohlengelirges aufiallen werden. Dieser Hinweis erscheint mir nicht überflüssig, weil ja docl das niederschlesische Carbon sowohl seiner räumlichen Stellung wegen als in Folge der von Stur vorgenommenen Parallelisirungen fuir die Beurtheilung der gleichaltrigen Bildungen in Mähren und Oesterreichisch-Schlesien das mächstliegende Analogon vorstellt.

${ }^{2}$ ) Lesen wir doch beispielsweise (Verh. d. k. k. geol. Reichs-Anst. 1875, pag. 102), dass ein so ausgezeichneter Kenner fossiler Pflanzen, wie gerade Stur' selbst, in manchen Fällen zwischen palaeozoischen und lebenden Farnen keinen wesentlichen Unterschied zu finden vermag, wie zwischen seiner Thyrsopteris schistorum des Dachschiefers und der lebenden Thyrsopteris elegans. Dass aus ganz ähnlichen Grïnden, nm hier ein weiteres Beispiel anzuführen, anch gewisse fossile Hölzer wie Araucariten keinen Werth fïr genauere Altersbestimmungen haben, musste ich ja selbst noch vor Kurzem bei einer anderen Gelegenheit auseinandersetzen (Verh. d. k. k. geol. Reichsanst. 1891, Nr. 17), und vielleicht werden mir auch heute manche Fachgenossen nicht verargen, wemn ich den seiner Zeit von Eck (vergl. dessen Schrift über Buntsandstein und Muschelkalk in Oberschlesien, in Commission bej Friedländer, Berlin 1865, pag. 39) im unteren Buntsandstein Oberschlesiens gefundenen Spuren einer triadischen Fauna mehr Werth beimesse als den in verwandten Schichten des Krakaner Gebiets auftretenden Hölzern. Ich bin natürlich heate ebenso weit als vor einem Jahre davon entfernt, die Dienste, welche die Phytopalaeontologie der Geologie zu leisten vermag, principiell gering zu schätzen, aber ich meine nach wie vor, dass die Verwerthung der phytopalaeontologischen Behelfe eine grosse Vorsicht erfordert.

Jahrbuch (1. k. k. geol. Reichsanstalt, 1893, 43. Band, 1. Het't. (Dr. L. Tietze.) 9 
tien des flötzführenden Gebirges eine gewisse Verwandtschaft dieser Partien mit dem Culm oder dem Kohlenkalk schon an und für sich anzeige, und der Eine oder der Andere, dem es mu die Abänderung der conventionellen Formationsbegriffe zu thun ist, könnte anf diesen Umstand ganz speciellen Werth legen. So findet es dem auch Stur (l. c. lag. 465 [359]) "sehr bemerkenswerth", dass die seinen Ostrauer Schichten gegen Karwin 711 folgenden Schatzlarer Schichten "keine marinen Thierleste enthalten".

Dem steht aber entgegen, dass die dem Kohlengebirge untergeordneten Faunen augenscheinlich an kein bestimmtes Niveau gebunden sind, wenigtens soweit dies nach Stur's eigenen Untersu('hungen gefolgert werden kann. Ich rede hier nicht von der armen, theilweise bereits durch Süsswassertypen bezeichneten Fama, welche über der vorhin erwälnnten Hauptfauna der Ostraner Schichten noch in dem oberen Theile der letzteren selbst auftritt (vergl. S t u r l. c. pag. 465), sonder'n von der' echt marinen, Cephalopoden fülnrenden Fauna, welche (vergl. ibidem, pag. 465 und 471, sowie Verh. d. k. k. geol. Reichs-Anst. 1876, pag̀. 269, 288) in Westfalen, Belgien und dem nördlichen Frankreich den Schatzlarer Schichten angehört und welche in Westfalen sogar in 2 Horizonten innerhalb dieser Sohichten auftreten soll. Da zeigt es sich also, dass das Auftreten mariner Einlagerungen rein als solches genommen für die Abgrenzung zwischen Culm und Obercarbon nicht verwerthbar ist, ausser man wollte die Schatzlarer Schichten auch noch zum Culm rechnen. D)a übrigens an der Basis der Ottweiler Schichten im Stur'schen Horizonte der über den Schatzlarer folgenden Schwadowitzer Schichten nach We is ebenfalls eine wenn auch verarmte Fauna vorkommt, so würle man auf diesem Wege bald die Hauptmasse aller Kohlenflötze in den Culm hinein bekommen, mag auch die Einschaltung mariner Faunen zwischen diese Flötze im Ganzen mehr eine Eigenthümlichkeit der unteren Glieder des Obercarbons berlenten.

Es bleiben also nur die Pflanzen ïbrig, aus deren Verhalten auf die von Stur vorgeschlagene Abgrenzung des Obercarbons gegen den Culm geschlossen werden könnte. Obschon ein solches rein phytopalaeontologisches Eintheilungsprincip von voruherein Bedenken hervorrufen muss, wenn dasselbe weder mit den Lagerungsverhültnissen noch mit dem Verhalten der Famen in Uebereinstimmung gebracht werden kann, so verlohnt es sich doch, etwas genauer nachzusehen, ob demn in der That die betreffenden botanischen Folgerungen von so überwältigender Beweiskraft sind, um den anderen soeben gemachten Erwägungen mit Erfolg entgegen gehalten zu werden.

Jene Folgerungen laufen, wie das im Sinne der Stur'schen Erörterung nicht anders sein kam, darauf hinaus, dass die Flora der Ostraner Schichten einerseits von der Flora der Schatzlarer Schichten, mit denen das eigentliche Obercarbon erst beginnen soll, verschieden ist, wälnend sie mit der Flora der Grauwakendachschiefer andrerseits eine engere Verwanitschaft aufweisen soll.

Dass mu eine Horistisch erkennbare Verschiedenheit zwischen den Ostrau-Waldenburger Schichten einerseits mol den Schatzlarer 
Shichten andrerseits besteht, braucht nicht in Ahede restellt mu werten. das hahen bozüghich der aequiralenten Bildmgen des nioderschlesischen Reviers beinert mo Gäplo ext bereits (Leyden 1850) in ihrer preisurekrönten Schrift, "üher die Beschattenheit und die Verloülnisse der fossilen Flora in den versohiedenen Stemkohlenablagermugen eines mol desselben Reviers" gezeigt, aber democh ist es Jahre lang Nicmandem in den Sinn gekommen, diese Thatsache dahin zu verwerthen. dass er zwischen den betreftenden Flötzzügen eine grosse Formatiousgrenze angenommen hütte. So eclatant ist jene Verschiedenheit auch ihren ersten Fntdecken nicht vorgekommen. Aber selbst im Lichte der St ur'schen Darstellungen ist sie, genan besehen, nicht so ansgeprägt als beim elsten flüchtigen Anschein.

Die Flora der Ostrauer Shlichten in Verein mit der der Waldenhurer Schichten, welche Stur als ein Aequivalent der ersteren auffasst mol deshalb gleichfials dem Culm zuweist, zählt uach der Bearheitumg des genamnten Autors 82 Arten, und vou diesen sollen allerdings nur 5 in die Sclatzlarer Solichten hinüberreichen (l. c. lag. 469 [363]). Immerhin aber sind, wie derselbe Autor schreibt (1. c. pag. 470), die Floren des Dachschiefers, der Ostrauer Schichten und der Schatzlarer Schichten nicht unverbunden: "Ein directer Znsammenhang der genamnten Floren", so heisst es, "wird dadurch hervestellt. dass sie nahe verwandte Arten enthalten, die sich zu pinander wie Vorgunger und Nachfolger verhalten und die es ansser Zweifel zu stellen scheincn, dass dicse drei Specialfloren sich eine ans der anderen in ler Aufeinanderfolge der Zeiten entwickelt luben". Fin solches Verhalten. welches, "den bestehenden in $\mathrm{n}$ g en Verband der erwähnten Floren" clarlegt, ist von $\mathrm{St} u \mathrm{r}$ auch im Verlanfe der Einzelbeschreibung bei melneren Arten genauer erörtert worden.

Bei solchen Diugen kommt es ja überdies seln auf die Methode der Speciesfassung an, je nach welcher man von einander ganz ahweichende P'etrefactenlisten erhalten kann. Ich erimnere hier beispielsweise daran. dass $\mathrm{S}$ tu $\boldsymbol{l}^{\circ}$ einen C'rlcmites ramifer auf'gestellt luatte. der angeblin nur in dem Horizonte der Waldenburger Schichten rorliommen sollte, wälırend F. We iss (Zeitschr. d. dentsch. geol. Ges. 1879. pag. 429) den Beweis lieferte, dass dieser Calamit mit dem in löheren Kohlenhorizonten mol speciell in dem (den Schatzlarer Schichten entsprechencien) oberen Flötzzuge ron Waldenburg gefumdenen C'ulamites rmmosus zu vereinigen sei.

Unter diesen Umständen. hat aber der erstgenamnte Autor schwerlich vollkommen recht, wemm er die Flora der Schatzlarer Schichten als „eine ganz nene" hezeichnet. und dass hierin ein schwacher Punkt seiner Beweisfüln'ung liegt, darauf hat schon F. Roem ex (Lethaea pralacozoica. Stuttgart 1880, pag. 64) lingewiesen.

Wäre aber auch in rler 'That die Flora der Ostrauer Schichten „gegen die nachst jüngere Flor'd der Schatzlarer Schichten sehr abgeschlossen und gut charakterisirt", dam würde diese Abgeschlossenheit wohl nux dam zur Iufstellung einer Formationsgrenze ersten Rauges benützt werden kömen, rem eine ähnliche Abgeschlossenlieit nach der anderen Richtung, das ist gegen die frauwackenflora zu nicht bestünde, wenn also die beiden nach Stur dem Culm an- 
gehörigen Floren der Ostrauer Schichten und des Dachschiefers keine besonderen Verschiedenheiten aufwiesen. Da ist man nun überrascht bei dem genamten Autor zu lesen, dass die "beiden Specialfloren der Cumzeit nicht minder gut charakterisirt" sind, als dies für den Vergleich zwischen Ostraner und Schatzlarer Schichten gilt.

Die ältere Flora der Culmgranwacke bezüglich des Daclischiefers zällt (vergl. die betreffende Aufzählnng bei Stux l. c. pag. 418-422) 90 Arten und die jüngere Flora der Ostraner Schichten, wie erwähnt, 82 Arten. Nun sollte man glauben, wemn schon wirklich die Verwandtschaft der beiden Floren so eng wäre, dass es gerechtfertigt erschiene, die Ostrauer Schichten vom Obercarbon abzutrennen, um sie dem Culn zuzuweisen, dass ein recht bedeutender Procentsatz an Arten diesen Floren gemeinsam sei. Statt dessen erfahren wir, dass nu 11 Alten a us der Flora des Dachsehiefers in dieder Ostrauer und Waldeubuger Schichten hiüubrichen (l. c. pag. 366 [300]) und wir lesen ausserdem (l. c. pag. 469 [363]), dass nicht reniger als 31 Arten unter jenen 90 der Flora des mährischschlesischen Dachschiefer's ganz eigenthümlich sind, während 36 Arten unter jenen 82 Arten sich bisher (d. h. bis zur Zeit der Abfassung der betreffenden Monographie) nur in den Ostraner und Waldenburger Schichten fanden. Das heisst doch soviel, als dass ein Schuitt zwischen dem Dachschiefer und den Ostrauer Schichten selbst vom phytopalaeontologischen Standןunkt aus nahezu dieselbe Berechtigung hat, wie eine Formationsgrenze zwischen den Ostraner und den Schatzlarel Schichten, namentlich wenn man erwägt, dass von Seite des Autor's sicherlich keine subjective Voreingenommenheit für die Demonstration möglichst scharfer Unterschiede zwischen seinen beiden Culmfloren vorlag oder vorliegen kounte, denu ihm kam es ja doch naturgemäss auf die Betonung des gemeinschaftlichen Cliarakters dieser Floren in ilnem Gegensatze zu der Fiora der Schatzlarer Schichten an. Wir haben also auch keinen Grund anzunehmen, dass die Methode der Begrenzung einzelner Species der Klarstellung jener Verschiedenheit zwischen den angeblichen beiden Culmfloren im Wege stand.

Maı könnte aber noch weiter gehen. Als Stul nämlich später die erste Abtheilung seinel Monograplie der schatzlarer Schichten vorlegte, deren Farne und Calanarien er in dem 11. Bande der Abhandlungen der geologischen Reichsanstalt (Wien 1885) beschriel), betonte er ansdrücklich (Verluandl. d. ks k. geol. Reichsanst. 1885, lag. 130), (lass (nach seinen Bestimmungen) keine einzige Art der Schatzlarer Schichten in die noch höheren Carbonstufen hineinreiche. Danacl waren also die Schatzlarer Schichten nach oben zu rou seinem plytopalaeontologischen Standpunkt aus noch schärfer abgegrenzt als nach unten zu, da sie ja doch mit den Ostrauer Schichten wenigstens 5 Arten gemein haben. Wenn also der Autor kein Berlenken trug. die Schatzlarer Schichten trotz der Selbstständigkeit ihrer Flora mit den darüber liegenden Horizonten enger zu verbinden, dann branchte er auch gegen die nähere Verknüpfung dieser Schichten mit den darunter liegenden Ostraner Schichten keine Einwände zn erheben. Wem unan demnach un jeden Preis einen Schnitt mitten durch die fötzfülırenden Absätze 
des Carbous hätte machen wollen, damn hätte dieser Schnitt mit grösserem Rechte über als unter den Shatzlarex Schichten gemacht werden müssen und die letzteren wiren anch noch zum Cum zu ziehen gewesen. Man sieht demnach, wohin eine consequente Durchfülurung des Stur'schen Eintheilungsprincipes geführt hätte und kann sich daraus über die Verwendbarkeit dieses l'rincips ein Urtheil bilden.

Schliesslich aber verlohnt es sich noch jene 11 Arten, welche die Flora der Granwacke mit der Flora der Ostraner und Waldenburger Schichten geneinsam besitzt, an der Hand der Stur'schen Beschreibung etwas genauer zu prï̈en.

Diplothmemu preteutisimm Litt. $s_{p}$. ist eine in Dachschiefer hïufigere Pflanze. wurde jedoch ans den Ostraner Schichten nur in 2 Stückclien bekannt, welche in den fötzleeren Partien der untersten Flötzgluppen gefunden wurden.

Torlen Lipoldi Stur wurde in der Granwacke der Gegend von Fuhnek in zwei Stücken gefunden. Bei Ostran wurde ein hierher bezoxenes Stück in dem flötzleeren Theil del rom Reichefötzerbstollen hurchquerten Sohichten gefunden und ausserdem in den Steinbriichen ron Koblau der "undeutliche $A$ bdruck" einer Blattspitze!

Ardheopteris Dursoni Stur ist in den Ostraner Schichten mur in "minder" guter Erlualtung" vorgekommen (1. c. pag. 290 [184]), in einem Bruchstiick nämlich, bei welchem, die Nervation der Lappen. soweit sie eben erhalten ist, mit der Dachschieferpflanze überemstimmt".

Calymmothece morarica Ett. sp. ist nur "in der tiefsten Partie der Ostrauer Schichten" entdeckt worden, mol zwar ist "bisher nur ein kleines Bruchstück" der Pflanze von dort bekannt (l. c. pag. 278 $[172])$.

Rhacopteris tiransitionis stur wurde bei Ostrau selbst gar niclit gefunden und nur ein einziges "Bruchstuck" dieser Pflanze kam in den Waldenburger Schichten von Ebersilorf bei Nemrode vor (l. c. pas. 319 und 320 [213 und 214]).

In der That legt mun auch $\mathrm{S}$ t u $x$ selbst anf die bis jetzt genannten fünf Pflanzen nur ein bescheidenes Gewicht. Es bleiben demuach für den Nachweis der engeren palaeontologischen Verkuüpfung der Culmgrauwacke mit den Ostrauer und Valdenburger Schichten eigentlich nur sechs Arten ibbrig, welche demzufolge von dem Autor auch besonders hervorgehoben werden und vou denen es heisst (I. c. pag. 466), dass sie in beiden Schichtencomplexen "häufig" vorkommen, und zwar bis in die obersten Flötzgruppen der Ostraner Schichten hinauf, während sie in den Schatzlarer Schichten fehlen.

Hieher gehört zuerst Archaeocalamites radiatus Bryt. sp., den man friiher vielfach unter dem Namen Calanites transitionis Göpp. kannte, ein in cler That recht alterthümlicher Typus von Calamiten. "Das Auftreten" dieser" Art, schreibt nu überraschender Weise Stu l' (1. c. pag. 180 [74]) „in den Ostrauer und Waldenburger Schichten ist fast selten zu nemnen" und del Autor fügt hinzu, er habe sogar lange daran gezweifelt, ob diese P'flanze daselbst überhaupt vorkomme. Das stimmt nicht ganz mit der Angabe überein, wonach alle jene 6 Arten besonders "häufig" in allen Regionen ihrer verticalen Verbreitun: anzutreffen seien. Fermer heisst es: „Der Erlaltungszustand 
der Reste des Arduerc roliatus in den Ostraner und Waldenburger Schichten ist abweichend von dem in den mährisch-schlesischen Dachschiefern. Während nämlich im Dachschiefer trotz langen Transportes auf der See und oft tiefeingreifender Maceration die zarteren Theile dieser P'flanze, ganze Blätter, beblätterte deste nnd Fruchtstände erhalten wurden, hat man in den Wildenburger Schichten trot\% sehr feinen Thones, in dem die Farne insbesondere sehr schön erhalten sind, beblätterte Aeste des A. radiutus nu eimmal gefunden und habe ans den Ostraner Sohichten bisher nur ein einziges Stück vom 3. Flötz des Salmscliachtes erlalten, woranf Blattreste dieser Pflanze eingestrent sind: meist liegen ans diesen" (soll wohl heissen Waldenburger) ,und den Ostraner Schichten nur entrindete Ast- und Stammbruchstïcke vor".

Könnte num schon diese verschiedene Art des Erhaltungsznstandes. welche, wie ja zugestanden wird, mabhı̈ngig von dem Modus der Ablagermo $\mathrm{zu}$ sein scheint, auf etwas veränderte Organisation wenigstens eines Theils der betreffenden Formen je nach den altersverschiedenen Schichtenconrplexen bezogen werden, so wird man in dieser Vermuthung noch bestälit, wenn man liest (pag. 183-184 [77-78]), dass die Stämme des betreffenden Calamiten im Dachschiefer stets armästig sind und zugleich ziemlich lange Internodien besitzen, während „in den Ostraner Srhichten neben der gewöhnlichen For'm mit langen Internodien solche Stämme vorkommen, die anffällig kurzoliedrig sind", so dass der" Antor "vorerst mul lange seitlier" daran dachte, die Ostrauer Stïmme müssten einer anderen Art angehören, die er Archaocalamites stigmutocomm nemnen wollte. Freilich hat num Stur an lem Beispiel seines Culunites Rittleri gezeigt, dass das Merkmal der relativen Lünge der Internodien nicht von wesentlicher Bedentung zu sein lorauche, indessen völlig wird man die Bemerkung nicht unterdrücken kömen. dass die Uebereinstimmmg der zu dem Avchreoc. radirutus gerechneten Stiicke in den beiden zu vergleichenden Schichtencomplexen keine so vollkommene sei, wie es für die Stur'sche Beweisführumg erwinstlit sein müsste.

Fine zweite jener 6 von Stul hervorgehobenen Arten drliantides tenuifolins (xöpl). sp. ist anscheinend mur durch Zufall in die betreffende Aufzälnung hineingeratlen. Sie wird von dem genamnten Autor in dessen Monographie der Culmtlora des mälnisch-schlesischen Dachschiefers (pag. 65) ansdriicklich als Dachschieferpflanze angeführt und wurde von Göppert zuerst ... in der Culmgrauracke von Landslnt in Schlesien" gefunden, wie in der hesagten Stur'schen Monoglaphie ansdrücklich hervorgehoben wird (vergl. übrigens Göplert, Fossile Flora des Uebergangsgebirues N. Jahub. 1847 lag. 675, sowie Zeitschr. dentsch. geol. Ges. 1851 pag. 185, endlich das unter diesem Titel erschienene Hauptwerk, Breslau u. Bom 1852). Spiter wird dann in der Monographie der Flora der Ostraner mol Waldenburger Schichten (pac. 286 |180]) mitgetheilt, dass der Autor dieser Momographie in (iesellschaft einiger anderer Herren sich vergeblich Mühe gegeben habe, an dem Göppert'schen Fundorte bei Landshut bessere Stiäcke als die Gölu pert'schen (higinale antzutinden. In gar keiner Weise aber wird ciläutert, was unmittelhar hinter dieser furählmg zn lesen 
stelnt: „Hiermach ist newiss (!) diese Art dem 1)achschiefer und den Waldenhurger Schichten gemeinsan". I)a scheint also ein lupsus calami rorzuliegen, denn die von $\mathrm{G} \ddot{\mathrm{p}} \mathrm{p}$ l e ext seiner Zeit vielfach ansgebeutete PHanzengranwacke von Landshut ist eben seit lange nur fïr Culn: im älteren Simue gehalten worden (rergl. z. B. Justus Roth, E1läntermngen zu geognostischen liarte vou Niederschlesien pag. 324).

Bezüglich einer dritten jener 6 Arten, Lepidorlendron Tolheimiamum st. (Sagenaria J'dtheiminun) muss zugestanden werden, dass sie gemiss den Stur'schen Angaben gar nicht selten in den Ostraner und Waldenburger Schichten rorkommt und da sic lange als eme der Leitprtanzen des Cnlm galt, übrigens auch im mälnisch-schlesischen Tarhschiefer gefunden wurde, so liegt hier in der 'That ein die verglichenen Floren vermittehndes Fossil vor. Je nachdem man also geneigt sein wird, einer solchen Pflanze den Vol'mg vor anderen gleichzeitig $7, n$ berincksichtigenden Materialien einzuräumen oder nicht, wird man sagen dürfen, das Lepridodendron I'elthemiamm spricht mehr oder weniger für Culn, aber man wird, und zwar mindestens mit gleichem Rechte auch sagen kömmen, es hat sich heransgestellt, dass diese Art noch in etwas jüngeren Schichten rorkommt und dass sie demznfolge nicht mehr als eine ausschliessliche LeitpHanze des Untercarbon gelten darf.

Fine vierte jener 6 Arten, shigmaria incequalis Gïpp. wird man bermhigt wieder ans der Liste der beiden Floren gemeinsamen Arten streichen können. Nicht als ob.diese Form nicht sowohl bei Ostran als in der Grauwacke vorkiame, aher man weiss ja seit H. B Geinitz. (Stcinkohlen Dentschlands, I. Bd., München 1865, pag. 28), (lass diese Stigmariu increqualis nichts anderes ist als die Wurzel der Sugenaric Teltheimicma und da Stur (veryl. Culmitlora des Dachschiefers 1. c. pag. 65) dieser Ansicht zustimmt, so liiesse es ein mud dieselbe PHanzenart doppelt aufzählen, wollte man die zu einander gehörigen Wurzeln und Stämme bei einer Beweisführung, wie die von Stur versuchte ist, als getrennte Arten figuriren lassen.

Die füufte jener 6 Arten Calymuothece (Sphomopteris) dinaricatr Göpp. sp. kommt nach Stur (siehe Flora d. Ostr. u. Waldenb. Schichten 1. c. pag. 272 [166]) bei Ostrau nur in „unsichern kieinen Bruchstücken" im flötzleeren Theil des Reicheflötzerbstollens vor, also jedenfalls sehr nahe der Grauwackengreuze. Wenn sie andrerseits aus den Waldenburger Schichten bei Altwasser in Nieder-Schlesien angeführt wirl, so mag es gnt sein, daran zn erimem, dass Göp pert ursprüuglich (Nova avta 1836) für die For'm der Waldenburger Schichten den Namen Cheilanthites mirrolobus vorgeschlagen hatte und dass die Vereinigung der zu dieser letzteren Art gestellten Stücke mit der Sphenopteris divarirata, welche Göpluert als getremte Art hehandelte, erst von St u (Cumflora des Dachischiefers 1. c. pag. 25) vollyogen wurde. Das hatte die Construction einer der Grauvacke und dem productiven Carbon gemeinsamen Pflanze zum Ergehniss, wie ich hier einfach constatire, olne mir freilich über die botanische Berechtigung dieses Vorganges irgend ein Urtheil anzumassen.

Ueber die noch ibrige Art: Diphothomema distans St. sp., habe ich keine näheren Bemerkungen zu machen. 
Da wie wir sahen, jener Arliantides nebst der Stigmarin ans der Liste der den verglichenen beiden Floren gemeinsamen Arten unbedingt 7u streichen sind, so bleiben nach dem Gesagten höchstens 4 ron den 6 Arten übrig, auf welche die vou Stur beantragte Zuzählung der Ostraner Schichten zum Culm sich hauptsächlich stiitzt. mnd anch bei diesen 4 Arten lassen sich, wie wir sahen, theilweise Einwendmingen erheben. Selbst aber wenn wir die Einwände die bezüglich des Archaeocalaniten und der Calymmotheca divaricata gemacht wurden, unberücksichtigt lassen, so sind 4 Arten auf dieser Seite auch nicht mehr als die 5 Arten, welche nach demselben Autor aus der Flora der Ostrau er Schichten in die Schatzlarer Schichten übergehen und denen man (nach Weiss) jedenfalls noch eine sechste (den Calamites romosus) hinzufïgen darf, wie oben gezeigt wurde. Aber anch wenn man zu jenen 4 noch die 5 anderen, seltenen, theils nur in den tiefsten Lagen der. Ostrauer Schichten gefundenen, theils etwas zweifelhaften Formen rechnen wollte, anf welche, wie schon gesagt, der genannte Autor bei seiner eignen Darstellnng nur geringes Gewiclit legt, dam wären 9 gemeinsame Pflanzenspecies für 2 Floren, die zusammen 161 Arten $^{1}$ ) aufweisen, noch immer nicht ansreichend, diese beiden Floren als so eng verwandt zn bezeichnen, dass in Folge dieser Verwandtschaft eine conventionelle und seit längerer Zeit allseitig festgehaltene Formationsgrenze zwischen den diesen Floren entsprechenden Schichtencomplexen anfzuheben sei. Man wird ja immerhin sich vergegenwärtigen können, dass das Lepidodendron T'eltheimiamum in beiden Schichtabtheilungen vorkommt und man wird es sicherlich anch interessant finden, dass ein dem Calamites transitionis nahe stehender Calamit mit einer über die Internodien des Stammes fortlanfenden Streifung sich noch in der tieferen Partie des flötzführenden Kohlengebirges hat anffinden lassen, aber sicherlich wäre es den Wenigsten eingefallen, deshalb die Grenze zwischen Culm und Obercarbon zu verschieben und mitten durch die verschiedenen Flötzgruppen hindurch zn verlegen, auch wem keine tektonischen und faunistischen Grïncle so direct gegen eine solche Verschiebung sprächen, wic das für mseren Fall gilt.

Uebrigens liest man ja bei Geinitz (Steinkohlen Deutschlands, I. Bd., pag. 177), dass gerarle die leztgenamten 2 Formen noch "in der Nähe der tiefsten Kohlenflötze Westfalens vielfach beobachtet" wurden, weshalb dieser Autor die 9 Flötze, welche dort noch unter dem Leitflötz "Hundsnocken" liegen (vergl. l. c. pag. 183), gern noch dem darunter folgenden flötzleeren Sandstein zutheílen möchte, welcher seinerseits daselbst „über den Culmschichten lagert“. Mlan sieht daher. dass anch anderwärts der Calamites transitionis und die Sagenaria Veltheimiam nicht grade unbedingt verlässliche Leitfossilien des echten Culms abgeben.

1) Nach rer Angalo Stur's nämlich $(90+82-11$ gemeinsame Arten) gelangt man zn dieser Zahl, wonach die 9 thatsächlich geneinsamen Arten noch nicht einmal of Percent der gesammten Flora ansmachen wiirden. 
Die Abtremmung der Ostraner und Waldenburger Schichten rom Obercarbon mnd ihre Zuzühlung zum Untercarbon ${ }^{1}$ ) bezüglicl zum Culm ist also. wie man getrost sagen kamm selhst phytopalaeontologisch nicht ausreichend begrimblet, und so wird man dem olme 7ögern eine Auffassumg verlassen dürfen. welche, obschon sie bisher keine directe Widerlegung erfuhr, doch nicht olme vielfaches Widerstreben aufgenommen wurde. Sprach es doch schon F. Roemel aus (Lethaer palctenzoice l. r. pag. 66), class man zögerı müsse, sich derselben anzuschliessen und dass man eine genaue Untersuchung: der verschiedenen emropäischen Kohlenbecken abwarten müsse, ehe man , über den Werth der St.u r'schen Gliederung zu einer abschliessenden Fntscheidung" gelangen könne ${ }^{2}$ ). Ebensowenig hat Giir ic h in seinem zusammenfassenden Werke über Schlesien sich von der Aufzählung der Ostrauer und Waldenburger Schichten beim productiven Kohlengebirge abhalten lassen. Auch D athe spricht in seinen neueren Publicationen stets ron den Waldenburger Schichten als von einem tieferen Gliede des Obercarbons, olme sich dafür des Wortes Culm zu bedienen. Ien Standpunkt des Praktikers aber hat J i c insky zur Geltung gebracht, obwohl er im Uebrigen begreiflicherweise sich in eine Discussion der wissenschaftlichen Berechtigung jener Gliederung nicht einliess. Er schrieb nämlich in der österreichischen Zeitschrift für Berg- und Hüttenwesen (Wien 1880, pag. 420): "Wissenschaftlich richtig gehörte der Theil unserer Steinkohlenbildung von Pečkowic bis Orlau noch zu den Culmschichten; ich kamn mich leider dieser Nomenclatur nicht anschliessen, weil wir Bergleute jene Gebilde, in denen banwürdige Steinkohlenflötze vorkommen und abgebaut werden, immer nur die productive Steinkohlenformation genannt haben und nennen werdeu". Das war jedenfalls ein wohl zu beachtender Protest gegen den Versuch evident zusammengehörige Ablagerungen wie die des Ostran-Karwiner Beckens auseinanderzureissen.

Immerhin könnte man sagen, die Wissenschaft brauche sich nicht in jedem Falle um die Bedürfnisse der Praktiker zu künmern und wemn es gelungen wïre zu zeigen, dass die Ostrauer Schichten thatsächlich solchen Ablagerungen äquivalent seien, welche man bis dahin unbestritten für Culm gehalten hatte, damn hätte das auch in der Nomenclatur zum Ausdruck kommen müssen. Tenn beispielsweise der Complex der Ostrauer Schichten statt concordant von Schatzlarer Schichten

1) Ich gebrauche hier die Ausdruicke Unter- und Obercarbon stets im hergebrachten Sinne, wonach das Untercarbon den Culm und den Kohlenkalk derjenigen Gegenden nmfasst, in welchen über dem letzteren die productive Abtheilung des Kohlengebirges auftritt. In den Stur'schen Schriften wird leider oft von diesem Gebrauch abgewichen, indem nur die ïber dem Culm befindlichen Schichten Carbon genannt und sodann ihrerseits in Unter- und Obercarbon getheilt werden.

2) Dass es nicht nöthig ist, so lange zn warten, glanbe ich in dem Voranstehenden dargethan zu haben. Wenn Jemand eine nene Ansicht aufstellt, so handelt es sich fiir Andere zunächst nur darum zn prüfen, ob es gelang, dieselbe zu hewe isen und zn dieser Prïfung geniigt in der Regel die genaue Durchsicht der betreffenden Arbeiten, wie der vorliegende Fall znr Genüge zeigt und wie vielleicht anch manche andere Erfahrung der letzten Lustren bestätigt. Ich erinnere z. B. an die Literatur über unser Neogen. 
bedeckt zu sein noch ron Gesteinen mit Posidonomya Becheri und anderen Leitfossilien des Cuhn überlagert würde, oder wenn sich in den Ostrauer Schichten selbst und direct solche Leitfossilien wie die genammte Positnnomya in genügender Vertretung gefundeu hätten, damn könnte an ihrer Zngehörigkeit zum Culm kein übergrosser Zweifel mehr olwwalten. Dann wiirde sich aber anch als natürliche Consequenz dieses Umstandes ergeben. dass der in unserem Fall durch die Grauwacke repräsentirte echte Culm der Gegenden, in welchen daneben Ostraner Schichten vorkommen nicht mehr die Gesammtmasse des culm vorstellt. sondern nur den unteren 'Theil einer anderwärts vollstïndiger entwickelten Formation.

Im Hinhlick auf diese lietrachtmm ist es lehmeich, etwas dem Eutwicklmgsgange der lier erörterten Stur'schen Ansicht nachzuspüren, und da ist es num höchst interessant zu sehen, dass Stur in der That anfünglich der Meimmg war, er habe es bei den Ostraner Schichten mit einen zeitlichen Aequivalent dessen zu thun, was man anclerwärts und früher Culm genannt hatte.

Laut den in der Einleitung (pag. IV) zu seiner Monographie jener Schichten gemachten Mittheilumgen erhielt der Verfasser dic erste Anregung zu seiner Annahme im Jahre 1867 durch eine PHanzensendung ans Ostran in welcher er den Colcomites transitionis zu erkennen glaubte. (Es war dies eine der später zu Archaencalimites ruliatus gebrachten Formen.) Es lag da allerdings ausserordentlich nahe auf Culm zu schliessen und so schon mit einem Torurtheil, wenn man das so nemnen darf, an die spätere Bearbeitung einer Flora heranzutreten, von welcher sich erst nachträglich ergab, dass sie mit der Flora des mälnisch-schlesischen Daclischiefers lange nicht so viel Berülrungspunkte anfwies, als man dies nach jenem Funde bei dem damaligen Stande unseres Wissens hätte erwarten können.

Dazu kam, dass es anch von andrer Seite nicht an Anregung fehlte, der einmal gefassten Vermuthung weiteren Raum zu geben.

Im Jahrgang 1872 der Sitzungsberichte der böhmischen Gesellschaft der Wissenschaften (Juli-December-Heft, Prag 1873, pag. 3) findet sich nämlich ein kưzer Vortrag $\mathrm{Helmhacker's} \mathrm{abgerlyuckt,}$ in welchem Vortrage zum ersten Male auf das Vorkommen mariner' Petrefakten an der Basis des Ostraner liohlengebirges in ausführlicher Weise aufmerksam gemacht wurde ${ }^{1}$ ). Der betreffende Fundpunkt befand sich im Petřkowicer Reiche-Flötz-Erbstollen und würde auf die Tagesobertläche projicirt genau in die Mitte rles Dreiecks, welches durch die Ortschaften Petřksowic, Ellgoth und Bobrovnik bei Hultschin gebildet wird, zı liegen kommen, also jedenfalls in die Nähe des echten Culms von Bobrovnik. Helmhacker fülnte nun die gefundenen Versteinerumgen mach Gattungsnamen auf und verglich cliese Fauna mit der von F. Roemer aus dem oberschlesischen productiven Kohlengehirge bekannt gemachten marinen Fauna. Speciesnamen wurten aber leei dieser Aufzählung rermieden, so dass also anch

3) Einige Funde von Anthracomyen, die hereits frïher (zuerst durch Schlehan im Jahre 1865) gemacht wurden, erlaubten noch keinen dentlichen Hinweis auf die anderwärts im Kohlengebirge gefundenen marinen Fauncn. 
eine angebliche Posidomomma, welche dabei figmirte, nicht näher bezeichnet wurde. Trotzdem meinte $\mathrm{Helm}$ hacker, dass diese Posidonom!r, sowie ein gleichfalls gefundener Goniatit, der indessen ebenso renig specifisch bestinmt wurde, auf Culm hinweisen müssten, was mit dem gleichzeitigen Vorkommen des Calamitss transitionis und der Sugenara Ieltheimiana in Uebereinstimmung zu bringen sei, da man allch von diesen Pflanzen in jenem Stollen Stürke gefunden latte. Fr betitelte seinen Vortrag daher auch sanz direct "Ueber neue Petrefaliten im C u ln an der schlesisch-pohnischen Grenze". Ferner meinte er, dass man mit der Zeit auch für die Roemer'schen Fundorte von marinen Carbonpetrefakten im oberschlesischen Kohlengebirge das Alter des Culm werde erweisen könneli.

Der Bamn der bisherigen Vorstellungen über das Alter der bei Ostrau entwickelten Bildungen war also gebrochen und diese $\mathrm{Helm-}$ hacker'sche Notiz, anf welche sich Stur dam im Jahre 1874 (Verhandl. d. k. k. geolog. Reichsanst. pag. 209) ausdrücklich berief, mag das ihrige dazu beigetragen laben, die Hypothese von dem unter'arbonischen Alter der Ostraner Schichten zur Reife zu bringen. Stur erwähnte ja in seinel Besprechung jener Notiz noch ganz besonders, dass Helmhacker das Vorkommen der Posidonomya Berheni bei P'etřkowic nachgewiesen lıabe, indem er den Speciesnamen Berheri zn der von $\mathrm{Helmhacker} \mathrm{nur} \mathrm{generisch} \mathrm{gegebenen} \mathrm{Bestim-}$ mun ergänzte, weil er ja schliesslich für wahrscheinlich halten komnte, dass diese Species bei der betreffenden Bestimnung gemeint sei. Später freilich verschwindet nicht allein die Posidomomy Becheri, sondem die Gattung Posidonomy überhanpt aus den Stur'schen Listen der marinen Ostrauer Versteinerungen, und schon im Jahre 1875, als sich der letztgenamnte Autor mit diesen Petrefakten etwas nïher zu beschäftigen anfing (Terhandl. 1875, pag. 153), ist von jener Muschel nichts mehr zu hören. Wir wissen ferner, dass specifisch unbestimmte Goniatiten ganz im Allgemeinen genommen auch noch. kein Beweis für das unter'arbonische Alter eines Schichtencomplexes abgeben. wie $\mathrm{Helmhackel}$ geneigt schien anzunelmen, und wir haben auch oben gesehen, dass der von Letzterem en'wähnte Calamit und die Sagenceria Teltheiminnu, so sehr sie anch der Ostrauer Flora einen etwas alterthümlichen Stempel anfdrücken mögen, nicht ausreichen, un diese Flora mit der echten Culmflora der Dachschiefer enger zu verbinden, abex der Impuls für eine derartige Gedankenrichtung erschien durch die $\mathrm{Helmlicker}$ achen, an und für sich überdies höchst verdienstvollen Mittheihmgen gegeben, wenngleich die Einzelheiten, auf denen dieser Impuls beruhte, später nicht mehr unter genau demselben Gesichtspunkte sich darstellen konnten, wie am Anfange.

Die bereits elwälnte l'ublication Stur's ans dem Jahre 1874 ist num aber noch nach einer anderen Richtung hin von historischem Interesse. Der Autor gab in derselben eine Uebersicht des damaligen Standes seiner Untersuchungen über die ausseralpinen Ablagerungen der Steinkohlenformation in Oesterreicll. Damals galten ihm die Waldenburger Schichten, welche er später in seiner grossen Monographie als ein echtes Aequivalent der Ostrauer Srhichten hinstellte, 
zwar attch schon für Culm, aber doch noch für etwas jünger äls die Ostraner Schichten, da er (vergl. 1. c. pag. 207) den C'ulamites tronsitionis (den $\mathrm{Helm}$ inacker von Ostrau angefühlt hatte) in jenen erstgenannten Sclichteu nicht finden kounte. Vergleicht man nun die Tabelle, welche der Autor (1. c. pag. 208) jener Uebersicht beigab, so ersieht man, dass er als Unterlage der Waldenburger Schichten "gestörten Culm" anfülnt, womit die niederschlesische Grauwacke gemeint ist, und dass er die Ostraner Schichten direct als ein zeitliches Aequivalent gerade dieser Grauwacke oder doch eines Theiles derselben betrachtete. Die Culmdachschiefer aber, welche er in derselben Tabelle als Grundgebirge der Ostraner Schichten aufführt, und wormuter die mähnisch-schlesische Granwacke gemeint ist, erscheinen daselbst als kein vollgiltiges zeitliches Aequivalent der niederschlesischen Culngrauwacke, sondern folgerichtiger Weise nur als eine tiefere Abtheilung des Culm, und zwar des Culm nicht im neneren Sturschen, sondern im älteren Simne. Auch noch in Jahre 1875 (Verhandl. d. k. k. geol. Reichsanst. pag. 155), wo Stur die Ostraner Schichten direct und ohne Unschweife für ein Aequivalent des alpinen Bleiberger Kohlenkalks ${ }^{1}$ ) erklärte, hielt er sie fïr thatsächlich viel älter als ilie Schichten, mit welchen man sonst das obere oder productive Kohlengebirge latte begimen lassen.

Wem es dem genannten Autor gelungen wäre, für diese duffassung schlagende Gründe beizubringen, dann liätte man zwar nicht für die Waldenburger, aber doch für die Ostrauer Schichten ohme Weiteres den Namen Culm in Anwendung bringen dürfen. Diese Anffassung wurle jedoch, weil offenbar umhaltbar, später verlassen. Die Ostraner Schichten wurden (vergl. z. B. die Tabelle in der citirten grossen Monographie, pag. 471) den Waldenburger Schichten als altersgleich lingestellt und damit war ausgesprochen, dass sie nicht mehr als das A equiral e nt eines Theiles der mälnisch-schlesischen Culmgrauwacke angesehen wurden. Ausclücklich worden ferner in der zuletzt citirten Tabelle anch die für Dentschland typischen Cuhmschichten von Herborn in Nassau als älter bezeichnet und von dem Bleiberger Kohlenkalk war nicht mehr die Rede. Die Parallele mit dem echten unzweifelhaften Untercarbon war also anfgegeben.

Was noch mit den Ostraner Schichten parallelisirt wurde, waren Dinge wie der Hötzleere Sandstein von Bochum und später (vergl. Jahrb. d. k. k. geol. Reichs-Anst. 1889) der englische Millstone grit, also Ablagerungen, welche bekanntermassen eine Nittelstellung zwischen Unter- und Obercarbon einnehmen, wie denn bereits Phillips (Manuel of geology 1855, pag. 157) den Uebergangscharakter des Millstone grit betonte, den man nach Belieben der unteren oder oberen Abtheilung des Carbon zurechmen köme. Indessen der Millstone grit, bezüglich der Hötzleere Sandstein ist nicht Culm, von dem

§) Ich mache darauf aufmerksam, dass Stache noch im Jahre 188t (Zeitschr. d. deutsch, geol. Gesellsch pag. 371) Bleiberg zum Untercarbon rechnete. Was etwa spätere Autoren noch aus dieser Lokalität machen werden, kommt hier nicht in Betracht, wo es sich nur um die Anffassung handelt, die Stur in jener Zeit davon haben konnte. 
man ihn in Deutschland schon sehr früh zu unterscheiden wusste (verg] Dechen im neuen Jahrl,., Stuttgart 1855, bag. jl), mögen auch einige der älteren Autoren diese Ausdrücke nicht immer scharf gemug auseinander gehalten haben und mag anch hepsius noch nenerdings (Geologie von Dentschland. I. 'Theil, pag. 111) geneigt sein, denselben dem Untercarbon anzureihen.

Man darf übrigens nicht ausser Acht lassen, dass Stur, der die Flora der Ostraner Schichten in England nicht nachzuweisen vermochte (Jalıb. d. k. k. geolog. Reichs-Anst. 1889, pag. 14), diese Schichten dem Millstone grit des nördlichen England nur auf Grumd der Lagerungsverhältnisse mit Wahrseheinlichkeit gleiclustellte. Wenn man weiter erwägt, dass die $\mathrm{Upper}$ Culm measures von Devonshire, die man doch sonst fü ein ungefähres Aequivalent des Millstone grit gehalten hatte, ron Stur, wie bereits oben (Ammerkmng Seite [8] dieser Arbeit) einmal erwähnt, den Schatzlarer Schichten zugerechnet werden, mol zwan' ans phytopalaeontologischen Gründen, so ergiebt sich, dass jene I'arallelisirung der Ostrauer Schichten (wemn anch weniger betreffis des Höt\%leeren Sandsteins in Westfalen, so doch bezüglich des englischen Villstone grit) selbst an und für sich noch mit einiger Vorsicht zu behandeln ist.

Freilich wurde ausser dem Millstone grit mud dem Hötzleeren Sandstein vou Bochum auch noch die Ablagerung von HainichenEbersdorf in den Vergleich mit den Ostraner Schichten einbezogen, in ähnlicher Weise, wie schon H. B. Geinitz (Steinkohlen Deutschlands, pag. 405 und 406) den untersten Waldenburger Flötzzug mit Hainichen - Ebersdorf verglichen hatte, und da gerade diese sächsische Ablagerung seit längerer Zeit als ein Beispiel für untercarbonische Kohle galt, so könnte man meinen, dass trotz alledem noch an eine Altersgleichstelhug der Ostraner Schichten mit dem echten Untercarbon gedacht wurde. Das wäre indessen ein Irrthum, insoferne ja Stur selbst in der oben erwähnten Tabelle auch das Hainichen-Ebersdorfer Kohlengebirge als einen Schichtencomplex hingestellt hat, der nach seiner Auffassung jünger wäre als der Culm von Herbor'n, eine Auffassung, für welche in der That lieute nach den bereits früher citirten Untersu'lungen Dalmer's nicht unwichtige Griunde zu sprechen scheinen. Yan kömnte also behaupten, Stul' habe durch seinen Yergleich zwischen jenen sächsischen und seinen Ostrauer Schichten die Stellung der letzteren in dem allgemeinen For'mationsschema nicht herabgedrückt, wohl aber die Stellung der ersterell heranfgeriickt.

Genamer besehen, lief also die ganze Action Stur's zum Schluss niclst mehr auf das Ziel hinaus, mit dem sie begonnen wurde. Sie gipfelte in Folgendem:

Eimmal gelang es, die Ostrauer und Waldenburger Schichten unter einander zu parallelisiren und es wurde versucht, ihnen beiden das Niveau des flötzleeren Sandsteines anzuweisen. Man kamn den Phytopalaeontologen von Beruf überlassen über die Zulässigkeit dieser Parallele zu discutiren, aber vielleicht sind gerarle gegen dieses Ergebniss noch die wenigsten Einwände zu erheben. nnd da dies dem Wesen nach das Hauptresultat der' Stu r'schen Untersuchungen ist, so 
könnte es für die eventuellen Vertreter von lessen Ansichten eine ausreichenrle Genngthumg sein, wemn letztere in diesem Prnkte einst eine mngefähre Bestätigung finden sollten ${ }^{1}$ ).

Zweitens wude mit den Ostraner Schichten das Niveau des Hötzleeren Sandsteines odler des Millstone grit in ganz entschiedener Weise fler Abtheilung des unproductiven Untercarbons ${ }^{2}$ ) beigesellt. Fis ist aber selır fraglich, ob gerade das Ostraner Beispiel in dieser llinsicht glücklich gewälnlt war, da ja gerade hier eine seln immige Verknüpfung des betreffenden Niveaus (die Dentmig desselben durch Stur als richtig vorausgesetzt) mit den darüber folgenden Absätzen eintritt.

Drittens endlich, und hier kommen wir anf den fïr die lieutige Auseinandersetzung wichtigsten Punkt, lief dalier jene Action darauf hinaus, eine Verrückung der conventionellen oberen Grenze des Culm vorzuschlagen, wie $\mathrm{ich}$ das schon bei einer früheren Gelegenheit vermuthet hatte (vergl. meine Beschreibung der geognostischen Verhältnisse der Gegend von Krakan. Jahrb. l. k. k. geol. Reichs-Anst. 1887, pag. 435 [13]), olne freilich damals dringendere Veranlassung oder Zeit zu haben, mich näher über den Gegenstand zu äussern. Aehnlich scheint aber auch $\mathrm{F}$. v. Ha $\mathrm{H}$ er den von $\mathrm{Stur}$ eingeschlagenen Weg heurtheilt zu haben, wemn es in des Ersteren Geologie (2. Autlage, Wien 1879, pag. 279) heisst, dass Stur den Ansdruck Culm in einem erweiterten Sime gebranche. Mit dem Aufgeben seines von ilm im Jahe 1874 und 1875 eingenommenen Standpunktes, wo el die Ostrauer Schichten noch mit dem Kohlenkalk und einem Theil der echten Culmgrauwacke parallelisirte, hat Stur nämlich auch die Annalıme von dem ansgesprochen untercarbonischen Alter jener Ostraner Schichten dem Wesen nach preisgegeben mo nur dem Namen nach aufreclit erhalten, indem er die mit dem Worte Culm in der deutschen Geologie verbumdene Tradition durchbrach.

Hält man nun ein solches Rütteln an den einmal adoptiıten Formationsgrenzen wenigstens bei dem hentigen Stande unserer Kémutniss überhaupt für störend und überflüssig, so wirkt dasselbe elst recht unnöthig verwirrend in einem Falle, in welchem fast jeder Unbefangene, wenn er tabula rasa vorgefmuden und inrch die $A b-$ grenzmo der um Ustran entwickelten Formationen erst einen Typus für andere Gegenden hätte aufstellen wollen, die Hauptgrenze zwischen den dort entwickelten palaeozoischen Bilimugen sicherlich lort gezogen hätte, wo man sie früher hatte, nämlich zwischen der Grauwacke und dem Hötzführenden Schichtencomplex. Es entfällt

1) Naclı Gïı ich (Erlänterungen zur geol. Uebersichtskarte von Schlesien, Breslau 1890, pag. 84) scheint in dem Revier von Zabrze-Myslowitz dem unteren Theil der Ostrauer Schichten ein flötzleeres Gehirge zu entsprechen, so dass die Flötzbildung hei Ostrau friiher legomnen liäte, als in anderen Theilen des oberschlesisch-mährischen Kohlenbeckens. Danach ist es allerdings sehr wahrscheinlich, dass wenigstens für die tieferen Lagen der Ostrauer Schichten der Vergleich mit dem eigenthümlichen Zwischenhorizont des "flötzleeren Sandsteins " zulässig ist.

$\left.{ }^{2}\right)$ Ich spreche hier sellstverständlich noch immer im hergehrachten Sinne von Unter- und Obercarbon und nicht in Simne Stur's, der, wie hereits frïher bemerkt wnide, den Ausdruck Carhon anf den Culm und Kohlenkalk gar nicht meln' bezieht. 
also wohl jede Nothwendigkeit für uns, den Begriff Cnhm anders zu fassen, als er früher gefasst whrde. md wir köuncn, so glaube ich, heute allseitig wieder zu jener vorzeitig verlassenen 'Tradition zurïıckkehren.

Es seien jetzt am Ende dieser Auseinandersetzung nochmals ausdrücklich die Hauptgesichtspunkte wiederholt, zu welchen wir gelangten.

1. Die Ostrauer Schichten sind durch die Lagerung mit den darüber folgenden Schatzlarer Schichten des Ostran-Karwiner Antheils des oberschlesischen Kohlenbeckens ebenso innig verbunden wio rlurch das in der Hauptsaclie analoge Verhalten ihrer Absatzbedingungen im Gegensatz zu der faciell von ihnen verschiedenen Culngrauwacke, von welcher sie durch eine I)iscordanz getrennt sind.

2. Die Ostrauer Schichten zeigen fammistisch bezüglich ihrer marinen Einschaltungen einen durchaus anderen Charakter als die Culmgrauwacke und die mit derselben verbundenen Schiefer.

Die blosse Anwesenheit solcher Einschaltungen ïbrigens kamn an sich selbst auch noch keine nähere Verwandtschaft mit dem marinen Untercarbon begründen, da derartige Finschaltungen in noch jüngeren Schichtencomplexen des Obercarbons ebenfalls vorkommen.

3. Die plytopalaeontologische Verschierlenheit zwischen den Ostraner und den Schatzlarer Schichten ist unbestreitbar, wie dem schon Göp pert ron einer solchen Verschiedenheit zwischen den mit jenen Complexen zu vergleichenden beirlen Flötzzïgen des Waldenburger Reviers wusste, ohne indessen diesen Umstand zum Ausgangspunlit einer neueu Haupteintheilung rles Carbons zu machen. Die Ostraner Schichten weisen aber andrerseits mit der Culmgrauwacke nicht wesentlich mehr phytopalaeontologische Berührungspunkte auf als mit den Schatzlarer Schichten, und in keinem Falle sind diese Berülurungspunkte ausreichend, einen besonders engen Terband dieser Schichten mit der Grauracke zu begründen.

Bezüglich der den letzterwähnten Bildungen angeblich gemeinsamen Pflanzenarten stellt sich noch speciell heraus, dass einige rlerselben in der betreffenden Aufrählung irrthümlicher Weise, andere auf Grund des Fumdes ziemlich mdeutlicher Fragmente enthalten sind, und dass überlies etliche der dabei citirten Funde uur dem allertiefsten flötzleeren Theil der fraglichen Bildung entstammen. Nur sehr wenige Arten verleihen thatsächlich der Flora der Ostrauer Schichten jenen alten Anstrich, der die Herstellung näherer Beziehungen dieser Flora zur Culmflora ermöglicht hat.

Wenn aber einige wenige Pflanzentypen von älterem Habitus bis in die Ostraner Schichten hinaufreichen, so beweist das nur (im Einklang: mit allen modernen Anschamugen über die Entwirkelung der organischen Welt), dass ehen eine strenge Alogeschlossenheit del Lehewesen der einzelnen Epochen nicht bestanden hat, eine Auffassung, die ja überdies principiell bei keinem Phytopaläontologen eine so warme Vertretung gefunden hat als bei Stur selbst.

4. Die Zutheilung der Ostrauer Schichten zum C'ulm wurde von Stur ursprünglich auf Grund von Voraussetzungen vorgenommen, 
welche spuiter nicht meln aufrecht erhalten werlen komnten. Diese Schichten wurden von dem genannten Autor anfänglich für ein thatsïchliches Aequivalent eines Theiles der Culmgrauwacke und des echten Kohlenkalkes gehalten, während sich bei der Fortsetzung der betreffenden Studien ihr jüngeres Alter den zuletzt genannten Bildungen gegenïber herausstellte. Trotzdem wurde der einmal für jene Schichten gewählte Name Culm niclit melnr fallen gelassen. Dieser Vorgang hatte dann zur natürlichen Folge, dass die Grenze zwischen Culm und Obercarbon in einer Weise verschoben wurde, für welche die Einzelheiten des uns zugänglichen Beobachtungsmaterials (wenigstens in ihrer Mehrheit) keinen ansreichenden Anhaltspunkt bieten.

5. Auf Grund aller dieser Thatsachen und Erwägungen erscheint es unzulïssig, die Ostrauer Schichten noch weiter als Culm zu bezeichnen. Es mag der weiteren Erwïgung Anderer anheimgestellt werden, ob sie jene Schichten als ein tiefstes Glied des Obercarbon oder (wenn auch vielleicht nur bezüglich ihrer unteren Partien) als die Zwischenstufe des Millstone grit sich denken wollen. Wählt man das Letztere, dann gehört die Ostrauer Gegend jedenfalls zu denen, in welchen jene Zwischenstufe mehr mit ihrem Hangenden als mit ihrem Liegenden verknüpft ist. Tom praktischen wie rom wissenschaftlichen Standpunkte ans scheint es deshalb dort geboten, die Hauptformationsgrenze innerhalb des Carbons unter und nicht über die Ostraner Schichten zu legen. 


\section{Zur Fauna der Pötzleinsdorfer Sande.}

Ton A. Rosiwal.

Gelegentlich der Herstellung der Rösche zum Baue eines Abzugskanales in Pötzleinsdorf, Badgasse, wurden im vergangenen Frïlijahre die Miocänsande an einer neuen Stelle aufgeschlossen. Dieselbe liegt in unmittelbarer Nachbarschaft des Punktes, von welchem Director Th. Fuchs seinerzeit eine faunistische Slizze gab '), in welcher er in Anbetracht der grossen Nähe der Localität hinter dem Kirclihofe, die den Typus der Pötzleinsdorfer Fauna feststellte, dennoch mannigfache Abweichungen von derselben constatiren konnte.

Dieser Umstand im Vereine mit der Erwägung, dass es trotz der vielen Vorarbeiten auf diesem Gebiete nicht ganz überflüssig sein mag, neue Aufschlüsse zu registriren und deren faunistische Belegstücke zu sammeln, um sie als Material für vergleichende Untersuchungen zu sichern, bewogen mich, der freundlichen Einladung des den Bau leitenden Herrn Ingenieurs K. Leskier des Wiener Stadtbauamtes, dem ich die Kenntniss des Aufschlusses und eine Reile voir Fossilproben verdanke, wiederholt Folge zu leisten, um die Baugrube zu besichtigen. Was ich bei diesen Besuchen zu sammeln vermochte, entstammt zum grössten Theile Blöcken, welche schon vorher aus dem Graben gefördert worden waren.

1. Der Aufschluss. Eine Skizze, deren ziffermässige Angaben nach den Mittheilungen des Herrn Ingenieurs K. Leskier eingestellt sind, zeigt die westliche Wand der Baurösche an dem oberen Ende des Kanalgrabens in einer Erstreckung von $15 \mathrm{~m}$. Der Begimn liegt $130 \mathrm{~m}$ vom unteren Eingange der Badgasse entfernt, gegenüber dem Hause Nr. 11. Dem Profile ist zu entnehmen, dass unter der ca. $40 \mathrm{~cm}$ mächtigen Hang- und Strassenschuttlage nur in einer wenig bedeutenden, kamm $1 \mathrm{~m}(50-90 \mathrm{~cm})$ mächtigen Schichte der typische gelbe Sand der Pötzleinsdorfer Schichten lagert. Unter demselben wurde ein Riff von Lithothamnienkalk aufgeschlossen, welches oben in mehreren Erosionsmulden eingeschwemmte Rollstücke,von Wienersandstein enthielt. Sandlassen in dem oberen Theile des Kalkes

1) Conchylien aus einer Brunnengrabung bei Pötzleinsdorf. Jahrb. d. k. k. geol. Reichsanst. 1868, pag. 285. 
waren hänfig und drangen nesterweise in kleinere Höhlıugen desselben ein; dort waren auch die Petrefacte in grösserer Zahl anzutreffen. Fine Bankung, schwach gegen die Hauptstrasse (nach NO und O) einfallend, war nur wenig ausgesprochen. Die stark sandige Beschaffenheit der oberen Partien nimmt nach miten $\mathrm{zu}$ ab, wodurch sich das Gestein einem normalen Lithothamnienkalk nähert.

Eine erwähnenswerthe Thatsache ist dieses Vorkommen eines von den Sanden bedeckten Lithothamnienriffes inmerhin an einer Stelle, wo in dem nahe benachbarten Brumnen des Badhauses nach Fuchs' Angaben nur mehr Sand und diumne Tegellagen durchfahren wurden. Damit wäre ein Verbindungsglied mit dem Leithakalk des Nussdorf-Grinzinger Strandes gegeben. Die aus der geol. Karte der Ungebung Wiens von $\mathrm{F}$ uch $\mathrm{c}$ s entnommenen Entfernungen unseres Aufschlusses betragen einerseits vom Strande (Grenze des Wiener Sandsteines bei der Kirche) $500 \mathrm{~m}$, andererseits vom Badehause $140 \mathrm{~m}$.

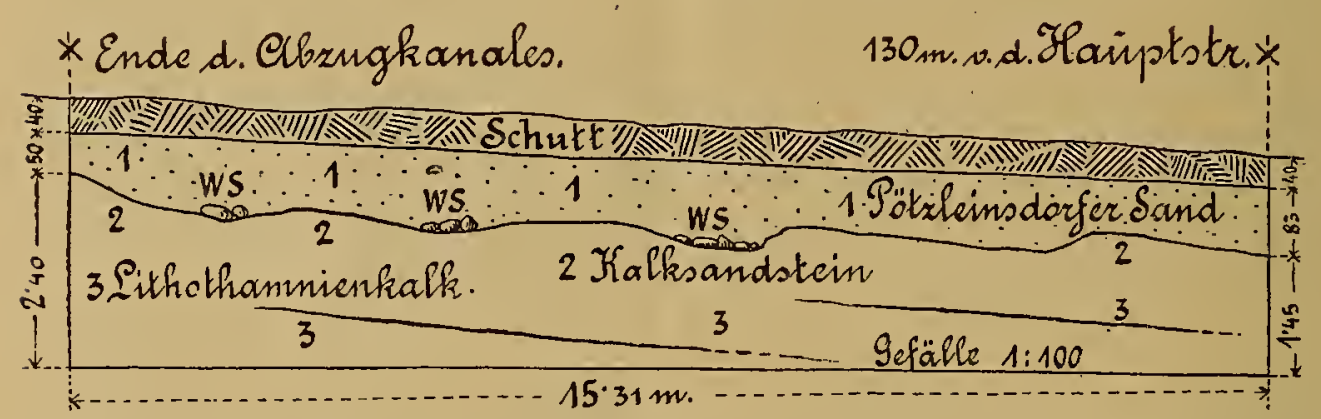

Profil des Kanalgrabens in Pötzleinsdorf, Badgasse, $130 \mathrm{~m}$ von der Hauptstrasse.

$(1: 145)$

1. Pötzleinsdorfer Sand.

2. Kalksandstein.

3. Lithothamnienkalk.

WS Rollstücke von Wiener Sandstein.

2. Das Material. Ueber dasselbe möge ergänzend nur kurz bemerkt werden, dass in dem oben besprochenen Profile drei Hauptschichten zu unterscheiden sind:

a) Feiner hellgelber $\mathrm{Q} u \mathrm{ar}$ s and, dessen Farbe von geringen Mengen Brauneisenocher herrührt. Bei Behandlung mit $H C$ Cl bleibt ein Lösungsrïckstand von etwas über 90 Procent, der u. d. M. fast nur aus feinen Quarzkörnchen, sehr wenig Feldspath- und Glimmer(Muscovit-) Theilchen besteht: $10 \mathrm{r}$ maler Pötzl e in s dor fer Sa nd.

b) Kalksandstein, die oberen Lagen des Riffes bildend, feinkörnig, hellbräunlichgrau. Die Behandlung mit $\mathrm{HCl}$ ergab zur Hälfte (52 Procent) einen Lösungsiückstand aus Quarzsand und etwas (3 Procent) Thon. Dieser Horizont ist lithothamnienfrei und reich an Bivalven.

c) Sandiger Lithothamnienkalk, ein Uebergangsgestein zwischen dem eben erwähnten Kalksandstein und echtem Leithakalk bildend. Die im Gesteine reichlich enthaltenen Algen sind gelbbraun (unverwittert blaugrau), das kalkig-sandige Füllunaterial zwischen den- 
selben aber grau wie obiges Gestein. Der Sand- und Thongehalt sinkt bis unter ein Tiertel der ganzen Masse (24 l'rocent Lösungsrǘclistand in II Cl, davon etwa $21 / 2$ Procent Thon). Gastropodemreich (R is s o e n kalk).

In beiden Gesteinen $b$ und $c$ kommen Taschen und Löcher, elfüllt mit Pötzleinsdorfer Sand, vor.

3. Die Fauna. Es ist schwer, die drei soeben petrographisch charakterisirten Ablagerungen in Bezug anf ihre Fauna streng auseinander zu halten, da, wie erwähnt, ein Eindringen des Sandes in die Kalke, welche selbst eine Sand-Facies unter ihresgleichen darstellen, stattfindet.

In den reinen Sandablagerungen des Hangenden wurde wenig gefunden. Ein vereinzelter zarter Pecten (Jugendform von Pecten aff. Malvina Dubois) sowie durch Schlämmen erhaltene Bryozoen rorwiegend Entulophor (Pustulopora) anomala Rss. ${ }^{1}$ ) und seltene (etwa 3 Individnen im $1 \mathrm{~cm}^{3}$ ) Foraminiferen: Rosalina Vicmensis d' Orl. bildeten die ganze Ausbente.

Reichlicher ist dieselbe in den Kalksandsteinen. Einige grössere Handstüclie lieferten beim Zerschlagen die folgende Gesellschaft:

Conus Dujurdini Desh.

Buccinum coloratum Eichu.

Cancellaria cancellata Lam.

Cevithium scabrum Olivi.

Turritella Archimedis Brony.

Trochirs pretulus Broce.

Natica helicina Broce.

Rissoina pusilla Broce.

Rissoc Lachesis Bast.

- costellata Griat.

Bulla comulus Desh.

- cf. clathratu Defi.

Psammosolen coarctatus Gmel.

Tellina compressa Broce.

- donacina Linn.

- sp. (Jugendformen).

Psarmobia uniradiata Brocc.

Circe minima Mont.

Cardium hians Broce.

- Trronicum Mayer.

Lucina dentata Bast.

Erycina Austriaca Hörn.

Area Turonice Duj.

Denditina Haneri d'Orb.

Melonia sphaerica Lam.

Weitaus die meisten Formen enthielten jene Blöcke, welche dem Lith o thamnienkalk angehören, und zumeist wieder an solchen Stellen, wo der gelbe Pötzleinsdlorfer Sand Hohlräume nesterartig

1) Reuss: Die fossilen Polyparien des Wiener Tertiärbeckens. Taf. VI, 13-20. - Manzoni: Bryozoend. Nioc. v. Oesterr.-Ung. Denksch. 38. Bd. T. IX, 33. 
erfüllte oder sich an die Grenze der verfestigten Gesteinspartien krustenartig angelegt hatte.

Was den Erhaltungszustand der Fossilien anbetrifft, so waren mit Ausnahme der Ostreen und zum Theile der Pectines Schalenexemplare nur partiell in den Kalksandsteinen, sonst wenig vorhanden, so dass die nachfolgenden Bestimmungen zumeist nur nach Kittabformungen oder Steinkernen vorgenommen werden konnten, was die Arbeit zum Theile unsicher machte ${ }^{3}$ ).

Im Nachfolgenden sei eine Zusammenstellung aller bestimmten Formen ohne Rücksicht auf deren oft nicht mehr ermittelbar gewesene Lage im Aufschlusse gegeben.

\section{Gastropoden ${ }^{2}$.}

* Conus cf. fuscocingulatus Bronn.

- Dujardini Desh.

* - ventricosus Bronn.

* Ancillaria glandiformis Lam. 1 .

* Ringicula buccinea Desh. h.

* Columbella scripta Bell.

* Terebra fuscata Brocc.

Bucrinum costulatum Brocc.

- prismaticum Brocc.

- serraticosta Bronn. ${ }^{3}$ )

*- coloratum Eichr. hh.

* Dujardini Desh.

- cf. polygonum Brocc.

*Strombus Bonelli Brocc.

$\uparrow$ Murex sublavatus Bast.

$\uparrow$ Fusus Schwaitzi Hörn.

Cancellaria cancellata Lam.

- Westiana Grat.

Pleurotoma cf. cataphracta Brocc.

* - Schreibersi Hörrn

* - granulato-cincta Münst. $I$.

- Jouameti Desm.

- obtusangula Brocc.

- pustulata Brocc. var. h.

†- liarpula Broce.

- Suessi Hörn.

- Tanquelini Payr.

- sp. ind.

* Cerithium vulgatum Brug.

- scabrum Olivi.hh.

1) Aus diesem Grunde und mit Rücksicht auf die Angaben der älteren Literatur wurden die Bestimmungen fast ausschliesslich nur nach M. Ho e rn e s' Monographie der Mollusken des Wiener Beckens vorgenommen.

$\left.{ }^{2}\right)$ Die mit* bezeichneten Formen kommen nach $\mathrm{Fu}$ chs auch im Badehausbrunnen vor.

$\dagger$ Bezeichnet: Unsicher bestimmbarer Rest.

$\left.{ }^{3}\right)$ Var. zu B. prismaticum Brocc. 
* Trerritella vermicularis Broce.

- tumis Bast.

* Archimedis Brong. le.

- *- bicarinata Eichrr.

- cf. subangulata Brocc. $\left.{ }^{3}\right)$

†*Tuibo rugosus Lim.

* Monodonta angulata Eichul. hh.

*Trochus patulus Brocc. llh.

Solarium moniliferum Broun.

Scalaria torulosa Brocc.

Vermetus intortus Lam.

Siliquavia anguina Linn.

Turbonilla costellata Grat.

- cf. gracilis Brocc.

$\uparrow$ - plicatula Brocc.

Sigaretus haliotoidens Linn.

Natica cf. Joseptrinia Risso.

- helicina Brocc.

* Nevita cf. Grateloupana Fiér.

$\uparrow$ † $s p$.

†Aclis Lovéni Hörn.

Rissoina cf. obsolete Partsch.

- pusilla Biocc.

$\dagger-s p$.

Rissoa Venus d'Orb.

- Montagni Payr. h.

- cuita Duj. hh.

- Lachesis Bast. l.

- Lachesis Bast. var. luevis.

- cf. Schwortzi Hörr.

* - costellata Grot. $h$.

- cf. angulata Eichu.

Bulla lignaria Lim. $h$.

- comilus Desh.

- convoluta Broce.

- cf. clathrata Defi.

- Lajonkaireana Bast.

Crepidula gibbosa Defr.

Calyptraea Chinensis Linn.

Dentalium tetragonum Brocc.

- pseudo-entalis Lam.

- fossile Linn.

\section{Bivalven.}

Teredo Norvegica Spengler. ${ }^{2}$ )

*Psammosolen coarctatus Gmel.

1) Viell. Jugendform von. T. bicarinata Eichw.

$\left.{ }^{2}\right)$ Gänge und Ausfüllungen derselben in Holzresten. 
* Parropaer Menardi Desh.

† Saxicava arctica Lim.

Ervilia pusilla Phil.

Cardilia Deshayesi Hörn.

*Tellina donacina Linn.

- compressa Broce.

- sp.

Psammobia uniradiate Brocc.

Tenerupis decussata Plit.

* Tapes vetula Bast.

Venus cf. multilamella Lam.

- sp.

Cytherea Pedemontana Ag. ${ }^{1}$ )

Circe minima Mont.

Pecchiolia argentec Mariti.

Cardium lians Broce.

* - Turonicum Mayer. $7 i h$.

* Lucina incs:assata Dubois h.

* - multilamellata Desh. $h$.

* _ dentata Bast.

- reticulata Poli.

- exigua Eichno.

* - cf. transversa Bronn.

Erycina Austriaca Hörn. h.

* Cardita cf. Partschi Goldf. (Fragment).

* - sp. cf. Jouanneti Bust. (Steinkern).

Nucula nucleus Linn.

* Pectunculus pilosus Linn. T.

* Arca Turonica Duj.

- lactea Linn.

Lithorlomus Avitensis Mayer.

* Pinna sp). (Fragment).

Lima inflata Chemn.

*Pecten Besseri Andr. 7 .

- aff. Malvinae Dubois.

- sp.

* Ostrea digitalina Dub.

- sp.

* Anomia costata Brech.

$\dagger$ 'Balanus sp. (Fragment).

Serpula sp.

Echinodermeneste.

Tioa $s p$.

Lepralia sp. cf'. L. recorata h'ss.

Celleporaria (Cellepora) globularis Broun.

Entalophora (Pustulopora) anomula Rss.

1) Vou Fuchs im Badhausbrunnen nicht aufgefunden, was von ihm besonders betont wird. A. a. 0. S. 286. 
Dendritina Haneri de Or.

Melonia sphaerica Lam. ${ }^{\text {) }}$ hl.

Rosalina Tiennensis d'Orb.

Quninqueloculina of peregrina d'Orb.

Die Fossilien befinden sich in der Sammlung der k. k. geol. Reichsanstalt, zum Theile in jener der Lehrkanzel für Mineralogie und Geologie an der k. k. techn. Hochschule in Wien.

Es mag bezüglich des vorstehenden Verzeichnisses noch betont werden, dass es die in den aufgesammelten Blöcken enthaltene Fauma trotz aller Bemühungen kaum vollstïndig wiedergibt. indem der Formenreichthum an Minutien selbst bei einer ins Kleinste gehenden Sichtung des Materials schwer erschöpft werden kamu. Von dem Charakter der Fauna des Vorkommens geben die sichergestellten Arten indessen ein linreichend getrenes Bild.

4. Resumé. Vergleicht man das Verzeichniss der Fauna des nenen Aufschlusses mit jenem, welches Fu chs vom Badhausbrunnen gegeben lat ${ }^{2}$ ), so findet man trotz der petrographischen Verschiedenheit der Ablagerungen - die meisten Formen stammen ja aus dem Lithothamuienkalk - eine ziemliche Uebereinstimmung. Auch hier hat man es mit einem von der reinen Sandfacies der Pötzleinsdorfer Schichten in nachstehender Hinsicht abweichenden Typus einer an Gastropoden reichen, in unserem Falle sandigen Strandfacies zu thum, deren Fauma bereits Fuchs in Parallele mit jener der Ablagerungen roll Gainfalnen und Grund (bezw. Enzesfeld und Grinzing) gestellt hat.

Zur näheren Charakteristik des Gesagten möge einer kleinen Tabelle die Zahl der bekamten Arten, sowie das Percentualverlältniss der Gastropoden zu den Bivalven an den nachfolgenden Localitäten entnommen werden.

Zahl der Arten überhaupt.

\begin{tabular}{|c|c|c|c|c|c|c|c|c|c|c|c|c|}
\hline & \multicolumn{6}{|c|}{ Pötzleinsđorf } & \multirow{2}{*}{\multicolumn{2}{|c|}{$\begin{array}{c}\text { Gain- } \\
\text { fahren }\end{array}$}} & \multirow{2}{*}{\multicolumn{2}{|c|}{ Grinzing6) }} & \multirow{2}{*}{\multicolumn{2}{|c|}{ Grund ${ }^{7}$ ) }} \\
\hline & \multicolumn{2}{|c|}{ Badgasse } & \multicolumn{2}{|c|}{$\begin{array}{l}\text { Badhaus- } \\
\text { brunnen }^{3} \text { ) }\end{array}$} & \multicolumn{2}{|c|}{ Kirchhof $\left.{ }^{4}\right)$} & & & & & & \\
\hline & $\begin{array}{l}\text { Zahl d. } \\
\text { bestimmt. } \\
\text { Formen }\end{array}$ & $\%$ & $\begin{array}{l}\text { Zahl } \\
\text { der } \\
\text { Arten }\end{array}$ & $\%$ & $\begin{array}{c}\text { Zahl } \\
\text { der } \\
\text { Arten }\end{array}$ & $\%$ & $\begin{array}{l}\text { Zahl } \\
\text { der } \\
\text { Arten }\end{array}$ & $\%$ & $\begin{array}{l}\text { Zahl } \\
\text { der } \\
\text { Arten }\end{array}$ & $\%$ & $\left|\begin{array}{c}\text { Zahl } \\
\text { der } \\
\text { Arten }\end{array}\right|$ & $\%$ \\
\hline Gastropoden & 73 & $64 \cdot 0$ & $\begin{array}{l}29 \\
(32)\end{array}$ & $\left(\begin{array}{c}51 \cdot 8 \\
(51 \cdot 6)\end{array}\right.$ & 131 & $63 \cdot 9$ & 228 & $71 \cdot 5$ & 127 & $70 \cdot 5$ & 190 & $59 \cdot 8$ \\
\hline Bivalven & 41 & 360 & $\begin{array}{c}27 \\
(30)\end{array}$ & $\left|\begin{array}{c}48 \cdot 2 \\
(48 \cdot 4)\end{array}\right|$ & 74 & $36 \cdot 1$ & 91 & $28 \cdot 5$ & 53 & 29.5 & 128 & $40 \cdot 2$ \\
\hline
\end{tabular}

1) = Alceolina melo d'Orb. Reihe zu Alv. Haueri d'O.b., sowie diese selbst.

$\left.{ }^{2}\right)$ Ein um einige Species erweitertes Verzeichniss dieser Fossilien findet sich in seinen "Erläuterungen zur geol. Karte d. Umgebung von Wien", 1s73, S. 22.

$\left.{ }^{3}\right)$ Die in ( ) stehenden Zahlen beziehen sich auf das zweite Verzeichniss Fu ch s'.

4 ) Aus Fuchs' Erläuterungen zur geol. Karte der Umgebung Wiens, S 19.

$\left.{ }^{5}\right)$ Aus F. Karrer: Geologie der Hochquellenwasserleitung. Abhdl. d k. k. geol Reichsanst. IX Bd. S. 109.

6) Fuchs Erläuterungen, S. 25

7) M. Ho e rnes: Mollusken des Wiener Beckens. 
Zieht man die mit den Vergleichslokalitäten gemeinsamen Arten unserer Fundstelle in Betracht, so ergibt sich folgende Uebersicht.

Zahl der gemeinsamen Arten.

\begin{tabular}{|c|c|c|c|c|c|}
\hline & \multicolumn{2}{|c|}{ Mit Pötzleinsdorf } & \multirow{2}{*}{$\begin{array}{c}\text { Mit } \\
\text { Gainfahren }\end{array}$} & \multirow{2}{*}{$\begin{array}{l}\text { Mit } \\
\text { Grinzing }\end{array}$} & \multirow{2}{*}{$\begin{array}{c}\text { Mit } \\
\text { Grund }\end{array}$} \\
\hline & $\begin{array}{l}\text { Badhaus- } \\
\text { brunnen }\end{array}$ & Kirchhof & & & \\
\hline Gastropoden (73 Arten) & $21=29 \%$ & $39=53 \%$ & $46=63 \%$ & $35=48 \%$ & $29=40 \%$ \\
\hline Bivalven (41 Arten). & $17=41 \%$ & $24=58 \%$ & $26=63 \%$ & $19=46 \%$ & $29=71^{\circ} \%$ \\
\hline Zusammen 114 Arten & $38=33 \%$ & $63=55 \%$ & $72=63 \%$ & $54=$ & $58=51 \%$ \\
\hline
\end{tabular}

Daraus folgt:

a) Das Verhältniss der Artenzalıl der Gastropoden zu den Bivalven ist gleich $(64: 36)$ wie in den Sanden der Lokalität hinter dem Kirchhofe;

b) Die Gastropodenfauna nähert sich am meisten (63 Percent gemeinsame Arten) jener vol Gainfahren;

c) Die Bivalven stimmen am meisten (71 Percent gemeinsame Arten) mit denjenigen von Grund überein;

d) Die gesammte Fauna steht abermals jener von Gainfahren (63 Percent gemeinsame Arten) am nächsten. 


\title{
Beiträge zur Geologie von Galizien.
}

(Siebente Folge.)

\author{
Yon Dr. Emil Tietze.
}

\section{Die Aussichten des Bergbaues auf Kalisalze in 0stgalizien.}

(Nit ejner lithographischen Tafel (Nr. III).

Als man vor mehr als 30 Jahren die sogenannten "Abraunsalze" der Gegend ron Stassfurt in ilırer Bedeutung für "Industrie und Landwirthschaft zu würdigen begann ${ }^{1}$ ), machte sich naturgemäss im Anschluss an die betreffenden Bestrebungen sehr bald der Wunsch geltend. auch in anderen Salinargebieten derartige Salze aufzufinden. Dieser Wunsch ging jedoch nur in sehr beschränkter Weise in Erfüllung. Man traf allerdings Spuren von Kalisalzen in der indischen Salt Range ${ }^{2}$ ) und in Colorado, allein es scheint nicht, dass diese Entdeckungen sich bisher als praktisch verwerthbar erwiesen haben und ebenso wenig hat man bis jetzt Gelegenheit gefunden, dem vielleicht etwas interessanteren Vorkommen von Maman in Persien ${ }^{3}$ ) nähere Aufmerksamkeit zuzuwenden. Nur an einem Punkte, an welchem man ebenfalls anstehende Kalisalze zu ermitteln so glücklich gewesen war, eröffnete sich eine Zeit lang ein gewisser Spielraum für den Unternehmungsgeist. Es war dies Kalusz in Ostgalizien.

H. Rose in Berlin dürfte der Erste gewesen sein, der in der fachmännischen Literatur auf die Auwesenlieit von Kalisalzen an jenem Punkte aufmerksam machte. In der Sitzung vom 6. Nov. 1861 der deutschen geologischen Gesellschaft gedachte er mänlich des Vorkommens yon Chlorkalium an dem bewussten Fundpunkte. Seit dieser Zeit ging man, wie Baron v. Hingena in der Sitzung der k. k. geologischen Reichsanstalt rom 21. Januar 1868 verlautbarte, in gewissen Kreisen immer und immer wieder mit der Idee um, die etwa in den galizischen Salinendistricten vorhaudenen Kalisalze nutzbar zu machen, und in demselben Vortrage konnte Baron Hingenau bereits an-

1) Vergl. hierüber die historischen Daten in P feiffer's Handbuch der KaliIndustrie. Braunschweig 1887, pag 105.

"' 'T's c herm a k's miner. Mittheil. 18i3, pag. 135.

$\left.{ }^{3}\right)$ Vergl meine Mineralreichthümer Persiens, Jahrb. d. k. k. geol. Reichsanst. 1879, pag. 568, und Goebel im bull. acad. Petersburg 1866, pag. 1. 
kündigen, dass sich ein industrielles Consortium gebildet habe, welches speciell in Kalusz sich mit der Gewinnung und Verarbeitung von Kalisalzen zu befassen beabsichtige.

Die Erörterung der Schicksale dieses Consortiums und der Gesellschaft, die sich dann aus demselben putwickelte, gehört nicht in diesen Bericht. Es genügt hier zu sagen, dass die anfänglich allzu sanguinischen Hoffnungen, welche sich an den Kaluszer Kalisalz-Bergban knüpften, nach wenigen Jahren einer mehr pessimistischen Auffassung del dortigen Sachlage Platz machten. 'Thatsächlich haben sich auch die Vergleiche, die man in jener hoffuungsreichen Zeit zwischen Kalusz und dem inzwischen durch seinen beispiellosen Reichthum an Abraumsalzen schon berïhnt gewordenen Stassfurter Bergbau anstellen zu können glaubte, nicht als zulässig elwiesen. Ist ja doch die jährliche Förderung von Kalisalzen heute für Stassfurt und Umgebung ganz wesentlich grösser ') als die Gesammtmenge des bei Kialusz zur Zeit überhanpt aufgeschlossenen, das heisst als vorhanden sicher nachgewiesenen Quantums an dergleichen Salzen! Dazu kam, dass die Qualität der bei Kalusz erschlossenen Salze bei dem damaligen Standpunkt der Aufbereitung uad Verwendung solcher Producte in der Hauptsache nicht den gestellten Anforderungen entsprach, und so ging; abgesehen von allen den anderen Schwierigkeiten, welche der betreffenden Gesellschaft in rein fiuanztechnischen Fragen erwachsen sein mögen, diese Unternehmung wieder zu Grunde.

In diesem Schicksal liegt indessen kein Beweis dafür, dass auch noch unter den vielfach geänderten heutigen Verhältnissen der bei Kalusz vorhandene natünliche Vorrath von Kalisalzen als werthlos zu betrachten sei. Sieht man nämlich von solchen Uebertreibungen, wie sie durch den Vergleich mit Stassfurt hervorgerufen werden könnten, von vornherein ab, so wird man immerhin berechtigt sein, dem Kaluszer Bergban für die Zukunft eine etwas grössere Beachtung zu schenken, als das jener durch Enttäuschung überspannter Erwartungen hervorgerufenen pessimistischen Auffassung entsprechen würde, wie das gleich hier vorausgeschickt werden soll und wie das vielleicht aus der folgenden Darstellung hervorgehen wird. Man braucht ja gewisse Mineralschätze nicht unausgebentet zu lassen, nur weil die zu erwas tende Ausbente geringer sein wird, als an mehr begünstigten Punkten. Wenn dies ohne Nachtheil geschehen kann, mag man vielmehr der Erde dankbar entnehmen, was ihr zu entnehnen ist, wo immer sie etwas bietet.

Von einer ähnlichen Erwägung ausgehend, haben denn auch die dem heute wieder verstaatlichten Kaluszer Bergbau vorgesetzten Behörden die Wiederaufnahme des Betriebes auf Kalisalze daselbst ver-

') Die Fördel'ung der Abraumsalze des Stassfurter Reviers (vergl. P r e c h t , die Salzindustrie von Stassfurt und Umgebung, Stassfurt 1891) vertheilt sich (1. c. pag 13) jetzt auf 9 Bergwerke. Die Jahresförderung betrug in Jahre 1890 in Tonnen à 20 Centner (l. c. pag. 17) an Carnallit und Kieserit 826.759 Tonnen oder 16,535.180 Centner, an Kainit 369.279 Tonnen oder 7,385.580 Centner. Man vergleiche damit die weiter unten zu machenden Augaben iber die bei Kalusz zur Zeit verfugbaren Mengen an dergleichen Salzen und man wird finden, dass eine gewisse Zurückhaltung in den Urtheilen uber Kalusz vorläufig noch am Platze ist. 
anlasst ${ }^{1}$. Ueberdies aber erhob sich bei der steigenden Bedeutumg solcher Producte die Frage, ob dieser Betrieb nicht auf crweiterte Grumdlagen gestellt werden kömnte, und es erwachte sogar clas Bedürfniss, Umschau zu halten, ob und wo anderwärts in Ostgalizien ähnliche Salze rorkommen möchten.

Seitens des hohen k. k. Finanzministerimms, als der obersten, dem Salzbergbau vorgesetzten Behörde, wurde deshalb im Einververnehmen mit dem hohen $k$. $k$. Ministerium für Cultus und Unterricht der Wunsch ansgesprochen, es möchte ein mit den Landesverhältnissen vertrauter Chefgeologe der k. k. geologischen Reichsanstalt nach Ostgalizien entsendet werden, $m$ in der angedenteten Richtung Studien zu machen. In Folge dessen wurde ich von der Direction der k. k. geologischen Reichsmistalt beauftragt, noch im Laufe des Sommers 1892 der bezeichneten Aufgabe nach Massgabe der mir im Hinblick anf meine sonstigen Obliegenheiten verfügbaren Zeit nachznkommen, und erlaube ich mir über die Ergebnisse der betreffenden Erhebungen hiemit Bericht zu erstatten ${ }^{2}$ ).

Die mir gestellte Aufgabe durfte, wie aus dem Voranstehenden ersichtlich, als in zwei Theile zerfallend aufgefasst werden. Erstens musste es sich darum handelı, zu prüfen, ob man amnelımen dürfe, dass die seit längerer Zeit bekamnte Kalisalzlagerstätte bei Kalusz sich über den Bereich der bisher dort gemachten Aufschlüsse hinans forterstrecke. Zweitens konnte man trachten, Punkte aufzufinden, für welche die Möglichkeit gegeben scheint, nene, bishel nicht bekamnte Kalisalzlager aufzudecken. Aus diesen beiden Gesichtspunkten ergibt sich anch von selbst die Gliederung der folgenden Schilderung. Selbstverständlich durfte dam für beide Fälle versucht werden, der Discussion des beobachtbaren Thatbestandes Vorschläge von Arbeiten anzufügen, durch welche die betreffenden Verhältnisse weiter aufgehellt werden kömnten.

Was zunächst den Bergbau von Kalusz nebst dem geologischen Autbau seiner Ungebung anlangt, so ist dariber, abgesehen von jenen

1) Bescheidene Anfänge dazu wurden bereits im Jahre 1887 gemacht, in welchem 500 Metercentner Kainit gefördert wurden. Während diese Production im Jahre 1891 schon auf 6.0 tio Metercentner gestiegen war, wurden, wie ich einer später noch einigemal zu erwähnenden 'Lusammenstellung Prof. Szajnocha's entnehme, im Jahre 1892 schon 31.1no Netercentner Kainit gewonnen. Das macht freilich noch immer einen dïrftigen Eindruck in Vergleich mit Stassfurt, das ich im Beginn des dortigen Aufschwungs, bei einem Besuche in Jahre 1869 (der da. maligen Carnallitconsum der dortigen Etablissements betrug allein bereits 214.177 Metercentner) bereits entwickelter vorfand, als Kalusz voraussichtlich je werden wird, aber für Kaluszer Verhältnisse ist die angegelene Production keine üble Leistung, welche der Thätigkeit der dortigen Verwaltung zu aller Ehre gereicht.

2) Ein vom 10. November 1892 datirter amtlicher Bericht, der das Wesentliche meiner heutigen Mitheilungen, zum Theile sogar in gleichem Wortlaute enthält, ist bereits im November vorigen Jahres dem hohen Finanzministerium zugestellt worden. Auch hatte ich in der Sitzung der Reichsanstalt vom 22. November 1892 Gelegenheit, den Inhalt derselben Mittheilungen znm Vortrage zu bringen (Verhandl. d. k. k. geol. Reichsanst. 1892, Nr. 14), wobei auf die hente nachfolgende ausführlichere Publication verwiesen wurde. 
oben bereits erwähnten Mittheilungen Rose's und Hingenau's. schon Mancherlei geschrieben worden. Insbesondere gab dazu der oben besprochene erste Versuch des Abbaues der Kalisalze Veranlassung, der zunächst zu einigen kleinen Arbeiten von F. Fötterle ${ }^{1}$ ) und C. v. $\mathrm{Hauer}^{2}$ ) führte, in welchen die Art des Vorkommens jener Salze näher erörtert wurde. Diesen Arbeiten schloss sich ein Aufsatz von $\mathrm{E}$. Windakiewi $\mathrm{cz}^{3}$ ) an, und endlich ist ans derselben Zeit, in welcher die verschiedensten Fachmänner vou den damaligen Besitzern der Grube um ihren Rath angegangen wurden, noch ein als Manuscript gedrucktes Gutachten der Herren v. Carnall, v. Co t a und Windakiewicz zu erwähmen, welches mir leider nicht zugänglich gewesen ist. Doch hat sich Prof. v. Szajn och a in Krakau Einsicht in dasselbe zu verschaffen gewusst, um den betreffenden Inhalt für eine von ihm verfasste Studie zul verwerthen. Diese zunächst nicht auf persömlichen Augenschein, sondern auf eine Reihe mit grossem Fleiss zusammengebrachter literarischer Behelfe gegründete Arbeit erscheint unter dem Titel "Sole potasowe w Galicyi, ich wystepowanie i zužytkowanie", und da ich der Freundlichkeit des Autors die Kenntnissnahme von einem grossen Theil der Correcturbögen diesel Studie verdanke, so war ich in der Lage unmittelbar vor der Drucklegung meines eigenen Aufsatzes in dem Text des letzteren noch eine Bezugnahme auf jenes Gutachten herzustellen. Es schien dies wünschenswerth, da man diesen gutachtlichen Bemerkungen, sei es dass dieselben direct oder blos durch Tradition bekannt sind, an manchen Orten gerade in letzter Zeit vielleicht in nicht ganz zutreffender Weise eine mehr als blos historische Bedeutung beilegt.

Auf Grund der bisher genannten und mehrerer anderer ihm vorliegender Berichte ${ }^{4}$ ) hat dann später E. Pfeiffer in seinem Buche ïlser die Stassfurter Kali-Industrie (Braunschweig 1887 pag. 72) eine übersichtliche, obschon kurze Darstellung der betreffenden Verhältnisse zu geben versucht. Die eingehendste Schilderung der letzteren rührt indessen erst aus neuester Zeit her. Es ist dies ein Aufsatz des Herrn Professor Julian Niedzwiedzki in Lemberg über "das Salzgebirge vou Kalusz" (Lemberg 1891), und ich will gleich hier die Gelegenheit zu der Erklärung ergreifen, dass ich mit den von Herrn Niedzwiedzli gemachten Angaben, soweit die Beschreibung des der Beobachtung zugänglichen Thatbestandes in und neben der Grube in Betracht kommt, in den meisten wesentlichen Punkten einverstanden

1) Verhandlungen der k. k. geol. Reichsanst. 1868, pag. 226 und 1871, pag. 65.

2) Jahrbuch der k. k. geol. Reichsanst. 1870, pag. 141 .

3) In den Sprawozd. Komisyi fizyograficzn. Krakau 1871.

$\left.{ }^{4}\right)$ Bezüglich der Literatur iiber Kalusz wäre noch zu vergleichen A. v. K r i p j) in der berg- und hiittenmännischen Zeitung von 1868, Nr. 45, Nr. 46, Nr. 49 und Nr. 50, sowic ein anonymer Artikel in demselben Jahrgang derselben Zeitschrift in Nr. 27. Ein zı Braunschweig 1875 erschienenes und Kalusz betreffendes Exposé ron A. Frank kounte ich mir nicht verschaffen. Nicht unerwähnt darf ein vom chemischen Standpunkte ans wichtiger Artikel bleiben, den C. v. John kiirzlich ,iiber die chemische Zusammensetzung verschiedener Salze aus den k. k. Salzbergwerken von Kalusz und Aussee" im Jahrbuch der k. k. geolog. Reichsanstalt (1892, pag. 341) veröffentlicht hat. 
bin '), wenngleich ich mir erlauben werde, betreffs der an die Darlegung jenes Thatbestandes anzuknüpfenden Vorschläge etwas von der Meinung des Genannten abzuweichen.

Diese Darlegung mag mit einer kurzen Schilderung der geologischen Zusammensetzung des uns hier interessirenden Gebietes begonnen werden, welches im Wesentlichen aus einer niedrigen, sich zwischen den Flussthälern der Lomnica und der Siwka erhebenden Hügelmasse besteht, an deren südwestlichem Fusse die Stadt Kalusz liegt.

Die Oberfläche dieser Hügelmasse wird ganz überwiegend von Diluvialbildungen eingenommen.

Insbesondere sind hier Höhenlehme vertroten, bei denen sich nicht überall leicht entscheiden lässt, inwieweit dieselben als Verwitterungsproducte der Unterlage oder als lössartige Gebilde zu betrachten sind. Am Wege von Kalusz über den Kamm der Hügelmasse nach der Svolek genannten Erluebung, von dort westwärts gegen die Siwka und gegen das Dorf Kopanka zu, sowie im Walde Kopan nördlich rom Dorfe Pohorki werden, soweit dort überhaupt etwas von der Bodenbeschaffenheit erkennkar ist, fast nur derartige Lehme angetroffen.

1) Mein Vergniigen dies aussprechen zu diirfen, ist um so grösser, als ich, wie vielfach bekannt, in einem anderen Falle, nämlich bezüglich der geologischen Verhältnisse von Wieliczka mit dem genannten Autor so wenig iibereinzustimmen Veranlassung fand, dass sich ans diesem Mangel an Concordanz der Ansichten eine langwierige Polemik ergab, die von Seite des Herrn Professors mit auffallender Gereiztheit geführt wurde und heute noch fortgese:zt wird (vergl. dessen neueste Schrift ,zur Geologie von Wieliczka“, Lemberg 1892).

Wenn ich ron jenem l'ergnügen rede, so bezielit sich das zunächst allerdings nur auf dic frendige Hoffnung, dass es mir diesmal möglich sein werde, die Wegc des Herrn $\mathrm{Ni}$ idzwiedzki zu berühren, ohne einen Zusammenstoss mit dessen Ansichten heıbeizufülıren. Weitere Erwartungen darf ich leider kaum wagen, so wiinsclienswerth es jnmerhin wäre, wenn man auch beziiglich Wieliczka's zı einer Verständigung, ich sage nicht einmal in der Auffassung des Sachverhalts, aber wenigstens in der Interpretation des textlichen Sinnes der betreffenden $\mathrm{Pu}$ blicationen gelangen köınte. Zu oft jedoch habe ich während jenes Streites die Erfahrung machen miissen, dass mein erhitterter Gegner nach ganz andern Denkgesetzen denkt, als icl und dass es leshalb nicht allein fruchtlos ist, denselben für meine Auffassungen gewinnen, sondern auch direct unmöglich ist, ihm diese Anschauungen unter Vermeidung von Missverständnissen klar machen zı wollen. Die genannte neueste Schrift liefert dafür weitere Beweise. Hat der Verfasser ja z. B. noch immer nicht zu erkennen vermocht, in wie unglaublicher Weise er den Sinn meiner Austiihrungen über gewisse Bohrergebnisse entstellt hatte und insinuirt er mir doch noch beute, die im Norden der dortigen Grube nach seinem Vorschlag ausgeführte, erfolglose Bohrung seinerzeit für hoffnungsreich erklärt zu liaben, trotzdem ich ausdrücklich von den "geringen" Hoffnungen in jener Gegend gesprochen hatte!

Ich beruhige miclı daher mit einem ähnlichen Gedanken, wie ihn dieser Autor (in der olien citirteu Schrift pag. 9) ausspricht, wo er (allerdings in der iłım geläufigen kräftigen Ausdruckweise) erwartet, dass der aufmerksame Lescr unserer beiderseitigen Auslassungen sich über die Einzelheiten dieser Discussion sein eigenes Urtheil bilden könne und dabei nicht nöthig habc, den Momenten rein persönlicher Natur weitere Rücksicht zu schenken. Nich fil meinen Theil interessirt jedenfalls bei diesen Dingen die Sache stets mehr als die Person, Ind so füble ich mich denn in dem einen Falle ebenso verpflichtet meinen Standpunkt einfach zu waliren, als in dem andern, wie das heute geschieht, meine Zustimmung zu äussern, auch wenn die Arbeit, der ich Beifall zolle, von einem Gegner herrührt, dessen Missfallen jemals überwinden zu können ich mir nicht schmeichle, 
Doch kommen auch Schotterbildungen vor. Wenigsteus sah ich dergleichen ans karpathischem Material bestehenden Schotter in der nächsten Nälıe des Schachtes $\mathrm{Nr}$. 7 bei dem Kaluszer Bergbau, was insofern hervorgehoben zu werden verdient, als dieser Punkt sich in einer ziemlichen, mehr als 100 Fuss betragenden Höhe über dem Siwkakette befindet. In ähnlicher Weise fand ich auch bei meinen diesmal von Kalusz aus unternommenen Ausfïgen am rechten Gehänge der Lomnica zwischen Babin und Medynia karpathischen Flussschotter in beträclitlicher Höhe über dem hentigen Flussniveau, was ich hier beiläıfig erwähne im Hinblick auf frühere Mittheilungen (vergl. diese Beiträge 4. Folge, Jahrb. 1889, pag. 346 und 5. Folge, Jahrb. 1891, pag. 66), in welchen ich anf die oft beträchlichen Höhenlagen des galizischen Diluvialschotters hingewiesen habe.

Unter allen diesen Diluvialbildungen steckt eine Unterlage von tertiären Schichten, welche den Keru der bewussten Hügelmasse bilden, ebenso wie sie sich unter den alluvialen Ausfüllungen der benachbarten Flüsse forterstrecken Das genauere Alter dieser Tertiärschichten ist das miocäne, wie allseitig zugestanden wird, und speciell bei Kalusz gehören dieselben demjenigen Schichtencomplexe an, den man sich gervöhnt hat, zum Unterschiede von anderen Miocänschichten Galiziens als die galizische Salzformation zu bezeichmen.

Leider sind nun diese Ablagerungen von den vorher erwähnten Diluvialgebilden derart verhïllt, dass sie nur in einer geringen Zahl ron Entblössungen an der Tagesoberfläche wahrnehmbar werden. So sieht man eine schwache Entblössung voul blauem Letten an dem sonst durch gelben Diluviallehm bezeichneten Wege, auf dem man rom westlichen Theile des Dorfes P'odhorki nach dem Walde Kopan gelangt, und einen ähnlichen Ausbiss von Salzthon kamn man an dem Wege beobachten, welcher nördlich der Grubenanlagen, etwa von der Wohnung des Salinenoberverwalters ostwärts gegen eine schon an den Hügel angebaute Häusergrupe linaufführt. Andere Spuren miocäner Thone beobachtet man beim Friedhofe von Kalusz. Das Meiste und Beste von derartigen Aufschlüssen kommt übrigens in der Nachbarschaft der Salzmine selbst vor, wo, wie bereits Professor Nie dzwiedzki hervorhob, gewisse, mit Sicherheit dem Hangenden der Kalisalze angehörige Schichten in ummittelbarer Nähe des Schachtes $\mathrm{Nr}$. 4 anfgedeckt sind. Zunäclist dem genamnten Schacht trifft man hier gypsfïhrende Thone und ein unreines Gypslager. In der Nachbarschaft des Gypses treten sodann Sandsteine anf, von denen nicht völlig klar ist, in welchem Verluältniss sie zu den Gypsen stehen. Etwas weiter südwärts erscheinen dann an demselben Gehänge theils bräunliche, theils röthliche Thone. Das ist aber auch Alles, was ron den dortigen Miocänbildungen ausserhalb der Grube zu sehen ist. Wirklich lehreiche Anfschlïsse liefert erst der Bergbau selbst.

Zum besseren Verständniss der folgenden Auseinandersetzung mag hier über die bei Kalusz gemachten bergbanlichen Anlagen Einiges hervorgehoben werden, wobei ich anf die dem Aufsatz beigegebenen Zeichnungen (Taf. III dieses Jahrbuchbandes) aufmerksam mache. Dieselben sind anf meine Bitte in Maassstabe 1:2500 von Herru Salinenverwalter II a $\mathrm{ch}$ in Kalusz entworfen worden. Figur 1 (unten) 
stellt dabei einen Grundriss vor, bei welchem die den verschiedenen Horizonten angehörigen Strecken jeweilig durch besondere Schattirungen bezeichnet sind. Die von den einzelnen Horizonten ausgehenden, bezüglich je zwei derselben direct rerhindenden Gesenke sind indessen weiss gelassen worden. Eine Täuschung über deren Lage ist nicht wohl möglich. Figur 2 (oben) gibt einen Anfriss, in welchem dieselben schwarzen Schattirmgen fiur die betreffenden Horizonte gewällt wurden wie beim Grundriss. Gesenke und Schachtlöcher blieben lier ebentalls weiss. Von Baulichkeiten ausserhall, der Grube wurden aber nur einige wenige hervorgehoben, die hei gewissen später zu besprechenden Vorschlïgen durch ihre Lage den Leser genauer orientiren können.

Die hier erwälnnten Anlagen befinden sich im Norden der Stadt Kalusz bei dem Vororte Bania in der Nïhe des Siwkaflusses, das ist am westlichen Abhange der vorher genamnten Hügelmasse. Schon im 15. Jahrhundert wurde hier Salggewimnung betrieben. Man gewann das Salz aus Soolen und legte endlich sogenannte Langschärhte an, die zunächst allerdings keine bedeutenden Tiefen hatten. Dic Zalıl dieser Schächte belief sich schliesslich auf 75 . Erst allmälig entwickelte sich durch Vertiefung einzelner Schächte und durch Streckenanlagen ein eigentlicher Bergbau, der indessen, da reines Salz bei Kalusz nicht zu erhalten war, im Wesentlichen seine Salzgewinnmg auf die Ausnützung ron Laugwerken basirte, die im Innern der Grube angelegt wurden. Damit gerieth die grosse Mehrzahl der alten Schachtanlagen in Verfall.

Gegenwärtig gibt es bei Kalusz nur mehr 3 Schächte, die von oben, das heisst von der Terrainoberfläche aus nach der Tiefe führen. Es sind dies der Schacht Nr. IV, der als Hauptschacht bezeichnet werden darf, der mehr auf der Höhe (33.38 Neter über Nr. IV) gelegene Schacht Nr. VII und der Soolenschacht Nr. II (Barbara), del seiner isolirten Lage negen und daun anch, weil er nur liegendes Gebirge aufschliesst, für die folgende Auseinandersetzung kaum in Betracht lommt. Ausserdem existirt noch ein (den 2. mit dem 3. Horizont verbindender) Grubenschacht, Namens Hingenan. Der Abbau aber bewegt sich in 3 Horizonten, von denen der unterste (3.) Horizont 108.43 Meter unter dem Tagkranze des Hauptschachtes Nr. IV sich befindet, während der 2. Horizont 76.62 Meter und der 1. Horizont 48.20 Meter tief ist. Im südöstlichen Theil der Grube ist ausserdem noch zwischen dem 1. und 2. Horizont ein ungeführ 12 Meter unter dem 1. Horizont gelegener Mittellauf vorhanden. Diese Horizonte sind, abgesehen ron den genannten Schächten, auch theilweise durch schräge Gesenke mitemander verbunden, wie das schon oben bei Besprechung der Tafelbeilage angedeutet wurde.

Das durch diese Arbeiten zugänglich gemachte Salzgebirge besteht nun der Hauptsache nach aus Haselgebirge, aus sogenantem Salzthon, der mehr oder. weniger durch Beimengungen von Steinsalz angereichert ist. Diese Beimengungen machen namentlich in den tieferen Theilen des Gebirges nicht selten die Hälfte der ganzen Masse ans, so dass man das betreffende Gestein manchmal anch beinalie als ein durch Thon stark verunreinigtes Steinsalz bezeichnen kömnte. 
Durch die bereits kurz erwähnten, innerhalb del Grube angelegten Laugwerke ${ }^{1}$ ) wird der betreffende Salzgehalt gewonnen, wozu noch der natïrliche Soolenzufluss kommt, der in dem ebenfalls schon erwähnten Schachte Nr. 2 auftritt ${ }^{2}$ ). Diese Anlagen zur Soolengewinnung beuten im Wesentlichen nur den liegenderen Theil des in der Grube aufgeschlossenen Schichtencomplexes bezüglich seines Salzgehaltes aus ${ }^{3}$ ), weil gerade dort dieser Salzgehalt noch nicht durch Beimischungen vou Abraumsalzen, die dem Soolensalz unerwünschte Eigeuschaften geben würden, beeinträchtigt wird. Das wirkliche Liegende indessen des gesammten Salzthous wird durch die Grube nicht aufgeschlossen und es muss dahingestellt bleiben, was es mit dem rothen Thon fïr eine Bewandniss hat, der älteren Berichten zufolge an der Basis des Kaluszer Salzthons vorkommeu soll.

Gegen die hangenderen Theile des Gebirges zu scheiden sich in dem Salzthon stellenweise etwas reinere, das heisst weniger durch Thon verunreinigte Steinsalzmassen aus. Sowohl diese als der hangenderé Theil des Salzthones selbst enthalteu kleine Beimengungen von leichter löslichen Salzen (Sulphate und Chloride vou Kalium und Magnesium). Ausserdem aber kommen hier (wenngleich keineswegs in den obersten Partien der Ablagerung) auch jene selbstständigen Massen von Kalisalzen vor, durch welche der Kaluszer Bergbau vor anderen galizischen Salinen eine gewisse Berülumtheit erlangt hat. Dass unter diesen Kalisalzen nur Sylvin (Chlorkalium) und Kainit (eine Verbindung rou Chlorkaliun mit schwefelsaurer Magmesia und Wasser) eine grössere Rolle zu Kalusz spielen, ist vielfach bekannt. Doch ist dabei zu bemerken, dass die Ausscheidungen von Sylvin, denen man anfänglich, nach der ersten Inangriffnalume des dortigen Abbaues vou Kalisalzen eine höhere Bedentung beimass, weitaus weniger mächtig und ausgedehnt sind, als die von Kainit, auf welches Material früher weniger Werth gelegt wurde, als heute, wo man dafür bessere Verwendung fiudet, als damals. (Vergleiche hierüber z. B. Musprat t's techuische Chemie, 3. Bd. pag. 1322).

Was die Lagerung des hier kurz beschriebenen Salzgebirges aulangt, so ist dieselbe, wie fast ïberall im Bereiche der subkarpathischen Salzformation, eine gestörte, das heisst nicht mehr horizontale. Die Schichten streichen in Stunde 9 (von NW nach SO) und fallen nach SW, also

1) Es bestehen in der Grube im 2. Horizont die Laugwerke Schwind, Szuszkiewicz, Wiesner und $\mathrm{Nr}$. 5 und im 3. Horizont das Laugwerk Rittinger.

2) Es kaun bei dieser Gelegenheit vielleiclit erwähnt werden, dass gegenwärtig vom 2. Horizont aus, und zwar von der Gegend des Schaclites Nr. IV her, ein (in dem Grundriss Fig. I links oben verzeichneter) Liegenddurchschlag getrieben wird, der zuerst in nordöstlicher Richtung abgeht, um dann nach einer jenseits der Gegend des Laugwerks Nr. 5 erfolgten Umbiegung gegen den isolirten Scliacht $\mathrm{Nr}$. Il zu gefuihrt zu werden. Dieser Durchschlag bewegt sich durchgehends in salzführendem Thon, olıne dass Besonderlieiten zu bemerken wären, abgesehen höchstens von dem stellenweisen Auftreten von Anhydritknollen, wie sie auch sonst bisweilen den liegenden Salzthon von Kalusz auszeichnen. Es scheint also der liegende Theil des dortigen Salzgehirges von ziemlich homogener Beschaffenheit $z u$ sein

3) Nur das Laıgwerk Wiesner ist mehr gegen das Hangende vorgeschoben. Doch sollen gerade die mit dieser Lage verbundenen Inconvenienzen zur späteren Herstellung des Langwerks Rittinger geführt haben. 
gebirgswirts'). Dabei wird das Fallen gegen die Tiefe und gegen SW zu ein Hacheres. denn wihlnend der Fallwinkel des liogenderen Salzgebirges, wie $\mathrm{Ni}$ ic $\mathrm{zwi}$ i $\mathrm{zk}$ i hervorhob, 40-45 Grad betrïgt. ja sogar bis anf 50 Grad sich belanfen kann, erscheint das gleich näher zu beschreibende Kainitlager in der Tiefe des 3. Horizonts nur' mehr mit 20-25 Grad geneigt. Dem entsprechend sind anch die das Kainitlager erschliessenden Gesenke in den oberen Theilen der Grube steiler als derartige Gesenke, die vom 3. Horizont aus den Kainit rerfolgen würden, zu sein branchten. Besondere Complicationen der Lagerungsverläiltnisse, wie sie z. B. die Benrtheilung des Salzgebirges ron Wieliczka erschweren, sind übrigens im Bereich der Grube ron Kalusz nicht vorhanden, weshalb hier auch leichter als in manchen anderen Füllen unter verschiedenen Beobachtern eine gewisse Uebereinstimmung der Auffassung siclı ergeben wird.

Die soeben erwähnte Art des Streichens und Fallens der Schichten beweist im Hinblick auf die örtliche Lage der hier in Betracht gezogenen Bildungen, dass die früher erwälnten, nnmittelbar linter Schacht Nr. IV am Berggehänge über Tage entblössten Gesteine in das Hangende der Salzthone der Grube gehörell, auf welchen Umstand rorgreifend bereits weiter oben bingedeutet wurde. Nach der Ansicht des Herru Professor Niedzwiedzki, der sich hierfür auf die Verhältnisse in zwei gegen das Hangende zu getriebenen Querschlägen der Grube bernft, würden die Gypsthone und Gypse hinter Schacht Nr. IT sogar mmittelbar mnd olme Zwischenschiebung anderer Bildungen auf den oberen Salzthon der Grube folgen ${ }^{2}$ ). Doch ist zur Zeit noch nicht ganz leicht zu beurtheilen, inwieweit die Beschaffenheit des hangenden Gebirges überall eine gleichmässige ist.

Jedenfalls ist ein Umstand vorläufig noch nicht genügend aufgeklärt, auf welchen hier noch hingewiesen werden soll. Der obere Salzthon von Kalusz nämlich gilt als wasserführend und ist dies thatsächlich an eimigen Stellen, wo man denselben angeritzt hat. Es ist dies eine immerhin beachtenswerthe Thatsache, insoferne thonige Gesteine sonst in der Regel als mehr oder weniger wasserundurchlässig gelten, während man beispielsweise sandigen Bildungen einen höheren Grad ron Wasserdurchlässigkeit zuzusprechen gewöhnt ist. Ist nun auch nicht zu verkennen, dass die Durchmischung eines Thones mit leicht löslichen Salztheilen dem Wasser einen leichteren Zutritt in das betreffende Gestein vermittelt (und ohne eimen solchen 7utritt

1) Auch in dem in einer vorangehenden Anmerkung erwähnten neuen, schon selır weit fortgeschritteneu Liegenddurchschlage wurde noch immer siidwestliches Fallen constatirt, so dass also im Bereich der Grube bis jetzt kein Anzeichen einer ansnahmsweisen Umkehr der Fallrichtung nachgewiesen werden kann

${ }^{2}$ ) Diese Angabe ist an und für sich richtig Der eine dieser Querschläge, welcher frither Balasits-Quelschlag hiess, befindet sich im 2. Horizont (er wird von $\mathrm{Niedz}$ i edzki als Hingenau-Qnerschlag aufgefüht, ist aher nicht mit der zwischen Schacht IV und Schacht VII hefindlichen Hingenanstrecke zu verwechseln) und ist noch zugänglich. Dagegen ist der andere dieser Querschläge, der vom 3. Horizont ausgeht, seit Jahren mit Bergen versetzt, doch ist hier das Hangende seiner Zrit constatirt worden. Ueherdies ist auch noch nenerdings im Jahre 1891 mit der dem 3. Horizont angehörigen zur /eit noch nicht näher benannten Strecke a der Gypsthon als Hangendes erreicht worden. 
wïrde es ja-keine Auslangmugsprocesse geben), so sprechen doch andrerseits gewisse Erfahrungen dafür. dass anch ursprünglich mit Salz imprägnirte Thone sich als ein Schutz gegen das Wasser ansehen lassen, wie dem z. B. bei den Wassereinbrüchen von Wieliczka die von Natur aus erfolgten Verschlämmungen durch Bestandtheile des Salzthongebirges zur Verstopfung jener durch Anritzung sandiger Bildungen hervorgerufenen Finbruche wesentlich beigetragen haben.

Bei meinen Besuchen in der Grube habe ich indessen nur an einer wenig ausgedehnten Stelle das Auftreten sandiger Bildungen constatiren können. Es war dies im 2. Horizont in der Hingenaustrecke zwischen Schacht IV und Schacht VII, und zwar etwas näher an Schacht IV. Dort sieht man. dass der Salzthon Sandknollen einschliesst. Ob nun, was ja möglich wäre, solche sandige Beimengungen sich local häufiger in den noch nicht anfgeschlossenen Partien des oberen Salzthones einstellen, oder ob in den liangeuderen Theilen des Gebirges stellenweise noch andere Verhältnisse Platz greifen, welche der partiellen Wasserführmg des oberen Salzthones Vorschub leisten, das entzieht sich vorlänfig der Beurtheilumg ${ }^{1}$ ).

Um num anf die speciellere Beschreibung der Kalisalzlagerstätte von Kalusz überzugehen, so mag mit der Darstellung des Auftretens des Kainits, als des heute wichtigsten hierher gehörigen Minerals, begommen werden. Der Kainit wird bereits im 1. Horizont, und zwar in der Nühe von Schacht Nr. IV, angetroffen. Dies ist jedenfalls nahezu der nördlichste Punkt seines Auftretens im Bereich der Grube, denn sehr viel weiter nach Norden kamn sich das hier fast am Ansgehenden angetroffene Lager kaum forterstrecken. Dieses Lager erscheint auch hier nur in der Breite von etlichen Metern. Geht man num im 2. Horizont von Schacht IV aus eine Strecke nach SW, so trifft man den Kainit wieder. Hier ist derselbe, wenn man sein Streichen verfolgt, bereits in einer Breite von 125 Meter anfgedeckt. Ueber die angegebene Erstreckung hinaus verschwindet der Kainit. Verfolgt man genan sein Streichen, so kommt man insbesondere in der südöstlichen Richtung, in der sogenamnten Schrvindstrecke schliesslich in ein salzarmes Gebirge, welches in grauen plastischen Thon iubergeht. wäluend man an nordwestlichen Eude der Strecke wasserfülurende Salzthonschichten bereits im Hangenden des Kainit gut anfgeschlossen findet. Im 3., noch tieferen Horizont erscheint der Kainit seinem südwestlichen Verflächen gemäss noch weiter südwestlich von Schacht Nr. IV entfernt. Das Lager wird hier aber durch den den 2. mit dem 3. Horizont verbindenden, frïher schon genannten Grubenschacht Hingenau erreicht, welcher sich eben eine gute Strecke südwestlich von Schacht Nr. IV befindet. Steigt man den Schacht Hingenan hinab, so trifft man den Kainit bereits bei der vorletzten Fahrt über der

1) Nach einer Mittheilung des Herrn Vorwalters Mach beträgt der Wasserzufluss aus der in der vorigen Anmerkung genannten Strecke a des 3 . Horizontes heute freilich nur 0.75 Liter per Stunde. Das scheint allerdings sehr wenig zu sein, indessen ist nicht zu iibersehen, dass die Stelle, wo hier das Hangende geritzt wurde, jetzt verdämmt ist. Andere Hangendquerschläge sind dagegen trocken. 
Schachtsohle, und nicht weit ron letaterer verlüuft die Grundstrecke des 3. Horizonts, durolı welche das hager hier hauptsärhlirh anfgeschlossen ist. Im 'Vebrigen sind der' 2. und 3. Horizont anch durch Gesenke verhmolen. welche dem Verflächen des Lagers entsprechend angelegt sind. Hier im 3. Horizont liess sich das hewusste Kanitlager rlem Streichen nach anf 225 Meter verfolgen. so dass also vom 1. zum 3. Horizont mit dem Einfallen des Lagers gegen die 'Tiefe und gegen SW hin eine zmehmende Verbreitermg dieses Lagers verbunden ist.

Das ist eine sehr erfreuliche 'Thatsache, welche weiter' unten noch zım Ansgangspmnkt einer weiteren Betrachtung gemacht werden soll, indessen sehe ich mich doch veranlasst hervorzuheben, dass dieser Thatbestand mit den ïbertriebenen Vermuthungen, welche man anfänglich über die zu erwatende Ausdehnmng der Kalıszer Kalisalzlagerstätte hegte, nicht ganz harmonirt. Liest man nämlich in der bereits erwälnten Schrift I'rof. S z a jn och a's die Bemerkungen, welche einst v. Carnall, v. Cotta und Andere über diese Ausdehmung gemacht haben. so trifft man allentlualben die Vorstellung, dass die Kaluszer Kalisalzlagerstätte ,eine weit grössere Breite eimmehmen müsse", als die bis dahin gemarchten Aufschlüsse ergaben. Besonders Cotta war der Meinung, dass die betreffenden Kalisalze "in der Streichrichtmo naw beiden Seiten noch weit über das gegenwärtig anfgeschlossene und in Angriff zu nehmende Gebiet linans in ganz amaloger Teise fortsetzen. wie in den jetzigen Grubenbauen" und er fügte hinzı, dass zu der entgegengesetzten Amahme "nicht der geringste Grund" vorliege, eine solche Ammahme daher" "vom wissenschaftlichen Standpunkte aus gïnzlich mbegriundet" sei. Der inzwischen erfolote weitere Aushan der Grube hat num aber einmal gerade hinsichtlich der Anmahme über die Streichnngsrichtung jenen Urtheilen nicht liecht gegehen, dem gar so bedentend wird man heispielsweise selbst im 3. Horizont die Steichmngserstreckung des liainit kaum: finden.

Ich hätte es gerade hierloei gerne unterlassen, die Aeusserungen der genamten hochverdienstvollen Mämer zu erwälnęn. Di aber nenerdinss von vers'hiedenen Seiten, nirht allein von der des Herru Prof. $\mathrm{Szajnocha} \mathrm{selbst.} \mathrm{sondern} \mathrm{auch} \mathrm{in} \mathrm{parlamentarischen} \mathrm{Kreisen} \mathrm{anf}$ jene alten Gutachten wieder ein ganz besonderer Werth gelegt zu werden scheint. so mag es nicht mulassend sein, daran zu erinnern, dass Erfalurungen. vor Vermuthungen stets den Vorzug verdienen.

In ähnlichor Weise wie bezüghich der Frage der Streichnngsfortsetzung hat man sich in jener Zeit auch manchmal über die Nengen der Kalisalze getänscht, welche man duch die Grube für aufgeschlossen hielt. Das zeigen die Verhältnisse unseres liainits nichit minder dentlich.

Die Mächtigkeit dieses lianitlagers schwankt, wie Professoi Niedzwiedzki. dessen Angaben inch hierin durchans zutreffend sind, bemerkt, zwischen 8 und 16 Meter mod beträgt in der Regel 10 bis 12 Meter.

Vielfach wird dieses Lager. wie noch hinzugefügt werden rarf. von einer Anhydritbank bedeckt. Stellenweise liegt dieser Anhydrit 
direct über dem Kainit, stellenweise aber schielst sich zwischen beide eine Schicht gewöhnlichen Salzes ein. Im letzteren Falle erscheint der Kainit reiner als gewöhnlich. Auch kommen im Kíainit selbst Salzlinsen vor") und wird derselbe fast durchgängig durch Beimengungen von Steinsalz und hie und da auch von etwas 'Thon verunreinigt. Ganz reiner Kainit tritt jedenfalls selten auf und dürfen deshalb gewisse neuerdings von John (1. c. pag. 352) untersuchte Proben aus dem 3. Horizont, welche 95.12, bezielnungsweise 95.18 Procent Kainitsubstanz aufwiesen, nicht als allgemein maassgebend betrachtet werden. Niedzwie d zki hat auf Grmond seiner Schätzung 65 und C. v. Hau er (1. c. pag. 144) auf Grund einer Durschnittsanalyse sogar nur ca. 62 Procènt als den wahrscheinlichen mittleren Gehalt der dem Kainitlager entnommenen Rolisubstanz angenommen. wozu der Letztere allerdings noch über 10 Procent (der Kainitformel nicht einfügbares) überschüssiges Chlorkalium rechnen zu dürfen glaubte.

Die Menge des diesem Lager angehörigen (in der angegebenen Weise mehr oder minder umreinen) Kainits, soweit dieselbe nämlich durch die heute im Betrieb befindlichen Strecken aufgeschlossen ist, kann anf ungefähn ${ }^{21}{ }^{1}$. Millionen Meter'entner geschätzt werden.

Diesen Ammäherungswertl. der mit der von Niedzwiedzki hierfür gegebenen Ziffer von 2 Millionen Metercentner so ziemlich übereinstimmt, erhält man nämlich, wemn man, wie das wohl selbstverständlich ist, nur die mittlere Mächtigkeit des Lagers in Rechmmg zieht und bei der Ausdehmung dieses Lagers die continuirliche Verschmälerung desselben nach Norden zu berïcksichtigt. Vielleicht kömte ans dem Tmstande, dass das Streichen der Kainitmassen kein ganz geradliniges, sondern stellenweise ein etwas gebogenes ist, noch eine kleine Vergrösserung jenes Werthes resultiren, viel wird das aber nicht ansmachen.

Dem gegenüber nehmen sich freilich gewisse ïltere Schätzungen viel imposanter aus. So hat F. Föt ter le (Verhandl. d. k. k. geolog. Reichsanst. 1871, pag. 66) geglaubt, dass die damals erzielten Aufschlüsse es erlaubten. die Menge des ., für den Abbau der näclisten Jahre" verfügbaren Kainits auf 15 Millionen und die des Sylvins auf 7-S Millionen Zoll-Centner bezifferı zu können. Es ist möglich, dass ihn zu dieser Amahme die in gewissen heut geschlossenen Gesenken des 3 . Horizonts gemachten Ermittlungen ermuthigten. Es ist anch denkbar, dass ihn ïbertriebene (ohme Rücksicht auf den Fallwinkel gemachte) Mächtigkeitsschätzmgen, wie wir sie beispielsweise bezüglich des Kainitlager's bei C. v. Ha u e r (1. ‘. Jahrb. 1870, pag. 142) finden, zu seinen Aufstellungen verleiteten. Immerhin aber ist es gut zu constatiren, dass auch in jener Zeit nicht allseitig so ausgiebige Zahlen genamit worden sind. Der damalige Oberbergcommissär Winclakiewicz wenigstens schätzte, wie ich den Mittheilungen

1) C. v. John hat (Jahrb. d. k. k. geolog. Reichsanst., 1892, pag. 346, Nr. Ill) die Probe einer derartigen Finschaltung analysirt, desgleichen Proben andrer Steinsalzpartien, die dem Kainit lirect benachbart sind, bezughich ïber demselben liegen. Wie vorauszusehen fanden sich dabei stets gewisse Beimengungen von Kali- und Magnesiasalzen. 
Szajnochas entnehme, in einem in Mai 1873 erstatteten Specialgutachten lie Nenge der damals fïr den Abhan rerfïgbaren KaliRohsalze zusammen nu auf etwas über 3 Millionen Metercentner und r. Calluall bezifferte die Menge des aufgeschlossenen Sylvin ant 1,982.500 Meter'entmer, die des Kainits aber nur auf 972.000 Metercentuer, indem er die mittlere Mächtigkeit des Sylvinlagers anf 12 Meter, die des Kainitlager's ebenfalls anf 12 Meter veranschligte, was in letaterem Falle der Wahrheit jedenfalls sehr nahe kommt.

7u den Fragen. welche sich zur Zeit noch nicht lösen lassen, rehönt die, ol das Kaluszer Kainitlager sich nach der Tiefe zu in ein ans andern Kalisalzen bestehendes Lager verwandeh möge.

Bekanntlich nimmt man an, dass hei Stassfurt der Kianit im Weseutlichen ein in den höheren Regionen des dortigen Berghaues unter dem Einfluss zusitzender Wüsser entstandenes Umsetzumgsproduct vou Carmallit rorstelle. Der Analogieschluss liegt num anscheinend nihle. dass auch bei Kalusz mit zumehmender Tiefe unter der Tagesobertlïche der Kainit in Carnallit übergehen dürfte. mo dieser Schluss scheint anch seiner Zeit, beim ersten Aufschwung der Kaluszer Kalisalzgewimumg. thatsächlich zu besonderen Hoffinmgen Veranlassung gegeben zu haben. insoferne damals. wie schon oben angedentet. der Kainit im Tergleich zn anderen Kalisalzen weniger geschätzt wurde. In Falle, dass jener Schluss begrïndet wähe. könnte man leicht zu der weiteren Ammahme gelangen, dass man in dem hesprochenen Kainitlager nur den nach oben gekehrten Zipfel einer nach der Tiefe zu rielleicht viel ansgedehnteren Kalisilzlagerstätte vor sich habe.

Wohl ware eine der:atige Ammahme noch immer nicht mit zwingender Sicherheit zn hegründen. dem schliesslich kamn ja eine räumlich eingeengte I'artie ebenso gnt theilweise Umwandlungen erlitten haben, als ein sich weit erstreckendes Lager oder man kann sogar mit einem Absatz zu thum haben, bei welchem die Metamorphose bereits eine fast durchg̈̈ngige geworden ist, so dass eine Vertretumg desselben durch andersartige Gebilde vergeblich gesucht werden würde, allein maṇ lässt sich ja inmer wieder geru zu lebhafteren Hoffuungen bestimmen, und so sehr ich mich auch verptlichtet glanbe einem nenestens wieder hervortretenden allzustarken Optimismus in Bezug auf Kalusz entgegenzuwirken. so liegt es mir doch fern, jene Hoffnumgen sofort nach jeder Richtung hin eindimmen zu wollen.

Von diesem Standpunkt aus erhalten einige praktisch vorläufig belanglose, weil räumlich sehr beschränkte Vorkommmisse von Carnallit in der Kaluszer Grube eine gewisse theoretische Wirhtigkeit. Dieselhen gehören bezeichnender Wreise dem 3. , also dem tiefsten Horizont der Grube an. Das eine dieser Vorkommeu befindet sich ein wenig südöstlich von der Basis des Grubenschachtes Hingenan. unweit eines Wasserschachtsumpfes, der dort inmitten der Strecke gelegen ist. Hier erscheint der Carnallit (Chlorkalium mit Chlormagnesium und Wasser) an der First (Derke) der Strerke ${ }^{1}$ ). Das zweite

\footnotetext{
1) Von diesem Punkte stammt augenscheinlich eine von John (l. c. pag. 344 und 352) analysirte Probe, derzufolge das letreftende Salz, allerdings nur 41.97 Procent Carnallit enthält und unter Anderem durch 42.19 Procent Koch$\mathrm{salz}$ verunreinigt ist.
} 
jener Vorkommen aber hefindet sich nordwestlich ron der Basis des Schachtes Hingenau. im nordwestlichen Theile der Grundstrecke des 3. Horizonts, und hier kommt der Carnallit an der Sohle der Strecke zum Torschein. Beide Male erscheint er in umittelbarem Contact mit dem Kainit und gehört dem liegenden Theile des Kainitlagers an. Man könnte also glauben, hiermit die ersten Andeutungen eines Ueberganges von Kainitlager zu einem Carnallitlager vor sich zu haben, und jene beiden kleinen Camallitpartien wären dann solche, welche zur Zeit noch der Umwandlung in Kainit widerstanden hätten.

Indessen darf andrerseits nicht übersehen werden, dass die Verhältnisse des halisalzvorkommens von Kalusz mit denen von Stassfurt, abgesehen von anderen Verschiedenheiten, anch beziiglich der Anordmung der betreffenden Salze in den verschiedenen Schichtencomplexen einen sicheren Vergleich nicht wohl zulassen. Fehlt ja doch beispielsweise bei Kalusz Alles, was man bei Stassfurt als Polylalit- und als Kieserit-Region bezeichmet! Also wird auch jener Analogieschluss bei Alwesenheit andrer Analogien kein unbedingtes Vertranen einzuflössen rermögen. Zudem hat Professor Niedzwiedzki auf gewisse Eigenthümiichkeiten des Kaluszer Kainits aufmerksam gemacht, als welche er die grosse Gleichförmigkeit und die dünnschichtige Structur des letzteren bezeichnet mind ans denen er geneigt ist, Folgerungen gegen die Anuahme einer secundären Entstehumgsweise dieses Kainits aus Carnallit zu riehen.

Immerhin hat anch Herr $\mathrm{Ni}$ e $\mathrm{l} z \mathrm{w}$ iedzki die Möglichkeit einer solchen Umwandlung nicht vollständig bestritten, und diese Möglichkeit wird jedenfalls im Ange zu behalten sein. Eine definitive Aufklärung aber über diesen Punkt ist erst von dem weiteren Ausbau der Grube zu erwarten.

Für die Kenntniss von den im Bereich unserer Abraumsalze möglicherweise stattfindenden Zersetzungs- und Unwandlungserscheinungen mag übrigens noch eine mir kur\% vor der Drucklegmm dieser Schrift durch Her'n Verwalter II a " h zugeliommene Mittheihng von Belang sein. Danach ist man in Januar dieses. Jahres beim Abbau des zwischen dem 1. mn 2. Horizont gelegenen Theiles des Kainitlagers auf eine Kluft gestossen, welcher Schwefelwasserstotf entströmte. Derselbe wurle angezündet und brannte einige Tage lang mit langer, ruhiger Flamme.

In gewissem Sinne unabhängig von llem besprochenen Kainitlager erscheint im südöstlichen Theile der Grube das Vorkommen von Sylvin. Dasselbe hängt mit jenem Lager nicht direct zusammen, wemn es anch nugefähr in der Streirhungsfortsetzung desselben auftritt. Der Sylvin gehört indessen auch dlem hangenden Theile des Salzgebirges an und ist P'rofessor $\mathrm{Ni}$ ed zw ie d zk i sogar der Meinumg, dass er ein etwas höheres Nivean als der vorher beschriebene Kainit einnimmt. da er im 3. Horizont ein wenig über dem südöstlichsten Theile res Kainitlagers auftritt. $\mathrm{Er}$ ist dur(ch alle drei Horizonte hindurch ronstatirt, wenn anch seine Hanptaufschlüsse dem 2. Horizont angelı̈̈reu.

Das Vorkommen des Sylvins ist viel weniger regelmässig als das des kainits im vorher beschriebenen Lager. Nur theilweise ist es 
ein schichtenförmiges, vielfach dagewen cin linsentömnges. wenn anch die hisweilen zu ziennlicher Mächtigkeit anschwellenden Linsen durch verschmälerte l'artien in mannigfacher Verbindung untereinander stchen. Diese Unregelmässigkeit macht eine Alschätzung der im Bereich der Grube vorhandenen Sylvin-Mengen schwierig. In jedem Falle aber sind dieselben riel mbedentender, als die Masse des bisher anfgeschlossenen Kainits und dürften kaum den vierten Theil diesel Masse betragen, mag auch die mit Sylvin angereicherte I'artie dem Streichen nach ausgedelnter sein als das Kainitlager. Namentlich ist auch zu berücksichtigen, dass der frühere Kalisalzberghan hierselbst sich rorzugsweise auf das erstgenannte Mineral geworfen hat, der natiirliche Vorrath desselhen also bereits mehr angegriffen erscheint.

Ueber die eventuelle Fortsetzung des Sylvinlagers (wenu der Ausdruck Lagel' hier der' Küurze wegen gestattet ist) nacl den sürlwestlichen Teufen zu hat man sich, wie es scheint. gelegentlich des ehemaligen Abbaus gerade in den mit der Führung dej Arbeit betrauten Kreisen keiu sehr gïnstjges Urtheil zu bilden rermocht. Das hängt wohl abenfalls mit der bereits betonten Unregelmässigkeit des Srlvinabsatzes zusammen.

Zu dieser Unregelmässigkeit gesellt sich die Ungleichwerthigkeit des fraglichen Materials, welche $\mathrm{P}$ feiffer (1. c. pag. 77) sogar als einen Hauptgrund für das Scheitern der älteren Unternehmung in Kalusz betrachten zu dünfen glault. Viele ungünstige Nomente meint der Genamnte wären nocl zu überwinden gewesen, wenn die Hoffnungen auf einen besseren Abbau in der Tiefe sich bewälurt hätten. „Statt dessen ging der Gehalt des Sylvinsalzes immer mehr zurück und dieses enthielt bald nur noch 25 Procent Chlorkalium, daneben aber etwa 25 Procent Chlornatrium und 50 Procent Thon und Anhydrit ${ }^{1}$ ) und schliesslich setzte es sogar streckenweise ganz aus und machte rladurch einon regelmässigenAbbau und Fabrikshetrieb völlig illusorisch".

Ob der Kaluszer Sylvin ebenso wie man das beim Kainit glauben kann, aus Carmallit entstanden sei, wie T s c ll e rm a.k (Sitzb. Wien. Ak. 63. Bd. 1871, pag. 305) und P fe iffe r (l. c. pag. 78) annehmen, bleibt vorläufig eine rein akademische Frage. Thatsächlich ist bisher inmitten der Sylvinzone noch kein Analogon zu den vorher beschriebenen Casnallitpartien des Kainitlagers nachgewiesen worden.

Ton einigem Interesse ist aber schliesslich der Umstand. dass mit dem Sylvin in beschränkter Weise Kainit verbunden ist. Man sieht das an einer Stelle in 2. Horizont, etwa in der Gegend zwischen dem Wiesnerlaugwerk und dem Schwindlaugwerk. aher näher an dem erstgenamnten. Dort beobachtet man eine etwa 2 Meter mächtige, aber nicht ausgedelnnte Partie von Kiainit. welche deutlich unter dem Sylvin liegt. Dem Kainit fehlt hier die Anhydrithank, welche, wie oben gesagt wurde, häufig das Hangende desselben im vorher beschriebenen Hauptlager bildet. Das ganze Torkommen ist übrigens ein rein locales. augenscheinlich ausser Zusammenlang mit dem Haupt-

1) Anfänglich hatte man freilich $50-6 n$ percentiges Sylvinsalz getroffen und auch Bruno Kerl (Salinenkunde, Braunschweig 1868, pag. 199) glaulute daher, dass Stassfurt unter der Concurrenz von Kalusz werde zu leiden haben. 
kainitlager stehendes. Jedenfalls liegt kein Grund vor. darin eine ummittelbare Fortsetzung des Hauptlagers zu erblicken.

Handelt es sich mum darmm, auf Grund des dargelegten Thatbestandes die Aussichten zu discutiren, welche für eine eventuelle Erweiterung rler bergbanlichen Anlagen bei Kalusz in Betracht kommen, so ist Folgendes zu bemerken.

Die Sylvin führende Zone der Grube darf für diese Betrachtung wenigstens vorläufig als ziemlich belanglos aufgefasst werden. Damit ist niclit gesagt, dass eine Ansbentung der zum Abban von friiher her vorgerichteten Sylvimmassen nicht statthaben kömme, sofern eine entsprechende Nachfrage gestellt werden sollte, indessen eine besoudere Rücksichtnahme anf diese Vorkommuisse kann in Gemässheit der voranstehenden Mittheilungen wohl entfallen, sobald es sich darum handelt, die nächstliegenden Zwecke in's Auge zu fassen.

Vor Allem müsste man neue Aufschliusse in dem Hauptlager des Kainits herzustellen trachten und daher wollen wir uns noch eimmal kurz Rechenschaft über die wahrscheinliche Art seiner Fortsetzmng oder Ausbreitung gebell.

Dass dieses Lager nicht wie eine gewöhnliche Schicht etwa in der Art mancher Sandsteinbänke in den Karpathen anf cine längere Erstreckung lin sich im Streichen fortsetzt, geht aus dem oben Gesagten, wohl zur Genüge hervor. Deshalb sind anch einige Bohrungen, welche man vor einigen 20 Jahren in der idealen Streichungsfortsetzung der Kalisalze unternommen hat. erfolglos geblieben. Die eine derselben befand sich in der supponirten nordwestlichen Streichungsfortsetzung der Kalisalze nordwestlich hinter dem heute als Kanzlei der Bergverwaltung dienenden Gebäude, die andere hatte die südöstliche Streichungsfortsetzung aufgesucht und befand sich mweit der von Kalusz nach Podhorki führenden Strasse, nahe dem Punkte, an welchem auf der Generalstabskarte ein Ziegelofen angegeben erscheint, das ist also in der Richtung gegen das Lomnicathal zu. Beide Bohrungen dürften zwar nach den darüber circulirenden Aussagen nur 'Tiefen von etwas über 50 Meter erreicht haben, sie hätten aber allem Anschein nach schon in dieser Tiefe die Kalisalze erreichen müssen, wenu die letzteren ein dem Streichen nach weit fortsetzendes Lager oder anch, weun sie, allgemeiner gesprochen, nur eine munterbrochene Zone der $\Lambda \mathrm{n}$ reicherumg des Gebirges bilden wïrden. Bei der südöstlichen Bohrung wurde ja nicht eimmal mehr das Sylvin-Vorkommen der südöstlichen Strecken des Bergbaues wiedergefunden.

Welche Gestalt besitzt mun das Hauptkainitlager? Nach dem eben Gesagten kann man dasselbe in wesentlicher Uebereinstimmung mit Herm Professor Niedzwiedzki als einen dem Kaluszer Haselgebirge eingelagerten, nach SW geneigten Lappen betrachten, der sich nach oben und NO $z$ mit moefüln elliptischem Umriss velschmälert, bezïglich auskeilt. nach der 'liefe mol SW hin aber verbreitert. Es liegt keinerlei Anhaltspunkt für die Amnahme vor, dass die Tendenz. dieser Verbreiterung einerseits mol die Fortsetzung dem Verflächen nach andererseits an den sichtbaren bisherigen Aufschlïssen im 3. Horizont der Grube schon ihr Ende erreiclst hat. Der Kainit steht überall in diesem Horizont, abgesehen von seinem Verschwinden an 
len Enden des Streichens, in mueschwächter Mächtigkeit an, und nach den eingezogenen Frkundigungen haben auch einige heut versetzte und deshalb unzugänglich gewordene Gesenke. welche vom 3. Horizont aus im Verflächen des Kainits weiter getriehen wurden, noch unverninderte Maichtigkeiten des genannten Minerals angetroffen. Dabei soll das Gesenke $\mathrm{Nr}$. 2 sogar eine tomnlägige Teufe ron nahezu 60 Metern erreicht haben. Daraus folgt. dass man in der Richtumg des Verflächens unter allen Umstänclen eine Fortsetzung des Lagers als erriesen amnehmen darf. Man darf aber auch nach derselben Richtung eine zunehmende Breite des Lagers vermuthen, da man kaum roranssetzen kamn, dass die Linien, welche für den anfgeschlossenen Theil des Kainitlagers dessen Cimrisse bezeichnen, plöt\%lich einen ganz andem Terlanf nehmen werden. Es ist demmach in holem Grade wahrscheinlich, dass die in der angegebenen Richtung zı erwartenden Kainitmengen grösser sein werlen, als die zur Zeit in der Ginhe aufgeschlossenen.

Will man indessen auf Informationen, die schliesslich nur vom Hörensagen lierstammen. wie die Angaben über das Gesenke Nr. 2 keinen hesonderen Werth legen und will man vorsichtshalber glauben. dass die heute im 3. Horizont sichtluare Breite in Folge eines ganz. besonderen Zufalls grade dem grössten Durchmesser des bewussten Lappens in der Streichungsichtung entspreche. so liegt noch immer die Toraussetzung nahe, dass die südwestlich rom 3. Horizont befindliche, zur Zeit noch unangeritzte Partie dieses Lappens ungeführ dessen zweite Hälfte vorstelle, dass also die früher angegebene Schätzung der heute aufgeschlossenen hainitmengen wohl ohne grosse Bedenken auf das Doppelte erhöht rerden kam, wemn man die zukünftige Ertragsfühigkeit rler Grube $\mathrm{zu}$ berechnen sich anschickt. Zum mindesten aber ist ein baldiges Aufhören des bewussten Kainitlagers nach den südwestlichen Teufen zu nicht zu besorgen, abgesehen hier überall natürlich von der weiter oben bereits besprochenen Möglichkeit. dass der Kainit in diesen Teufen theilweise durch gewisse andere Salze. wie Carnallit, ersetzt wird. was aber den Werth der Ablagerming nicht mindem würde'). Dabei ist im Hinblick auf die schon früher berïhrten Verbältnisse des Einfallens $z u$ vermuthen, dass dieses Lager mit zunehmender Tiefe zunächst eher flacher als steiler geneigt sein wird, so dass der Bergbau daselbst nicht einmal übertrieben grosse Tiefen aufzusuchen genöthigt sein dürfte, wenigstens so lange, als er sich von den jetzt im Betriebe stehenden Strecken nicht allzuweit nach Südwesten entfernt.

Lim Gewissheit über die Art der eventuellen Forterstreckung des bewussten Kainitlagers zu erlangen. sind vor Kurzem laut einem mir in Kalnsz zur zeitweiligen Einsicht üherlassenen Acte von Seite des Herrn Professor Niedzwiedzki zwei Bohrungen vorgeschlagen worden. Die eine derselhen wird westlich hinter dem heutigen Kanzleigebände projectirt in der Nähe jener alten Bohrung, von der

1) Es wäre das höchstens von Einfluss auf die Ausdehnung der Einrichtungen. welche (ausserlalb der Grube) speciell der Zubereitung eines verkäuflichen Kainitproduefes dienen, win z. B. die jetzt zur Fertigstellung gelangende Kainitmühle. 
vorhin die Rede war, aber etwas sühlicher als der alte Bohrpunkt. Das zweite Bolnloch wurde in siidwestlicher Richtung vom Schacht Nr. IT, etwa in Stumde 16 von dort und 200 Meter vom genaminten Schacht entfernt, beantragt, und würde gan\% in der Nühe der Salzmagazine anzuschlagen sein. Soviel Veranlassumg aber auch ich bis jetzt hatte, der Darstellung beizupflichten, welche Professor Niedzwiedzki ron den Verhältnissen der Grube geboten hat, so glaube ich doch gerade die letztgenamnten Vorschläge vorläufig nicht unterstïtzen zu sollen.

Bezüglich der Bohrung, die westlich hinter dem Kanzleigebäude projectirt wurde. lässt sich allerdings sagen. dass sie entschieden rationeller vorgeschlagen ist als der alte Bohrpunkt, eben weil sie etwas südlicher und deshalb mehr in Berücksichtigung des Verflächens der Schichten in Aussicht genommen ist. Indessen erweckt es dloch ron rornherein Berlenken, wenn man in der Gegend eimes resultatlos gebliebenen Versuchs eine neue Versuchsarbeit beginnen will, und es würde diese neue Bohrung wohl auch in der That kein wesentlich guinstigeres Ergebniss lieferm. als jenes alte verfehlte Bohrloch, da sehr wahrscheinlich der westliche Rand des aufzusuchenden Kainitlager's noch immer etwas östlicher verläuft ${ }^{1}$ ), als die Lage des projectirten Bohrpunktes, das Bohrloch daher in tauhes Gestein gerathen und bein Aufsuchen grösserer Tiefen schliesslich in das Liegende der Kainit führenden Zone gelangen würde.

Anders verhält es sich mit der zweiten rler. vorgeschlagenen Bolnungen in der Nähe der obgenamnten Magazine. Dieses Bohrloch würde aller menschlichen Voranssicht nach das Kainitlager ungeführ in der bei dem Vorschlage in Aussicht genommenen Tiefe von 150 Meter (unter dem Aufschlagspunkt) erreichen, oder doch in einer Tiefe, die nicht sehr viel über diese Ammahme hinausgeht, da man ja doch wohl mit der vorhin erwähnten Abnahme des Verfläcliungswinkels gegen diese Seite zu rechmen darf. Aber eben weil hier, wo man sich so ziemlich über ler Fortsetzung der mittleren Theile des sich nach SW verflächenden Kainitlappens befindet, eine fast an Sicherheit grenzende Wahrscheinlichkeit für die Existcn\% jenes Kainitlagers in der Tiefe spricht, ist eine Bohrumg überflüssig, rlenn versuchshalber bohren wird man in erster Linie doch nur dort, wo die der Beobachtung zugänglichen Verhältnisse ein genaneres Urtheil ïber die in der Tiefe anzutreffenden Gesteine und nutzbaren Mineralproducte nicht zulassen. Die hetreffende Bohrung müsste ja doch eine Kerubohrung sein, und die relativ nicht unbedentenden Kosten einer solchen sollten besser elspart bleiben. damit die betreffende Summe den für die directe Erweiterung des Abbans zu machenden Anlagen zu Gute kommen könne, oder damit mehr an solchen anderen Punkten gebolnt werden könnte, für welche zwar die Möglichkeit, aher ein geringerer Grad ron Gewissheit bezüglich des Auftretens von Kalisalzen vorliegt.

1) Mehr nder 'minder unregclmässige Aushuchtungen dieses Randes nach Westen zu sind zwar denkbar, indessen sind doch wohl dergleichen Unregelmässigkeiten nicht unter unsere Voraussetzungen einzubeziehen. 
Will man in der Gegend der heim Silmmagazin beantragten Bohrung in die Tiefe gehen und dort das Kanitlager anfsuchen, so wird es sich emptehlen, dies lieber wleich nit einem brharht anstatt mit einem Bohrloch zu thun. Es wired sich ja roranssichtlich (namentlich im Falle gesteigerter Nachfrage narh einheinischen Kalisalzen) in nicht allzuferner Zeit das Pedürfuiss herausstellen, den hisherigen drei Horizonten der Grube einen tieferen vierten hinzuzufügen, dessen Strerkenbau südwestlich von den bisherigen Grubenstrecken zu verlanfen laben würde. Die beiden hente rer Verbindung der Grube mit der Tagesoberfläche dienenden Schächte (Nr. 4 und 7) lassen aber nach dem Urtheil Sachverständiger eine weitere Vertiefung nicht zu, da ihre Umgebung dur'h die in der Grube betriebenen Lauglnoresse zu stark angegriffen ist. Ueberdies müssten, selbst im Falle man dennoch diese beiden Schächte gefahrlos vertiefen kömnte, ron der neu zu gewinnenden Basis derselben aus lange Strecken nutzlos gegen das Hangende zu getrieben werden, ehe das Kainitlager erreicht werden würde. Soll also ein vierter Horizont geschaffen werden, so wird sich schon an und für sich die Anlage zum mindesten ein es neuen Srliachites empfehlen $\left.{ }^{1}\right)$ und es wird zweckmässig sein, den letzteren so amzulegen, dass er umittelbar zu dem Kainitlager herabfülıt. Bei der Abteufung eines solchen Srlachtes könnten iiberdies die Kemntuisse, welche man über die Beschaffenheit des Gebirges im Hangenden des Kainitlagers besitzt, durch weit znverlässigere Daten ergänzt, und es kömnten auch ülser die Art der Fortsetzung dicses Lagers selhst vicl bessere Aufklärungen grewonnen werden. als beim Niederbringen eines Bohrloches, wälneind andererseits eine Vertiefung der Schärblte $\mathrm{Nr}^{2} .4 \mathrm{und} 7$, anch wemn dieselbe möglich wäre, nur einen nenen Anfschluss in den ohnedies bekannteren Liegenduartien des Kaluszer Haselgebirges vorstellen würdie.

Für den Angenblick aller(lings kaun vielleicht mit der Anlage jenes neuen Schachtes noch gewartet werden. Zunächst mag man sich daher damit begnügen, das bewusste Kainitlager in Anschluss an die bestehenden Grubenstrecken noch weiter aufzuschliessen; das lieisst es möge daran gedacht werden, jenes Lager durch nen anzulegende Gesenke rom 3. Horizont aus nach der Tiefe zn verfolgen. Man wird hierbei zwar hegreifticherweise vermeiden, mit dem Hangenden in allzu viele Berührung zu kommen. aber in anderer Hinsicht könnten auch bei diesem Vorgange für die /ukunft schïtzloa:e Erfahrungen gemaclit werden, namentlich bezüglich etwaiger Aenderungen des Verflächens mud der Mächtigkeit des Kainits, sowie bezüglich einer etwaigen partiellen Umänderumg des letzteren in Carmallit. Jedenfalls wird durch die Herstellumg derartiger (iesenke, welche ja doch mit einem unnittelbaren Abban les verfolgten Minerals verbunden ist, eine gewisse Steigerungr der Kainitproduction ron Kalısz ermöglicht,

1) Dass dieser Schacht, im Falle er das Kainitlager in gewiunselıter Weise erreicht, beim spüteren Ansbau der Grube nicht geniigen und dass schon wegen ler Wetterführung eine zweite Schachtanlage nothwendig werden könnte, ist allerdings in Petracht zu ziehen. Ineh hleibt dlies eine der Zukunft vorhehalten Frage. 
wie sie wenigstens in der nächsten Zeit noch als ansreichend befunden werden $\operatorname{mag}^{1}$ ).

Wollte man aber bei Kalusz trotz alledem noch an eine Boh. rung denken, dann wäre ich der Meinung, dass ein derartiger Versuch, wem der Ausdruck gestattet ist, mit einer gewissen Kühnheit und Opferwilligkeit ins Werk zu setzen wäre. Es dürfte sich dabei nicht blos darmm handehn, zu emitteh, ob das Kainitlager sich überhaupt nach der Tiefe zu noch eine Strecke weit fortsetzt, was ja an sich so gut wie unzweifelhaft ist, sonder'l es mïsste darauf ankommen, zu constatiren, ob diese Fortsetzung eine räumlich viel ansgedelntere ist, als man vorläufig anzmehmen ein Recht hat. Eutsprechend dem oben geschilderten Verhalten des bewussten Lager's wiirde man auch hierbei nicht nach dem Beispiel der alten Bohrungen das Streichen, sondern die Richtung des Verflächens aufansuchen liaben, aber nicht in der relativ Vertrauen erweckenden Nachbarschaft der Grube bei den Salzmagazinen, sondern viel weiter entfernt würde man den Bolrpumkt zu bestimmen haben. Dann hätte man erst die Möglichkeit, zu erfahren, ob Kalusz aus dem immerhin bescheidenen Rahmen mehr herauszutreten im Staucle ist, in welchem es auch nach erfolgreicher Durchführung der oben gemachten Vorschläge noch immer verbleiben würde.

Die grösseren Tiefen, mit denen man in diesen Falle bei einer Bohrung zu reclnnen hätte, brauchten wenigstens vom rein technischen Standpunkt aus nicht abzuschrecken. Hat man ja doch z. B. gerade bei Stassfurt ganz bedentende Tiefen mit Erfolg durch Bohrungen aufgèsucht ${ }^{2}$ ). Doch stellen sich, wie nicht verschwiegen werden

$\left.{ }^{1}\right)$ Bezüglich der Einzelbeiten lei der Anlage dieser Gesenke dem Urtheil der speciell technischen Fachmänner vorzugreifen, halte ich nicht für meine Aufgabe. Vielleicht kann man hier verschiedene Wege einschlagen. Man könnte z. B. mit einem dieser Gesenke etwa von der Mitte des Kainitaufschlusses ans in grössere Tiefen vordringen und dann von den gewonnenen Tiefenpunkte aus seitliche Strecken von grösseler Länge dem Streichen nach ausrichten. Die Ausfïhrbarkeit dieser Arbeit, mit welcher fïr die Erweiterung nnserer Kenntnisse sicherlich viel gewonnen würde, hängt wohl lediglich von einer geeigneten Lösung der Ventilationsfrage für die betreffenden Anlagen der Tiefe ab. Andernfalls könnte man auch den Versuch machen, die Flanken des Kainitlagers zu untersuchen, indem man jeweilig in einel gewissen nicht allzu grossen Entfelunng von den Enden der Streichungserstrecknng jenes Lager's aus die Arbeit beginnt. Auf diese Weise wäre wenigstens leicht zu ermitteln, ob nach der Tiefe zu sehr bald eine Verschmälerung des fraglichen Kainitlappens eintritt, oder ob das Lager in seiner Streichungserstreckung nocb eine Weile lang Ijimensionen aufweist, die mindestens auf die Constanz seiner Ausbreitung schliessen lassen, denn bei rascher Verminderung dieser Dimensionen miisste man ja mit dell bewnssten seitlichen Gesenken nach kürzerer Frist in tanbes Gestein gerathen.

In jedem Falle aber, auch wemn ohne Riicksicht auf die eben gemachten Andeutungen rein im Sinne einer gewissen Erweiterung des Abbanes von soust zweckmässig erscheinenden Punkten aus vorgegangen würde, könnten die anzulegenden Gesenke dazu beitragen, unser Wissen über clie Natur des Kaluszer hainitlagers zu vermebren.

$\left.{ }^{2}\right)$ Ein Bolrloch, welches der preussische Fiscus bei Unseburg niederbringen liess, um die Verhältnisse des Salzgebirges bei Magdeburg zu untersuchen, hat die Tiefe von 1293.4 Meter erreicht. (Vergleiche Precht, die Salz-Industrie von Stassfurt unl Umgebung, Stassfurt 1891, pag. 7.)

Zum Vergleich erwahne ich lier noch einige andere Daten. Was Bohrloch von Sperenberg bei Berlin besitzt die Tiefe von 1.273.01 Meter, das von Lieth in 
darf, dem bezeichneten Versuch andere Schwierigkeiten entgegen, welche in den Localverhältmissen begründet sind.

Das Terrain, an welches ich hier zumächst denken würde, liegt näunlich ungefäh an der Grenze zwischen einem zur Saline gehörigen Gebäudecomplex und der Ortschaft Neu-Kalusz und erscheint durch öffentliche Wege wie durch Banlichkeiten occupirt. Es wäre also wohl nicht sehr leicht für eine Tiefbohrung. die etwa in der Nähe der dort befindlichen Finauzwachkaserue ausgeführt werden könnte, den nöthigen Platz ausfindig zu machen. Auf eineu directen Vorschlag in der bezeichneten Richtung will ich deshalb vor der Hand verzichten, indessen komnte ich nicht mmhin einem Gedanken Ausdruck zu geben, der vielleicht unter geeigueten Umständen zu anderer Zeit (eventuell nach Vervollständigung unserer Erfahrungen durch die oben vorgeschlagenen Anlagen) in ernstlichere Erwägnng zu ziehen wäre.

Ohne indessen anf derartige weitergehende, bezüglich ihres Erfolges nicht unbedingt sichere Experimente vorläutig Rücksicht zu nehmen, glaube ich doch mit der voraustehemlen Darlegung den Beweis erbracht zu haben, dass die Verhïltnisse bei Kalusz eine Versuchsaction wenigstens in bescheidenen Grenzen gerechtfertigt erscheinen lassen. Wem nämlich anch, wie hier nochmals betont werden soll. ein Vergleich iles Kalisalzvorkommens von Kalusz mit den reichen Kalisalzlagern von Stassfurt durchaus mustatthaft ist, so hat sich doch ergeben, dass die Möglichkeit einer Erweiterung des Kaluszer Bergbaues besteht, und so mag demn die Hotfinmug ausgesprochen werden, dass unter einer thatkrïftigen und zielbewnssten Leitung die P'roduction vou Kalisalzen bei Kalusz wieder zu etwas grösserer Bedeutung gelange, wie sie ihr in Interesse der heimischen Landwirthschaft zu wünschen ist.

Nur eine Bemerkung kann ich hierbei nicht unterdrücken. Ich würde es nämlich für berlenklich halten, diese Hoffnung gleichsam zu escomptiren. und aus diesem Grumcle könnte ich mich nicht für das kostspielige Fxperinent der baldigen Frriclitung von Fabriksaulagen begeistern, welche eine chemische Umarbeitung der zu gewimmenden Salze zum Zwecke hätten. Dieser von anderer Seite gemachte Vorschlag ist sicherlich gut gemeint, indessen scheint mir,

Holstein die von 1.338 Meter, während das ebentalls auf Kosten des preussischen States niedergebrachte Bnhrloch von Schladehach zwischen Dirrenberg und Leipzig, mit welchem man die Fortsetzung des Wettiner Kohlengebirges anfsuchen wollte, nach einem Bericht H uyssen's vom 3. Oct 1885 (vergl. Compte rendı din congrès géologique international, 3 session 1885. Berlin 1888, pag. 55) damals bereits eine Tiefe voll 1.656 Jicter oder 5.260 preuss. Fuss erreicht hatte. Es galt damals als das tiefste Bohrloch der Welt. sollte, da es noch immer $44 \mathrm{~mm}$. Weite hatte, rein in wissenschaftlicher Absicht weiter vertieft werden und hat schliesslich, wie ich einer Angahe aus dem neuesten Werke von Hipp. Haas entnehme (Aus d. Sturm- u. Drangperiode der Erde. Berlin 1893, pag. 23), die Tiefe von $1.745^{\circ} 4$ Meter erzielt.

Nicht uninteressant mag es sein hier anzufígen, dass gemäss der oben citirten Mittheilung Hu yssen's der preussisclue Staat durch 20 Jahre hindurch behnfs der Erforschung des Untergrundes des norddentschen Flachlandes je 150.000 Mark auswarf, welche Sunıme dann in Jahre 1884 auf 200.000 Mark erhöht wurde. 
um mich bildlich auszudrücken, dass der Bau eines Hauses nicht mit einem grossartigen Dachstuhl begonnen werden darf, am allerwenigsten, so lange als ein Banplatz von genügenden Dimensionen noch nicht beschaffit ist.

Der Verbrauch an Kalisalzen ist bekamntich zur Zeit im Bereich der Länder der österreichisch-ungarischen Monarchie noch kein allzugrosser $\left.{ }^{1}\right)$. Doch gibt es in Oesterreich und speciell in Galizien genug Ländereien, fïr welche, wie für Sand- und Noorböden. nach lem Dafürhalten der gebildeten Landwirthe eine Kalidüngung angezeigt wäre ${ }^{2}$ ). Daher ist anzunehmen, dass das betreffende Bedürfniss. stetig wachsen wird, und in diesem Falle wird auch eine Frweiter'ung. des.Kaluszer Bergbaues nicht im Stande sein mehr als einem Theile jenes Bediurfnisses abzuhelfen. Aus diesem Grunde würde es sicher von grossem Vortheile sein, wemn es gelänge anch noch an anderen P'unkten der Monarchie abbauwürdige Lager solcher Salze aufzıschliessen.

Wem dazi überhaupt Aussichten vorhanden sind, so sind dieselben nach den bisher vorliegrenden Thatsachen noch an ehesten in Ustgalizien vorauszusetzen. Indem ich mir num erlaube diese Aussichten, soweit dies meine bisherigen Erfahrungen zulassen, zn prüfen und claran einige Vorschläge zu knüpfen, trete ich an ilen zweiten Theil der mir gestellten Aufgabe heran.

Auch hierbei wird es älnnlich wie in Bezug auf Kalusz selbst nöthig sein, sich von jeder vorgefassten Meinung entfernt zu lialten, llemu weder ist es vorläufig berechtigt ein absprechendes Urtheil zu fällen und die Anwesenlıeit der gesuchten Salze rundweg zu negiren, noch scheint es am Platze, vorzeitig Hoffinungen oder sogar Ansprüche zu erwecken, welche schliesslich doch vielleicht zu Enttäuschungen fïlıren und eventuell zu Recriminationen, von denen es fraglich bleibt, ob sie stets an die richtige Adresse gelangen.

Es ist keinesfalls völlig zutreffend, wemn ein durch seine Anregungen in allen Salzfragen, ähnlich wie durch seine sonstige Initiative für öffentliche Interessen lochverdientes Parlamentsmitglied vor einigen Jahren behauptete, der Reiclithum Oesterreich-Ungarns an Steinsalz büroge auch für das Vorhandensein von Kalisalzlagerstïtten

1) Vergleiche Iier beispielsweise die Abhandlung von Lierke über die Stassfurter Kali-Indnstrie, Gedenkschrift zur Allgemeinen land- und forstwirtlschaftlichen Ausstellung in Wien 1890 (Wien 1891, Seite 27). Bezeichnend ist auch die Thatsache, dass seit der Wiederinbetriebsetzung des Abbanes anf Kalisalze in Kalnsz die jährliche Nachfrage fast immer etwas geringer war als die Próduction. Daraus geht hervor, dass vou Seite des Publicums mit dem Rut nach Kalisalzen, wic er heute ertönt, wenigstens zunächst nur ein theoretisches Verlangen zum Ansdruck gehrailit wird. Es wird sich also darnm handeln, dass anch von dieser Seite lier die von Kalısz verlangte Steigerung der Production lurch practische Bethätigung des gezeigten Interesses ermöglicht werde.

$\left.{ }^{2}\right)$ In einzelnen Fïllen scheint man sogar mit gewöhnlichem Salz (in beschränkter Anwendung) schon gute Frfalirungen gemacht zu haben. Ich habe gelegentlich meiner Besprechung der Salzsteppen (Jahrb., l. k, k. geol. Reichsanst. 1877, pag. 345) einige Daten hieriber msammengestellt. 
(Gra f 11 ompesch, das Salmmonopol in Oesterreich-Ungarn. line Studie, Wien 1886, pag. 7), und os sei "zweifellos anzunelımen", dass neben Kalusz "bei intensiverer Suche" anch andre derartige Lagerstäten aufgeschlossen werden wïden. An wie rielen l'muten sind niclit beispielsweise in Deutschland Steinsalzlager hekinnt und doch gelang es mu in einem einzigen jener Reviere anch bauwürdige $\mathrm{Ab}$ ramsalze zu entdecken! Graf Hompesch zweifelte indessen fü diesen Fall sogar an rlem ernstlichen Willen der österreichischen Finanzverwaltung und el bezou sich auf. Wieliczka. wo man zwar vou der Grube heraus mach Kalisalzen gesucht habe (was bekanntlich zu dem Wassereinbruch von 1868 führte), wo man jedoch unterlassen habe. in der Ungebung des Bergwerks \%u forschen. Nun diese Forschungen sind jetzt in grossen Umfange vorgenommen worden, man hat 3 Bohrlöcher zu bedeutenden Tiefen niedergebracht, arbeitet an dem vierten, aber die Kalisalze sind ausgeblieben. Schon vor Jahren hat man ferner hierauf bezügliche Untersuchungen in den alpinen Salzgebirgen angestellt und das Resultat war nur, dass dortselbst zwar Partien volkommen, welche eine gewisse Verwandtscluaft zu der Stassfurter Polyhalitregion aufweisen, (lass aber abbauwürdige Kalisalze zu fehlen scheinen.

Für solche negative Ergebuisse kamn Niemand verantwortlich gemaclıt werden. Das Aufsuchen ron Kalisalzen gehört eben überhaupt niclst zu den einfachsten Aufgaben, dem vor Allem stehen uns au der Tagesoberfläche mur spärliche, dafür verwendbare Indicien zu Gebote.

Insofern dieser Aufsatz auch manchen der Geologie ferner stehenden Lesern in die Hände kommen könnte, mag es nützlich sein vor dem Fingehen auf specielle Localfragen die jene Indicien betreffenden Gesichtspunkte etwas ausführlicher zu besprechen, weil ich glaube, dass dies zn einer gerechten Würdigung und ruligen Bemrtleilung der Sachlage heizutragen im Stande ist.

Zunächst darf wohl im Allgemeinen daran erimert werden, dass die Auffindumg von Kalisalzen in der Natur viel -schwieriger ist als die Auffindung der meisten anderen mutzharen Mimeralien. In der Riegel kamn es ja doch nur unter mehr oder minder trockenen. Climaten vorkommen, lass Salzlager gleich andern Gesteinen an der Tagesoberfläche anstehend in auffälliger Weise sichtbar werden, wie das beispiclsweise in der indischen Saltrange, bei Pilluana am Huallaga (nach Pöp pig) in den regenarmen Anden Peru's, an eimigen Punkten in Persien, sowie bei Cardona in Spanien in grösserem Massstabe der Fall ist oder auch am I)jebel Usdom in Palästina und bei Taudeni in der westlichen Sahara rorzukommen scheint. "Im Bereich der salzführenden Gegenden der österreichisch-mngarischen Monarchie finden sich aber bekamntlich nu' in Siebenbürgen natürliche Salzaushisse in etwas grösserer Ausrlehmung und Häufigkeit '), obschon hei Weitem nicht ron der Bedeutung wie in den vorher genannten

1) Vgl. z. B. Hauer und Stache, Geologie Siehenbürgens, Wien 1863. Verlag von Braumiiller, pag. 601, hesonders aber Czekelius iiler die Verbreitung der Salzquellen und des Steinsalzes in Siebenliurgen in den Verhandl. des siehenbürgischen Vereines für Naturwissenschaft zu Hermannstadt 1854, pag. 39 etc. 
Gebieten. Siebenbürgen mit seinem Ringwall von Gebirgen, welche die atmosphärischen Niederschläge bis auf einen gewissen Grad abhalten, ist aber anch schon mit einem trockeneren Clima hegabt, als beispielsweise das Salzkammergut. In Galizien steht die Sache schon anders. In Westgalizien zeigt sich meines Wissens das Steinsalz nirgends als anstehender Felsen und auch in dem etwas trockeneren Ostgalizien kommen gemäss den von mir eingezogenen Erkundigungen eigentliche Ausbisse von Salz nur an zwei Punkten vor, bei Delatyn und Utorop. In regenreicheren Landstrichen muss ja das vielleicht durch irgendwivelche Vorgänge mit der Tagesoberfläche in Berührung gebrachte Salz der baldigen Auflösung und damit dem Verschwinden ausgesetzt sein. In solchen Landstrichen werden jedenfalls auch die etwaigen zeitweiligen Entblössungen zumeist Terrainrutschungen veranlassen und die mit dem Sal\% in der Regel verbundenen Thongesteine werden dann sich über die entblössten Stellen legen und die weitere Anflösung erschweren, zugleich aber das Salz an der Oberfläclıe wieder verbergen.

Wenn dies aber schon für das gewöhnliche Steinsalz gilt, so muss das erst recht für die Absätze der vièl leichter löslichen Kalisalze gelten, die sich nur unter besonders gïnstigen und Schutz bringenden Verhältnissen conserviren konnten, womit jedenfalls auch die Seltenheit ihres Anftretens theilweise zusammenlängt. 'Ausbisse solcher Salze in der Art, wie man Kohlenausbisse orler Andentungen von Erzlagerstïtten an. der Tagesoberfläche findet, wird man also in Galizien wolll vergeblich suchen. Man wird daher bei den hierauf bezüglichen Nachforschungen andere, mehr oder weniger indireste Anhaltspunkte in Betracht zu ziehen haben.

Von voruherein dürfen bei solchen Nachforschungen natürlich nur solche Gebiete Galiziens berücksichtigt werden, in welchen die dortige miocäne Salzformation nachgewiesen ist orler wo doch deren Vorhandensein vorausgesetzt werden muss. Wenm nämlich auch in einigen anderen Bildungen, die an der Zusammensetzung des galizischen Bodens theilnehmen, wie in den Flyschbildungen der Karpathen oder sogar auch im Bereich der ostgalizischen, bezüglich podolischen, tertiären Gypsablagerungen ein gewisser Gehalt ron salzigen Bestandtheilen theils (wie besonders in rlem einen Falle) durch das Anftreten salziger Schachtwässer, theils (wie in dem andern) durch das Vorkommen salziger Quellen angedeutet erscheint, so ist doch diese theilweise Inprägnirung der betreffenden Gesteine durch Salz fïr die vorliegende Frage ohne Bedentung, demı zur Bildung von Salzlagern ist es in jenem Lande nur in Gebiet der miocänen Salzformation gekommen. Folglich können auch Kalisalze nur imnerlalb dieses Gebiets gesucht werden.

In den allgemeinen Umrissen sind die betreffenden Landstriche durch die bisherigen geologischen Aufnahmen in Galizien sehr wohl bekannt. Da aber diese Landstriche vielfach ron diluvialen Bildungen und von Verwitterungslehmen hedeclit werden und da die Entblössungen der die miocäne Salzformation zusammensetzenden Gesteine sehr unzusammenhängend und spärlich sind, wofür ja schon die Gegend von Kalusz selbst ein bezeichneudes Beispiel abgibt, so wird 
es oft schwer. die Einzelheiten des Auftretens gewisser Gesteinsabarten oler der Schichitenstellung dieser Gesteine zu ermitteln. Auch genanere, mit mehr Zeitanfwand dnr'chgeführte Aufnahmen als die seitherigen geologischen Arbeiten in Galizien könnten diesen in der Natur des Terrains selbst begrïndeten Uebelständen nur zum selı' kleinen Theile abhelfen. wenn sie auch stellenweise \%ur Gewinnumg etlicher neuer Daten fülnen sollten, was ja nicht bezweifelt werden kamn. Yon einem sehr wesentlichen Finfluss anf die hier vorliegende specielle Frage nach dem Vorkommen von Kalisalzen würden derartige Neuaufnahmen der in Betracht kommenden Gebiete indessen kaum werden.

Durch die so eben vorgenommene Betrachtung erscheint also jene Frage nur insoweit einer Lösung nüher gerüclit, als bei der Aufsuclıung neuer Kalisalzlager die weiten, von der miocänen Salzformation n i cht eingenommenen Gebiete Galiziens ausser Rechnumg komnen und eine Beschränkung der Hoffinungen anf bestimmte Landstriche eintritt. In Rücksicht aber anf den Umstand, dass man auch von diesen Landstrichen nur eine lückenhafte Kemtniss geologischer Einzelheiten zu erlangen im Stande ist, welche in vielen Fällen nicht ausreichen wird, nähere, der Lösung besagter Fragen eventuell förderliche Schlussfolgerungen zu begründen, bleibt für den Weg, den die betreffende Untersuchung einzuschlagen hat, noch immer ein viel zu grosser Spielranm übrig. Es hiesse in der That sich (lem Zufall Preis geben, wollte man an beliebigen Punkten im Bereich rer galizischen Salzformation kostspielige Tersuche zur Aufsuchung von Kalisalzen begimnen.

Zwar sind einzelne Partien der subkarpathischen Salzformation (und zwar ganz besonders in (ler Nachbarschaft des Flysches) durch den Salz- und zum Theil auch durch den Naphtha-Bergbau soweit aufgeschlossen, dass man behaupten kann, wenn Kalisalze dort in abbauwürdiger Menge vorkämen, so wären sie längst gefunden, und man kam deshalb hente schon mit einem ziemlichen Grade von Walırscheinlichkeit aussagen, dass wenigstens längs grosser Strecken inner'halh der den Karpathen zunächst liegenden Partien der Salzformation das Auftreten von Kalisalzen nicht $z u$ erwarten ist. Aber auch damit ist nur eine weitere Einschränkmug des Untersuclimngsfeldes erzielt, während es doch erwünscht sein muss, insbesondere für den ziemlich breiten Streifen, den im östlichen Galizien die Salzformation bereits in einiger Entfernung vom Gebirge einnimmt, positive Hinweise anf einzelne Punkte zn gewimnen.

Solche Hinweise sind num bei dem lieutigen Stand unserer Kenntnisse fast nur aus der Beschaffenheit der Wasserzuflüsse abzuleiten, welche sich in Bereich iler ins Auge zu fassenden Landstriche in Brumen orler in gewissen Schächten sammeln.

Bekanntlich bestanden in Galizien in früherer /eit viel mehr Salinen als heute, mnd an zahlreichen Stellen wurden Sooleschächte abgeteuft, deren Wasserzufluss sich mit dem Salz der benachbarten Ablagerungen der Salzformation anreicherte. Manche dieser alten Anlagen sind heute zusammengelorochen orler verschüttet, andere aber bestehen noch. mul an manchen ()rten haben die betreffenden Ge- 
meinden sogar das Rerht, die Salzsoole jener Schächte von Zeit zu Zeit zu schöpfen, um damit den Salzbedarf für das Vieh der Gemeindeangehörigen zu deckell. Da entsteht die Frage, ob und eventuell wo in diesen Soolen sich die Anwesenheit einer auffälligeren Menge von Kalisalzen nachweisen lässt.

Glücklicher Weise-liegen bereits seit einigen Decenmien Untersuchungen über einen grossen 'Theil rler hier in Betracht kommenden Soolen vor, und zwar sind diese Untersuchungen schon in Riicksiclit auf das Vorkommen ron Nebensalzen gemacht worden, welche vielleicht einer speciellen Verwerthung zugeführt werden könnten. So hat $A$. v. K lipp eine Reihe rerartiger Analysen ausgeführt, von welcher Arbeit dann C. v. H a u e r im . Jahrbuch der k. $k$. geologischen Reichsanstalt von 1869 (Seite 75 etr.) einen kurzen Auszug mittheilte. Später hat dam K elb im Jahrbuch der k. k. geologischen Reichsanstalt von $1870^{\circ}$ einen wichtigen Aufsatz über die Soolequellen Galiziens veröffentlicht und bei dieser Gelegenheit auch eine Tabelle verfasst, anf welcher die chemische Beschaffenheit jener Soolen im Vergleich. mit der der alpinen Soolen und des Meerwassers ersichtlich gemarht wird. Auf diese Weise war die Möglicllkeit geboten. schon jetzt und olme Inangriffnahme neuer chemischer Vorstudien zu muïfen, ob sich in der Beschaffenheit der galizischen Soolen thatsächlich solche Differenzen ergeben, welche für bestimmte Punkte. die sich im Gegensatz, zu andern durch das eventuell reichere Vorkommen von Kaliverbindungen auszeichnen. ein hesonderes Interesse zu erwecken geeignet wären.

Doch muss gleich hier bemerkt werden, dass nicht ohme Weiteres jeder Brumen oder Soolenschacht, in welchem sich vielleiclit die Anweseuheit von gewissen Nebensalzen als namhafter Bestandtheile der betreffenden Salzsoole nachweisen liesse. als Beweis für das Vorhandensein grösserer Mengen solcher Salze in. den umgebenden Schichten genommen werden darf. Wenn nämlich das Wasser in salzigen Brumen und Sooleschärhten durch lange Zeit stagnirt, so wird es sich mehr und mehr mit leichter löslichen Salzen. zı denen ja auch die Kalisalze gehören, sättigen, mögen solche auch nur in geringen Mengen in den betreffenden Schichten vertheilt sein. Die Analyse eines solchen Wassers wird also dam ein zu Ungunsten des gewölmlichen Chlornatriun-Gehaltes verschobenes Resultat ergeben, aus welchem ein sicherer Schluss auf das Verhältuiss der den betreffenden Gehirgsmassen angelı̈rigen Salze nicht gezogen werden kamn. Von diesem Gesichtspunkt ausgehend. hat anch schon Kelh darauf aufmerksan gemacht, dass heispielsweise dic Soolen von Starasol, deren Gewimnung seit 1853 aufgelassen ist. und von denen sich inshesondere die les dortigen Schachtes Nr. 1 durch einen grösseren Gehalt von schwefelsaurem Kali auszeichnete, eine weitere Beachtung nicht verdienen mögen. Für dlen del heutigen Betrachtung: rorliegenden Zweck wird es sich also emptehlen nur auf solche Brumen oder Soolenschächte zu reflectiren, aus welchen von Zeit zu Zeit geschöpft wird, deren Wasserzuthuss sich also immer wieder ernenert. Kleinere 'Tüuschungen werclen freilich auch hier nicht zu vermeiden sein, insofern man nicht. den zum Theil auch von deu 
wechsehden Witterungsterhältnissen ahbängigen sättigungsgrad der zı untersuchenden Soolen mit berücksichtigt.

Endlich aber muss noch daran erinnert werden, dass es sich selbst hei solchen Soolen, deren grösserer usprünglicher Gelualt an Kalisalzen anch im Simme der vorstehenden Betrachtung ausser Zweifel ist, nu' salzlagerstätten zwar führen kömen. aber nicht müssen, dem es kam schliesslich ein Haselgebirge mit derartigen Salzen imprägnirt sein, ohne dass es in demselben zur Ausscheidung von eigentlichen Lagern solcher Salze gekommen ist. Vor einer Ueberschätzung des Werthes der anf dio Kenutniss der Soolen gegründeten Methode nach Kalisalzlagerstaitten zu forschen, soll deshalb noch ausdriicklich gewarnt werden. Diese Methode wird gewiahlt, weil es eben dermalen einen anderen Weg für die vorzunehmende Intersuchung niclit gibt.

Im Allgemeinen trifti man aller(lings anch auf diesem einrig möglichen. Wege nicht. viel Fimuthigendes, und die meisten galizischen soolen zeigen keine hesondere Hoffinmen erwerkende Zusammensetzung. Doch hat heroits $\mathrm{K}$ elh auf einen Punk aufmerksan genacht, welcher in jener Hinsiclit eine erfouliche Ausnalmme bildet. Fis handelt sich hier um den Soolenschacht von Turzal wielka.

Dieser Srlacht befindet sich in der Inftlinie gemessen etiva 20 Kilometro nordwestlich von dor Kaluszer Grube und etwa 17 Kilometer nördlich von Dolina, wïlnend die anf den vorhandenen Wegen zurvïkzulegonden Verbindungsstrecken zwischen den genannten Oertlichkeiten allorelings etwas heträchtlicher sind. Der Schacht liegt, um die hetroffende Localität noch näher zu beschueiben, unweit des Südendes des Dorfes 'Iur\%a wielkia, anf' der rechiten Scite des 'TurzankaBaches in einem Nehenthälchen dessolhen mol ist von dem ärarischen Forsthause ron Thua wielki aus in wenigen Minuten zu erreichen.

lieser Soolenschacht wehört zu dences, ans welchen die betrettende Gemeinde in Finverstandniss mit den Finanzwachorganen monatlich zu schöpfen horechtigt ist. Sein Wasser muss für gewölnlich zu den stärier gesaittigten Soolen gerechnet werken, denn es enthält nacl einer von Kelb mitgetheilten Analyse Kripp's in 100 Theilen 24.58 'Theile Sal\%. Dieses Salz aher ist durch eine reichliche Beimengung von Nebensalzen ansgezeirlnet (15.5 Theile auf 100 Theile Salz) und unter: diesen Nebensalzen wurden 10.2 'Theilè als schwefelsane Magnesia, die den Hanptantheil dieser Beimengung ausmarcht. sowie 3.7 Theile als Chlorkalium berechnet, ein wesentlich löherer Gehalt an diosen Substanzen als er bei allen andern der von K elb berïrksichtigten galizischen Soolen vorkommt.

Jiese anfmunternde 'Thatsache wird vielleicht noch durch den Cimstand erginzt, das's der betreffende Punkt zwar nicht genan im Streirhen des Kahuszer Lager's sich hefindet (demn er liegt thatsächliclı etwas südlicher als dies dem Verlauf der Kaluszer Streichungshinie entsprechen würle), dass er aber doch dieser Streichungshinie sich ziemlich nähert. und dass er eine ähnliche Lage zum Rande des älteren karpathischen Gebirges aufweist wie Kalıs\%. Wenn nämlichl auch bei lialus\% selbst in der munittelbaren Streichungsfortsetzung der dortigen Kalisalzlagerstätte die Aussiclsten anf Erreichung einer 
thatsächlichen Fortsetzung des bewussten Lagers im Sinne der weiter oben mitgetheilten Betrachtungen sehr eingeschränkte sind, so könnte doch das Kaluszer Vorkommen im weiteren Simne einer Zone gleichwerthiger Absatzbedingungen angehören, imnerhalb welcher sich in gewissen (nicht gerade regelmässig zu denkenden) Abständen die Kaluszer Verhältnisse mehr oder weniger zu wiederholen im Stande sind, und von diesem Standpunkt aus kömnte der Soole von 'Turza. wielka ebenfalls eine gewisse Bedeutmg beigenessen werden. In jedem Falle also sollte hier früher oder später der Versuch gemacht werclen, die tiefer liegenden Gebirgschichten durch eine Tiefbohrung aufzuschliessen.

Deshalb lıabe ich mir in Hinblick auf die Ermittelung eines zweckmässigen Platzes für eine solche Bohrung einige Mïhe gegeben, diejenigen Punkte in der Gegend von Turza wielka aufzufinden. welche einen etwas besseren Einblick in die Beschaffenheit der dortigen Gebilde gewähren könnten. Was in dieser Beziehung dort zu sehen ist, beschränkt sich indessen anf folgende Einzehnheiten.

Kaum 1 Kilometer östlich vom oben genannten Forsthause entfernt, befindet sich südlich von dem von hier aus nach Zawadka führenden Wege eine tiefe Schlncht, in welcher zwar vorzugsweise diluvialer, den Karpatlen entstammender Flussschotter aufgedeckt elscheint, in der abel auch an einigen Stellen unter dem den Abhang bekleidenden Scliotter ein grün und roth gefärbter, den bunten Thonen der Salzformation entsprechender 'Thon zum Vorschein kommt. Mau glaubt an diesem ein Streichen von NW narh $S()$ walızunehmen. Etwas weiter nördlich von hier verlaufen unterhalb des Waldes Drabiczny gegen das Dolf Turza wielka zu, eine Reihe von tief eingerissenen Regenschluchten, in welchen ein älnlicher Schotter wie der vorher genannte gefunden wird. Unter diesem tauchen ebenfalls Thone auf, theils bunte, theils graue, denen hier stellenweise Gypsknollen in grösserer Venge untergeordnet sind. Schichtenstellungen lassen sich in diesen Thonen nicht beobachten. Weitere Aufschlüsse von Salzthon trifft man dann unweit des genannten Soolenschachtes selbst. Dort sind durch kleine Wasserader'ı einige freilich lı̈̈chst unbedeutende Partien von grauem Thon entblösst, in welchem das Vorhandensein kleiner glänzender Gypskryställchen nachgewiesen werden konnte. Ungefähr westlich vom Schachte sieht man auch am rechten Ufer der Turzanka (gleich nördlich von der dortigen Waldgrenze) einen übrigens scl wer zugänglichen, von Wasser unterspülten Aufschluss, durch welchen griün und roth gebänderte Thone aufgedeckt werden, welche südwestlich zu fallen scheinen. Im Uebrigen unterwäsclit der Bach sowohl weiter nördlich längs des Durfes als auch auf eine ziemliche Strecke weiter südlich von dem angegebenen Punkte nu diluviale Gebilde (Lehm und Schotter). Frst ein gutes Stück weiter südwestlich kommen in Dorfe Belejów unterhalh der Kirche graue Sandsteme mit blaugrauen Schieferzwischenlagen hervor. welche ein Streichen in Stunde 9 bis $9 \%$ erkennen lassen und mit 40-43 Grad nach SW fallen. Sie gehören einer Facies der ostgalizischen Salzformation an, die man als Dobrotower Schichten bezeichnet hat und die sich von hier aus sïdlich noch eine ziemliche Strecke weit fortzuziehen scheint. 
Nach Ke lb (Jahrb. d. k. k. geol. Reichsanst. 1876, pag. 138, vergl. ibidem Taf. VII) kommen weiter südwärts bej Trościaniec nochmals die Thone der Salzformation zum Vorschein. Es folgen zwischen diesem Ort und Słoboda Schichten. welche er mit denen unter der Kirche ron Belejow verglejcht. Bei Sloboda werden aber anf's Nene die Thone angetroffen, und tritt daselbst ,eine sehr bitter schmeckende Quellsoole in einem Tümpel" anf. womit wohl selbst für jene von Trurza wielka schon fast eine Mejle entfernte Gegend noch Spuren von Nebensalzen als nachgewiesen erscheinen könnten. Ein ähnlicher Werhsel der Gesteine stheint dam noch weiter gegen Dolina zu stattzufinden. An einer Stelle unterhall, Słoboda sah K elb übrigens cewisse, der Beschreibung nach zu den Dobrotower Schichten gehörjge Sandsteine mit $65^{\circ}$ nach SO vertiachen, was anf partielle Unregelmässigkeiten der Streichmngshinie in dieser Gegend zu deuten scheint. Ueber den tektonischen Charakter des ganzen Profils kam Kelb indessen nicht in's Reine, da die Sparlichkeit der Entblössungen ihn, wie er hervorheht, ein beruhigtes Urtheil nicht erlanbte.

Dieser hier geschilderte theils anf eigenen Wahmehmmngen beruliende, theils durch die alten Beobachtungen lielb's ergänzte Befund liefert uns zwar schon eine Reihe schätzbarer Anhaltspmnkte, aber er geniigt mun leider noch keineswegs, um ein so sicheres Bild vou den Aufban und der Aufeinanderfolge der das Salzgebirge von 'luza wielka zusammensetzenden Glieder zu gewäh'en, wie man es bei der Tormahme bergmämischer Arbeiten ger'n besitzen würde.

Das südwestliche Fallen der Dobrotower Sandsteine unter der Kirche von Belejow kömnte zu der Yermuthung fïhren. dass diese Schichten in clas Hangende der Thone von Turza wielka gehören, wenn nicht bekannt wäre. dass in allen noch von den karpathischen Faltungen betroffenen Schichtencomplexen Ostgaliziens das südwestliche Fallen derart vorwaltet, dass überaus häufig evillent ältere Schichten in das scheinbare Hangende jüngerer Bildungen zu liegen kommen ${ }^{1}$. Dass aber die Dobrotower Schichten alter seien als die grauen und bunten Salzthone wurde wenigstens von manchen Autoren (wie von Herrn Z n ber) behauptet und ist, obschon schwerlich überall, so doch vielleicht stellenweise richtig. Auf jeden Fall sind die Sandsteine der Dobrotower Schichten, obgleich dieselben der Salzformation angehören. im Speciellen liein Ort der wirklichen Salzführung und wiirde es sich aus diesem Grunde nicht empfehlen, bei einer Bohrung anf Salz diesen Sandsteinen zu nahe zu kommen.

Was aber das Verhältniss der bunten Thoue zu den granen Salzthonen anlangt, so kömmen nach meiner schon anderwärts geäusserten Meinmmg solche bunte oder speciell lothe Thone in verschiedenen Niveaus

$\left.{ }^{1}\right)$ So entstehen ja vielfach dort, wo die Gesetze der karpathischen Tektonik herrschen, jene einseitig geneigten Wiederholungen von Schichtabtheilungen, welche man nicht mit einer fortlaufenden (und dann folgerichtig äberaus mächtigen) Schichtenfolge verwechseln darf, wie das z. B. Niedzwiedzki für die Salzgruppen der Grube von Wieliczka gethan hat, und welche, wie schon ais Kelh's Darstellung hervorgeht, anch für das Protil zwischen Turza wielka und Dolina zur Geltung gelangt sind. 
der subkarpathiscl:en Salzformation auftreten. Nach / ub e ${ }^{1}$ ) folgen sie an manchen Orten der Gegend ron Dolina unnittelbar über Dobrotower Schichten und nach der aiteren: Meinme dieses Autors (Jahrb. l. k. k. geol. Reichsanst. 1882) würden sie sogar ilnen constanten Platz unter dem grauen Salzthon eimnelnmen; bei Kalusz existiren dergleichen aher sicher im Hangenden der salzführenden Bildumg, während freilich wie frïher erwähnt murle, nach einer älteren Angabe auch als Liegendes dieser Bildung solche Thone vorkommen sollen. Bei 'Turza wielka liegt aber wenigstens ein 'Theil der dortigen rothen 'Thone (dort wo sie am rechten Ufer der 'Turzanka nicht allzuweit vom Soolenschachte aufgeschlossen sind) im scheinbaren Hangenden der salzführenden Schichten, da mämlich als salzfühnend vorlüufig mm der yrane.'Thon daselbst gelten kam. der in der Nachbarschaft des bewussten Schachtes ansteht. K elb hat nun auch in der 'That (l. c.) die rothen Thone von Turza wielka als "Hangendthone" angesprochen.

Alles in Allem genommen halte ich selbst in der hiesigen Gegend (dem Alter nach von oben mach unten geordnet) die Reihenfolge bunter Thon, graner Salzthon und Dobrotower Schichten (vielleicht bei nochmaliger Einschiebung bunter Thone zwischen die letztgenannten Complexe) für die wahrscheinlich richtige, allein das ist schliesslich nur em subjectiver Eindruck, welchen ich bei einer heikeln Frage, wie die heutige ist, nicht für heweiskräftig ansgeben möchte.

In Hinhlicke auf die Unsicherheit, welche demznfolge über die genauere gegenseitige stratigraphische Stellung der einzclnen hei T'urza wielka anftretenden Gesteine noch herrscht und welche anch vor der Hand bei dem Mangel an genigend zusammenhängenden Aufschlüsen in jener Gegend norh nicht behoben werden kamn, haben also weitreichende, aber nicht ausreichend zu begrimdende theoretische Combinationen bezüghich der Wahl eines Bohrpunktes daselbst zu entfallen. Es erscheint viehmehr angemessen, mit der hier eventuell vorzmehmenden Bohrumg sich ron- lem Bereich der sirher salzführenden Thone nicht allzıweit zu entfernen und in der Nähe des bestehenden Soolenschachtes zu bleiben.

Immerhin wird man berüccksichtigen dürfen, dass aller Wahrscheinlichkeit nach das Finfallen der salzführenden Zone ein südwestliches'sein mag. Das entsuräche eimmal dem allgemeinen tektotonischen Verhalten. der von den karpathischen Störungen betroffenen Schichten Galiziens, bei denen ja gamz überwicgend gebirgswärts gerichtete Neigungen beobachtet werden, und das widerspriiche auch! nicht den allerdings sehr lückenhaften Beobachtungen. die sich bezüglich des Streirhens und Fallens speriell für die Umgehme von Turza wielka thatsächlich ergeben hals'n. Gleichvie] nun, ob man es in der Nähe des hesagten Schachtes mit einer normalen oder einer überkippten Reihenfolge zu thun hat, wird leshall, eine weitere Wahrscheinlichleit dafür bestehen. lass das anfzusurhende Kalisalzlager,

2) Beziiglich der hier erwähnten Ansichten / uber's kann dessen in polnischer Sprache yesehriebener Aursatz in der Zeitschrift liosmos, (Lemberg 1ะ87) verglichen werden, anf welchen ich bereits in cler 4. Folge dieser Beitrïge (Jahrb. l. k. k. geol. Reiclisanst. 1889 , pag. 353 etc.) $\%$ verweisen in der Lage war. 
sofern ein solches hier überhaut vorhanden ist, sicherer rom factischen Hangenden aus als rom factischen Liegenden der beim Soolenschacht sellst rorhandenen Bildungen her erreicht werden kann, da man diesen Bildmngen gleichsam den Werth eines Aushisses der: mit Salz imprägnirten Gosteine heizulegen hat. Daher würde ich am liebsten vorschlagen, die hefürwortete Bohrung an einem 30 bis 40 Schritt ron dem Schacht in südwestlicher Richtung entferinten Pmikte zu begimnen. respective (sofern die. Terrain- mol aich die Besitzrerhältnisse einen gewissen Spielranm bei der Answahl des Bohrpunktes münschenswerth machen) an einem l'unkte, der in einer den Schichtenstreichen entsprechenden nordwest-südwestlichen Isinic gelegen ist, welche durch den anf die angegehene Weise zuerst ermittelten Punkt hindurchgeht. Dorh sollte dieser eventuell zu wählende zweite Punlit keinesfalls über $80-100$ Schritt von dem Soolenschacht entfernt sein. Für alie Fïlle aber wäre bei dieser Bohrung auf eine zu erreichende grössere 'Tiefe ron mindestens 400 Meter von Anfang an Bedacht zu nehmen, da es ja denkbar ist, dass die ron dem bewussten Schacht ansgelaugten Schichten ein Gehirgsğhied rorstellen. welches ähnlich wie ein Theil des oberen. Kalisalze führenden Salzthons ron Kalusz noch in gewisser Mächtigkeit dem eventuell vorhandenen eigentliclıen Kalisalzlager aufruht.

Abgesehen von der oben besprochenen Oertlichkeit bei Turza wielka gibt es übrigens in Ostgalizien noch einen Punkt, welcher gemäss den vorhandenen Erfahrungen die Nachforschung nach Kalisalzen besonders $z u$ ermuthigen scheint, wenn auch auf denselben in den älteren P'ublicationen iiber galizische Soolen noch nicht hingewiesen wurde. Dieser Punkt liegt in der Nähe des zwischen Strỵi und Bolechów befindlichen Badeortes Morszyn und auf ihn hat kürylich Herr Professor L. r. Szajnocha in seiner Abhandlung riber galizische Mineralquellen die Aufmerksamkeit gelenkt ${ }^{1}$ ).

Hier befindet sich neben einigen alten Soolenschächten eine: ebenfalls durch einen Schacht gefasste Quelle. Namens Bonifacy, deren stark salziges Wasser zur Erzeugumg des für Heilzwecke benützten sogenannten Norszyner Bergsalzes dient, und welches einen nicht unbedentenden Gehalt an Kali in Lösung entlıält. Gemäss einèr ron Herrn Szajnorha mitgetheilten Analyse des Chemikers, Her'ru Radziszewski enthält diese Quelle anf 10.000 Theile Wasser 702 Theile anfgelöste Stotte. Unter diesen figurirt das gewöhnliche Kochsalz blos mit etwa 123 Theilen. schwefelsames Natron rlagegen mit 284 Theilen, Chlormagnesium mit 101 Theilen, schwefelsaure Magnesia mit fast 61 Theilen, während von schwefelsamrem Kalk nur 11 Theile vorhanden sind und einige andere Substanzen eine noch unbedeutendere Rolle spielen. Ton Kalisalzen jedoch wurden 59 Theile schwefelsaures Kali und fast 58 Theile Clilorkalium nachgewiesen, so lass die Kaliverhindungen ziemlich genau den sechsten Theil der in Lösung befindlichen Salze vorstellen würden. Nach gewissen Angaben, die sich in der hier häntiger ritirten Schrift des Professor Xiedzwiedzki über eine ebenfalls ron Rartis\%ewski

2) Źródla mineralne Galicyi, Krakan 1891, pag. 26 und 98. 
ausgefiulurte Untersuchung der Bonifacy-Quelle finden, würde sich das Verhältniss der verschiedenen Salze zueinander zwar etwas anders ausnehmen und auffallender Weise das Verlältniss von Chlornatrium zu den Kalisalzen wie 70 zu 11 sein. Immerhin aber würde auch nach dieser Tersion noch ein bedeutender zum Nachdenken anregender Gelaalt an Kalisalzen im Wasser jener Quellen vorlanden sein.

Ich habe mir nun gelegentlich eines Besuchs von Morszyn von dem Verwalter jener Quelle eine Probe frisch abgedampften Salzes aus eben dieser Quelle erbeten. wie es angeblich als Morszyner Bergsalz versendet wird, und Herr C. v. John, Vorstand des Laboratoriums der k. k. geologischen Reichsanstalt lıat die Güte gehabt, dieses Salz. zu untersuchen. Gemäss dieser inzwischen bereits (Jahrb. d. k. k. geol. Reichsanst. 1892, pag. 352) publicirten Analyse enthielt die betreffende Probe der Hauptsache nach Glaubersalz oder schwefelsaures Natron, nämlich 63.26 Procent, sodann 10.43 Procent Kochsalz, 4.38 Procent schwefelsaurer Magnesia, 0.27 Procent schwefelsauren Kialk, nebst 11.60 Procent schwefelsaurem Kali, wobei die etwas geringere Menge von Kali und besonders die relative Armuth an Magnesiasalzen (Chlorïren und Sulphaten) daraus erklärt werden liönnte, dass diese leicht löslichen Salze bei der mit der Soole vorgenommenen Procedur mit der Mutterlauge entfernt sein dürften. Wie immer man über die Uebereiustimmung oder Nichtübereinstimmung dieses Ergebnisses mit den vorher erwälnten Angaben denken möge, auch lier tritt der ziemlich namhafte Gehalt der betreffenclen Soole an líali noch immer dentlich hervor, obschon die Figenthïmlichkeit der Zusammensetzung des Salzes der BonifacyQuelle nicht auf jenem Kaligehalt allein beruht.

Diese Eigenthümlichkeit ist vor Allem in der auffallenden Rolle begründet, welche hier schwefelsaure Verbindungen spieien und des. halb findet auch die Salzfïhrung des Gebirges oder Gebirgstheiles, dem jene Quelle angehört, soweit eben aus den Analysen auf jene Salzfühırung geschlossen werden kann, in den Verhältnissen des Kaluszer Salzgebirges kein rechtes Analogon. In gewissem Sinne könnte man vielmehr. wemngleich auch nicht unbedingt an die an schwefelsauren Verbindungen bekanntlich reichen Regionen erinnert werden, welche bei Stassfurt $n \mathrm{n}$ ter der dort so geschätzten Camallitregion auftreten.

Da nun gewisse Frfahnmoen, wie man sie beispielsweise in den alpinen Salzlagerstätten gemacht hat. andeuten, dass unter Umständen solche Salze wie die der Stassfurter I'olylalitregion selbstständig auftreten können, so muss man schliesslich auch hier mit der Möglichlkeit von Enttäuschungen rechnen.

Immerhin kann ich gnten Gewissens der Ansicht des Herru Professor y. Szajnocha, dass die Localitat Morszyn wegen des besagten Vorkommens von Kali in den Salzen der Bonifacy-Quelle ein besonderes Interesse gewährt. völlig beipflichten. Die Kosten einiger Fxperimente sollten deshalb hier nicht geschent werden. Man würde dann ja auch ermitteln kömen. ob auch in einer dem Karjathemrande viel benachbarteren Lage, als dies die Lage ron Kalusz orler Turza wielka ist. sich Lager von Kalisalzen befinden und im Falle eines 
güustigen Erfolges hätte man hier die ummittelbare Nähe einer Bahnstation als besonderen Vortheil zu betrachten. Leider aber liegen hier die Verhältnisse für die genanere Feststellung eines geeigneten Bohrpunktes ganz besonder's ungünstig.

Das Terrain um Morszyn ist derart mit Diluvialbildungen, insbesondere mit zumeist eluvialen Lehmen bedeckt, dass ein Einblick in die Zusammensetzung der betreffenden Hügelmassen noch schwieriger wird als bei Turza wielka. Nach der Ansicht unseres galizischen Collegen $\mathrm{Z}$ u b e r, eines gewiss kenntnissreichen Fachmannes, würde man sich hier in Bereich der trüher schon erwähnten Dobrotower Schichten beflnden. In diesem Falle wären freilich die Aussicliten auf Erschliessumg brauchbarer Salz- und damit auch Kalisalz-Lager bei Morszyn keme glänzenden. Es ist aber zum mindesten wahrscheinlich, dass diese Schichten hier nicht ausschliesslich verbreitet sind. Jedenfalls sieht man neben den alten Soolenschächten dieser Gegend wie beispielsweise auch bei dem nicht weit ron Morszyn gelegenen Soolenschacht ron Bania (Gemeinde Lisowice) und bei dem Soolenschacht von Dolhe Spuren des einst bei der Schachtgrabung zu 'Tage geförderten Materials liegen urid dieses erweist sich als gramer Salzthon. Directe Anhaltspunkte aber über Streichen und Fallen der Schichten kounten wenigstens in der Nähe von Morszyn selbst nicht ermittelt werden.

Auch hier wird es deshalb gerathen sein, bei einer eventuellen Bohrung sich nicht allzu weit von der Localität zu entfernen, von welcher die Spuren von Kalisalzen bekannt geworden sind. Diese Vorsicht ist umso mehr geboten, als eine andere Quelle bei Morszyn, die sogenannte Magdalenenquelle, wie aus einer gleichfalls von Professor S zajnoch a mitgetheilten Analyse des Herrn $R$ adzis zews ki hervorzugehen scheint, nur mehr einen relativ geringen Gehalt an Kalisalzen aufweist, welche letztere in diesem Falle auch nicht den vierzigsten Theil del gelösten Salze ausmachen, ein Umstand, der wohl nicht ausschliesslich auf den verschiedenen Sättigungsgraden der betreffenden Lösungen beruht. Dabei ist üherdies zu bemerken, dass auch die der Umgebung von Morszyn angehörigen Soolen von Bania bei Lisowice und vou Dolhe keine nemnenswerthen Mengen von Kalisalzen enthalten. Betreffs der Soole ron Dolhe ist mir zwar keine Analyse bekannt, aber schon der blosse Geschmack derselben verräth, dlass Nebensalze dor't schwerlich eine Rolle spielen. Bezüglich aber der Morszyn noch viel benachbarteren Soole von Lisowice ergab eine vor Kurzem im Laboratorium der geologischen Reichsanstalt ausgeführte Analyse, dass diese (in der Tiefe von 52 Meter geschöpft) ungefähr 17 procentige Soole unter $17 \cdot 05$ festen, in Lösung befindlichen Bestandtheilen nur etwas iber 0.02 Bestandtheile Chlorkalium aufwies. Die Schichten, deren lösliche Bestandtheile durch die Bonifacy-Quelle ausgelaugt werden, scheinen also entweder in der Ungebung von Morszyn keine allzu weite Verbreitung: zu besitzen oder doch nu in beschränkter Weise in die Nähe der Tagesoberfläche zu treten.

Angesichts der mannigfachen Unsicherheiten, die demuach für die beabsichtigte Nachforschung bei Morszyn noch herrschen, käme es mir sehr zweckmässig vor, mit einer Bohrung daselbst zunächst 
noch zu warten. Viehnehr möchte es sich empfehlen zuvor in dieser Gegend einige Schurfarbeiten rorzunehmen, durch welche vor Allem eine bessere Kenntniss von lem dortigen Terrain gewomnen werden kann und durch die man wenigstens über Streichen und Fallen der daselbst entwickelten Schichten. sowie anch über die eventuelle Verschiedenheit der an dem Aufbau der letzteren betheiligten Gesteinstypen in's Klare zu kommen vermag.

$\mathrm{Zu}$ diesem Behufe sollte hei Morszyn zunächst mindestens ein Schurfschacht von nicht weniger als 20 Meter Tiefe gegraben werden. Bei einer derartigen hlossen Vorarbeit mag es bequem sein, sich nicht auf Grundstücke Privater begeben zu nüssen. Deshalb kömite als Anschlagspunkt für jenen Schacht ein Punkt in dem der BonifacyQuelle benachbarten ararischen Walde ansgewählt werden. Insofern aber doch einige Rücksicht anf das muthmassliche Streichen der Schichten genommen werden müsste, würde der betreffende Punkt ungefähr in südöstlicher oder allenfalls sülsüdöstlicher Richtung von jener Quelle zu bestimmen sein und zwar so nahe als möglich dem Rande des Waldes. welcher Waldrand hier zugleich die ärarische Gebietsgrenze vorstellt.

Schliesslich will ich hier noch einige Worte ïber die Saline Stebnik südöstlich von Drohobycz anfügen, die ich zwar persönlich bisher nicht zu besuchen Gelegenleit fand, über welche aber Prof. S z a jn o c h a in seiner frülser citirten bereits im Druck befindlichen Arbeit einige werthvolle Mittlueilungen gibt, anf welche ich deshalb hinweisen zu müssen glimbe, weil Stebnik vielleicht die Oertlichkeit ist, welche nächst Turza wièlka und Morszyn noch den meisten Anspruch anf Berïcksichtigung für unsere Frage erheben darff.

Die 1867 durch K lip p gemachten Analysen des dortigen Salzthons lenkten die Aufnerksamkeit von Windakiewicz anf diesen Punkt und im Jahre 1873 wurde in 80 Klafter Tiefe vom Kübeckschachte aus die Strecke Flechmer geschlagen, um zu ermitteln, woher die Beinengungen von Kalisalzen stammen möchten, welche durch jene Analysen im Salzthon nachgewiesen worden waren. Man fand stellenweise ein ungewöhnliches Salzgebirge mit ausgeschiedenen röthlichen und matt durchscheinenden weissen Salzen, welche letztere sodann durch Kripl, Windakiewicz und Lill analysirt wurden. Diese Untersuchungen, für welche offenbar Proben von verschiedenen Punkten der Strecke entnommen worden sind, ergaben in dem einen Fall 15.254, in andern 8.17 und im dritten Falle 27.14 Procent schwefelsaures Kali, ansserdem Chlornatrium, schwefelsame Magnesia, mehr oder weniger bedentende Nengen von schwefelsaurem Kalk. etwas Wasser und in dem einen Fall noch etwas schwefelsaures Natron. Man erschien berechtigt, das Vorkommen von Salzen der Polyhalitregion zu constatiren und speciell bei der dritten, von Lill durchgeführten Analyse erwies sich die Probe als fąst reiner Polylalit. (Vergl. Jahrb. geol. Reichsanst. 1874, 'I's c h e rmak's min. Mitth. pag. 89.)

Dieses Ergebniss veranlasste Windakiewic z die Vermuthung zu äussern, dass zu Stebnik auch andre Kalisalze wie Sylvin oder dergleichen vorkommen möchten. Doch betrachtet. S z a ju ocha mit Recht einen derartigen Schluss als verfiüht, da ja, wie schon wieder- 
holt bemerkt wurle, zwischen den galizischen Salzlayerstätten und Stassfurt keine bestimmte Analogie besteht. Auch ist zu bedenken. lass nicht alle Fachleute zn einer so günstigen Aufassung bezüglich ler Kalisalze bei Stebnik gelangt sind, wie Windakiewicz. Kell, hat (1876 l. c.) dessen Ausfülnumgen keine weitere Anfmerksamkeit geschenkt, und seiner Zeit sprach Hingenan (Verhdl. 1868, pag. 29) gerale auf Grund der vorausuängigen lí rip p'schen Analysen sogar direct von einem "negativen Resultat" in der besagten Hinsicht. Inau kommt, dass bei den Schachtabtenfungen im Hangenden des Stebniker Steinsalzes (vergl. Hingona u l. c.) Kalisalze nicht nachgewiesen wurden. Windakiewicz freilich sucht das (Oest. Zeitschr. f. Berou. Hüttenw. 1876, pag. 30) daraus zu erklüren, dass die betreffenden Regionen zu sehr der Auslaugung durch zusitzende Tagwisser ansresetzt waren, und so mag man clem immerhin das Berlanern Szajnocha's theilen, dass die hier vor Jaluen projectirten Arbeiten, welche vielleicht luätten über die tiefer unter der (O),erfliche gelegenen Theile des Hangenden einige kiarung schaffen kömen, nicht zur vollen Ausführung gelangt sind ${ }^{1}$ ).

Eine viel geringere Bedentung als Stehnik scheint für unsere Betrachtung das dem Karpathemrande mehr genälerte, durch seine eigenthümlichen Mineralvorkommnisse, sowie durch seine Schwefelquellen bekamnte Truskawiec beans]ruchen zn dürfen, wo die Sudsalzgewimung 1784 mufgelassen wurde. Die dortigen Mineralquellen enthalten zwar nach Analysen Radyiszewski's, wie Szajnocha mittheilt. gä̈ssere Mengen ron Kalisalzen als manche andre subkarpathische Soolenquellen (die Marientuelle 15.07 Theile schwefelsaures Kali. die Quelle Surowica 35.13 Theile Chlorkalium in 10.000 Theilen Wasser"), aber dieser Gehalt ist viol geringer als beispielsweise in der Soole von Turza wielka oder in der Bonifacyquelle bei Mor'szyn. Es ist also diese Oertlichkeit für Versuche in dar uns interessirenden Richtung zunächst nicht in Aussicht zu nehmen.

Damit wären num die Pmute besprochen, welche vorlänfig bei der lialisalzfrage ()stgaliziens meln orler weniger ermsthaft in Betracht kommen kömen. Doch mag elwähnt werden, dass Dr. L. Pfe iffer in seinem schon fiüher citirten Handbuch der Kalimdustrie (anf Seite 76) angiebt, dass sich bei Utorol, sowic bei len südlich von Ottyuia gelegenen Ortschaften Holoskow und Strupków Andentungen von Kalisalzen gefunden haben, ohne indessen für diese Angabe eine Quelle anzufühıren. Mir liegen nühere hieranf bezïgliche I)aten jedenfalls nicht vor, elenso wenig wie für chas von $\mathrm{Szaj} n$ ocha in Verbindung mit diesen Namen genamnten Rosólna, so dass ich über die eventuelle Bedentung jener P'unke nicht in der Lage bin mich zu äussern.

Auch ïber verschicdene andere Pankte, welche ich gelegentlich meiner auf Veraulassung des hohen k. k. Finanzministerinms unter-

1) Szajn och a weist iberdies darauf hin, dass gewisse dasellist in den Jahren 1842, 1843 u. 1844 gemachte Bohrungen, deren Znsammenstellnng (N. Jalnb. 1845, pag. 256) wir Pusch verdanken, die grosse Mächtigkeit ler bei Stebnik entwickelten reinen Salzlager erwiesen haben, worans gefolgert werlen könne, dass sich dic Inangriftnahme grössercr Arbeiten daselbst anch ohne die Auffindung von Kalisalzen loluen diirfte. 
nommenen Reise noch besichtigt habe, wie Nowica, Landestreu, Petranka, Chlebiczyn und Ottynia glaubte ich hier njoht berichten zn sollen, da die betreffenden Excursionen zu einem speciell die Kalisalzfrage berührenden Resultate nicht geführt haben.

Da mumehr diese Anseinandersetzung an ihrem Schlnss angelangt ist, so sei. es gestattet, die Vorschläge, welche ich mir in Verlanfe derselben zu machen erlaubt habe, nochmals kurz zusammenzufassen:

1. In Kalusz selbst sollte man durch Gesenke, die vom 3. Horizont aus rlem Verflächen nach $z u$ treiben wären, das dortige Kainitlagen weiter aufschliessen. Anderseits aber sollte man sich mit dem Gedanken befreunden. dass in nicht allzufermer Zeit mit der Coustruction eines nenen Schachtes werde begommen werden müssen, dessen Platz im obigen Exposé näher bezeichnet worden ist. Von Bohrungen indessen sollte bei Kalusz selbst vorlänflg ganz abgesehen werden. Erst in späterer Zeit und wenn gewisse Localyerhältnisse dies erlauben, sollte anch an eine Bohrung gedacht werden, welche der Richtung des Verflächens entşprechend situirt, aber in einer viel grösseren Entferuung von der Grube gelegen sein sollte als der projectirte neue Schacht.

2. Bei Turza wielka sollte in der im obigen Exposé näher bezeichneten Gegend eine Tiefbohrung auf Kalisalze unternommen werden. Selbstverständlich würde dieselbe zum grossen Theil als Kernbohrung auszuführen sein.

3. Bei Morszyı sollte eine ähnliche Bohrung zwar für lie Znkunft in Anssicht genommen werden, aber vorher sollte an einer in der obigen Auseinandersetzung bezeichneten Stelle ein Schurfschacht unter sorgfältiger Registrirung der im Verlauf der Grabung zu machenden Beobachtungen abgeteuft werden.

Indem ich mich der Hoffinm hingebe, dass dieșe Vorschläge von competenter Seite die geeignete Würdigung finden und dass die voranstehenden Ausführungen dazu beitragen werden eine objective, das heisst weder allzu sanguinische noch pessimistisch befangene Auffassung der Kalisalzfrage Ostgaliziens anch in weiteren Kreisen anzubahnen, erührigt mir noch dem hoh̨en k. k. Finanzministerium für: das bei dieser Gelegenheit in mich gesetzte Vertrauen meinen ehrerhietigen Dank abzustatten.

Gleichzeitig kanı ich nicht umhin für die Unterstützmng zu danken, welche ich für mein Vorhaben und bei der Frfüllmug meines Auftrays sowoll bei der k. k. Finanzlandesdirection in Lemberg, als bei dem unter Leitung des Herrn Oberverwalter $M$ ï mle r stehenden Salinenpersonal von Kalusz gefunden habe. Ganz speciell möchte ich aher hierbei noch des stets dienstbereiten Entgegenkommens gedenken, welches ich bei Herrn Verwalter Ma c h anzutreffen Gelegenlieit hatte, der mich nicht allein bei den Begehungen in der Grube und bei einigen von Kalusz aus unternommenen Excursionen begleitete, sondern der mir auch noch später anf verschiedene Fragen bereitwilligst Auskmnft ertheilte und endlich, wie schon Eingangs erwähnt, den Entwurf der auf der beigegebenen Tafel erscheinenden Zeichmungen freundlichst besorgt hat. 


\title{
Ueber die Fauna der durch das Bohr- loch nächst Gross-Opatovice durchteuften Neogengebilde.
}

\author{
Von Vlad. Jos. Procházka.
}

Im verflossenen Jahre übergab mir anf mein Ansuclien Herr Sanitätsrath Merl. Dr. K. Katholický aus Brüun den Schlämmrïckstand einer näclıst Gross-Opatovice in einer Tiefe von 75 Meter erbohrten Tegelprobe zur Untersuchung, über deren interessante Fauna ich bald darauf eine kleine Notiz ${ }^{3}$ ) veröffentlichte.

Damals kounte ich nicht umhin, mich der Meinung anzuschliessen, dass die erwähnte Probe die einzige sei, welche ihrem Zwecke zugeführt wurde, eine Ansicht, für velche einige glaubwärdige Momente nebst einigen Bemerkungen des Herrn Dr. K. K atholický zu sprechen schienen.

Indessen war dem nicht so.

Vor einiger \%eit theilte mir Herr Oberbergrath I)r. E. 'Tietze fremdlich mit, dass es ihm gelungen sei, in den Besitz einer ziemlich grossen Anzahi von aus verschiedener Tiefe stammenden Bohrproben zn gelangen, die von einer im vorigen Jahre mweit des Dorfes Opatovice durchgeführten Bohrung nach Kohle herrühren. Indem Herr Dr. F. 'Tietze mir diese Proben zur Untersuchung übergab, theilte er mir freundlich einige Daten ïber die Lage und die Terhältnisse des nach seiner Ansicht aussichtslosen Bohrloches mit, welches sich in der Niederung südlich der Gewitscher Strasse befindet, für welche Mittheiluagen ich meinen herzlichen Dank ansspreche.

Neines Wissens riskirte man im Verlaufe rler letzten Zeit sïdwestlich des Dorfes Gross-Opatovice nur ein einziges Mal die Kosten einer 'Tiefbohrung in der Hoffinumg, dieselben durch das Auffinden abbauwündiger Kohlenflötze vielfach decken zu kömnen. Es untèrliegt demnach wohl keinem Zweifel, dass die bereits von mir zur Rede gebrachte Tegelprobe von demselben Bohrloche her ist. aus dem die von Herrn Dr. E. Tietze mir anvertranten Proben stammen. Dies beweist nicht allein der Umstand, dass dieselbe genan in die weiter unten angeführte Probenreihe passt, sondern es weist

5) Vl. Jos. Proc bá ka: Das Miocaen von Mähren I. Beitrag zur Kenntniss der Fauna der marinen Tegel und Mergel des nordwestlichen und mittleren Gebietes von Mähren. Sitzungsher. der köngl. bölım. Gesellsch. d. Wissensch. in Prag, Jahrg. 1892, pag. 459.

Jahrbuch d. k. k. geol. Beichsanstalt, 1893, 43. Band, 1. Heft. (V. J. Procházka.) 
rarauf vor allem anderen anch der Faunencharakter dieser Probe hin, welcher mit jenem der aus der Tiefe von 60 und 80 Meter stammenden Proben rollkommen übereinstimmt.

Die Wichtigkeit dieser Tegelproben für die Kemntniss des Opatovicer Miocaens ist eine nicht zu unterschätzende. Dieselben gewinnen aber auch noch unser ganzes Interesse, halten wir uns die Thatsache vor Augen, dass es in dem dortigen Gebiete nicht einen einzigen Aufschluss gibt, welcher im Stande wäre. entweder über die Mächtigkeit, oder die lithologische beschaffenheit, oder aber über die Lagerungsver]ualtnisse der einzelnen Glieder eine nur annälsernd richtige Auskunft zu verschaffen.

Die obgenamnten Bohrproben gewähren dies, wenn ancli in beschränktem, so doch immerhin in genügendem Maasse.

Das in Rede stehende Bóhr] och ging bis ca. 130 Meter tief hinab. Es schloss das Opatovicer Miocaen bis anf die dem (nach Tietze permischen) Grundgebirge höchst wahrscheinlich direct anfliegende, jedo(b) dem Miocaen noch mit Sicherheit angehörige Lage auf, als welche die in der Tiefe von 126 Meter erbohrte, ziegehothe Thonlage zu betrachten ist. In einer Tiefe bis zu 70, theilweise noch bis 80 Neter durchbohrte der Bohrer einen lichtblauen Thon, der dann etwas sandiger wurde und unter 100 Meter stellenweise eine röthliche Färbung anzunehmen begann. Man kam in der Tiefe von 105 Yeter in: eine mit Quarzsand stark gemengte Lage und holte dam bis zn einer Tiefe von 117 Meter stets sandigtegelige Proben zu 'Tage. Unterhalb. dieser sandigtegeligen Sedimente erbohrte man schliesshich in der 'Tiefe von 124 Meter' eine ziegelrothe Lage, die bis 126 Meter anhielt: Bei 127 Meter fand man s'hon einen rothen feinkörnigen Sandstein. den Herr 'T ietze für umgeschwemmtes Rothliegendes hält.

Der in den oberen 'Teufen anhaltende Tegel des Bohrloches ist fein, lichtblau, frisch angestoclien dunkelblan und plastisch; geschlämmt linterlässt derselbe eine verhältnissmässig grosse Menge. von organischen Ueberresten, neben einem unbedentenden Quantum: von sehr feinkörnigem Quarzsand. Das Mengenverhä]tuiss des organischen Einschlusses und des Sandes ist ein derartiges, dass es im ersten Angenblicke der Untersuchung scheint, als ob der Schlämml'ückstand nur ausschliesslich aus Sehalen der Foraminiferen etc. znsammengesetzt sei. Dies letztere gilt in erster Limie von dem Schlämmrückstande der ans der 'liefe von $25,60,75$ und 80 Veter stammen(len Tegelproben. Für die Rückstände der in ther T'iefe von 95 und 96 Meter erbohrten Proben hat dies jerlorlr nicht mehr seine volle Geltung: hier begimnt hereits der Sandgehalt zuzunehmen, während gleichzeitig damit die Menge des organischen Einsclulusses in stetiger Abnahme begriffen ist. Diese mit der 'Tiefe im Znsammenhange. stehende Zunahme des Sandgehaltes des erwälnnten 'Thones mol die. damit in enger Verbindmo sich lefindende Abnalme seines organischen fimschlusses vermay man hereits der nachfolgenden 'Tabelle. in welcher die mir ühergebenen 'Tegelproben sammt ilurem Schlämmrḯckstand narlı der 'Tiefe geordnet sind, zu entmehmen, inshesondere aber lamm, wem man gleichzeitig mit der Betrachtung derselben dic l'üfung des machfolgenilen Faunenverzeichnisses rornimmt. 


$\begin{array}{rccc}\text { Meter } & \begin{array}{c}\text { Gewicht der } \\ \text { Tegelprobe } \\ \text { Gramm }\end{array} & \begin{array}{c}\text { Gewicht des } \\ \text { Schlämmrickstandes } \\ \text { Gramm }\end{array} \\ \text { I. . . . } & 25 & 95 & 0 \cdot 3 \\ \text { II. . . . } & 60 & 130 & 1 \\ \text { III. . . . } & 80 & 190 & 2 \\ \text { IV. . . . } & 95 & 250 & 6 \\ \text { V. . . . } & 96 & 130 & 3 \\ \text { II. . . . } & 105 & 295 & 19 \\ \text { VII. . . . } & 114 & 130 & 4 \\ \text { VIII. . . . } & 115 & 130 & 5 \\ \text { IX. . . . } & 117 & 150 & 5 \\ \text { X. . . . } & 124 & 224 & 17 \\ \text { XI. . . . } & 126 & 200 & 15\end{array}$

Zur Erläuterung dieses Verzeichnisses sei hinzugefügt. dass die zu prüfenden Proben, vor ihrem Schlümmen genau gewogen und dass erst nachher das Gewicht ihrer Schlämmrückstände bestimmt wurde. Dieser Vorgang möge nicht unterschätzt werden, besonders in Fällen wie der unsrige ist, wemn nämlich nur ein kleines Stück voln der zu untersuchenden Lage zu Gebote steht und man democh Näheres über den petrographischen und faunistischen Charakter derselben in Erfahrung zu bringen bestrebt ist. Dass man auch auf diesem Wege schätzenswerthe Beobachtungen zu machen vermag, sobald die diurch das zu Gehote stehende Material vorgezeichneten Grenzen nicht überschritten werden. liegt auf der Hand.

Die aus der Tiefe von 105 Meter stammende Probe weist auf eine sehr stark mit Sand gemengte Thonlage hin, in welcher der Sand rorherrscht. Dieselbe gleicht den in der 'Tiefe von 114, 115 und 117 Meter erbohrten Proben yollkommen. Der Tegel dieser Proben ist lichtaschgrau, fett und plastisch, iln Sand hesteht aus feinem Quarzsand ron zumeist weisser Farbe.

Dem petrographischen Habitus nach gleicht der obere Tegel ron Gross-Opatovice (von 25 bis 96 Meter) den Thonen der Umgebung ron Mähr. - Trübau, Kuchnic, Boskovic, Lay̌ány, Tischnowic. Borac etc., dahingegen stimmen die dortigen unteren sandigtegeligen Bänke mit den gelegentlich eimer Tiefbohrung ${ }^{1}$ ) nächst Mähr. - Trüba u in verschiedenen Tiefen erbohrten sandigtegeligen Lagen. ron denen nur eine einzige, die in der Tiefe ron 145 Meter ertenfte Bank. 2 Meter mächtig constatirt wurde.

Von den obenerwähnten reinen Tegeln und sandigtegeligen Lagen ist die in der Tiefe ron 124 und 126 Meter erbohrte Thonlage petrographisch verschiedeu. Dieselbe besteht aus einem ziegelrothen Thon, dem in der unteren Lage feinkörniger Quarzsand beigemengt ist. Feine Bänder dieses sandigen ziegelrothen Thones finden sich bereits in den ans der Tiefe von 117 Meter stammenden Probe-

1) J. Procházka: Ein Beitrag zur Kenntniss der Fauna des Miocaengebietes der Umgebung von Mühr.-'Tribau. Verhandl. d. k. k. geolog. Reichsanst. 1891, pag. 100. 
stücken vor, welche mit jener der lichtaschgranen sandigthonigen Masse dieser Lage yechseln.

Ueber den Fossilienreichthum der Gross - Opatovicer Neogengebilde gibt das nachfolgende Verzeichniss eine ziemlich gute Auskunft. Bis auf die Lamellibranchiaten, welche nur durch eine Ostren. - die höchstwahrscheinlich Ostrea cochlear sein dürfte, vertreten erscheinen, wurden die Repräsentanten der übrigen Classen in vorzüglichen Erhaltungszustande festgestellt. Namentlich schön erhalten sind die Foraminiferen und die Ostracoden. Die Schalen der ersteren und die Gehäuse der Gastropoden zeichnen sich durch eine lichtbranne Farbe aus, welche den Fisch-Otolithen ebenfalls eigen ist.

Die in den Colounen des Verzeiclinisses vorfindlichen Buchstaben bezeichnen: $h h$ selı häufig, $\eta^{*}$ lıäufig, $s s$ sehr selten, $s$ selten, wälıend die darin angeführten 7ahlen die wirkliche Individnemmenge der in den untersuchten Proben entdeckten Formen angeben.

\begin{tabular}{|c|c|c|c|c|c|c|c|c|c|c|c|c|}
\hline & & \multicolumn{11}{|c|}{ Tiefe } \\
\hline & & 25 & 60 & 80 & 95 & 96 & 105 & 114 & 115 & 117 & 124 & 126 \\
\hline & & \multicolumn{11}{|c|}{$\mathrm{M}$ e t e $\mathrm{r}$} \\
\hline & Foraminifera. & & & & & & & & & & & \\
\hline 1 & Spiroloculina canaliculata d'Orb. & $h$ & $s$ & - & - & - & - & 1 & - & - & 1 & - \\
\hline 2 & excavata d'orb. & - & $s$ & 一 & - & $s s$ & - & - & - & 1 & - & - \\
\hline 3 & tenuis Rss. : & $s s$ & $s s$ & - & - & - & - & - & - & - & -1 & - \\
\hline 4 & Mitiolina Ungeriana d'orb & - & $s s$ & - & 一 & $s$ & 一 & - & - & 1 & - & - \\
\hline 5 & " longirostris d $0 v b$. & - & $s$ & - & - & - & - & - & - & - & -1 & - \\
\hline 6 & lucida Karr. & - & $8 s$ & - & - & - & - & - & - & - & - & - \\
\hline 7 & foeda Karr. . & $s$ & $s$ & - & 一 & ss & - & - & - & - & - & - \\
\hline 8 & Textularia carinata d'orb. & $h h$ & - & $h h$ & $s$ & $s$ & - & 2 & - & - & - & - \\
\hline 9 & " deperdita Rss. & - & - & - & - & - & - & - & - & - & 2 & - \\
\hline 10 & acuta Rss. . & $h$ & - & 7 & $s:$ & - & - & - & - & - & - & - \\
\hline 11 & pectinata Rss. & $h h$ & - & - & - & - & - & -1 & - & - & - & - \\
\hline 12 & cf subangrelata d' Orb. & - & - & - & - & ss & - & - & - & - & - & - \\
\hline 13 & Stur K Karr. . & 一 & - & $s s$ & - & - & - & - & - & - & - & - \\
\hline 14 & Clavulina commumis d' $0 . b$. . & $h$ & $h$ & - & $s$ & $s$ & - & 6 & 2 & 6 & 2 & - \\
\hline 15 & Bulimina Bucliana d'Orb. . & $s s$ & $一$ & $s \&$ & - & - & - & - & - & - & - & -1 \\
\hline 16 & affinis d' Orb. . . & $h$ & - & - & - & - & - & 1 & - & 1 & - & - \\
\hline 17 & pupoides d' $0 \cdot 7$. & $h$ & - & 一 & - & - & - & - & - & - & - & - \\
\hline 18 & Bolivina punctata d'0.l. . . & 一 & $s s$ & - & - & - & - & - & - & - & -1 & -1 \\
\hline 19 & Cheilostoma trigona Rss. . & - & - & - & - & - & - & - & 1 & - & - & - \\
\hline 20 & Cassidulina laevigata d'Orb. & 一 & - & 7 & - & $s s$ & - & - & - & - & - & - \\
\hline 21 & Lagena globosa Walk . . . & - & - & $s s$ & - & - & - & - & - & - & - & - \\
\hline 22 & " apiculate Rss.. . . & $s s$ & - & $s$ & - & - & - & - & - & - & - & -1 \\
\hline 23 & caurlata d'Orb. . . & - & - & - & - & $s$ & - & -1 & - & - & - & -1 \\
\hline 24 & Nodosaria Beyrichi Nerg. . & - & $s s$ & - & - & - & - & -1 & - & - & - & - \\
\hline 25 & Krejęii Proch.. . & $s s$ & 一 & 一 & - & - & - & - & - & - & - & - \\
\hline 26 & Kuchuiciana Karr. & - & - & $s s$ & $s s$ & $s$ & - & - & - & - & - & -1 \\
\hline 27 & $\begin{array}{c}\text { Kuchuiciana var. } \\
\text { striatula Ka). }\end{array}$ & $s$ & - & 一 & - & $s$ & - & 1 & - & - & - & - \\
\hline 28 & sp. ind. . & $s$ & $s s$ & $s s$ & - & - & - & - & - & - & - & - \\
\hline 29 & lispida d'Orb. . & - & $\therefore s$ & $s s$ & - & - & - & -1 & - & - & - & - \\
\hline 30 & bacillume d'Orb. & - & $s \&$ & 一 & - & - & - & - & - & - & - & -1 \\
\hline 31 & consobrima d'Orb. & - & $s s$ & - & - & - & - & - & - & - & - & -- \\
\hline 32 & (d) Bodréana d' 0,7 . & $s$ & $s s$ & - & - & - & 一 & - & - & - & -1 & - \\
\hline
\end{tabular}




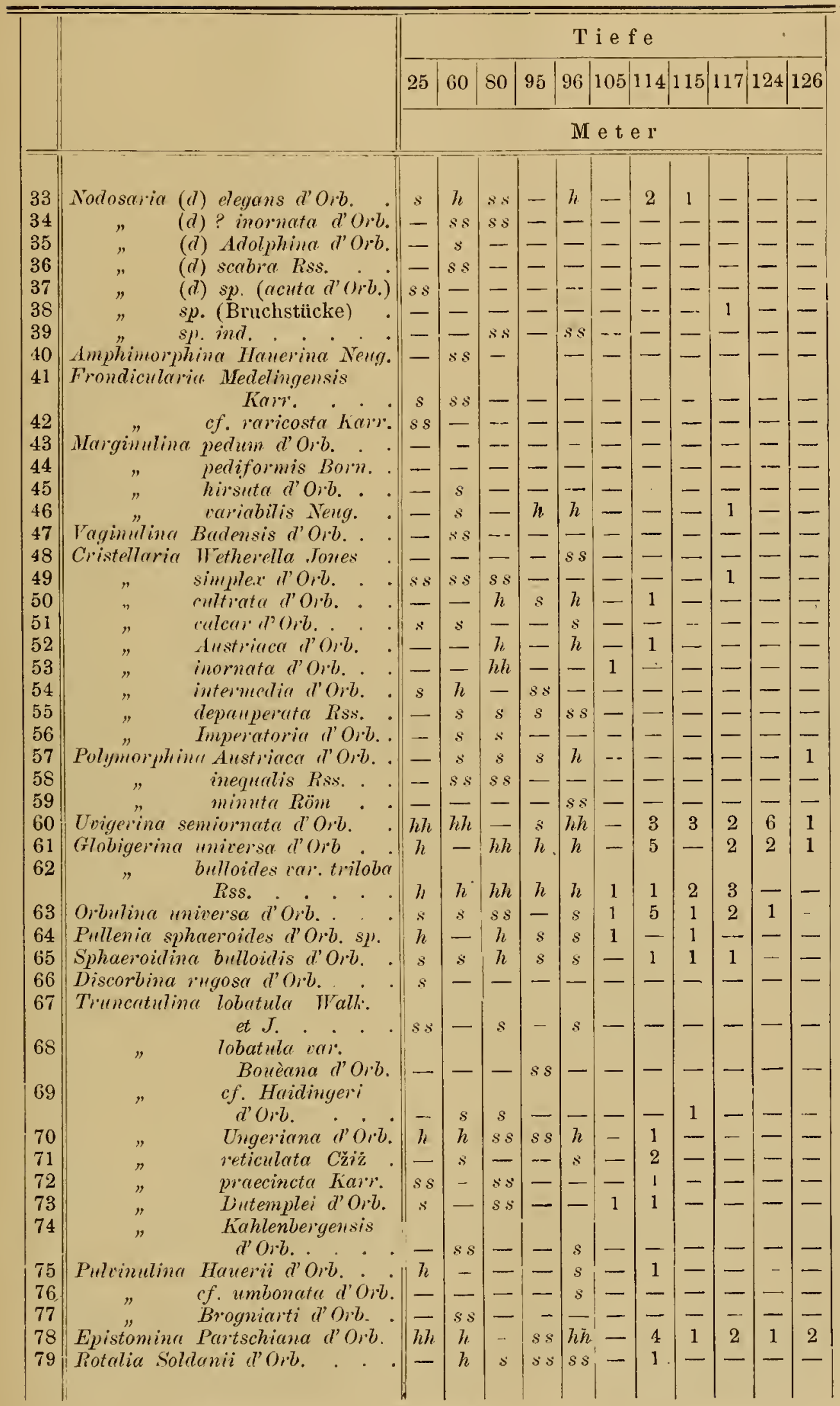

Jahrbuch rl. k. k. geol. Reichsanstalt, 1893, 43. Band, 1. Helt. (V. J. Procházka.) 17 


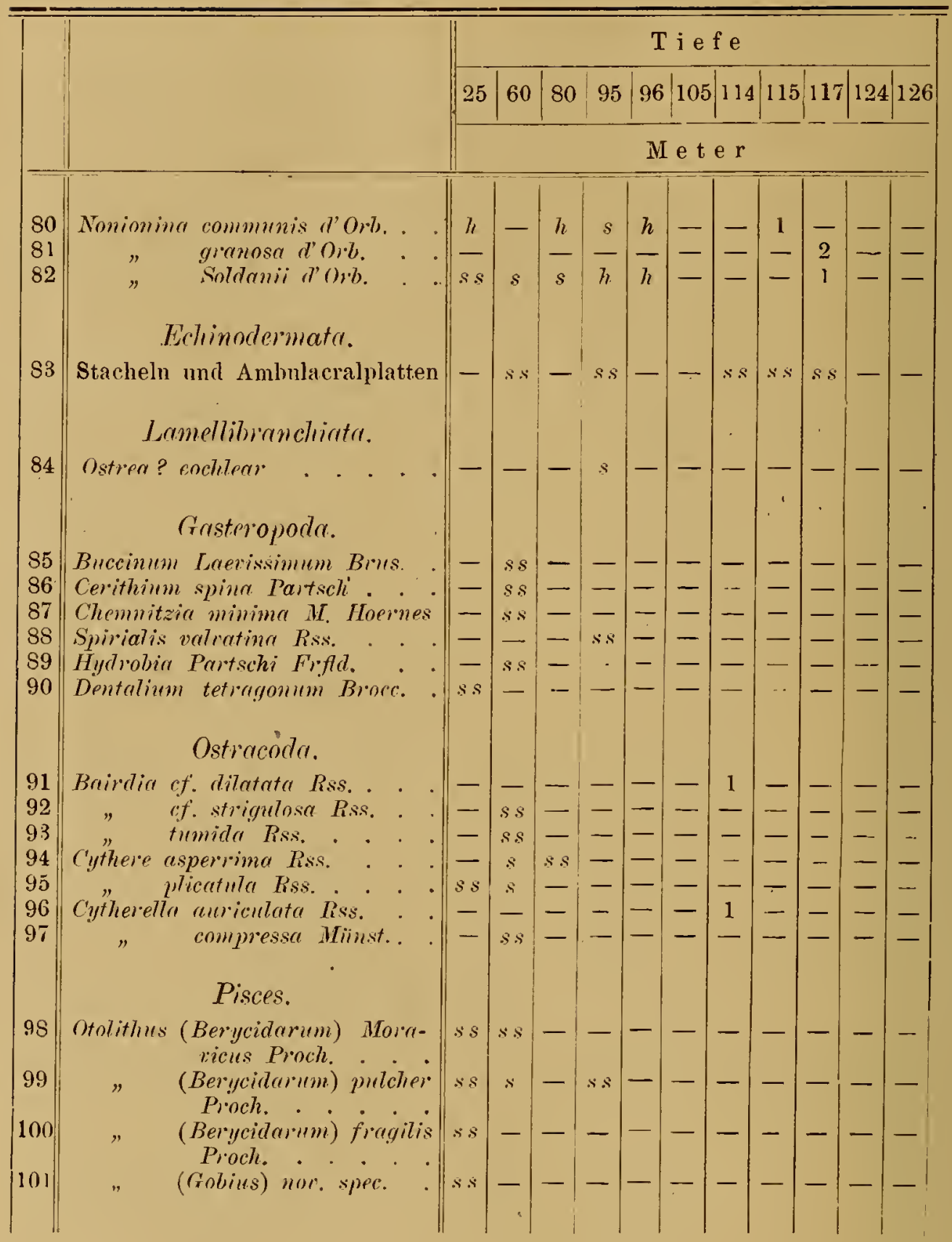

Nach dem hier angeführten Verzeichnisse erweisen sich die Miocaensedimente von Gross-9patovice als verhältnissm ïsig fossilreich. Diese Bezeichnnm verdienen sie recht wohl. schon mit Rücksicht auf die geringe Menge des diesmal nntersuchten Materials, dessen Gesammtgewicht etwas mehr als anderthalb Kilogramm beträgt. Durch diesen Umstand ist anch die geringe Arten- und Individnenmenge der Molnsken des vorliegenden Terzeichnisses himlünglich erklürt.

Im Ganzen lieferte las Gross-Opatovicer Probenmaterial 101 verschiedene Formen, ron welchen der Lijwenantheil, 81 Arten, auf 
die Foraminiferen entfällt. während mur of Formen den Gastropoden, blos 7 den Ostracoden und 4 den Fisch-Otolithen zukommen.

Ein Blick auf die in dem obigen Verzeichnisse angefüln'te Foraminiferen-Fanna genügt vollkommen, um zu erkennen, dass dieselbe jener der bereits besprochenen, ans einer 'Tiefe von 75 Meter stanmenden Bohrurobe angehörigen Thierwelt entspricht. Unsere Foraminiferen-Fanna ist ansgezeichnet einerseits durch das Vorherrschen der Formen der Gattungen Norlostrio, ('vistellaria, Textulavia und der Grupue Rotalina, andererseits anftallend durch das vollkommene Fehlen der Art Amplisteyina Haneri, dann durch das Zurüicktreten der Miliolinen und schliesslich durch das verhältnissmässig seltene Vorkommen von Globigerinen, ferner dei Arten Orbulinu universu, Pullenia spliaeroides, der Arten der Gruppe Vonionina und Polystomella; diese Fauna präsentirt sich als ein in den bläulichen Thonen des nordwestlichen und westlichen Mälıren weit verbreiteter Typus, den ich bereits wiederholt an vielen Localitäten festgestellt habe.

Bereits in meinem kleinen hier erwähnten Aufsatze über die Fauma des Mähr.-Trübaner Miocaens, hob ich die Artenarmuth der sindigen Tegel an Foraminiferen hervor, als einen Charakterzug der Foraminiferen-Fauma, auf den bereits Herr F. Ka $\left.r^{\prime} r^{\prime} r^{\prime}\right)$ aufmerksam gemacht hatte. Erwähnte Eigenschaft beruht ausschliesslich darin, dass die Foraminiferenfauna der den Tegeln eingelagerten Sande lund sandigen Lagen sich als eine reducirte Fauna des diese Sande und sandige Lagen einswhliessenden Tegels darbietet, demnach gibt sie dieselbe Eigenthümlichkeit zu erkemnen, welche die Foraminiferenfauna der Sandfacies so sehr auszeichnet. Beweise für die Richtigkeit dieser Ansicht lieferte die Fauna der Niocaensedimente von Mähr.-Trübau. Weitere Beweise dafür gewälırt nun auch die Foraminiferen-Fama der hier zur Rede gebrachten Gross-Opatovicer Ablagerungen.

Bis zu einer Tiefe ron 96 Meter lieferten die von dort herrïhrenden Tegelproben einen verluältnissmässig bedeutenden Reicl]thum an Foraminiferen-Arten, worunter sich Formen mit einer bedentenden Individuenmenge fanden. Am formen- und individuenreichsten erwiesen sich jedoch die aus der Tiefe ron 60, 75 und 80 Meter stammenden Thonproben. Immerhin reich, wemn auch merklich ärmer, präsentirte sich die Foraminiferenfauna der folgenden Proben, deren Schlämmrückstand bereits ziemlich viel Quarzsand enthielt. Ton dem Foraminiferenreichthume dieser Lagen sticht jener der sandigtegeligen Bämke bedeutend ab. Die Armuth dieses Sediments nimmt mit der Tiefe $z n$, inwieferne, clarïber gibt dlas Uebersichtsver\%eichniss eine genïgende Auskunft.

Verfolgt man daher die Foraminiferenfana der Gross-Opatovicer Niocaengebilde an der Hand der hier zur Rede gebrachten l'roben Schritt für Schritt und nimmt man zugleich anch auf den petro-

1) F. Karrer: Ueher das Auftreten der Foraminiferen in den Mergeln der marinen Uferbildungen (Leithakalk) des Wiener Beckens. Sitzungsb. d. wath.naturw. Classe der k. Akad. d. Wissensch. in Wien L. Rand, pag. 5. 
graphischen Charakter derselben die demselben gebührende Rücksicht, so gelangt man zu dem natürlichen Schlusse, dass die vorerwälnte Entfaltung der Foraminiferenfauna der Gross-Opatovicer Mioraengebilde sich in einem innigen Zusammenhange mit der in der verticalen Richtung nach oben stattfindenden Abnahme an Sandgehalt finden muss, und dass isowohl jene Entfaltung, als anch die Abnahme des Sandgehaltes durch dieselben physikalischen Verhältnisse hervorgerufen wurde.

Von den Echinodermen konnten nur kleine, dünne Stacheln und kleine Ambulacralplatten in geringer Menge festgestellt werden.

Ebenfalls selten sind die Lamellibranchiaten und die Gastropoden in den Tegelproben gewesen, letztere scheinen in der in einer Tiefe voll 00 Meter erbohrten Lage ziemlich häufig vorzukommen, wenigstens beweist dies der Umstand, dass in dem von dort stammenden kleinen Thonstücke nicht weniger als vier verschiedene Formen entdeckt wurden. Das Vorhandensein der Formen: Cerithium spinu, Buccinum laevissimum im Verein mit den übrigen Arten diesel Lage stimmt mit dem Charakter der Foraminiferenfauna vollkommen überein. Damit hängt aber auch der. Clarakter der Ostracoden und Fisch-Otolithen innig zusammen.

Fasst man nun alles das, was hier über den faunistischen Charakter des Gross-Opatovicer Miocaens anf Grund der hier dmrchgeführten Untersuchung der obgenannten Bohrproben gesagt wurde, zusammen, so ergibt sich daraus, dass die rlortigen bläulichen Tegel sammt den dieselben unterteufenden sandigthonigen Lagen und den ziegelrothen Bänken der im nordwestlichen und westlichen Mähren weit verbreiteten Tegelfacies angehören, die, wo immer sie gleichzeitig mit den Mergeln und Leithakalken auftritt, diese stets unterteuft. Die Faunentypen dieser Facies belierbergen die Tegel von Boskovic, Lažánsky bei Rudic und Bolač. 


\title{
Neue Koninckiniden des alpinen Lias.
}

\author{
Von A. Bittner.
}

Mit einer lithugraph. Tafel (Nr. IV).

In Jalubuche 1887, S. 281-292 hatte ich Gelegenheit, den Nachweis des Torkommens vou Koninokiniden im alpinen Lias zu führen. Es wurden daselbst drei Formen unter dem Namen Koninchina Eberhardi m., Koninclima st.jriace m. und Amphiclinodonta liasina m. beschrieben, ausserdem eine Koninckina arstriacc m., deren Provenienz, ob aus Lias oder aus der Trias, unsicher geblieben war.

Seither habe ich wieder einige ähnlicle Formen von neuen Locilitäten erhalten. zunächst von Her'rn Dr. F. IV ̈̈hner Stücke aus mehreren verschiedenen Niveaus des Lias vom Sonnwendjochi, an welcher Localität inr Vorkommen schon durch Pichler bekannt geworden war (vergl. Jahrb. 1887, S. 286). Eine grössere Auzahl von Koninckiniden wurde gewomnen aus einer Sendung petrefactenführender Liasschichten rom Ischler Schafberge, die aus dem Salzburger Museum Carolino-Augusteun durch meinen hochgeschätzten mol lieben Freund Prof. E. Fugger zur Durcharbeitung an die geolog. Reichsanstalt eingesendet worden waren und welche mir von Herru $G$. G e y er freundlichst iiberlassen wurden, trotzdem derselbe gegenwärtig selbst den Lias des Schafberges palaeontologisch zu bearbeiten begonnen hat. Die Kratzalpe bei Golling, die Gegenden ron Adneth und Aussee lieferten ebenfalls einiges Materiale an solchen Brachiopoden, so dass ich in dem nachfolgenden zweiten Beitrage abermals einiges Nene zur Kemntniss dieser bisher noch wenig berïcksichtigten Organismen des alpinen Lias mitzutlieilen in der Lage bin.

Die Literatur über alpine Arten liasischer Koninckiniden ist seit 1887 nux um wenige Daten bereichert worden. G. G e y e r beschrieb in seiner Monographie der Hierlatz-Brachiopoden (Ábhandl. d. geolog. Reichsanst. 1889, XV. Bd., S. 79, Tab. IX. 17-18) die schon Jahrb. 1887, S. 286 elwäinte Form vom Hierlatz bei Hallstatt; ich selbst labe in "Brachiopoden der alpinen Trias", Abhandl. XIV

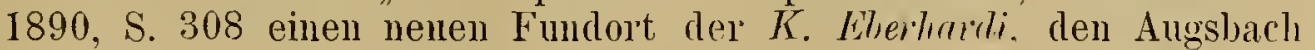
bei Altaussee, angefülırt. 
Von italienischen Fundorten ist durch die "Revisione della Fanna liasic'a di Gozzano in Piemonte" von C. F. Parona, Turim 1892, Gozzall o mit zwei Arten von Koninckinen, Koninclina (?) Aquoniue Par. und K. of. Eberlardi Bittr. linzugetreten; beide Arten werden von I'arona übrigens als nicht vollkommen sichergestellt angesehen.

Es existirt somit hente schon eine ganz stattliche Reilıe dieser lormen in Lias. Fs lassen sich in der Gesammtheit derselben mehrere Typen muterscheiden, die wohl untereinander nicht völlig scharf getremnt erscheinen, democh aber durch gewisse habituelle Merkmale je eine grössere Anzahl von Einzelformen zu einer engeren Gemeinschaft vereinigen. Der am längsten bekannte Typus kann nach cler ausseralpinen Koninclell. linsina Bonch. genannt werden. Er unschliesst ansser dieser Art etwa noch folgende Formen: Koninct. Bouchurdi Dav., Lepterena gibbosule Gemm., Lept. spec. tab. IV, Fig. 16 bei Parona: Contrib. allo studio della fauna lias. dell Apemino centrale 1883, ferner L. Meneghinii Gemm. Die von mir beschriebene Konirchina styriaca 'scheint-von dieser zu einer' zweiten Gruple, welche man als jene der Konincliellu fornicutu Con. $\left.{ }^{1}\right)$ bezeichnen kann, hinüberznfïlnren.

Zu diesem fornicrta-Typus können provisorisch gestellt werden: Koninchella formicute C'an. spec. K. Eberliaidi m., K. (?) Aquoniae Pur.. die von Geyer aufgeführte Hierlatzart, vielleicht auch Leptuenc sicula Gemm.

Diesen Formen reihen sich zunächst gewisse schwachgethügelte Arten mit zugeschärften Flügelecken an; es sind solche von Paro na loc. cit. Tab. III, Fig. 17-19 als Leptuena (?) spec. und Leptuena spec. erwähnt mol abgebildet worden. An sie schliessen sich endlich die Formen mit kräftig entwickelten Flügeln und sehr breitem Schlossrande an, wie Leptaena Paronai Can. (Lept. sper. bei Parona l. ¿. Tab. III, Fig. 16), Koninchinu anstriace m. (vielleicht triadisch), während andere äusserlich ganz älnliche formen theilweise zu dem neuen Leptaenidengeschlechte Carlowella Mun. Chulm. gestellt werden, dessen Typus Leptaenu Moorei Dar. ist. Fs wiirden sonach doch auch Leptaeniden im weiteren Simne unter den elnemaligen "Liasleptaenen" vertreten sein. Wohin nach den neneren Untersuchungen Leptucnu. Duvidsoni Desl. ${ }^{2}$ ) bekanntlich die grösste aller "Liasleptaenen" zu stellen wäre, ist mir mbekannt geblieben. Nach den Abbildungen dieser Art bei D e slo $1 \mathrm{gch}$ a m ps in Mém. Soc. Limn. Norm. Bd.9 1853, würde $\mathrm{i}$ (h) dieselbe unbedingt zu den Konincliniclen zu bringen geneigt sein. Dass unter den spitzflügeligen, der Lept. Lloorei in der äusseren Gestalt älnlichen Formen thatsiichlich anch typisclie Koninckiniden existiren, ist ganz ausser Zweifel; die von mir beschriebene $K$. austriucr ist eine solche Form, und ilne Gestalt stimmt ja wieder ganz überein mit jener der Mehrzahl der Trias-Koninckinen.

1) Ich habe bereits Abhandl. XIV, S. 308 hervorgehoben, dass diese Art, deren Original ich selbst zu sehen Gelegenheit hatte, eine ausgezeichnete honincliella ist.

?) Ihr wird sich wohl $L$. Choffrati Grm. duschliessen. 
Eine letzte Gruppe ron lias-Koninchiniden besitzt ausgesprochenen Amphiclinentypus. Ihr fällt zu Amplliclinodontr lirsina m., ferner wohl

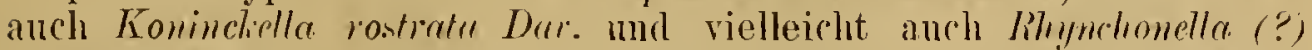
Lopensis Moove (1) a vidson: Suppl. ()ol, and Lias. Brach. XXVII. F. 8, 9), welche in diesem Falle die jüngste aller bisher bekamnten Koninckinidenformen reprïsentiren wïrde.

Generisch rollkommen zweifelhatt bleibt Laptaena (?) apenminira ('an.

Anf die generische Stellung einer Anzahl der hier besprochenen Formen, welche noch einige Schwierigkeiten bictet, wird besser am Schlusse dieser Mittheilung eingegangen werden. \%mürlst sollen hier die Beschroibmaen einiger neuer sowic Mittheilmnen ïher bereits bekamite Formen angeschlossen werden:

\section{Koninckina Eberhardi Bittn.}

Tah. IS, Fig. 1. 2.

Jahrb. d. k. k. geolog. Reichsanstalt 1887, 37. Bd., S. 284, Tab. XIY, Fig. 1-5.

Dic Mehrzahl der Stücke dieser Art erlaubte nicht, die Gestalt und Beschaffenheit der Area reutlich zu erkemmen. Nachtraiglich habe ich aber doch noch in dem grössten der Exemplare (abgebildet. Fig. 1) die Begriinzıng der Area, das geschlossene Psendodeltidium und das Vorhandensein des Srhmabelloches llurch weiteres Präpariren nuzweifelhaft feststellen können. Der Schlossrand erstreckt sich demnach etwas weiter nach aussen. als die erste Abbildung zeigte und es wurde diesmal eine verbesserte Abbildung jenes Exemplares beigefügt. K. Ehcollardi müsste rlemnach eigentlich zu Koninckella Mun. Chalm. gestellt werden. wemn man das Vorhandensein einer Area mit Deltictium als bezeichnend für diese Gattmug gegenüber Koninchina ansieht. Doch daron soll später die Rerle sein. Specifisch würde sich diese Form somit sehr bedeutend der Lept. fornicata Cam. nähern. die. wie bereits erwälnt wurde, bestimmt zu den Koninckiniden zählt. Indessen scheint $K$. fomicrta ( $(a) . s p$. weit stärker gewölbt zon sein, auch ist ihr Schlossrand wohl noch beträchtlich breiter als jener ron K. Eherhardi.

Die als K. Eloerhardi bezeichneten Formen scheinen im Lias der Nordalpen ziemlich verbreitet zu sein. Nachdem sie bereits rom Untersberge und ron der Kratzalpe im Salzburgischen. sowie ron Gams in Steiermark rorlagen, komnte ich (Abhandl. XIV, 308) dieselbe Form aus einem anderen Gesteine, einem mergeligen, dmkclgranen Crinoiden und Pentacriniten führenden Liasnivean dos Augsbaches bei Altaussee anführen und in einem ganz ähulichen Gesteine, das als den "Obtususschichten" des moren Lias angehörend hezeichnet ist mol aus dem Stambachgraben nächst Goisern stammt. fanden sich neben zahlreichen anderen Brachiopoden auch ganz ähnliche Koninckiniden wierler. Ihr Auftreten scheint einigermassen an jenes ron Crinniden gebunden zu sein, wie das schon Des- 
longchamps für die "Liasleptaenen" der Normandie hervorhebt. Doch gilt das wohl nicht ausschliesslich.

Ein weiteres Vorkommen einer Art, die ich von K. Eberhardi nicht tremmen wiurde, ist vom Ischler Schafberge zu verzeichnen. Sie schliesst sich an die breitere Form dieser (l. c. Fig. 2) an und unterscheidet sich von ihr höchstens durch ein etwas spitzigeres Schnäbelchen der grossen Klappe. Da die Exemplare sich besser aus dem Gesteine lösen als jene rom Untersberge und zumeist mit einem glatten dunklen Häutchen iuberzogen siud, so lassen manche von ihnen die Arealpartien sehr genau erkennen (vergl. Fig. 2). Die Seitentheile der Area der grossen Klappe sind glatt, die Area der kleinen Klappe ist sehr schmal. der Schlossfortsatz dieser Kílappe kräftig, das Pseudodeltidium ist gewölbt und mit bogenförmig darüber laufender Anwaclısstreifung versehen: eine sehr schwache horizontale Streifung nimmt man wohl auch auf den ebenen Seitenflächen der grossen Area wahı. Das Schnabelloch ist vollkommen deutlich.

Auch das hereits oben erwälnnte Stück aus den grauen Liasmergeln des Angsbaches bei Altaussee, das sich seiner Form nach an K. Eberhardi Fig. 1 l. c. (hier wieder abgebildet Tab. IV, Fig. 1) anschlliesst, lässt die Area deutlich walnuehmen.

Die Stïcke des Schalberges entstammen den Margaritatusschichten dieser Localität, wie mir Herr G. G e y e l' freundlichst mittheilte. Dieselben führen noch andere verwandte Arten, wie gleich gezeigt werden soll.

Koninckina Pichleri nov. spec.

Tab. IV, Fig. 3.

Die Form ist der vorher beschriebenen K. Eherhardi m. ähnlich, aber ein wenig dentlicher geflügelt, inr Wirbel etwas spitzer, die Flügel sind ein wenig stärker al)gesetzt. ihre Ecken ein wenig schürfer ausgeprägt. Die Umrisse ebenfalls ein wenig rerschieden. indem die grösste Breite näher dem Stirnrande liegt und das Gehäuse von da aus gegen die Wirbel sich stärker zusammenzieht als gegen ren Stimrand; die Contouren sind also weniger elliptisch als bei $K$. El,erhardi, sondern neigen zum Trapezoidischen hin, ähnlich wie bei $K$. st!yricaca m., die aber weit schmäler und viel stärker gewölbt. ist, während $K$. Pichleri noch flacher bleibt als $K$. Elberhardi. Die kleine Klappe ist dementsprechend sehr flach concar. Der Schlossrand erreicht die halbe Breite des Gehäuses. Auch diese Art muss sonst zunächst mit $K$. formicuta $C^{\prime}(a n . s p$. verglichen werden, steht derselben in der Form vielleicht noch näher als die ganz abgerundete $K$. Eberhordi, bleibt aber flacher uncl ihre Area schmäler, als jene der italienischen Art.

K. Pichleri erhielt ich in mehreren Exemplaren von Dr. Fr. W äh $\mathrm{ll}$ e r, der sie in Hierlatzrhyuchonellenschichten des unteren Lias an vorderen Sonnwendjoche auffand. Ob das seinerzeit von Prof. Pichler eingesandte, Jahrb. 1887, S. 286 erwähnte Stück identisch ist, kamn ich dermalen nicht entscheiden. 
Koninckina Wïhneri nov. sper.

Tah. 1V, Fig. 11.

Eine zweite Art rom Sonnwendjoche, welche den bisher im alpinen Lias (- abgesehen ron Ablagerungen der apenninischen Halbiusel -) noch nicht bekinnten 'Typus der Knnimolsella liasina Bonch. - also die echten Kioninckellen - vertritt.

Die For'm, ist eine rerhältnissmässig schmale und rabei hochgewölbte, die kleine Klappe tiefconcav, der Schlossrand halb so breit oder ein wenig breiter als das Gesammtgehäuse. In dieser Hinsicht steht dliese Form in der Mitte zwischen der Sct. Cassianer Koninchella trimlica $m$. und der ausseralpinen K. liasina Bouch., schliesst sich aber beinahe enger an die letztere an. Eine offenbar nahestehende Form ist auch Lept. Meneghinii Gemm. aus Sizilien: es wird aber angegeben, dass dieselhe einen sehr breiten Schlossrand besitze, der bis an rlie Seitemrinder reiche. Die Faserstructur der Schale ist auch bei $K$. N"̈̈hneri ganz deuthch erkennbar, indessen weniger grob als bei den meisten der übrigen Koninckiniden les alpinen Lias und der Trias. Die Arealgegend ist nicht deutlich gemmg erhalten, aber doch - soweit erkembar - von dem gewöhnlichen Typus nicht verschieden. es ist eine doppelte Area, ein geschlossenes Pseudodeltidium, eine Schnabelöttinung in der grossen, erhöhter Wirbel der kleinen Klappe vorhanden.

Vorkomm en. Es liegen mir zwei Exemplare dieser Art. von überaus gebrechlichem Erhaltungszustande ror': sie wurten ron 'Dr: Fr. II ähner am Sonmwendjoch gesammelt und stammen aus einem für derartige Organismen mogewöhnlichen Gesteine, aus einem offenbar durch hochgradige Verwitterung beeinflussten weichen, kreideartigen Spongiennadehnlaufwerke von grauröthlicher Farbe, des nach Dr. Wähner rem oberen Lias ober vielleicht sogar schon dem Dogger angehört und keine anderen organischen Finschlüsse geliefert hat.

Koninckina (Konincliodonta nov. subgen.) Fuggeri nov. spec.

Cab. IV, Fig. 4-9.

Fine Form, die in den brachiopodenreichen rothen Crinoidenkalken ier Margaritatusschichten rom Ischler Schafberge ebenso häufig zи sein scheint. wie $K$. Eherlurrti am Salzburger Untersberge. Es ist eime der grössten bisher aus alpinem Lias bekannt gewordenen Arten:

Länge rom Schuabel zur Stirn: $6-9-9 \cdot 5-10$

Breite (in Millimetern): $\quad 7-11-11.5-11.5$

Sie wird indessen noch grösser, da ein Fragment von fast 12 Millimeter grösster Lünge vorliegt. Nur wenige Arten les Lias (etwa Lept. Daridsoni Desl., Kon. Aquoniar Par.) übertreften sie au Grösse. Unter den nordalpinen Arten ist sie gegenwärtig die stattlichste.

Jahrbuch d. k. k. geol. Reichsanstalt, 1893, 43. Band, 1. Heft. (A. Bittner.) is 
Das Gehäuse ist gerundet, wenig breiter als lang, hochgewölbt. fast halbkugelig bei manchen Exemplaren, die kleine Klappe tiefconcar. Der Schlossrand ist beträchtlich breiter als bei den iibrigen bisher bekannten Arten der nordalpinen Lias, bei einem Stücke ron 11 Millimeter Gesammtbreite wird er' 8 Millimeter breit. Der Wirbel ist zwar scliwach entwickelt, doch immerhin weit kräftiger als bei $K$. Eberhardi, deren Wirbel äusserst reducirt erscheint: die Absätze des Wirbels gegen die Ohren oder Flügel sind schürfer markirt, die Fclien der Flügel stumpf. Die Schale ist grobfaserig. mu ein äusserstes ïberaus rlünnes nnd nur gelegentlich erhaltenes Häutchen ist glatt. An der grossen Klappe tritt nicht weit vom Schnabel eine ähnliche mediane Schalenverdickung anf, wie bei vielen Sprivger $x$-Arten, Rhynchonellen u. A. Die Armspiralen sind lose aufgernllt, aus kamm vier Ungängen gebildet und von dem bekannten, oft beschriebenen diplospiren Baue aller Koninckiniclen. Sie wurden in Folge der günstigeren Gesteinsbeschaffenheit dieses Vorkommens leicht an $\mathrm{z}$ a hl $\mathrm{l}$ ei ch en Exemplaren, und zwar theils durch Anschaben und Aetzen von aussen her, theils durch Querschliffe nachgewiesen (Fig. 5 und Fig. 7) ${ }^{1}$ ).

In der Region zwischen der Hauptwölbung und dem Flügelund Schlossseitemrandsaume zieht eine breite dunkle Linie durch. wclche nächst dem Wirbel beiderseits beginnt und sich gegen den Stirnrand hin in einzelne, in mehrfacher Reihe oder ziemlich umregel-

') Ich bedaure, wenn ich durch Mittheilung dieser Beobachtung wieder mit den Ansichten des Herrn Dr. A. Rothpletz in Collision gerathen sollte, der seinerzeit (Monogr. d. Vilser Alpen, 1886, S. 165) wie es scheint, blos auf dem Wege des Nachdenkens zu der Anschauung gelangt war, dass die "Liasleptaenen" keine festen Armspiralen besitzen können und deshalb die von $\mathrm{MI}$ un i r-Chalmas und mir gelieferten Nachweise solcher für unglaubw ürdig erklärt hatte. Iç habe schon bei früherer Gelegenheit (Jahrb. 1887, S. 282) darauf hingewiesen, was fuir einen ungewöhnlichen Gerlankengang Herr R othplctz, als er seine gelehrten Bemerkungen ïher die "Liasleptaenen" niederschrieh, durchgemacht haven miisse, da man ja doch bei einem so hervorrageuden Forscher nicht annehmen darf, dass er diese Bemerkungen in einem Anfalle von Gedankenlosigkeit von sicl gegeben habe. Leider scheinen die Studien, die, wie man wohl annehmen darf, Herr Dr. A. Rothpletz diesem Gegenstande auch fernerhin gewidmet haben wird, noch nicht abgeschlossen zu sein, denn meine damaligen Bemerkungen - es sind seither fast 5 Jahre verflossen - wären wohl ein hinreichender Grund für ihn gewesen, den definitiven Nachweis auch auf inductivem Wege zu erbringen und zu publiciren, dass diese Brachiopoden keine festen Armspiralen besitzen, wie das ja hereits deductiv von ihm sichergestellt worden war. Oder sollte er sich vielleicht gar seither uiberzengt haben, dass er sich - es ist das aber kaum glaublich - damals geirrt. hahe? In diesem allerdings ganz unwahrscheinlichen Falle müsste man freilich annehmen, dass seine damaligen Bemerkuugen, um einen sehr milden Ausdruck zu gebrauchen, mindestens total uberflissig waren, wie anch Andere, beispielsweisc D. Oehlert in Ann. géol. aniv. 1888, S. 798, erkannt zu hahe.: scheinen. Vielleicht veranlassen ihn die hier ausgesprochenen Zweifel, die einzig und allein dem Interesse an der Sache entspringen, seine Reserve anfgchen und einem weiteren Kreisc seine gegenwärtige gewichtige Ansicht üher den in Rede stehonden Fall nicht läıger vorenthalten zu wollen. Eine blosse Erklärung, dass er jetzt an das Vorhandensein der festen Armspiralen hei den "Liasleptaenen" glaube, nachdem seiner Forderung gemäss diese Beobaclutungen wiederholt wurden, wäre aber nicht hinreichend, denı ich hale schon früher gezeigt, dass diese Organismen seit ilem ersten Nachweise durch Munier-Chalmas und die alpinen Formen darunter seit 1886 vollkommen berechtigt waren für spirentragend zu gelten, ganz gleiclıgiltig, ob gerade Herr Rothpletz an diese Thatsache glanlon mochte oder nicht! 
mässig netzartig angeordnete, kleinere, dunkle Flecke auflöst. Beim Anätzen zeigt sich, dass auch die dunkle Linie ans ziemlich eng aneinandergereihten. mit einander verfliessenden dunklen Flecken bestehe, über deren Natur als Schalenverdickungen kein Zweifel sein kann. Querschliffe (Fig. 9) lehren, dass man es hier mit einer entfernt ähnlichen. aber weitaus nicht so regelmässig entwickelten Verschlussvorrichtıng der Schlossseitemrïnder zu thun habe, wie bei Ampliclimodonta (vergl. Abhand]. XIV. S. 306). Es entwickeln sich hier in den verdickten Rïndern der Klappen nächst den Schlossseitenrändern mehrfache ineinandergreifende Schwielen, zu einer Bildung: wie die regelmässig gebauten Zahnleisten von Amphiclinoclontu sind, kommt es jedoch hier nicht. Immerhin wird dadurch der Querschnitt (vergl. Fig. 8 und Fig. 9) dem von Ampliclina und Amphiclinodontu ähnlich durch die weiter gegen die Stirn hin sich verdickenden Aussemränder', die bei Koninchina mul Koninchella. nur wenig vom Wirbel entfernt, scharf und dümn bleiben. Aensserlich dagegen besitzt diese Form vollkommen den 'Typus von Koninctina und Konincliella, die hier beschriebene Art sogar, wie erwänt, einen auffallend breiten Schlossrand, im Gegensatze zu dem constant äusserst schmal bleibendden Schlosstande von Amphiclinu und Amphiclinorlontre. Man kann sie daher kurz als eine Koninchellı oder Koninchinu mit einer Art von Amphiclinodontenver'schluss der Imenränder bezeichnen. Da sie sich dadurch aber sowohl von Koninchina und Koninchella einerseits, andererseits von Ampliclinc uni Ampluclinodonte unterscheidet, indem sie zwar Charaktere beider Gruppen vereinigt. ohne aber zwischen beiden eigentlich zu vermitteln, vielmeln als eine besonclere Abzweigung des Koninckinentypus aufgefasst werden clarf, cler gewissermassen die Verschlussvorrichtung des Ampliclinentypus nachahmt, so ist man wohl berechtigt, einen - vorlüufig nur subgenerischen - eigenen Namen für diese Form in Vorschlag zu bringen, als welchen ich den bereits oben angesetzten - Konincliodontu - wähle, um damit einerseits ilnre Verwandtschaft mit Konimblina und Koninclellu, andererseits gemisse Eigenthiumlichlkeiten, die an Amplirdinodonta erinnern, zum Ausdrucke zu bringen. Nicht alle Lias-Koninckinen oder -Koninckellen gehören zu dieser Gruppe; ich vermuthe, dass der Typus von Koninckellu, $K$. liasina, diese ineinandergreifenden Pandrerdickmgen der beiden Klappen nicht besitzt, da ich sie bei der nahestehenden $K$. tricudic $m$. nicht beobachtet habe, wenn man von den Verdickungen der Schale ganz in der Nähe der Wirbel absieht, die allen Koninckiniden zukommen. Dagegen düufte allerdings eine Anzahl der alpinen Arten sich als zu dieser Gruppe Kouincliodont" gehörend erweisen, vielleicht auch $K$. Elberhordi $m$. und $K$. formicatr C'an., überlaupt solche Arten, die einen gefleckten oder punktirten Randsaum besitzen, wie die beiden genamnten, der wie bei Amphiclinodontr aus der Auflösung der Schlossseitenrandschwielen in ein Netzwerl ron Körnern, die eine Art Rand('renelirung an der Stirn bilden, hervorzugehen scheint.

A eusserlich steht auch $K$. Fugyeri der $K$. fornicata C'an. wieder selır nahe, noch näher vielleicht als $K$. Eberhmoli und $K$. Pichleri, wegen ihres breiteren Schlossrandes, da aber der innere Ban rou K. fornicutu Can. sp. niclut bekamnt ist, kamn anf keinen Fall eine 
Identificirung vorgenommen werden. Dasselbe gilt gegenüber der grossen $K$. Aquoniae Parona.

\section{Koninckina (Koninckodonta) Geyeri nov. spec.}

Tab. IV., Fig. 10.

Nachdem im nordalpinen Lias Vertreterinen der oben muterschiedenen Fornicata-Gruppe ziemlich zahlreich sich finden, nachdem in $K$. Wähneri vorangehend eine Vertretung der echten Koninckellen o.ler der Liasina-Gruppe beschrieben wurde, haben wir in $K$. Geyeri eine Repräsentantin auch der starkgeflïgelten dritten Gruppe vor uns. Ein einziges Stück hat sich bisher vergesellschaftet init der viel häufigeren K. Fuggeri in den rothen Brachiopoden reichen Kalken der Margaritatusschichten vom Ischler Schafberge gefunden. Es erreicht eine Länge von 9 auf eine Breite von 11 Millimetern, kommt also an Grösse der Mehrzahl der mitvorkommenden Exemplare der K. Fuygeri gleich, unterscheidet sich aber sofort nicht nur durch den etwas kräftiger entwickelten, dickeren Wirbel, sondern vor allem durch die viel stärkeren Flügel, in denen die grösste Breite des Gehäuses liegt. welche demnach ohne Zweifel auch einem ebenso breiten Schlossrande entsprechen und die gegen aussen ein wenig aufgebogen und stumpteckig sind. Das Gehäuse selbst ist von Seite zu Seite nicht regelmässig gewölbt, wie bei $K$. Fuggeri und den verwandten Formen. sondern am Rücken merklich abgeflacht, gegen den Stirnrand selbst mit einer leisen Andeutung einer medianen Furchung, die den Stirnrand unmerklich ausrandet. Die dunkle Fleckenlinie der Koninckodonten wurde an der einen Seite durch leichtes Auätzen vollkommen deutlich gemacht. Yon der kleinen Klappe ist nichts bekannt, da das einzige Exemplar dem Gesteine ansitzt. Die Schale ist grobfaserig wie bei den Verwandten.

Diese Art erinnert an gewisse Koninckiniden der Trias, vor alleu an $K$. Telleri, besitzt aber einen kräftigeren Wirbel als die Mehrzahl der formenähnlichen triadischen Arten. Der Schlossrand darf ganz sicher nach Analogie dieser Formen als bis in die Ecken der Flügel sich erstreckend angenommen werden; in dieser Hinsicht ist sie (abgesehen von den genamnten Trias-Koninckinen) ebenso wie in ihrer Gesammtform unter den bekannten liasischen Arten nur mit Leptaena Davidsoni Desl. zu vergleichen, die (wenn sie überhaupt zu den Koninckiniden gehört, wie ich allerdings nach der äusseren Form annehmen würde) indessen noch breitere Flügel und eine regelmässigere Wölbung besitzt.

\section{Amphiclinodonta liasina Bittn.}

Tab. IV., Fig. 12.

Amphiclina (Ampliclinodonta) liasina Bittn. im Jahrb. 1887, S. 288, Tab. XIV., Fig. 7.

Von dieser Art liegen mir ein grösseres Exemplar und mehrere elı kleine und flache jugendliche Stücke anch aus den Margaritatuschichten des Ischler Schafberges vor. Das grössere Stück, das hier 
abgebildet wurde. stimmt ganz nit lem hereits frïher abgebildeten Stiicke ron der Kratzalpe bei Golling äberein, so weit das der betrïchtlich rerschiedene Frhaltungszustand zu constatiren erlaubt. Ihre nächsten Verwandten besitzt diese For'm in den Amphiclinodonten (rorzüghich Amphiclinodonta Zummaneri m.) der norischen ${ }^{1}$ ) Hallstätter Kalke von Niederösterreich.

\section{Amphiclinodonta adnethica nov. speec.}

Tab. IV., Fig. 13.

Diese Form unterscheidet sich von $A$. liusinu sehr auffillend durch ihre weit schmälere Gestalt, ihre ein wenig stärker eingezogenen Schlossseitenränder und ihren abgestntzten nnd leicht answerandeten Stirmand. Ein sehr stumpfer medianer Kiel verlunft vom spitzen Schnabel an auf der Wirbelhälfte der grossen Klappe und scheidet die beiden sehr ebentlächigen Seitenabfälle. Die Zahnlinie der Ampliclinodonten war nicht ganz deutlich zu machen, daher die Zugehörigkeit zu dieser Gruppe ein wenig msicher ist. Jedenfalls hat man es aber mit einer ron Amph. liasina verschiestenen Form zu thun. Sie erimmert mehr an die Formen der südalpinen Trias als an jene der Hallstätter Kalke.

Vorkommen. Zwei Exemplare aus dem weissen líalke les Brumaner Tropfbruches bei Adneth, aus einem Niveau also, das an der Greize von Rhät und Lias steht, ohme dass heute völlig sicher zu entscheiden wäre, ob man es noch zum obersten Rhät, oder bereits in den untersten Lias stellen solle, dessen Zonen palaeontologisch zu Arlneth bekanntlich nicht repräsentirt sind. Das Vorkommen ist ron einigem Interesse deshalb, weil es mit beweist, dass diese Organismen in allen Schichten der oberen Trias und durch das Rhät in den Lias hinauf vertreten sind.

Wrir haben gegenwärtig somit folgende Koninckinidenarten des nordalpinen Lias (wem wir von der ihrem Lager nach unsicheren Koninchina austriaca $m$. absehen. und von Geyer's unbenamter Hierlatzart, die sich enge an $K$. Eberhardi oder $K$. Pichlesi anschliesst), zu verzeichmen:

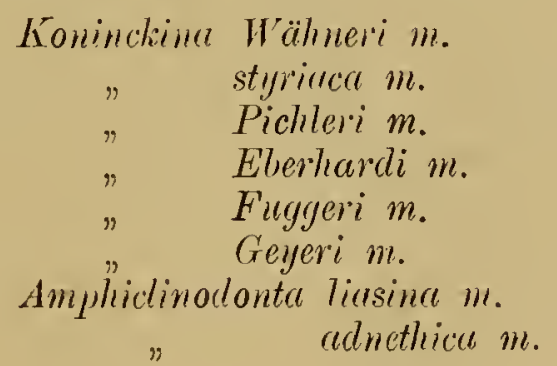

1) Ich gebrauche den Ausdruck "norisch" selbstverstandlich im alten, ursprünglichen Sinne, nachdem ich Jahrb. 1892, S. 387 grezeigt habe, dass die von E. v. Mojsisovics ueuestens vorgenommenc Uebertragung dieses Namens vollkommen unbegriundet, unberechtigt und willkiirlich ist, laher anfs Eutschiedenste zuriickgewiesen werden muss. 
Von den Koninckinen oder Koninckellen gehört K. TYähnevi wahrscheinlich zur Gruppe der typischen lioninckellen. deren erster Repräsentant die ausseralpine $K$. liasina ist, während die übrigen sïmmtlich oder der Mehrzahl nach zu jenen beiden nur der Gestalt nach eingangs unterschiedenen Gruppen der $K$. formicatu Cur. sper. und der stark geflügelten Koninckellen zu ziehen sind, die siclı aber wohl von einander nicht scharf abgrenzen lassen, was unter Anderem daraus hervorgehen würde, dass $K$. Fungeri und $K$. Geyeri beide zu der oben aufgestellten subgenerischen Abtheilung Koninchodontu gebracht werden müssen.

Es stellt sich mehr und mehr heraus. dass es schwierig sei, die Gattungen Koninckina Suss und Konincliella MLun. C'tulmas schart auseinander zu halten. Ueber diesen Gegenstand müssen noch einige Worte beigefügt werden. Betrachten wir die Gesammtheit der bisher bekannten Koninckiniden aus Trias ') und Lias, so fällt vor Allem der durchgehende Unterschied des Koninckinen- und des Amphiclinen-Typus in die Augen. Allenthalben selnen wir diese beiden Typen scharf getremnt neben einander auftreten und existiren. Es ist allerdings merkwürdig, wahrzunehmen, dass beide Typen im Lias zuerst als Leptaenen, später als Koninckellen von allem Anbeginne an vereinigt worden sind, während sie in der Trias lange Zeit nicht einmal als naheverwandt erkannt, sondern in verschiedenen Familien untergebracht wurden. Das rührt von dem Umstande her, dass gerade in dem lange Zeit allein bekannten Urtypus von Koninckina, der Sct. Cassianer $K$. Leonliardi, ein besonders aberranter Zweig der Familie vorliegt, bei welchem durch die mächtige Entwicklung des ïbergebogenen Wirbels Schlossfeld und Schnabelöffunng ganz verdrängt wercien. Der Vergleich zwischen dieser extrem entwickelten Form und den Amphichinen La ube's von Sct. Cassian wal demmach namhaft erschwert und von vornherein nicht besonders naheliegend.

Die Unterschiede des Koninckinen-Tyjus (mit Koninckinu und Koninckella) und des Amphiclinen-Typus (mit Ampliclina und dimpliiclinodonta) lassen sich nach den gegenwärtigen Erfahrungen folgendermassen präcisiren:

De r Íoninckinen-Tyjus besitzt ein Schlossfeld von sehr veränderlicher Grösse und Ausdehnung, welches in dieser Hinsicht sich ganz und gar von der allgemeinen Form, der Breite des Gehäuses und der Entwicklung der Flügel abhängig erweist. Im Allgemeinen ist die Breite des Schlossfeldes eine selir beträchtliche und sie sinkt nur in seltenen Fällen auf die Hälfte der Gesammtbreite oder sogar noch unter diese (Koninclella trialica m.) hinab.

Der Ampliclinen-Typus ist im Gegensatze zu dem Koninckinen-Typus durch sein constant sehr schmal bleibendes Schlossteld ausgezeichnet. Mag die Breite des Gehäuses in den

1) Eine kleine Amphiclinenform, die erste ausseremropäische dieser interessanten Familie, konnte ich vor. Kurzem in 2 Exemplaren in dem Materiale, das Dr C. Dien el aus der Brachiopodenzone iber den Tropitesheds des Bambanagprofils der Himalayas mitgebracht hat, nachweisen. 
mannigfaltigsten Abstufungen wechseln, mag dasselbe Flügel ansetzen muldie hreite Leptacnenform der grossen lionindkinen anf's Tämschendste imitiren, immer hleibt das gesammte Schlossfeld der Amplichinen auf einem minimalen haum beschränkt mol gleichsam rudimentür. Fin Bhick auf die Tal. IT beigegebenen Abbildmoen Fig. 12-16 wirk das besser als viele Worte erlänteru.

Es darf somit wohl behauptet werden. dass die Unterschiede zwischen dem Koninchinen- mid dem Amphichen-Typus die wesentlichsten sind, anf welche wir innerhalb der Familie der Koninckinirden stossen. und dass sie deshalb bei einer maturgemässen Gruppirung der lieherzuzihlenden Formen in erster Iinie festgehalten werden müssen. Ueber dic Unterahtheihng der dem Amphichnen-Typus zufallenden Formen (Amplriclinima) in die beiden Gattungen Amphichina Lambe mud Ampliclinodonta m. soll hier weiter nicht gesprochen werden, ich kam hier anf meine Arbeit über die Triasbrachiopoden S. $304 \mathrm{ft}$. rerweisen.

Einigermassen schwierig begimnt sich gegenwärtig die Unterscheidıng der beiden Gattungen res Koninckinen-Typus (Konimliminae) zul gestalten. Wem wir hicr an der msprüughich für Koninchina nach der: einzigen bekannten Art Ḱnminchina Leonlurdi gegebenen Gattungsrliagnose starr festhalten wollen, miissen wir diese Gattmng eigentlich auf $K$. Leouhro'di beschränken, da schon die nächstrelwandte $K$. oligocoele $m$. von Sct. Cassian sich nicht mehr zwanglos in diese Diagnose fügt. Nimmt man das Nichtrorhandensein ron Area mod Deltidium als charakteristisch und wichtig für Koninchino an. so gehören wahrscheinlich anch die sämmtlichen ïbrigen ron mir beschriebenen triadischen Arten nicht zu Koninckina, nachdem ich erst kïrzlich noch das Vorhandensein von Area. Psendodeltidium und Schmabelloch bei den beiden wichtigsten Typen derselben, bei $K$. Leopoldi Austrine und bei $K$. Telleri $m$. (vergl. Tah. IV. Fig. 1t, 15) mit voller Schärfe nachweisen komnte. Die grössere oder geringere Breite des Schlossfeldes kamn hier keinen Anhaltspunkt für Tremmungen und Unterabtheilungen geben, da dieselbe in allen Dimensionen schwankt, wie das besonder's bei den Lias-Koninckellen klar ersichtlich ist. Man wird also hier zu der Alternative gedrängt, entweder die Gattung Koninchinc anf $K$. Leonhridi (und allenfalls $K$. oligocoela) zn beschränken und dann alle ïbrigen triadischen mol liasischen Arten zu Koninckella zu stellen oder den Begriff' Koninchina zu erweitern und dann die Gattung Koninckella als überflüssig aufzugeben und fallen zu lassen. Es ist keineswegs leicht zu entscheiden, welcher Vorgang der richtigere und ziveckentsprechendere ist. Ich habe mich seinerzeit Abh. XIV, S. 307 bereits für den letzteren Schritt. die Ansdehnung des Namens Koninchima, anssprechen zn sollen geglanbt. möchte dieser Anseinandersetzung heute aber nicht mehr Werth beilegen als den einer persönlichen Meinungsïusserung oder eines Torschlages, da ich damals selbst noch Koninchina und Kóminchella auseinanderhalten zu können glaubte. Es muss ja hier auch errogen werlen, welchen Werth man einzelnen morphologischen Eigenthümlichkeiten, in unserem Falle dem Verschwinden der Area bei $K$. Lemhardi u. dgl. mehr beilegen will und dartuber kömmen die Neinmgen getheilt sein; auch kommen I'rioritäts- 
regeh der Nomenclatur in Betracht, uber deren richtige Anwendung nicht so leicht entschierlen werden kann. Schliesslich muss aber doch jedem Autor das Recht zugestanden werden, eine bestimmte Diagnose zu emendiren oder zu erweiteru und wem ich demzufolge heute den Namen Konincling für alle triadischen und liasischen Formen dieses Typus anwende, so ist ja damit Niemandem verwelnt, das zu bestreiten. und etwa diesen Namen wirklich anf die altbekaunte Cassianer Form zu heschräuken. Wichtiger erscheint mir gegenwärtig die genauere Untersuchung der einzelnen Arten dieses Typus, mag man sie nun als Koninckinen oder Koninckellen bezeichneu. auf ilnen inneren Bau hin, da sich. wie oben gezeigt wurde. anch in diesem - vielleicht wichtigere Eigenthümlinhkeiten als jene ler Arealbihnng sink, noch nachweisen lassen werlen. Die oben unterschiedene Gruppe Koninchorlonter würde damn vielleicht eine ähnliche parallele Eutwicklnugsrichtung in der Abtheilung der Konimchirninas darstellen wie Amphiclinodonta unter den Amphidininae. Auf alle Fälle bieten diese complicirt gebauten kleinen Brachiopodenformen noch ein weites Feld für erneucrte Untersuchumgen und Forschmngen. 


\title{
Ueber die Entwicklung und Verbreitung der Partnachschichten in Vorarlberg und im Fürstenthum Liechtenstein.
}

\author{
Ton Dr. Theodor Georg Skuphos aus Paros.
}

Mit 1 lithographischen Tafel (Nr. V) und 9 Zinkotypien im Text.

\section{EINLEITUNG.}

Der Wunsch, die Partnachschichten auch ausserhalb der Nordtiroler und Bayerischen Alpen kennen zu lernen und zu untersuchen, führte mich während der Monate August und September und nochmals im Monate November vorigen Jahres nach Vorarlberg und Fürstenthum Liechtenstein. Die bei meinen Begehungen, bei denen das Hauptaugenmerk stets nur auf diesen Schichtencomplex gerichtet war, gewonmenen Resultate will ich im Folgenden darlegen.

Meinen verehrten Lehrern, den Herren Professoren Dr. von Zittel und Dr. A. Rothpletz, sowie meinen Freunden Herren Dr. Johannes Böhm und Dr. Willıelm Salomon und Emil Bös e șpreche ich meinen herzlichsten Dank für ihre freundliche Unterstützung aus.

\section{A. Historischer Theil.}

Da ich schon in gleichen Theil meiner früheren Arbeit ${ }^{1}$ ) mehrfach das hier behandelte Gebiet berührt habe, so werde ich mich an dieser Stelle nur auf eine kurze Anführung der hauptsächlichsten, speciell Vorarlberg etc. berührenden Werke beschränken.

1) Th. Skuphos. Die stratigraphische Stellung der Partnach- und der sogenannten Unteren Cardita-Schichten in den Nordtiroler und Bayerischen Alpen. (Geogn. Jahreshefte, IV. Jahrgang 1892, pag. 87 fi.)

Jahrbuch d. k. k. geol. Reichsanstalt, 1893, 43. Band, 1. Heft. (Dr. Th. G. Skuphos.) 19 


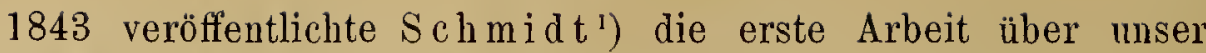
Gebiet, die von einer geologischen Karte und einer grossen Anzahl voll Profilen begleitet ist. Dem Standpunkt der damaligen Alpengeologie entsprechend, wird, jeder Formationsbestimmung fern, nur das Vorkommen der verschiedenen Gesteinsarten registrirt. Er sagt auf pag. 107: „Die Gebirge Vorarlbergs bestehen aus folgenden petrographisch verschiedenen Gebilden:

A) Gneissglimmerschiefergebilde; gehörig;

$B$ ) Grauwackengesteine und Gebilde zum alten rothen Sandstein

C) Kalkgebilde, die zu verschiedenèn Formationen gehören; gehören."

$D)$ Sandstein und Nagelfluhe, welche zur Formation der Molasse

Die Gruppe $C$, die für uns gerade von Wichtigkeit ist, wird auf pag. 116 in acht petrographisch unterschiedene Hauptarten zerlegt.

Escher's Arbeit ${ }^{2}$, die zehn Jahre später erschien, ist reich an wichtigen Einzelbeobachtungen und gibt unter Berücksichtigung der Fossilien ein Formationsschema von Vorarlberg, das er mit dem anderer Gebiete vergleicht. Unter Ziffer 16 sind die Partnachschichten zn verstehen, nur ist ihre Stellung noch nicht richtig angegeben, da die Lettenkohle unter ihnen kommen soll.

Gümb e ${ }^{3}$ ) fasste 1856 die gesammte Schichtenserie zwischen dem Verrucano und dem hentigen Hauptdolomit, den er damals als unterste Etage des Alpenlias betrachtete, als unteren Alpenschiefer zusammen, ohne eine weitere Gliederung desselben zu versuchen.

Das Verdienst, die Untersuchungen Escher's wirklich fortgesetzt und systematisch in mehrjähriger Arbeit Vorarlberg und Nordtirol in ihrem geologischen Aufbau mit umfassendem Blick gegeben zu haben, gebührt von Richthof ell ${ }^{4}$ ), dessen Resultate drei Jahre nach Gümbel's Publication in der ersten Abtheilung seines Werkes niedergelegt wurden. Fr stellte folgende Gliederung der Kalkalpen von Vorarlberg auf:

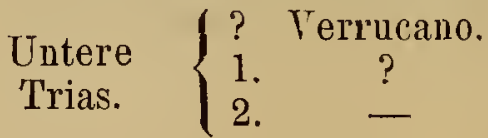

1) A. R. Schmidt. Vorarlberg nach den von dem geognostisch-montanistischen Verein für Tirol und Vorarlberg veranlassten Begehmugen beschrieben und in ciner geogn. Karte dargestellt und mit Anhängen von Revisions-Bemerkmngen von F. W. Friese. (Innsbruck 1843.)

2) Escher von der Linth. Geolog. Bemerkungen üher. das nördliche Vorarlberg und einige angrenzende Gegenden. (Neue Denkschriften d. schweiz. Naturforsch. Gesellsch., Bd. XIII, 1853.)

3) Gü mbel. Beiträge $2 n r$ geoguostischen Kenntniss von Vorarluerg und dem nordwestlichen Tirol. (Jahrb. d. k. k. geol. Reichsanst. 1856, pag. 1-39.)

${ }^{4}$ ) Ferd. v. Richth o fe n. Die Kalkalpen von Vorarluerg und Nordtirol; mit zwei lithogr. Tafeln. (Jahrb. d. k. k. geol. Reichsanst. 1859, pag. 72 ff.) 
$\begin{array}{ll}\text { Obere } & \left\{\begin{array}{l}\text { 3. Virgloriakalk. } \\ \text { 4. Partnachschichten. } \\ \text { 5. Arlbergkalk. } \\ \text { 6. Raibler Schichten mit Rauchwacke und Gyps. }\end{array}\right. \\ \text { Lias. } & \left\{\begin{array}{l}\text { 7. Unterer Dachsteindolomit. } \\ \text { 8. } \text { Kössener Schichten. } \\ \text { 9. Oberer Dachsteinkalk. } \\ \text { 10. Adnether Kalk. } \\ \text { 11. Algäuschichten. }\end{array}\right.\end{array}$

Die Ziffern 1 nnd 2 werden im östlichen Tirol und in Salzburg durch Werfener und Guttensteiner Kalke repräsentirt.

Im Jahre 1862 erschien die Fortsetzung der Arbeit von Richthofen's ${ }^{1}$, an deren Anfang er die Lagerung und den Gebirgsban zwischen Bludenz und dem Arlberg bespricht und in einer grossen Anzahl von Textprofilen und einer Profiltafel erklärt.

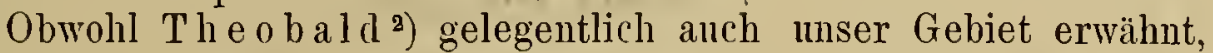
und auf seiner Karte (Blatt Feldkirch-Vaduz) einen grossen Theil von Vorarlberg, den er der Karte von Studer und Escher³) entlehnte, wiedergibt, fügte er doch im Ganzen genommen sehr wenig Neues für unser Gebiet hinzu.

Von Neuem wurde dann unser Gebiet eingehend untersucht von Edm. v. Mojsisovics ${ }^{4}$ ). Obwohl der Autor anf pag. 151 sagt: "Die vorliegenden Skizzen erheben daher durchaus nicht den Anspruch, v. Rjchthofen's Darstellung zu ersetzen, sie wollen nur als eine Ergänzung zn derselben betrachtet werden, so würde es uns zu weit führen, wollten wir auf alle die zahlreichen Abweichungen an dieser Stelle eingehen, welche sich bei einem Vergleiche mit v. Richtho f en's Darstellung ergeben.

Aus jüngster Zeit (1892) haben wir noch die Arbeit von T a r'n ut z e r ${ }^{5}$ ) zu erwähnen. Leider werden wir diese Arbeit nicht benützen können, da dieselbe wenig neue Beobachtungen in unserem Gebiet erwähnt und nur die schon von Escher, v. Richth ofen und von Mojsisovics gegebenen Resultate wiederholt. Mit Bezug auf die Partnachschichten sagt Verfasser auf pag. 27: „Mit den Partnachschichten endigen nach unten die St. Cassianer Gebilde, zu welchen noch die Raibler Schichten und der Arlbergkalk gehören."

1) Ferd. v. Richth ofen Die Kalkalpen von Vorarlberg und Nordtirol. Zweite Abtheilung. (Jahrb. d. k. k. geol. Reichsanst. Bd. XII, 1861/62, pag. 87 ff.)

$\left.{ }^{2}\right)$ Theobald. Geologische Beschreibung d. NO Gebirge von Graubïnden, mit vielen Profilen und geol. Uebersichtskarte 1:100.000. 1863. $1: 380.000$.

$\left.{ }^{9}\right)$ B. Studer u. Escher von der Linth. Carte Geologique de la Suisse.

4) Edm. v. Mojsisovics. Beiträge zur topischen Geologie der Alpen. Nr. 3. Der Rhätikon (Vorarlberg) mit einer geol. Uebersichtskarte und einer Profiltafel. (Jahrb. d. k. k. geol. Reichsanst. Bd. 23, 1873, pag. 137 ff.)

5) Tarnutzer. Der geologische Bau des Rhätikongebirges. (Jahresber. d Naturforsch. Geselisch. Graubündens. Jahrg. XXXV, Chur 1892, pag. 1-123.) 


\section{B. Geologischer Theil.}

Das untersuchte. Gebiet erstreckt. sich vom Stanzerthal bei Flirsch im Osten über Bludenz und Feldkirch bis zum Rhein im Westen. Im Sürlen wird es von dem krystallinischen Gebirge begrenzt, welches sich entlang des Stanzer- und Klostertlials und südlich des Kristbergs und Silberthals hinzieht. Es umfasst jenseits der IIl das Gauerthal, die Scesaplana und das Fürstenthum Liechtenstein. Die nördliche Grenze wird ungefähr durch den $47^{\circ} \quad 10^{\prime}$ nördlicher Breite bezeichnet. Ich beziebe mich im Folgenden auf die Generalstabskarte der Oesterreichisch-Ungarischen Monarchie, Blätter Zone 17, Colonne I, II und III im Maassstab 1:75.000.

\section{ABTHEILUNG.}

\section{Stratigraphie.}

Folgende Formationsglieder nehmen an dem Aufbau des untersuchten Gebietes von unten nach oben Theil:

2. Muschelkalk $=$ M. K.

3. Partnachschichten $=$ P.S.

Trias. $\quad\{$ 4. Raibler Schichten $=$ R.S.

5. Hauptdolomit $=$ H. D.

6. Kössener Schichten $=$ K.S.

7. Dachsteinkalk $=-\mathrm{D} . \mathrm{K}$.

Jura. $\quad\left\{\begin{array}{l}\text { 1. Rother Lias }=\text { R. L. } \\ \text { 2. Algäuschichten = A.S. }\end{array}\right.$

Tertiär. $\quad$ 1. Flysch $=$ F.L.

Quartär. $\quad$ 1. Diluvium $=$ D.L.

Im Weiteren wird jedes Formationsglied petrographisch und palaeontologisch beschrieben werden.

\section{Trias.}

1. Buntsandsteinformation= B.F.

Da Verrucano ${ }^{2}$ ) „bald die Bezeichnung für Gesteine eines bestimmten Alter's, bald für Gesteine einer bestimmten Ausbildung" geworden ist, so habe ich aus Gründen, die aus dem weiterlin Mit-

1) Die Buchstaben werden als Abkiirzungen der Formationsglieder in den Profilen dienen.

2) L. Milc h. Beiträge zur Kenntniss des Verrucano. Erster Theil. Leipzig, 1892, pag. 1-97 und Tabelle. 
getheilten sich ergeben werden, diesen Ausdruck als Formationsglied aufgegeben und durch den obigen für unser Gebiet ersetzt.

Nur kurz sollen hier die Schichten, die diesen Complex zusammensetzen, besprochen werden, da sie von den früheren Autoren eingehend beschrieben sind:

1. Rothe, fein- oder grobkörnige glimmerreiche Sandsteine und Conglomerate, die oft mit Glimmerschiefer älnnlichen Gesteinen wechsellagern.

2. Feste, feinkörnige, grïnliche oder weisse, zuweilen auch röthliche Quarzite, in welchen Glimmerblätter verstreut sind.

3. Lockere bräunliche und grane grobkörnige Sandsteine, in die grosse Gerölle von Quarzit, Gneiss oder Glimmerschiefer eingebettet sind.

4. Dünnschichtige, feine rothe Mergel, die 15-30 Meter mächtig sind und zwischen fein- oder grobkömigen rothen Sandsteinen und Quarziten eingelagert sind. $\mathrm{Ab}$ und $\mathrm{zu}$ findet man in dem harten, festen Sandstein oder Quarzit abgeplattete, Thongallen ähnliche Gebilde, die petrographisch völlig mit den oben beschriebenen Mergeln identisch sind, mitunter rothe: feinkörnige sandige Mergel, die eine Ausbildung besitzen, wie sie so häufig die Werfener Schichten aufweisen.

5. Lockere, rauhe Mergelkalke von hellgrauer Farbe, stellenweise vereinzelte Glimmerblätter führend, und fast nur aus Bruchstïcken von Versteinerungen zusammengesetzt.

6. Rauchwacken von verschiedener Färbung.

Von besonderem Interesse und grosser Wichtigkeit sind die obersten Schichten (Nr. 4, 5 und 6) der Buntsandsteinformation. Zwischen Sandsteinen finden wir typische Werfener Schichten eingelagert an Marias Ablang nördlich von Dalaas und südöstlich und südlich von diesem Dorfe, sobald man am Kristberg linaufsteigt. Fermer gehören hiezu sowohl die sandigen und lockeren Mergelkalke, welche für die alpine Buntsandsteinformation charakteristisch sind, als auch die daranf folgende Rauchwacke bei Schnan und Flirsch. Die obersten Schichten Nr. 5 und 6 sind wohl die Schichten mit Natica Stanensis Pichler's.

Es ist hervorzuheben, dass auf den Karten und in den Beschreibungen fast überall ein weit grösseres Verbreitungsgebiet der Buntsandsteinformation angegeben wird, als in Wirklichleit der Fall ist. Aus zerstreut umherliegenden Blöcken ist auf ihr Vorkommen an dem Orte geschlossen worden. So wird an Marias Abhang, am Triesnerberg bei Brand, am Latz etc. die Einzeichnung auf rlie Hälfte einzuschränken sein.

Anstehend beobachtete ich die Buntsandsteinformation bei Flirsch, Schnan, St. Christof, an Marias Abhang; ferner an den nördlichen Abhängen des Kristberges, und zwar südöstlich und sütllich vom Dorfe Dalaas, am Montafon (die zwei letzterwähnten sind als ein einziger Zug zu betrachten), bei Latz (?), Brand und am Triesnerberg.

Die Mächtigkeit der Buntsaudsteinformation ist in unserem Gebiete eine sehr verschiedene, immerhin beträgt sie aber $50-200$ 
Meter, sofern man die Rauchwacke und die lockeren Mergelkalke mit hineinzieht.

Versteinerungen, die nur in den lockeren Mergelkalken vorkommen, fand ich in der Schlucht zwischen Fallwand und Eisenkopf bei Flirsch und am Schnamer Bach bei Schman in Tirol, und zwar:

1. Myophoria costata Zenk. sp. Flirsch und Schnan.

2. Modiola (?) Böhmi nov. spec. Flirsch.

3. Myacites $s p$.

Flirsch und Schnan.

Diese Versteinerungen, die concordante Lagerung der aufgeführten Schichtenreihe unter dem Muschelkalke, die den Werfener Schịchten höchst älnlichen Einlagerungen im Sandsteine und Conglomerate, die Rauchwacke und die lockeren Mergelkalke, die sich in eben solcher Entwicklung in der unteren Trias der Bayerischen Alpen finden, haben mich veranlasst, diesen ganzen Complex als eine einheitliche Bildung, die der Buntsandsteinformation entspricht, aufzufassen.

\section{Muschelkalk = M.K.}

Als Muschelkalk bezeichne ich den überwiegend kalkigen Schichtencomplex. welcher über der Buntsandsteinformation und unter den Partnachschichten liegt. Er besteht aus schwarzen bis liellgranen harten Kalksteinen, deren Schichtoberfläche mehr oder weniger uneben ist; auf ihr treten wulst-, wurzel- oder wurmförmige Bildungen hervor und heben sich durch dunklere Färbung von dem ïbrigen Gestein ab. Dadurch, dass sehr düme Mergelschichten zwischen den mehr oder weniger dicken Kalkplatten abgelagert sind, tritt die Schichtung: deutlicher hervor. Häufig kommen Kieselausscheidungen und unregelmässige Hornsteinkmollen vor, letztere sogar ab und zu in so grossen Knauern und solcher Menge, dass fast ganze Bänke daraus bestehen. Die typische Ausbildung dieser Kalke kamn am besten und bequemsten in den Steinbrüchen von Bürs bei Bludenz, St. Leonhard bei AusserBraz, Kirche bei Inner-Braz, Flexen und Rauz bei Stuben u. s. w. studirt werden.

Am Schnaner Bach und Griesbach bei Schnan und Flirsch in Tirol tritt ausser den Kalken noch Rauchwacke von gelblicher, röthlicher bis bräunlicher Färbung und verschiedener Porosität auf. Diese und sehr lockere sandige, Versteinerungen führende Mergelkalke, gleich im Hangenden der Buntsandsteinformation, gehören meiner Meinung nacls nicht mehr zum eigentlichen Muschelkalk, sondern noch zur Buntsandsteinformation.

Es ist noch zu erwähnen, dass am Rauzbach unterhalb der zum Pass sich in Serpentinen hinaufziehenden Landstrasse bei Stuben und am Bergsturz bei Langen sehr eigenthümliche, Thonschiefer ähnliche Bildungen, die von Kalkspathadern reichlich durchzogen sind, vorkommen. Diese kaum 15 Meter mächtigen Schichten haben als Hallgendes den typischen Muschelkalk, als Liegendes das krystallinische Gebirge, und zwar zuerst diejenigen Gebilde, welche von Richt- 
hof en als "Uebergänge" vom. Verrucano zum Glimmerschiefer bezeichnete.

Es ist schwer, die Mächtigkeit des Muschelkalkes mit Genauigkeit anzugeben, da gerade dieses Schichtenglied sehr stark der Zerstörung ausgesetzt war; sie dürfte sich jedloch auf 25-100 $\mathrm{Meter}^{\circ}$ berechnell.

Die Verbreitung dieser Schichten ist eine ziemlich beträchtliche. Sie ziehen in einer langen schmalen Zone entlang unseres Gebietes von Flirsch in Tirol bis nach Taduz im Fürstenthum Liechtenstein, sodann in einer südlichen Zone in Montafon zwischen dem Silber- und Klosterthal, ferner SW von Brand bis an die westlichen Abhänge der kleinen Furca am Rhätikon und schliesslich im Saminathal und der Triesner Alp bis oberhalb der Valina Alp.

Versteinerungen kommen an verschiedenen Orten vor, und zwar: 1. St. Leonhard bei Ausser-Braz, 2, nördlich der Kirche von InnerBraz, 3. Dalaas östlich rom Restaurant zum Paradies und am Pfarrlıus, 4. Flexen bei Stuben, 5. Kurhaus Suicca bei der Triesner Alp im Fürstenthum Liechtenstein, 6. Gamperton und 7. Virgloria-Pass. Ich sammelte die folgenden:

1. Diplopora panciforata Gïmbel sp. Vr.: 1 und 4 in Menge.

2. Entrochus liliiformis Schlotheim. Vr.: 5 in Menge.

3. Entrochus gracilis Buch. Vr.: überall in Menge.

4. Spirigera trigonella Schlotheim. sp. Vr.: 5 und 7, St. 10.

5. Retzia Schurageri Bittner. Vr.: 5, St. 1.

St. 5 .

6. Waldheimia (Aulacothyris) angusta Schlotheim. sp. Vr.: 1 11. 3,

7. Waldheimia (Aulacothyris) angusta Schlofh. sp. unr. incrassata Bittner. Vr.: 1, 3 und 4, St. 4.

8. Rhynchonella decurtuta Gir. sp. var. vinada Bittner. Vr.: 5, St. 4.

9. Perten conf. Alberti Goldfuss. 1 Stück von 4.

Aus dem Vorkommen dieser Tersteinerungen dürfte erhellen, dass der Localname Yirgloriakalk ${ }^{1}$ ), den $v$. Rich thof e n eingeführt hat, heute wohl anfgegeben werden kann, da in diesen Kalken kein petrographisch wie palaeontologisch wohl charakterisirtes System oder ein ausgezeichneter Horizont, sondern fast in seiner ganzen Entwicklung nnr echter alpiner Musclielkalk vorliegt.

\section{Partinachschichten $=$ P.S.}

Obwohl dieses Formationsglied nummehr als sicher dem Muschelkalk zugehörig erkannt wurde ${ }^{2}$ ) und dlemgemäss hier als oberer Alpiner Muschelkalk angeführt werden müsste, so möchte ich mich

') Vergl. Benecke: Ueber einige Muschelkalkablagerungen der Alpen. Geogn. palaeont. Beiträge von Benecke, Schloenbach lind Waagen., Bd. II, pag. 57 ff. und Mojsisorics l. c. pag. 153.

$\left.{ }^{2}\right)$ G. Th. Skuphos Die stratigr. Stellung der Partuachschichten etc. Geogn. Jahreshefte. Jahrg. IV, pag. 139 und 141, 1892. 
doch noch einstweilen des Localnamens Partnachschichten bedienen, um Missverständnissen vorzubeugen ${ }^{1}$ ).

In Vorarlberg und in dem Fürstenthum Liechtenstein sind unsere Schichten petrographisch, stratigraphisch und palaeontologisch nicht von denjenigen in den Bayerischen : und Nordtiroler Alpen:iverschieden. Ich kann daher jetzt bestätigen, was ich schon in ineiner friheren Arbeit vermuthete und aussprach ${ }^{2}$ ): „Die: mir nur aus der Literatur bekannt gewordenen Partnachschichten in Vórarlberg sind nach den Lagerungsverhältnissen mit unseren Partnachschichten höchst wahrscheinlich ident".

Petrographisch bestehen sie aus folgenden Gesteinsarten:

1. den grauschwarzen, weniger harten und etwas mehr kalkigen Mergeln mit ausgezeichnet muschligem Bruch, nach allen. beliebigen Richtungen schalig zerspalten und zerklüftet, , so dass es unmöglich ist, Handstiicke zu erhalten;

2. den knolligen, dunklen oder hellfarbigen Kalken. mit unregelmässiger, narbiger oder bıckeliger Oberfläche, die durch die Verwitterung sich rauh anfühlt und dadurch ein ausgezeichnetes Mittel zur Erkemung unserer Schichten liefert. In diesen kommen auch Versteinerungen vor, welche meist mit Schwefelkies vergesellschaftet sind;

3. den dunklen oder hellfarbigen, mehr oder weniger festen, von Kalkspathadern durchzogenen Kialken, ab und zu mit eingelagerten Mergelpartien:

4. den grauschwarzen, festen, haiten und sehr kalkarmen Mergeln mit schwach muschliger Bruchfläche. In ihnen fanden sich Bactryllium Simmidii. Heer, Partanosaurus Zitteli Skuphos und Microleptosaurus Schlosseri Shuphos;

5. deı blaugrauen, fettglänzenden Mergeln, deren kleinste Bruchstückchen noch mit feinen Häntchen von Kalk überzogen sind, und die kleinbröckelig verwittern;

6. den grauschwarzen, sehr dünnblättrigen, thonreichen Mergeln, welche bei der Terwitterung einen zählettigen Boden liefern:

7. den hellgrauen, sehr kalkreichen und dümschieferigen Mergeln, welche überall Bactryllium Schmidii Heer in grosser Mlenge fülıren ;

8. den hell- orler dunkelgrauen mergeligen Kalken mit unebener Oberfläche, welche die Bactryllien in bester Erlaltung einschliessen.

Diese Reihenfolge der Gesteinsarten ist nicht nach ihrem Lagerungsverhältnisse, sondern nur nach ihrer Mächtigkeit angegeben. Innerhalb des Complexes der Partnachschichten ist keine weitere Eintheilung möglich. Die angeführten Gesteinsarten wechsellagern an den verschiedenen Stellen des Gebiets völlig verschiedenartig nit einander.

Die Mächtigkeit der Partnachschichten ist in Vorarlberg und im Fürstenthum Liechtenstein eine weit grössere, als in den Bayerischen

1) G. Th. Skuphos. Vorläufige Mittheilung itber Pavfanosaumus Zitteli, ein neuer Saurier aus der Trias. Zoolog. Anzeiger 1893, pag. 67. Non. 413.

2) G. Th. Skuphos. D. ștr. Stell. etc., pag. 140. 
und Nordtiroler Alpen. In den letzteren sinkt sie, wie schon früher erwälnnt, in einigen Gegenden bis zu 10 Meter herab und schwillt in anderen bis zu 200 Meter an; gewöhnlich schwankt sie um 100 Meter. Dagegen schwillt sie in diesem Gebiete bis zu 250 Meter an und schwankt gewölnnlich zwischen 150 und 200 Meter.

Die Terbreitung unserer Schichten fällt fast mit der des Muschelkalks zusammen. Im Westen erwälnen wir ihr Auftreten am Triesner Kulm, ferner erscheinen sie in dem grossen nördlichen Zug, welcher oberhalb Schaan (Liechtenstein) begimut und entlang den nördlichen Abhängen der drei Schwestern, Alpilla, Gurtisspitz-Gampberg, Nenzingerberg: dann auf der anderen Seite des Ill sich entlang nördlich des Alfensbachs in zwei Züge spaltet, deren südlicher sich, vielfach vou Thalschutt verdeckt, bis nach Flexen bei Stuben erstreckt, und von dort an den südlicheu Abhängen des Trittkopfs, der Schiudlelspitze bis zur Eisenspitze bei Flirsch in Tirol. Weitere Züge sind im Montafon derjenige, welcher östlich bis an das krystallinische Gebirge an Kristberg reichit und sich westlich als ein noch nuächtiger Zilg von Verudorus über Rellsalp bei Schaffafall fortsetzt, und schliesslich der Zıg von Brand, welcher über den Virgloriapass nach Gamperton u. s. w. fülırt.

Versteinerungen fand ich am westlichen Abhang des Eisenkopfs bei Flirsch (1), südlichen Abhang der Schindlerspitz bei St. Christof (2), Flexen und Rauz bei Stuben (3), Hinter-Gandegg (4) und Marias Abhang (5) bei Dalaas, Masonfall bei Imner-Braz (6), St. Leonhard (7) und Rungeliu ( $\varsigma$ ) bei Bludenz, Virgloriapass (9), Gampertonalp (10) und Triesner Kulm (I1) im Fürstenthum Liechtenstein :

1. Bactryllium Schmidii Heer. Vr.: überall in grosser Menge.

2. Lingula Christomani nov. sp. Vr.: (6) in grosser Menge.

3. Spiriferina Lipoldi Bittner. Vr.: (3) 12 Stück.

4. Spiriferina Lipoldi Bit'ner nov. var. hemirycla. Vr.: (6) 8 St.

5. Retzia Schuageri var. media Bittuer Vr.: (3) 3 Stück.

6. Rlıynchonella faucensis Rothpletz. Vr.: (4 und 6) 80 Stück.

7. Partanosaurus Zitteli Skuphos. Vr.: (6).

8. Mikroleptosaurus Schlosseri Shuphos. Vr.: (t).

In Bezug auf die Verbeitung der Partnachschichten kann ich jetzt noch zwei weitere Vorkommen ausserhalb dieses Gebietes elwähnen. Das erste in den Hohenschwangauer Alpen entdeckte mein Freund und College E. B ös ${ }^{1}$ ), der mir seine bezüglichen Resultate freundlichst mit der Erlaubniss ihrer Publication mitgetheilt hat.

Die Partnachschichten treten in jenem Gebiete in zwei Zügen auf. Sie ziehen einmal als sïdlicher Zug voun Säuling über die Blöckenau nördlich entlang am Strausberg und der Hohen Krähe, bis sie sich in der Gumpe auskeilen. Der zweite nördliche Zug beginnt nördlich von Tegelberg am Thorschroffen und zieht bis zum Loberthal. In diesen Schichten kommen folgende Versteinerungeu vor:

1) Die Arbeit über die geologischen Verhältnisse des hier besprochenen Gebietes wird demnächst in den Geognostischen Jahresheften unter dem Titel: "Geologische Monographie der Hohenschwangauer Alpen" publicirt werden.

Jahrbuch der k. k. geol. Reichsanstalt, 1893, 49. Band, 1. Heft. (Dr. Th. G. Skuphos.) 20 
1. Cidaris cfr. dorsata Münst. Vr.: Ilgenmösle.

2. Koninckina Leonhardi Wissm. sp. Vr.: Sänling, Blöckenau und Schnegeckerln.

3. Spirigera cfr. quadriplecta Münst: sp. Vr.: Schönleiten.

4. Terebratula tenella Bittuer. Vr.: Ilgenmösle.

5. Halobia sp. Vr.: Säuling und Schnegeckerln.

Die Mächtigkeit der Partnachschichten beträgt ungefähr 80 bis 100 Meter. Sie liegen zwischen Muschelkalk und Wettersteinkalk, und so, dass der Musclielkalk das Liegende und der Wettersteinkalk das Hangende bildet.

Zweitens hat Bittne $\mathrm{l}^{\prime}$ ) im Envsthale in Oberösterreich aus einem Gestein, welches mit jenem des Wendelsteingebietes ganz übereinstimmt, Versteinerungen der Partnachschichten, wie:

1. Koninckina Leonhardi Wissm. sp.

2. Koninckella triadica Bittner.

3. Spiriferina Fraasi Bittner.

4. Retzia Schwageri Bittner.

5. Retzia nov. spec.

6. Rhynchonella bajuvarica Bittner.

7. Aulacothyris spec. indet.

8. Discina spec.

nachgewiesen und gezeigt, „dass hier (Weyer in Oberösterreich) wirklich ein dem Partnachmergel der Bayerischen Alpen analoges Mergelniveau entwickelt ist, das vielleicht von einer localen Entwicklung eines Kalkniveaus, analog dem Wettersteinkalke des Wendelsteingebietes, überlagert wird".

\section{Raibler Schichten=R.S.}

Unter der Bezeichnung Raibler Schichten fasse ich den Arlbergkalk von Richth of en's, die Lunzer Schichten Theobald's, die Sandsteine, Gypse und Rauchwacke von Mojsisovics' und die Raibler Schichten von Richth of en's selbst zusammen, d. h. den gesammten Schichtencomplex zwischen den Partnachschichten und dem Hauptdolomit. Die Gründe. welche mich dazu veranlasst haben, werde ieh weiterhin anführen.

Die höchst mannigfaltige und verschiedenartige Gesteinsentwicklung der Raibler Schichten lernt man am besten kennen, wenn man zum Gallinakopf von Latz aus, zum Stierkopf bei Bludenz, zur: Gamsfreiheit durch den Letschwald bei Braz, zum Trittkopf über Flexen und Rauz bei Stuben, zur Schindlerspitz von St. Christof aus etc. aufsteigt.

1) Alex. Bittner. Ein Vorkommen petrefactenführender Partnachschichten im Ennsthale in Oberösterreich. (Verhandl. d. k. k. geol. Reichsanst. Nr. 12, 1892, pag. 301-303.) 
1. Auf die Partnachschichten folgt zuerst ein Complex dunkelgrauer, fester oder cavernöser Kalke, welche mit dümnen Mergellagen wechsellagern. In den zuweilen mit Eisenoxydul ausgekleideten Hohlräumen stecken .in grosser Menge kleine Exemplare von Megalodon triqueter Wulfen sp.

2. Darauf folgen dunkel- oder hellbraune, feinkörnige Sandsteine mit Pflanzenresten.

3. Schmutziggraue Mergel, mit denen ab und zu bituminöse dümmbankige Kalke wechsellagern.

4. Dumkelgrauer fester Kalkstein, welcher allmählich in verwitterten hellfarbigen körnigen Dolomit übergeht und Megalodon triqueter Wulf. sp. in mittlerer Grösse enthält.

5. Damn folgen Kalkbänke etc. wie $\mathrm{Nr}$. 1, aber nicht so mächtig, darüber noch einmal Sandstein, Mergel, Gyps und Rauchwacke. Diese obere Rauchwacke ist an den nördlichen und östlichen Abhängen des Gallinakopfs mächtig entwickelt, sie bildet 10-35 Meter hohe Erosions-Pyramiden.

Die Mächtigkeit der Raibler Schichten schwankt, innerhalb unseres Gebietes sehr bedeutend, sie hängt von der geringeren oder stärkeren Entwicklung der Oberen Rauchwacke oder der untersten Kalkbänke, die auf den Partnachschichten aufrulien, ab. Immerhin lässt sich so viel sagen, dass sie nur der des Hauptdolomits nachsteht, so dass diese beiden Formationsglieder den grössten Antheil an der Gebirgsbildung Vorarlbergs und des Fürstenthums Liechtenstein nehmen. Die Raibler Schichten dürften höchstens 300 Meter, durchschnittlich aber 150-200 Meter mächtig sein.

Die horizontale Ausdehnung dieser Schichten fällt fast überall mit der des Muschelkalks und der Partnachschichten zusammen, so dass eine weitere specielle Aufführung derselben unnöthig erscheint.

Versteinerungen aus diesen Schichten habe ich von folgenden Fundorten zu erwälnnen: Gampalp (1) bei Nenzing, Galgentobl (2) bei Bludenz, südliche Abhänge der Gamsfreiheit (3), Alle Höhe (4) bei Dalaas, Ochsenboden (5) bei Stuben, südliche Abluänge der Schindler Spitz (6) bei St. Anton:

1. Myophoria fissidentata Wöhrmann (2, vou Pater Kohlberg in Feldkirch in mehreren Exemplaren).

2. Megalodus triqueter Wulf. sp. Vr.: (3, 4 und 5 und zwar sowoll in den tieferen als auch in den oberen Schichten) in grosser Menge.

3. Pterophyllum longifolium. Vr.: (1, 2, 5 und 6).

Ausser diesen sind von Escher von der Linth nachfolgende Versteinerungen aufgefunden worden:

1. Equisetites columnare St. Zwischen Zug und Thannberg.

2. Equisetum. Zwischen Zug und Thannberg.

3. Pterophyllum Jägeri. Vaduz und Thammberg.

4. Pterophyllum. Thannberg.

5. Bactryllien. 
Ich habe schon bei anderer Gelegenheit ') erwähnt, dass die Partuachschichten in Vorarlberg über dem Muschelkalk und unter dem Arlbergkalk liegen, der mir nach den Beschreibungen der Autoren nur ein Theil der Raibler Schichten zu sein schien. In Folge dessen nahm ich an, dass der Wettersteinkalk in den westlichen Nordalpen fehlt.

Diese Vermuthumg wurde nun durch die Untersuchung an Ort und Stelle im verflossenen Sommer bestätigt. Folgendes sind die Gründe :

1. Gleich über den Partnachschichten folgt der ganze Complex, welcher zwischen ihmen und dem Hauptdolomit gelagert ist; er besteht aus Kalkstein-, Mergel-, Sandstein-, Rauchwacke-, Gyps- und dolomitischen Bäuken, welche mit einander wechsellagern, so dass wenigstens innerhalb dieser Schichten keine Trenuung gemacht werden kann.

2. Diese Ausbildung der Gesteine und ihre Reihenfolge zeigt den Habitus der Raibler Schichten, wie wir ihn im Karwendelgebirge, Wettersteingebirge, Wendelsteingebiet, Kaisergebirge etc., kurzum in den Nordtiroler und Bayerischen Alpen entwickelt finden.

3. Die Versteinerungen, welche sowohl in den unteren als in den oberen Schichten vorkommen und bis jetzt nur in den Raibler Schichten der übrigen Alpen gefunden wurden, sind der beste Beweis dafüir, dass der ganze Complex zwischen Partnachschichten und Hauptdolomit ein einheitliches Formationsglied darstellt, und zwar die Raibler Schichten.

Es unterliegt keinem Zweifel, dass westlich von Landeck, d. h. im westlichen Nordtirol; in Vorarlberg und Fürstenthum Liechtenstein der Wettersteinkalk nicht mehr vorlianden ist.

Nach unserer Auffassung ist also die "für sich stehende Gy psund Rauchwackeformation", welche Mojsisovics weder zu den Carditaschichten noch zum Hauptdolomit zieht, nur der obere Theil der Vorarlberger Raibler Schichten. Ferner stimmen die Lunzer Schichten Theobald's sowohl petrographisch als auch nach den Versteinerungen, soweit sie bis jetzt bekaunt geworden, mit den Raibler Schichten vollständig überein, so dass also fermerhin auch dieser locale Name, so wie auch die Gyps- und Rauchwackeformation von Mojsisovics fortfallen können.

\section{Hauptdolomit $=$ H.D.}

Auf die Rauchwacke der Raibler Schichten folgt der Hauptdolomit in ausgezeichnet geschichteten Bänken. Er besteht zum grössten Theil aus hell-oder dunkelgrauen festen versteinerungsleeren Dolomiten. Die Eigenthümlichkeit des Hauptdolomits in den übrigen Alpen, unter dem Schlage mit dem Hammer in kleine Stücke zu zerbröckeln, zeigt sich hier nicht in gleicher Weise, sondern man erhält immer grössere, mit einem gelbweissen Ueberzug bedeckte

1) Skuphos. Strat. Stell. d. Partnachschichten etc. pag. 140. 
Stïcke. Sehr: selten ist der Hauptdolomit vou. Kalkidern kurchzogen, und dies nur in den oberen Lagen an der Grenzè gegen die Kössener Schichten. An einigen Stellen, wie z. B. der Saladinaspitz, Gamsfreiheit etc., ist er von gelblich weisser Farbe und feinkörniger Structur.

Die Mächtigkeit des Hauptdolonits kann man zwischen 4-500 Neter ansetzen; er ist von sämmithchen Formationsgliedern in unserem Gebiete das mächtigste. Er bildet fast überall die höchsten Spitzen und Bergkämme (Rogelskopf, Saladinaspitz, Gansfieiheit, Gallinakopf etc.).

Der Hauptdolomit geht von Osten nach Westen durch unser ganzes Gebiet hindurch.

Versteinerungen sind wenigstens in unserem Gebiete weder von mir noch von Anderen bis jetzt gefunden worden.

\section{Kössener Schichten=K.S.}

Die Grenze zwischen den Kössener Schichten und dem Hauptdulomit lässt sich wegen der auffallend verschiedenen petrographischen Ausbildung ausserordentlich scharf ziehen. Auf die letzten Bänke des Hauptdolomites folgen die Kössener Schichten: kohlschwarze Kalke in Wechsellagerung mit Mergeh von ähnlicher Färbung. Die Kalke sind mehr oder weniger dünnbankig und ihre Mächtigkeit verhält sich zu derjenigen der Mergel wie $1: 3$, hie und da wie $1: 10-15$, so dass die mergelige Bildung überwiegt.

Die Gesammtmächtigkeit der Kössener Schichten ist sehr gering im Verhältniss zu den übrigen Formationsyliedern, so besonders gegenüber dem Hauptclolomit; sie schwankt zwischen 20-50 Meter.

Ihre Verbreitung ist in unserem Gebiet ebenfalls eine sehr beschränkte. sie treten auf in einem schmalen nördlichen Zuge, welcher vom Lech über den Formarin-See u. s. w. zieht, dam in einem zweiten am Eingang des Montafonthals, welcher ungefäln von Osten nach Westen zieht, und einem dritten im Rluätikon an der Scesaplana selbst.

Tersteinerungen kommen überall vor, wo die Kössener Schichten entwickelt sind. Von folgenden drei Fundorten: 1. um den Formarin-See herum und zwar hauptsächlich an dessen östlichem Ufer; 2. am Eingang des Montafonthals auf dem rechten Ufer der Ill, etwa 100 Neter hinter der hölzernen Brücke, und 3. im Rhätikon an der Scesaplana selbst, habe ich diese Versteinerungen zu erwähnen: plaren.

1. Bactryllium deplanatum Heer, überall in zahlreichen Exem-

2. Thamnastraea rectilamellosa Winlil. Vr.: 2; 7 Stück.

3. Thecosmitia sp. Vr.: 1.

4. Cidarisstacheln. Vr.: Überall.

5. Spiriferina Jungbrunensis Petzhold. Vr.: 1 und 2; 5 St.

6. Rhynchonella cornigera Schafl. sp. Vr.: 1;20 kleine St.

7. Pterophloios Emmrichi Gümbel. Vr.: 1; 1 Stück.

8. Terebratula gregaria Süss. Vr.: $3 ; 4$ Stück. 
9. Waldheimia norica Sïss $s p$. Vr.: 1, 2, 3; 3 Stück.

10. Ostrea alpine Winll. Vr.: 3; 1 Stück.

11. Lima praecursor Quenst. sp. Vr.: 2; 1 Stück.

12. Pecten acuteauritus Schafh. Vr.: 1,$2 ; 4$ Stück.

13. Pecten Falgeri Mer. Vr.: 2; 2 Stück.

14. Avicula sp. Vr.: 1; 1 Stück.

15. Nucula sp. Vr.: 1; mehrere Stücke.

16. Dimyodon intustriatum Emmr. sp. Vr.: 1, 2, 3; 5 Stück.

17. Protocardia rhätica Sïss. Vr.: 1; 1 Stück.

18. Dentalium (?) Vr.: 1; 1 Stïck.

\section{Dachsteinkalk ${ }^{1}$ ) = D.K.}

Die Kössener Schichten gehen in ihren oberen Lagen almählich in Dachsteinkalk über, und zwar lässt sich ihr Auskeilen in Dachsteinkalk und umgekehrt vorzüglich vom Formarin-See aus an den NW-Abhängen der Saladina-Wand beobachten.

Der Dachsteinkalk besteht aus einem gelbwfissen dichten Kalkstein, welcher durch die Verwitterung eine weissliche Oberfläche bekommt; er ist von Kalkspathadern durchzogen. Ferner erscheinen noch etwas dunklere Kalke, die aus kleinen weissen oolithischen Körnern zusammengesetzt und sehr charakteristisch für unseren Horizont sind. Bei der Verwitterumg der Kalke treten die Körner auf der Oberffäche hervor.

Die Mäclitigkeit dieses Formationsgliedes ist ebenfalls gering, ich schätze sie auf 40-80 Meter. Seine Verbreitung fällt mit der der Kössener Schichten zusammen.

Von Versteinerungen labe ich nur Megalodonten-Durchschnitte zu erwähnen, welche ïberall, wo der Dachsteinkalk entwickelt ist, fast immer in den gelbweissen dichten Kalksteinen auftreten, ferner Korallenäste, die aber völlig unbestimmbar sind.

\section{Jura.}

1. Rother Lias $=$ R.L.

Auf den obersten Schichten des Dachsteinkalks liegen 1-2 Meter mächtige gelbweisse feste Kalke, in welche unregelmässig gewundene Schmitzen von dichtem rothen Kalke eingeknetet sind. Diese bunten Kalke sind erfüllt mit gänzlich unbestimmbaren Schalenbruchstückchen von Gastropoden und Lamellibranchiaten.

Aus dieser wenig mächtigen Kalkbank entwickeln sich die echten rothen Liaskalke, welche durch ihre Fürbung und Versteinerungsarmuth in unserem Gebiete charakterisirt sind. Es sind rothe Knollen, welche mit sehr dünnen rothen mergeligen Häutchen überzogen sind.

1) Dachsteinkalk im Sinne Gümbel's, nicht im Siune der Wiener Geologen! 
Diese Schichten kommen vor am Rothen Kopf bei Flirsch in Tirol. Zürspass und Pazielalp bei Stuben, an der Saladinawand, am Rothen Horn bei Dalaas etc.

Die Mächtigkeit dieser Schichten beträgt höchstens 20 Meter. An Versteinerungen werden ausser Crinoiden-Stielghiedern, welche ich anch gefunden habe, von Es ch er Ammoniten von Spuler-See angeführt:

1. Ammonites radians Schloth.

2. $\quad$ torulosus Schühl.

3. " heterophyllus Sorr. etc.

Sollten vielleicht die beschriebenen $1-2$ mächtigen bunten Kalke, welche über dem Dachsteinkalk und unter dem rothen Liaskalk vorkommen, den Hochfellen-Schichten entsprechen?

\section{Algäuschichten=A.S.}

Dem rothen Liaskalk liegt fast überall ein mächtiger gefalteter Complex meist weicher Mergel und Kalke auf, welchen schon 1856 Gü mbel'1), wegen seiner schönen Entwicklung in den Algäuer Alpen, Algäuschichten genannt hat. Diese Schichten sind auch in unserem Gebiete entwickelt und führen fast überall rothe Hornsteinbänke, wie z. B. an der Rothen Wand und am Rothhorn bei Dalaas, an der Perseier Alp und am Rothenkopf bei Flirsch in Tirol u. s. w.

Von Yersteinerungen habe ich oberhalb der Perseier Alp und an der Rothen Wand bei Dalaas nur die sogenannten Fucoiden gefunden:

1. Chondrites latus Gümbel.

2. Chondrites minimus Gümbel.

Die Mächtigkeit dieser Schichten dürfte 150 Meter betragen. Sie sind stark gefaltet und horizontal weit verbreitet.

\section{Tertiär.}

$$
\text { 1. Fly sch = F. L. }
$$

Da ich dieses Formationsglied am Nenzing bei Bludenz und bei Vaduz in Fürstenthum Liechtenstein nur berührt habe, so beschränke ich mich hier darauf es anzuführen. Vacek ${ }^{2}$ ) stellt es über die eocaenen Nummulitenschichten.

\section{Quartär.}

\section{Diluvium = D. L.}

Bevor iclı den stratigraphischen Theil abschliesse, möchte ich Einiges über die quartären Bildungen, welche entlang des Gampertonthales abgelagert sind, hinzufügen. Sie bestehen aus einem lockeren

1) Gümbel: Beiträge geogn. Kenntniss Vorarlherg. (Jahrbuch d. k. k. geolog. Reichsanstalt 1856 , pag. 9 .

2) M. V a cek. Ueber Vorarlberger Kreide (Jahrb. d. k. k. geol. Reichsanst.

Bd. XXIX, Heft 4, 1879, pag. 654-758. 
Sandstein, der meistens das Liegende bildet, und aus einem festen groben Conglomerate im Hangenden, welche den engen Eingang des Gampertonthals besonders am Aussichtspunkt "Buder-Höhe" veranlassen. Aehnliche Ablagerıngen bilden'mächtige Wände am Bürs bei Bludenz auf beiden Ufern des Alvier Bachs am Eingang des Brandner Thals.

In dem lockeren und lehmartigen Sandsteine sind Stosszähne von Elephas mimigenius gefunden worden. Sie wercten zum grössten Theil in Bregenzer Museum aufbewahrt.

Meter.

Die Mächtigkeit dieser Bildung erreicht hier und da 40 bis 60

Auf rlem Thalschutt und den von Triasgesteinen gebildeten Abhängen des Nenzinger- und Gampberg's finden wir mächtige erratische Blöcke, die auch von Mojsisovics erwälınt.

\section{ABTHEILUNG.}

\section{Tektonik.}

Durch neun Profile, welche durch verschiedene Theile unseres Gebietes gelegt werden, werde ich versuchen, die in vorhergehenden Abschnitt aufgeführten Thatsachen nachzuweisen. Ich werde mit dem Profil: 1. Bings bei Bludenz-Stierkopf-Gamșfreiheit wegen seiner

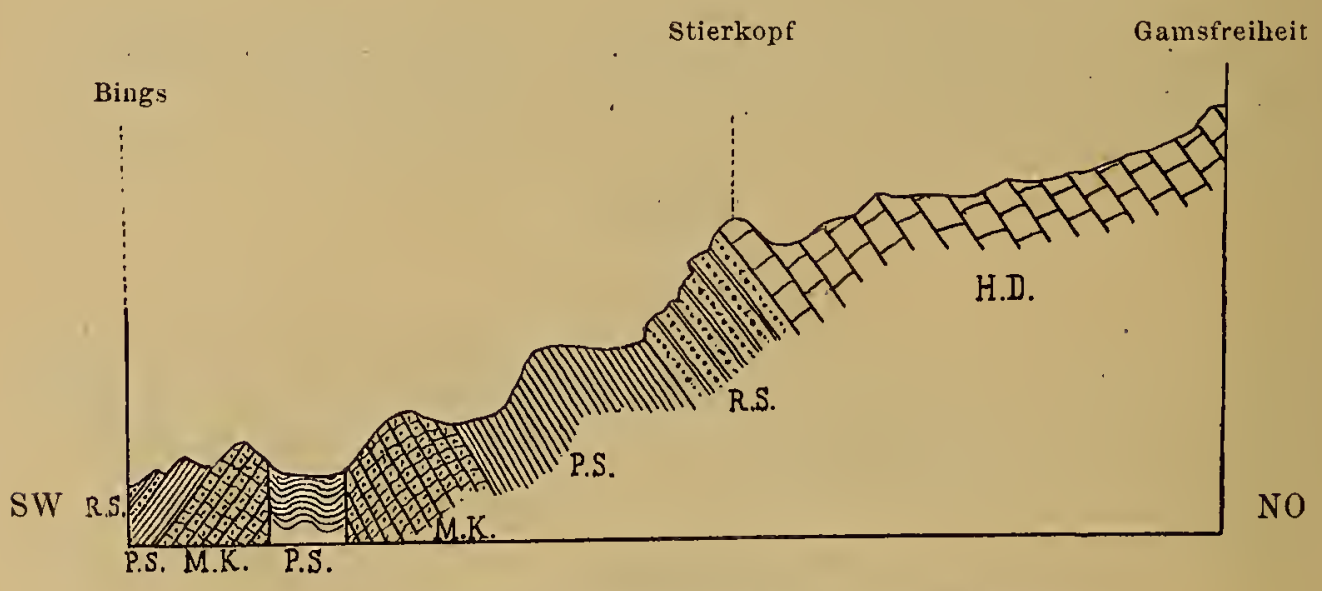

Fig. 1. Von Bings iiler den Stierkopf zur Gamsfreiheit. Maasstab : $1: 50.000$.

M K. = Muschelkalk. P. S = Partnachschichten. R S = Raibler Schichten. H. ' ${ }^{\prime}$ = Hauptdolomit.

Einfachheit in der Tektonik und der Klarheit in der Aufeinanderfolge der Schichten anfangen und sodann zuerst solche im O bis Flirsch, alsdann solche im S im Montafon, und weiterhin nach $\mathrm{W}$ bis nach Vaduz besprechen. 
[17] Ueber die Entwicklung und Verbreitung der Partnachschichten. 161

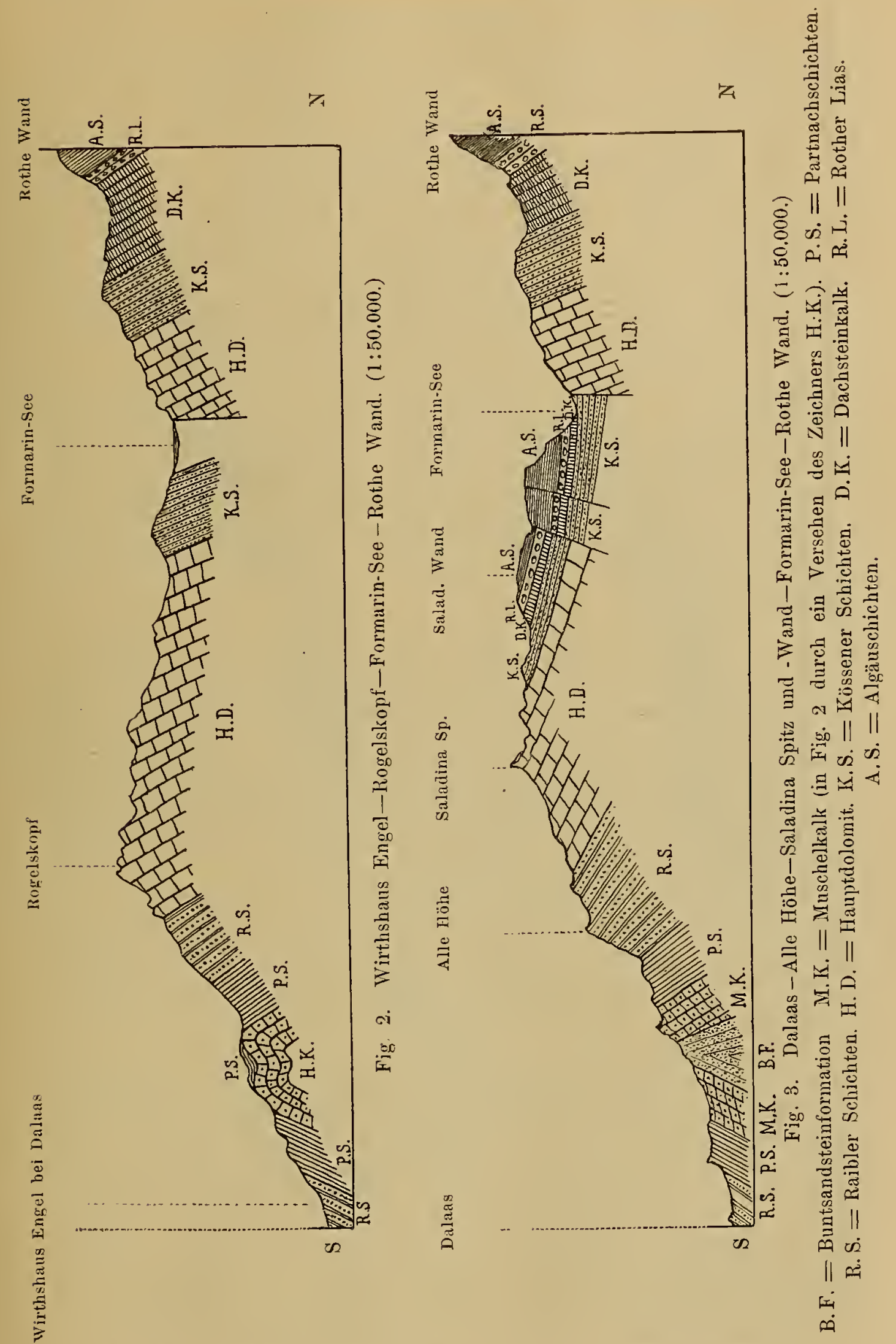

Jahrbuch der k. k. geol. Reichsanstalt, 1893, 43. Band, 1. Heft.(Dr. Th. G. Skuphos.) 21 
1. Das Profil Bings-Stierlkopf-Gamsfreiheit ist von SW nach NO gelegt. Die Schichten bilden einen Sattel, dessen Axe von W nach O: gerichtet und dessen First durch zwei Verwerfungen zerstört ist. Den Kern der Axe bildete msprünglich Muschelkalk; durch die beiden Verwerfungen sank derselbe in die Tiefe, und so finden wir in dem eingesunkenen Firste die Partnachschichten.

Im südlichen Flügel, dessen Schichten N $80^{\circ} \mathrm{W}$ streichen und mit $75^{\circ}$ SSO einfallen, folgen über dem Muschelkalk, welcher im Steinbruch bei St. Leonhard vorzüglich aufgeschlossen ist, die Partnachschichten, welche die steilen Wiesen des Gasünd bilden, und über diesen die untersten Raibler Kalke, welche durch die Eisenbahn angeschnitten sind. Die beiden Verwerfungen haben die Partnachschichten am Höllwald als zweites Torkommen eingesenkt.

Im nördlichen Flügel liegen auf dem Muschelkalk, der den Hügel zwischen Höllwald und Grubsbach bildet, die Partnachschichten im Thälchen des Grubsbachs und an der unteren Hülfte der südlichen Abhänge des Stierkopfs, darüber die Raibler Schichten, welche die obere Hälfte der Abhänge bilden, und schliesslich der Hauptdolomit als ein mächtiger Zug im Stierkopf, in der Gamsfreiheit, im Weissen Rössl, in den Pitschiköpfen u. s. w. Sämmtliche Schichten des nördlichen Flügels streichen N $82^{\circ} \mathrm{W}$ und fallen $50^{\circ}-80^{\circ} \mathrm{NNO}$ ein, und zwar die älteren Schichten steiler (M. K. 80), die jüngeren flacher (H.D. 500).

2. Das zweite Profil: Gasthaus Engel bei Dalaas-RogelskopfFormarinsee-Rothe Wand hat die Richtung von S nach $\mathrm{N}$. Wir haben es auch hier mit einem Sattel zu thun, dlessen First zwar nicht durch Verwerfungen gestört ist, aber in Folge einer Faltung, der älteren Schichten (M.K.) eine Sattelmulde bildet. Dagegen ist der nördliche Flügel am Formarin-See selbst durch eine Verwerfung ab)geschnitten. Die Axe des Sattels hat die Richtung von NO nach SW, so dass man sagen kann, der ganze Sattel ändert mit dem Verlauf des Klosterthals auch seine Richtung.

In diesem Profil ist der südliche Flügel ebenfalls selır kurz, der nördliche dagegen sehr lang. Den Kiern der Axe bildet der Muschelkalk, südlich und nördlich folgen auf ibm die jüngeren Schichten, und zwar im südlichen Flügel in derselben Weise wie in Profil 1. In der Sattelmulde liegen die wenig mächtigen Partnachschichten.

Im nördlichen Flügel folgen auf die Partnachschichten, die NW von Hintel-Gantegg vorzüglich aufgeschlossen sind, die Raibler Schichten an den steilen südlichen Abhängen des Rogelskopfes, dann der Hauptdolomit, welcher den Rogelskopf mit seinen siirllichen, westlichen und nördlichen scharfen Kämmen bildet. In einer kesselartigen Einsenkung des Hochplateaus, in der auch der Formarin-See liegt, finden wir auf dem Hauptdolomit die Kössener Schichten. In Folge einer Verwerfung, die längs dem nördlichen Ufer des Seees verläuft, wiedlerholt sich die Reihenfolge der Schichten. An den steilen $\Lambda$ bhängen am Sürlufer haben wil somit wieder den Hauptdolomit mit flachem NO-Einfillen, darauf die Kössenel Schichten unterhalb des 
[19] Ueber die Entwicklung und Verbreitung der Partuachschichten. 163

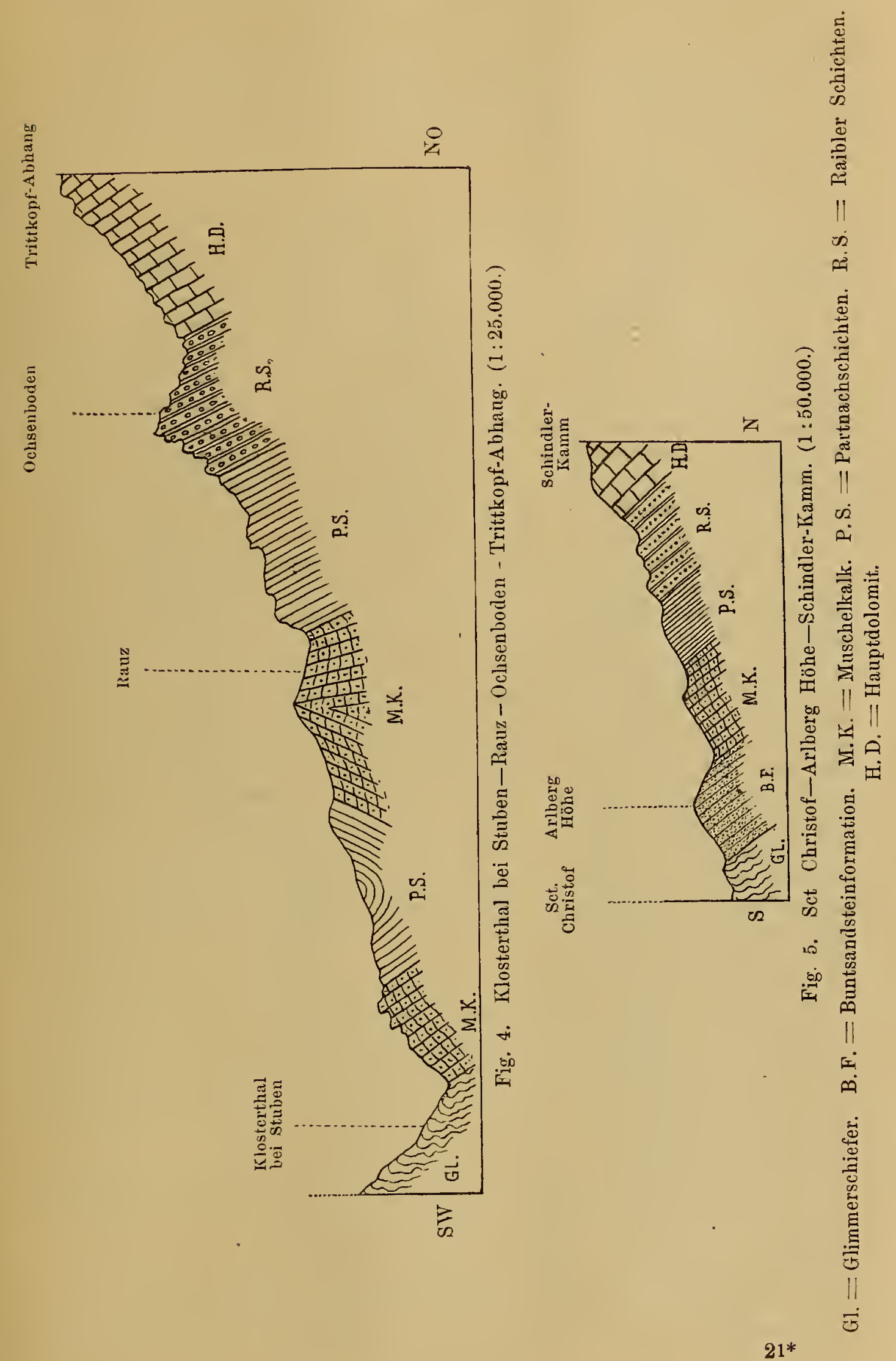


Rothhorns, daun den Iachsteinkalk, an der Rothen Wand und dem Rothhorn die rothen Liaskalke und Algäuschichten, welche die senkrechten oberen Wände der Rothen Wand und des Rothhorn bilden.

Die Schichten beider Flügel streichen N $60^{\circ}-70^{\circ} \mathrm{O}$ und fallen $50^{\circ}-70^{\circ} \mathrm{SW}$ respect. NO ein, und zwar wieder die älteren Schichten steiler als die jüngeren.

3. Das dritte Profil liegt zwar unweit des zweiten, jedoch ist der Unterschied zwischen ihmen ein so auffallender, dass ich es besprechen möchte. Es ist von $\mathrm{S}$ nach $\mathrm{N}$ gelegt: von Dalaas über Marias Abhang, Saladinaspitz und -Wand und Rothe Wand.

Im Kern des Sattels, mit dem wir es hier wiederum zu thun haben, dessen Axe eine fast WO-Richtung hat, erscheint die Buntsandsteinformation. Der südliche Flügel ist hier gleichfalls bedeutend kürzer als der nördliche. Der erstere besteht aus der Buntsandsteinformation, welche an Marias Abhang sehr gut aufgeschlossen ist, dem Muschelkalk, welcher bis an das Gasthaus zum Paradies reicht, den Partnaclıschichten, welche die kleinen Hügel nördlich vom Dorfe Dalaas bilden, und schliesslich den Raibler Kalken mit aufgelagertem Raibler Mergel. Letzterer ist neben dem Gasthaus zur Post gut aufgeschlossen.

Im nördlichen Flügel folgen auf die Bundsandsteinformation an Marias Abhang die Muschelkalkbänke an den steilen Abhängen der Alle Höhe, damn die Partnachschichten und Raibler Schichten, welche letztere bis an den Masonkamm reichen, darauf der Hauptdolomit, welcher die Saladinaspitze und einen Theil der Saladinawand bildet. sodann die Kössener Schichten, der Dachsteinkalk, die rothen Liaskalke und zum Schluss die Algäuschichten im oberen Theil der Saladinawand. Sämmtliche Formationsglieder sind, vom Hauptdolomit an, an den steilen Abhängen des kesselartig eingesenkten Formarinsees aufgeschlossen, so dass die Aufeinanderfolge von den Kössener Schichten bis zu den Algäuschichten hinauf deutlich zu verfolgen ist. Durch die Verwerfung, welche wir schon im vorher beschriebenen Protil erwähnt haben, sind die erwähnten Schichten scharf nach Norden abgeschnitten. An ihr fülnt entlang der Fussweg zur Formarinalp. Die Fortsetzung des Profiles ist von hier an eigentlich nur eine Wiederholung des zweiten Profiles.

Bevor ich dieses Profil abschliesse, möchte ich noch daranf hinweisen, dass man die Saladinawand an besten von Unter Wald bei Dalaas durch den Radonatobl über die Mehrenalpe und Alle Höhe erreicht. Die Saladinawand zeigt in Folge zweier kleiner Verwerfungen eine treppenartige Absenkung, die sich schon von der Mehrenalye aus beobachten lässt, indem die in verschiedenen Höhenlagen befindlichen rothen Liaskalke sich deutlich markiren.

Ferner sieht man beim Aufstieg vom Radonatobl auf die Mehrenalpe ein gut aufgeschlossenes Profil zwischen Thannecker-Plattenwald und der Arlbergbahn. Man erkemnt darin deutlich die antiklinale Wölbung der Schichten, ebenso wie am Rogelskopfe.

Die grosse Verwerfung, welche wir in den beiden letzten Profilen kemnen gelernt haben und welche entlang des Formarinsees in der Richtung vou WO verläuft, hat die Bildung des Formarinsees 
[21] Ueber die Entwicklung und Verbreitung der Partnachschichten. 165

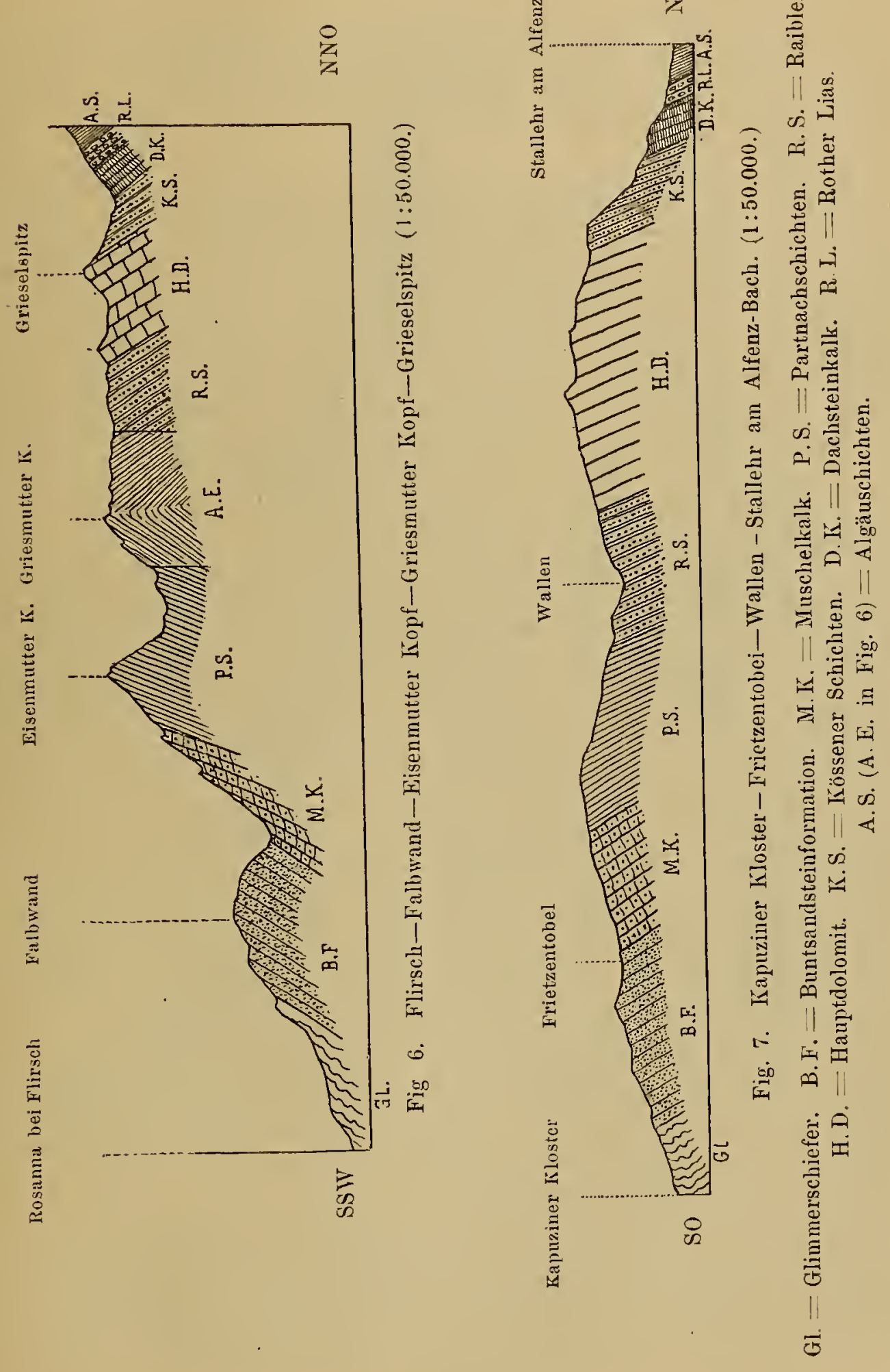


verursacht. Der Ausfinss des Sees ist unterirdisch; erst weiterhin nach Osten im Radonatobl sieht man plötzlich ans der Wand eine Wassermenge herausfliessen, welche lıöchstwahrscheinlich von dem See stammt.

4. Das Profil Stuben-Rauz-Ochsenboden-Trittkopfabhang ist in der Richtung SW nach NO gelegt und setzt sich zusammen aus einer Mulde, die aus Muschelkalk und Partnachschichten gebildet wird, und aus einem Sattel, welcher die Fortsetzung des in den Profilen $1-3$ bescluriebeuen ist.

Der kleinen Mulde gehören die Vorberge, welche bei Stuben in das Klosterthal hereinspringen, an. Am Rauzbach treten eigenthümlich schieferartige, von Kalkspathadern durchgezogene Thongebilde auf, darauf folgen die ächten Muschelkalkbänke, welche durch die in Serpentinen geführte Landstrasse angeschnitten sind, darauf die Partnachschichten. Diese drei Glieder bilden den südlichen Flügel der Mulde. Ihr nördlicher Flügel, welcher aus Partnachschichten und Muschelkalk bestelit, ist gleichzeitig der südliche Flügel des grossen Sattels, welchen wir schon bei Bings in der Nähe von Bludenz kennen gelerut haben und welcher das ganze Klosterthal durchzieht.

Der First des Sattels, dessen Flügel mit $75^{\circ}-85^{\circ}$ nach Süden resp. nach Norden einfallen, ist durch Denudation abgetragen und erscheint daher nicht mehr als Wölbung.

Der nördliche Flügel besteht 1. aus dem vorhergenamuten Muschelkalk. welcher in den Steinbrüchen bei Flexen und Rauz mit südlichem und nördlichem Einfallen aufgeschlossen ist, 2. aus den Partuachschichten, welche bis au die fast senkrecht stelienden Raibler Kalke des Passes mach Zurs u. s. w. leichen, 3. aus den Raibler Schichten in ihrer vollen Entwicklung, die bis zur Ochsenbodenalp reichen, und schliesslich 4. aus dem Hauptdolomit, welcher die Abhänge des Trittkopfes bildet.

Aus diesen vier Profilen ersehen wir, dass der grosse Sattel, der sich entlang des Klosterthals hinzieht, in seinem Verlauf vou W nach $O$ verschiedenartig ansgebildet ist. Aus dem ersten (1.) Profil ersehen wir, dass durch die zwei Verwerfungen, die im First des Sattels weiter nach Osten hin (bis etwas vor der Eisenbalnustation Hintergasse) verlaufen, und durch spätere Abtragungen der südliche Flügel gleich östlich von St. Leouhard-vollstïndig zerstört ist, wodmrch das verhältuissmässig breite Thal bei Braz entstanden ist.

Aus dem zweiten (2.) Profil erlrellt, dass der Sattel hier zwar wieder vollständig und nicht durch Verwerfungen zerstört ist, dass er aber eine kleine Sattelmulde enthäl, ferner, dass sein nördlicher Flïgel am Formarinsee durch eine Ver'werfung abgeschnitten wird, so dass sich die Schichten vom Hauptdolomit an bis zu den Algänschichten noch einmal wierlerholen.

Aus dem dritten (3.) Profile ergibt sich, dass 1. an dem Kern des Sattels sich anch ältere Formationsglieder, als die Buntsandsteinformation, betheiligen, 2. dass der nördliche Flügel ebenfalls durch die oben erwälnute Verwerfung abgeschnitten ist, dass so der.Formarinsee entstand mid 3. dass ansserdem an der Saladinawand treppen- 

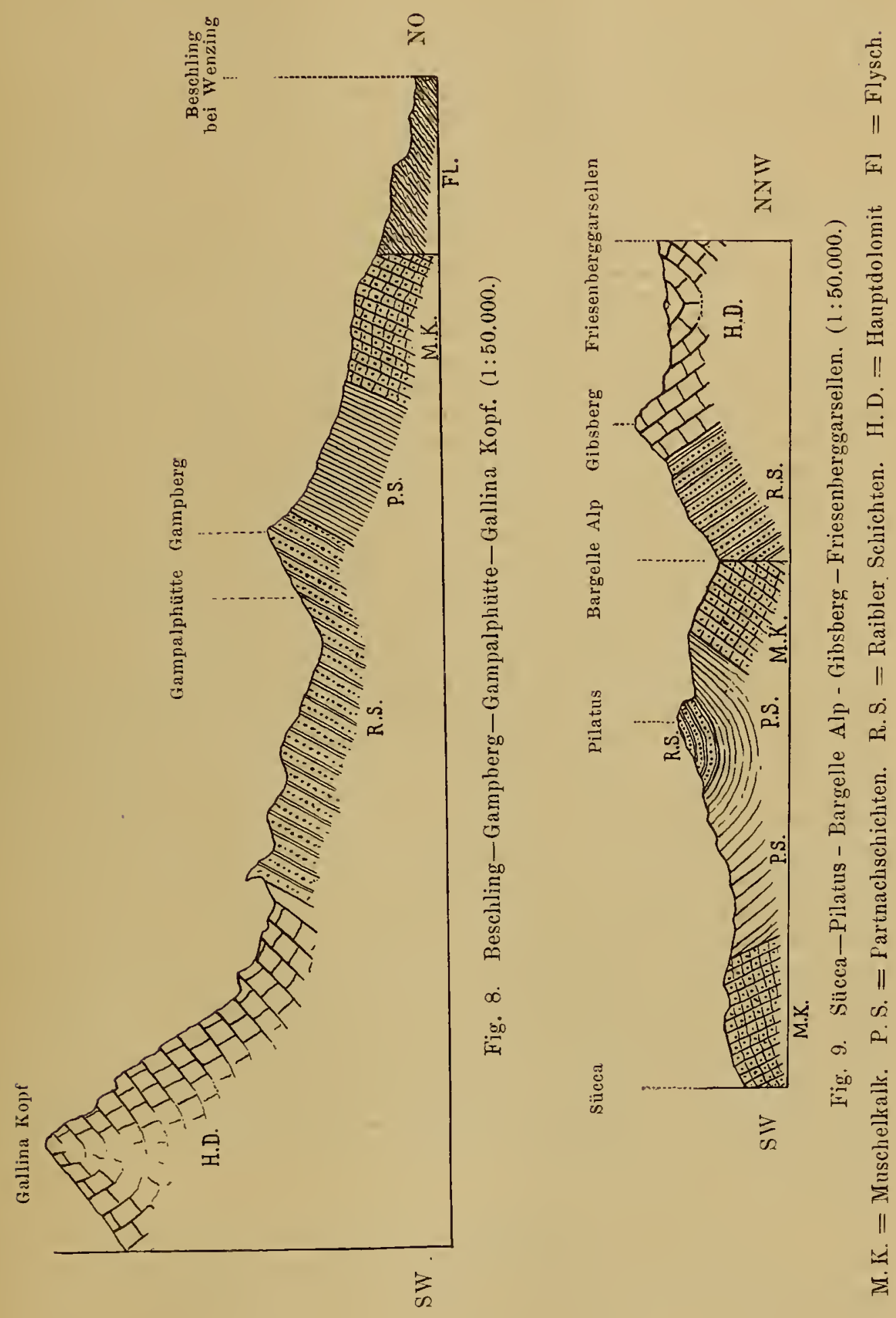
förmige Absenkungen der Schichten durch zwei kleine Verwerfungen stattgefunden haben. Von hier an ist weiter östlich die Wölbung des Sattels zum Theil abgetragen oder befindet sich noch im Stadium der Zerstörung, wie nämlich der Bergsturz bei Klösterle-Langen ') gezeigt hat; hierïber Näheres am Schlusse dieses Theiles.

Im vierten (4.) Profile ist der Sattel wieder völlig vorhanden und sein südlicher Flügel zu einer kleinen Mulde zusammengefaltet.

Etwas NNO von Stuben, in der Höhe der Walfayer Alp, bekommen wir einen Fingerzeig über die Ursachen der Bergstürze, welche im Kilosterthal sowohl in früherer Zeit als anch im verflossenen Sommer stattgefunclen haben nod noch in Zukunft stattfinden werden.

Die Höhe der Walfayer Alp bildet den First des weiter verlaufenden Sattels und besteht aus Muschelkalk. Dieses Hochplateau ist durch Spalten in allen Richtmingen so zemissen, dass man bei seiner Durchquerung jeden Augenblick in Verlegenheit kommt, welche Richtung man zu nehmen hat, um glücklich dem Spaltengewirr zu entkommen. Die längeren und tieferen Kilüfte verlanfen von NO nach SW, verschiedene andere, kürzere und längere nach allen möglichen Richtungen. Die Länge, Breite und Tiefe dieser Spalten ist rerschierlen. Die Länge schwankt von ein Paar Metern bis zu 50,80 Meter und melır, die Tiefe ebenfalls von wenigen bis zu 10 und 15 Meter. Sie sind mehr oder weniger mit Schutt erfüllt. Hervorzuheben ist, dass man beim Gehen auf diesem Platean ein eigentlinmliches Geräusch wie beim Auftreten auf hohlen Wölbungen lıört.

Fs verstelit sich von selbst, dass in einem solchen Gebiete, wo der First des Sattels aus steil einfallenden Flïgeln besteht und sich darauf solche Spalten und Risse befinden, das Wasser, der Schnee, überhaupt der Wechsel der Jahreszeiten nach und nach sowohl mechanisch wie anch chemisch einwirken und sich in Folge dessen die Spalten erweiter'n und vertiefen; schliesslich sind die zwischen den mehr oder weniger dümmbankigen Kalken liegenden Mergel genıg erweicht, bis dlann auf einmal grosse Theile des südlichen Flügels herunterstïrzen.

Auf diese Weise ist der Bergsturz von Klösterle-Langen rom vorigen Sommer zu erklären. So wird auch frühıer oder später der südliche Flïgel der Walfayer Höhe herunter nach Rauz stürzen und dasselbe wird ancl bei der Eisenbalmstation Hintergasse stattfinden. Auf diese Wreise ist die Erweiterung des Klosterthals zu erklären, wie z. B. zwischen Bings und Hintergasse, bei Dalaas u. s. w. Thatsächlich ist auch überall da, wo das klosterthal breit ist, unser Sattel zerstört und sein südlicher Flügel nicht mehr zu beobachten, weil er von Thalschutt berleckt ist, wie man dies an dem Bergsturz KilösterleLangen sehen kann.

5. Das Profil: St. Cluistof-Arlberg Höhe-Schindlerkamm, das von $S$ nach $N$ gerichtet ist, stellt den siidlichen Flügel einer Mulde vor, deren nördlicher Flügel in dem ron uns untersuchten Gebiet

1) J. Blaas: Bericht über den am 9. Juli 1892 bei Langen am Arlberg niedergegangenen Bergsturz (Verhandl. d. k. k. geolog. R.-A. 1892, pag. 261-266.) 
fehlt. Auf dem kiystallinischen Gebirge liegt die Buntsandsteinformation der Arlberg Höhe, daranf der Muschelkalk an dem untersten Theil der Abhänge des nördlichen Ufers des Steisshaches. Auf die zum 'Theil mit Vegetation berleckten Nuschelkalkbänke folgen unter den steilen Wiesen die Partnachschichten, dann die Raibler Schichten, die in ihrer ganzen Eutwicklumg anfgeschlossen sind. Aus Hauptdolomit bestehen die zackigen Kämme der Schindlerspitz. Sämmtliche Srhichten streichen $\mathrm{N}^{\mathrm{N}} 45^{\circ} \mathrm{O}$ und fallen $65^{\circ}-80^{\circ} \mathrm{NO}$ ein.

6. Das Profil: Rosamna bei Flirsch-Eisemmutterkopf-Griesmutterkopf-Griesspitz ist von SSIr nach NNO gelegt. Wir haben hier in seinem ersten Abschnitt eine Ueberkippung, an welcher die krystallinischen Schichten (?), die Buntsandsteinformation, der Muschelkalk und die Partnachschichten Theil genommen haben. Durch zwei Verwerfungen sind die Algäuschichten und die Triasformation eingesenkt, und zwar' so. dass sie für sich selbst zu einem Sattel gefaltet sind, dessen First mit dem Griesmutterkopf zusammentrifft. Im zweiten Abschnitt, jenscits der Verwerfungen, folgen normal alle Formationsglieder ron den Raibler Schichten bis zu den Algäuschichten.

Ans den Profilen 5 und 6 ersehen wir, dass der vom Klosterthal her bekamite Sattel nicht mehr ausserhalb Vorarlberg fortsetzt, sondern, dass die Triasformation etc. in Folge von Störungen im Profile 5 als der Flïgel einer Mulde vorhanden sind, denn weiter nach Osten liu ist, wie Profil 6 zeigt, der nördliche Flügel des Sattels ganz normal entwickelt, dagegen der südliche als Ueberkippung vorhanden und durch die Einsenliung der Algänschichten unterbrochen.

Kehren wir jetzt nach Vorarlberg zurück, un den Theil der Sedimentgesteine im Montafon zu besprechen, welche nordöstlich des Ill liegen.

7. Das Profil: Stallelir am Alfenzbach-Wallen bei St. AntonFrizentobl-Kapuzinerkloster im Moutafon ist ron NW nach SO gelegt. Wir haben es hier mit einer Mulde zn thun, deren nördliche Flïgel zum Theil durch die grosse Verwerfung: welche entlang des Klosterthals verläuft, abgeschnitten ist, da die ganze Reilıenfolge zum Theil ron den Rajbler Schichten bis zu den Algäuschichten hier fehlt. Dieses Profil steht in directer Verbindmug mit dem Profil 1, dessen südlicher Flügel der zerstörte uördliche Flügel unserer Mulde ist, so dass am Anfang und Ende des Klosterthals entsprechende tektonische Bildungen (vergl. Profil Nr. 4) stattgefunden laben. Der einzige Unterschied liegt darin, dass an der Bildung der Mulde des Profils Nr. 4 nur Muschelkalk und Partnachschichten, dagegen hier anch noch viel jüngere Schichten (bis zu den Algäuschichten) theilgenommen haben. Ferner ist der Nittelflügel im Profil 4 unzerstört geblieben. hier dagegen durch die schon erwähnte Klosterthalverwerfung zerstört.

Die Schichten des südlichen Flügels, welche fast von W nach O streichen und $\mathrm{N}^{70}$ einfallen, ziehen durch die keilförmige Scholle hindurch und stossen mit ihrem östlichen Ende an das krystallinische Gebirge dles Kristbergs u. s. w., ziehen dagegen mit südwestlicher Biegung weiter im Montafon bis zum Rhätikou. 
8. Das Profil : Beschling bei Nenzig-Gampberg-GampalphütteGallinakopf, welches von NO nach SW verläuft, gibt uns mit dem folgenden Profile (Nr.9) einen allgemeinen Ueberblick über den Anfban des westlichen Theiles unseres Gebietes. Es geht durch den nördlichen Flügel einer seln ausgedehnten Mulde. Ihren Kerm bildet der Hauptdolomit des Gallinakopfes; ihre Axe verlänft von W nach $\mathrm{O}$; die Schichten streichen $\mathrm{N} 82^{\circ} \mathrm{W}$ und fallen $\mathrm{S} 40^{\circ}-50^{\circ}$ ein. An den südlichen Abhängen des Gallinakopfes fallen die: Hauptdolomitbänke $N 45^{\circ}$ ein, so dass schon am Gallinakopf selbst ein verschiedenes Einfallen der Schichten beobachtet werden kann.

Gleich an der Verwerfung, welche die Flysch-Zone bei Beschling u. s. W. von der Triasformation tremnt, tritt Muschelkalk auf, welcher die nördlichen Abhänge des Gamplerg bildet, darüber folgen die Partnachschichten, welche fast bis zur Gampberg Höbe reichen und von den vorzüglich entwickelten und anfgeschlossenen Raibler Schichten überlagert werden. Diese sind hier ihrer Verbreitung und Ausbildurg wegen voln grossem Interesse. Schon landschaftlich fallen sie sowohl durch die hohen Rauchwackepyramiden als anch durch die kesselförmigen Tertiefungen an den Stellen, wo der Gyps ausgelaugt worden ist, auf. Es folgt der Hauptdolomit des Gallinakopfes, welcher muldenförmig nach Norden und Süden einfällt.

9. Das Profil im Fürstenthum Liechtenstein: Saminathal-Sücca (Curort) - Pilatus - Bargellealp - Gijsberg - Friesenberggarsellen, welches von SSO nach NNII gertegt, stellt eine kleine Mulde und den südlichen Flügel der vorher besprochenen Mulde vor. Der Bergkamm, welcher an Fürke, an der südlichen Grenze des Fürstenthums Liechtenstein und der nördlichen Grenze der Schweiz anfängt. und das ganze Fürstenthum von Süden nach Norden durchzieht, gibt uns in Verbindung mit dem Saminathal Gelegenheit, die kleine Mulde am Sücca-Pilatus in unserem Profil eingehend kemnen zu lemen. Diese Bodenconfignration legt sämmtliche Formationsglieder von allen Seiten frei. Die Schichten ihres südlichen Flügels der kleinen Mulde streichen $\mathrm{N}^{\top} 60^{\circ} \mathrm{TT}$ und fallen $45^{\circ}-60^{\circ} \mathrm{NNTT}$ ein: an ihrem Aufban nehmen Muschelkalk, Partnachschichten und Raibler Schichten Theil: die Buntsandsteinformation, welche am Triesnerberg anfgeschlossen zu sein scheint, haben wir nicht in unser Profil mit eingezogen, da wir sie am Saminathal nirgends anstehend, sondern nur umherliegende Blöcke gesehen haben.

Die Raibler Schichten schliessen an der Pilatusspitze anch die Megalodon führende Dolomitbank ein. Die Schichten des nördlichen Flügels streichen wie die des südlichen, nur fallen sie etwas steiler mach SSO ein.

Diese kleine Mulde stösst durch eine Terwerfung an den südlichen Flügel der im Profil 8 erwähnten Mulde. Die Schichten dieses Flïgels bestehen nur aus Raibler Schichten und Hauptdolomit, sie streichen von $\mathrm{IT}^{\mathrm{r}}$ nach $\mathrm{O}$ und fallen mit $50^{\circ}-60^{\circ} \mathrm{N}$ ein. In diesem Profil bildet der Hamptdolomit ebenfalls den liern der Mulde.

Wohl haben wir mit diesen Profilen nicht alle tektonischen Verhältnisse elschöpft, da unser Gebiet an verschiedenen Stellen noch 
viele Längs- und Querverwerfungen durchstreichen, die erst durch weitere geologische Aufnahmen in Maassstabe 1:25.000 hervortreten würden.

\section{Palaeontologischer Theil.}

In dieser Abtheilung werden wil ausser den Velsteinerungen, welche in den Partnachschichten entweder zum ersten Mal anftreten oder dur'h ihre Vorkommen uns Veranlassung zur Besprechung geben, noch zwei aus den Schichten mit Natica Stunensis Pichler stammende Fossilien und eines aus den Raibler Schichten berïcksichtigen.

\section{Brachiopoden.}

\section{Lingula Christomani nov. spec.}

Taf. V, Fig. $3-10$.

In den Partnachschichten an Masonfall bei Braz kommt eine diumbankige Mergelschichte vor, welche ganz erfüllt ist mit einer Lingula, die sich von den bisher beschriebenen Arten specifisch unterscheidet.

I)er Umriss unserer Limgula Christomuni ist oval. Der Wirbel ist spitzig, die Wirbelkanten bilden einen Winkel von $75^{\circ}$, die Seiten der Klappen und der Stirnrand bilden zusammen eine Curve. Die Schale ist sehr dünn, hornig, glänzend und mit ziemlich dichtstehenden Anwachsstreifen bedeckt. Lingula Christomuni ist fast gleichklappig; die Schalen sind schwach gewölbt.

In nerer Ba der Dorsalschale: Im Grunde des Schnabels befindet sich ein runder Muskeleindruck, unterhalb dieses Eindruckes beginnt die dicke Medianleiste, welche sich fast bis zum Stirnrand hinunterzieht. Links und rechts davon liegen zwei kräftige, grosse, ovale Schliessmuskeleindrücke. Zwei Furchen, welche parallel zu den Wirbelkanten bogenartig verlaufen, treffen in der Mitte der Klappe zusammen; sie schliessen den Theil der Schale ein, in welchem das Thier sass. Zwischen diesen Furchen liegen zwei kleine, ovale Muskeleindrücke, ferner links und rechts der Medianleiste ebenfalls zwei rundliche bis ovale Muskeleindrücke.

Lingula Christomani hat eine gewisse Aehnlichkeit mit der Lingrula temissimu Bronn, unterscheidet sich aber von dieser erheblich; die letztere hat eine hochgevölbte Schale, welche sich vom Stirnrand gegen den Wirbel hin allmählich zusplitzt (s. Beschreibung und Abbikdung Bron n, Taf. XIII, Fig. 6, pag. j1). Ferner unterscheiden sich beide Arten durch den oben beschriebenen inneren Bau der Dorsalschale.

Die Lingula Zenlieri von A lb e l'ti unterscheidet sich von Limgula C'mistomani durch ihre mehr oder weniger vierseitige und sehr tlache Form. Bei ihr ist der Stimrand fast gerade, seine Enden sind abgerundet; die Seitencommissuren verlaufen fast parallel. Die Schloss- 
linie geht kreisförmig in die Seitencommissur über. Der Wirbel ist spitzig, jedoch bilklen die Wirbelkanten einen Winkel von ca. 105". Ferner unterscheidet sie sich durch den inneren Bau der Dorsalschale. Diese zeigt bei ihr eine Medianleiste, welche von dem Wirbel bis zum Stirmrand reicht und fächerförmig ausstrablt. Weitere Unterschiede bestehen in der Anordnung der Muskeleindrücke, welche eine andere Gestalt haben und in abweichender Weise getheilt sind.

Zum Vergleich bilden wir auf Taf. V, Fig. 13, 14 zwei Limmula temissima Bronn aus der Buntsandsteinformation (Werfener Schichten) von Hammerstiel bei Berchtesgaden (Münchener Staatsmuseum) ab, sowie Fig. 11, 12 drei Lingula Zenkeri von Alberti, von denen die eine den inneren Bau der Dorsalschale von oben gesehen zeigt. Sie stammen aus dem dolomitischen Keupermergel der Steinbrüche bei Sinsheim in Baden (aus der Privatsammlung des Herrn Dr. A. Rothpletz).

Diese Species benenue ich zu Ehren meines Lehrers, Herrn Prof. Christomanos zu Athen.

\section{Spiriferina Lipoldi Bittner.}

1890. Spiriferina Lipoldi Bittner. Brachiopoden der alpinen Trias, pag. 139, Tab. XXVIII, F'ig. 20 und 21.

Aus den Partnachschichten von Flexen bei Stuben liegen mir 20 Stücke vor, welche ich zusammen mit Retzia Bittneri nov. spec. gefunden habe. Sie stimmen mit Bittn e r's Spiriferinci Lipoldi überein. Es sind fast nur einzelne Schalen. Einige Exemplare sind zwar zweiklappig, aber immer ein wenig verdrïckt. Sie sind im Allgemeinen ein wenig keiner, als die von Bittner beschriebenen nnd abgebildeten Exemplare. -

\section{Spiriferina Lipoldi Bittner nov. var. hemicycla.}

Taf. V, Fig. 15, $15 a-d$.

Umriss: Langoval mit einer Neigung zum dreieckigen.

Commissur: An der Seite sowohl wie an der Stirn stark gezackt und an letzterer eine schwache Curve beschreibend.

Grosse Schale: Hoch gewölbt, ein Sinus zielıt sich vom Schnabel bis zur Stirn, in ihm liegt eine secundäre Rippe, welche nach der Stirn zn dieselbe Höhe wie die anderen amnimmt.

K leine Schale: Ebenso stark gewölht wie die grosse: der secundären Rippe des Sinus der grossen Schale entspricht eine gespaltene Rippe der kleinen Schale.

Schnabel der grossen Schale mässig hoch und schwach gebogen. Area hoch, mit nicht besonders scharfen Seitenkannten, sie sind abgerundet. Der Schmabel der kleinen Schale ist ebenfalls gut entwickelt; auch hier ist eine Area vorhanden, welche fast lialb so hoch ist wie die der grossen Schale. 
Orı a mentirung: Anf beiden Seiten des Sinus sind je 4-5 Rippen vorhanden, die füntte Rippe bildet jedoch eigentlich nur die begrenzung des leldchens, welches zwischen ihr und der $\Lambda$ realkante liegt. Auf der kileinen Schale besteht der Wulst etwas unterhalb des Schnabels ans einer Ripje, die sich in ilnem Verlauf nach dem Stirmand hin in zwei secmuäre Rippen theilt und der Mittelripue des Simus der grossen Srhale entspricht.

Dimensionen :

$$
\begin{aligned}
& \text { Höhe: } 3{ }^{a} \mathrm{Mm} \text {. } 3.5 \mathrm{Mm} \text {. } \\
& \text { Breite: } 3.6 \mathrm{Nm} \text {. } 4.3 \mathrm{Nm} \text {. } \\
& \text { Dicke: } 2.7 \mathrm{Mm} \text {. } 2.7 \mathrm{Mm} \text {. }
\end{aligned}
$$

Unsere Spiriferinc hat eine grosse Aehnlichkeit mit der von Bittner beschriebenen und abgebildeten Sprifierina Lipoldi, unterscheidet sich aber durch den weniger gebogenen und entwickelten Schnabel der grossen Schale, durch die längere Schlosslinie, in welche die breiteste Stelle unserer Spiriferina fällt, und durch ihre bedeutend kleineren Dimensionen.

Wir betrachten unsere Spiriferina als eine Varietät der Spirifevim Lipoldi Bittuer und geben ihr den Namen hemic!nclu, wegen der vollständig halbkreisförmigen Gestalt des Umıisses der kleinen Schale.

Vorkommen in dem verwitterten rauhmergeligen Kalke der Partnachschichten des Masonfalls bei Braz. \& Stücke, in Limonit umgewandelt.

\section{Retzia Schwageri var. media Bittner.}

$$
\text { Taf. V, F̈ig. } 1 a-e ; 2 a-e .
$$

1870. Retzia Schuageri var. medic Bittner (Brachiopoden der alpinen Trias pag. 164, Tab. XLI, Fig. 12).

Umriss: Langoval mit einer Neigung zum dreieckigen.

C 0 m m is s ur: An der Seite auf dem Lateralfelde gerade, damn gefaltet, an der Stirn stark gezackt ohme Curve.

Grosse Schale mässig gewölbt, Sinus nicht vorhanden.

Kileine Schale stärker gewölbt als die grosse, die drei mittleren Rippen treten wulstartig hervor.

Schnabe l: Hoch, gerade, von Kanten begrenzt, welche eine deutliche Area einschliessen.

Ornamentirung: Auf der grossen Schale sind s scharfe und hohe primäre Rippen und auf der kleinen 9 ebensolche. $\Lambda$ uf dem Steinkern liegt stets in der tiefsten Stelle der Einsenkmugen zwischen je zwei primären Rippen eine feinere gerundete Riple; ferner befinden sich auf der seitlichen Abdachung der mimären Rippen je 3, 4 oder sogar j feinere Rippen, welche längs den primären Rippen verlanfen.

Grösste Breite etwas unterhalb der Mitte. 
Dimensionen der abgebildeten Exemplare von Flexen ( $(1)$ und Wendelstein $(b)$ :

$$
\begin{array}{lll}
\text { Höhe : } 8.6 \mathrm{Mm} . & 7 \cdot 8 \mathrm{Mm} . \\
\text { Breite : } 7.3 \mathrm{Mm} . & 7 \cdot 0 \mathrm{Mm} . \\
\text { Dicke: } 5.6 \mathrm{Mm} . & 4.6 \mathrm{Mm} .
\end{array}
$$

Armgerüste unbekannt.

Auf Bittne r's Originalabbildung ist wohl durch ein Versehen des Zeichners die secundüre Beripyung des Steinkernes micht angedeutet. Ich bilde daher das betreffende Stück noch einmal und zum Vergleiche ancli ein Exemplar von Flexen ab.

Vorkommen: 3 Stiicke aus den Partnachschichten bei Flexen in der Nähe von Stnben (Vorarlberg). Ferner 6 Stiicke aus den Partnachschichten am Soin Grat im Wendelsteingebiet.

\section{Rhynchonella faucensis Rothpletz.}

Taf V, Fig. 19, 20, 21, $21 a, 22,23,23 a-c$.

1862. Terebratula Ramsaneri Beyrich: Vorkommen St. Cassianer Versteinerungen im Calvarienberg bei Füssen pag. 35.

1871. Terebrutula Ramsuneri Quensterlt: Brachiopoden lag. 368.

1886. Rhynchonella faucensis Rothpletz: Vilser Alpen pag. 134, Taf. XIII, Fig. 6, 9-11.

1890. Waldheimia (Crurctuld ta faucensis Roth pl. sp. bei B it tı e r: Brachiopoden der alpinen Trias pag. 204 u. 254, Taf. VII, Fig. 23-26.

1892. Hhynchonella faucensis Skuphos: Stratigraphische Stellung der Partnachschichten u. s. w. in den Nordtiroler und Bair. Alpen. pag. 136.

An zwei verschiedenen Stellen, nämlich am Masonfall bei Braz und am Gamtegg bei Dalaas, fand ich oberhalb der Schichten, in welchen Partunosaurus Zitteli mihi und Microleptosmums Schlosseri milhi vorkommen, ca. 80 Exemplare der Rhynchonella fancensis Rothpletz. Leider sind meistens blos einzelne und zwar hintere Schalen vorhanden; nur 9 Stücke weisen beide Klappen auf. Diese berreisen, dass die von Rothpletz 1886 aufgestellte Rhynchonello faucensis thatsächlich zum Genus Rhyynchonella gelört und nicht zu Waldheiniut, wie Bittne r (loc. cit.) annahm. An dem Fig. 19 abgebildeten Stïick, welches zufällig fast in der Medianebene zerbrochen ist, sehen wir sehr schön die kurzen, säbelförmigen Crura, welche durchaus mit denjenigen der urewöhnlichen Rhynchonellen übereinstimnen. Wir sehen aus demselben Stück, dass die Crura nicht abgebrochen sind; die Species kamm also weder zu Waldheimia noch zu Rhynchonellinu gehören. I)er Schnabel ist an diesem Stäck in seiner ganzen Länge erhalten und zeigt uns, dass an der Spitze kein Foramen vorhanden war. Dasselbe muss also in der Deltidialspalte gelegen sein, wo es aber in Folge des Frhaltungszustandes nicht melur zu sehen ist. Bei sämmtlichen Exemplaren ist die Schale faserig und nie punktirt. Wir kömnen somit die Species nur zu Rhıychonella stellen. 
Hervorzuheben ist, dass Rhynchonell fmucensis stark variirt; sie ist entweder breit dreieckig oder hochoval oder hochdreieckig. Auf der kleinen Schale ist ein langes, hohes Medianseptum sichthar. Ia der Sclmabel sehr hart, spitz und gekrimmt ist, bricht er leicht ab und dam sieht er so ans. wie ihn die Mbbildmngen bei Bittuer und Rotlipletz darstellen.

\section{Lamellibromehirutr.}

\section{Modiola (?) Bölmmi nov. sp.}

\section{Taf. Y, Fig. 24.}

In den lockeren mergeligen Kalken der Schichten mit Naticu Stanensis Pichl. habe ich hei Flinsch in Tirol zusammen mit Myophoria rostatr Z/pml. sp. eine wohlerhaltene linke Klappe dieser nenen Speries gefunden. Sie ist kräftig gewölbt, hat einen hohen gerundeten Rürken und länglichovalen Unmiss. Der Unterrand ist schwach eingehogen, der. Wirbel ist fast terminal gelegen. Unter dem Wirbel befindet sich. durch eine schwache Einsenkung ron dem hinteren Theil der Schale abgetremnt, eine flache Vorwölbung. Eine Muskelleiste, wie sie für Myoconcha charakteristisch ist, lässt sich nicht daranf wahrnehmen. Ans diesem Grunde habe ich die vorliegende Form zu Modiolı gestellt. indessen ist zuzngeben, dass ihre generische Stellung erst nach Untersuchung weiteren Materiales gesichert werden kann. Jedenfalls ist sie aber specifisch von allen bekamnten Modiolu- mol Myoroncha-Formen der Trias verschieden. Die grösste Breite liegt an dem hinteren Ende der Schlosskante. Die Länge der geraden Schlosslinie beträgt $14 \mathrm{Mm}$. die ganze Länge der Schale $30 \mathrm{Mm}$. Ihre breiteste Stelle misst $12 \mathrm{Mm}$. Die Oberfläche ist mit sehr feinen Auwarhsstreifen verziert. Böhm.

Diese Species widme ich meinem Freunde Herru Dr, Johannes in Tirol.

Vorkommen: Schichten mit Natira Stanensis Pichler yon Flirsch

\section{Myophoria costata Zenk. sp.}

Taf. V, Fig. 25, 26.

Da dieses charakteristische Leitfossil der oberen dentschen und alpinen Buntsandsteinformation in meinem Gebiete bisher noch nicht gefunden rar, und da es mir eine genane Altersbestimmung des Schichtencomplexes, aus dem es stammt, ermöglicht, so will ich zwei verhältnissmässig gut erhaltene Exemplare davon abbilden.

Torkommen: Es setzt bei Schnan und Flirsch in Tirol ganze Bänke fast allein zusammen. Bei Flirsch fand ich in denselben Bänken die Modiola Böhmi nov. sp. und einen unbestimmbaren "Myarites". 


\section{Megalodus triqueter Wulfen $s p$.}

Taf. V, Fig. 16, 16 $\alpha, b, 17,18$.

1793. Cardium triquetrum Wrulfen, Abhandlungen von kärntnerischen pfauenschweifigen Helmintholith oder dem sogenannten opalisirenden Muschelmarmor, Erlangen, bei Joh. Jac. Palm.

1862. Megalodon triqueter (pars) Gïmbel, Die Dachsteinbivalve (Megalodon triqueter) und ihre alpinen Verwandten. Sitzungsberichte d. kais. Akad. d. Wiss. Bd. XLT, pag. 362, Taf. III, Fig. 7-8. 1880. Megalodus triqueter Hörues. Innographie der Gattung Megalodus. (Denkschrift d. kais. Akad. d. Wiss. Bd. XL, yag. 22 ff. Taf. I, Fig. 2 und 3.)

1887. Megalodus triqueter $v$. Möhmam, Die Fauna der sogenannten Cardita- und Raibler-Schichten in d. Nordtiroler und bayerischen Alpen. Jahrbuch d. k. k. geolog. Reichsanstalt Bd. 39, pag. 224, Tab. IX, Fig. 24-25.

Wir bilden drei Exemplare des Megalodus triqueter Wulfen sp. von verschiedener Grösse ab, welche in den unteren und oberen Raibler Schichten in Vorarlberg und dem Fürstenthum Liechtenstein vorkommen. Wo sie auftreten, findet man sie immer in grosser Zahl. Leider ist die Erhaltung ungïnstig. Ich fand kein einziges beschaltes Exemplar; indessen stimmen die Steinkerne so vollständig mit den Abbildungen voll $\mathrm{H}$ o e $\mathrm{r}^{\prime} \mathrm{es}$ auf 'Taf. I, Fig. $2 a b c$ und 3 überein, dass kein Zweifel über die Zugehörigkeit unserer Stücke zum echten Megalodus triqueter Wralfer sp. bestehen kamn.

Vorkommen: Raibler Schichten ron dem südlichen Ablange der Gamsfreiheit. Alle Höhe bei Dalaas, Ochsenboden bei Stuben etc.

\section{Reptilien.}

\section{Partanosaurus Zitteli Skuphos.}

Dieses Reptil, das ans den Partnachschichten am Masonfall bei Braz stammt, habe ich in den Abhandhnngen der $k$. k. geologischen Reichsanstalt (1893, Bd. XT., Heft 5) eingehend beschrieben.

\section{Mirroleptosamus Schlosseri Skuphos.}

Ebenda habe ich dieses Fossil beschrieben.

Aus dem Torhergehenden ersehen wir, dass in den Partnachschichten ausser den 55 Versteinerungen, welche bis jetzt ïberhaupt in imen gefunden worden sind, in diesen Gebiet zum erstemmal 5 neue Versteinerungen, und zwar 1. Limyma Christomani nov. sp.. 2. Spriferima Lipoldi Bittner, 3. Spiviferina Lipoldi Bittnev now. var. hemicycla, 4. Protanosaurus Zitteli Shinplios und 5. Wicroleptosaurus Schlosseri Slinphos auftreten. Ton diesen 5 nenen Versteinerungen 
kommt die spiriferina Lipoldi Bittrev auch in den Raibler Schichten, der Patanosunrus Zitteli milhi höchstwahrscheinlich in dem ausseralpinen Muschelkalk-Bonebed ron Crailsheim vor. Die übrigen drei sind bis jetzt nur in den Partuachschichten gefunden worden.

\section{Zusammenfassung.}

Ich möchte in diesem Abschnitte in Kurzem die Ergebnisse der vorhergehenden Untersuchmngen in Torarlberg und im Fürstenthum Liechtenstein geben, welche ron allgemeinem Intelesse sind. Der Uebersicht wegen werde ich sie nach der Reilhenfolge der Schichten ron unten nach oben geben:

1. Unter ver Bezeichnung Buntsandsteinformation bahe ich einen Complex zusammengefasst. welcher von miten mach oben aus folgenden Schichten bestelit: Das was bis jetzt als Verucano bezeichnet wurde mit den Werfener Sthichten ähnlichen Einlagerumgen, die lockeren rersteinerungsfülıenden Mergelkalke und die Rauchwacke. Diese letzteren entsprechen wohl den Mrphorienschichten Rothpletz.

2. Der Name Verucano ist nach meiner Auffassung wenigstens für unser Gebiet nummelir aufzngeben.

3. Der ganze Schichtencomplex mitsammt dem Verrucano etc. gehört zur unteren Trias. wie schon die Bezeichnming Buntsandsteinformation besagt.

4. Der Locahname Virgloriakalk $\mathrm{Richthofen's} \mathrm{ist} \mathrm{gleichfalls}$ aufzugeben, da er nicht ein bestimmtes oberes Glied des Muschelkilks darstellt, sondern in Grossen und Gauzen der Muschelkalk im weiteren Simne ist.

5. Die Partnachschichten liegen in diesem Gebiete ebenfalls stets über dem Muschelkalk. Sie bilden das Hangende des „alpinen Muschelkalks" mud gehören zum oberen "deutschen Muschelkalk". Diese letztere Auffassung erhält ilne Stïtze auch durch das Yorkommen des Partrnosaurms Zittpli im Mlnschelkalk-Bonebed zu Crailsheim.

6. Die Partuachschichten dieses Gebietes sind petrographisch, stratigraphisch und famistisch ident mit denen der Nordtiroler und Bayerischen Alpen.

7. Die Grenze zwischen dem Muschelkalk und den Partnachschichten sind nirgendswo scharf zu ziehen.

8. Sandsteine sind in den Partnachschichten in diesen Gebiet ebenfalls nicht beobachtet.

9. Die Mächtigkeit der Partnachschichten schwillt bis zu $250 \mathrm{Meter}$ an und schwankt gewöhnlich zwischen 15:-200 Meter; es ist also in Vorarlberg und im Fürstenthum Liechtenstein ihre Mächtigkeit eine weit grössere als in den Bayerischen und Nordtiroler Alpen.

10. Ausser in Vorarlberg und im Furstenthum Liechtenstein sind die Partnachschichten durch die nenesten Forschungen Bittner's und Böse's auch im Emsthale in Oberösterreich bei Weyer und in den Hohenschwanganer Alpen nachgewiesen; es ist anzunehmen, dass sie 
nunmehr als ein charakteristischer Oberer Horizont des alpinen Muschelkalks in den nördlichen Ostalpen (vom Fürstenthum Liechtenstein im Westen bis nach [Wien?]) We yer entwickelt sind.

Fs hat sich die in neiner frïheren Arbeit unter 10 ausgesprochene Ansicht, dass die Parallelisirung der Partnachschichten mit den Zlambachschichten im Salzkammergut nicht durchführbar ist, bestätigt, im Gegensatz zu Fraas ${ }^{1}$ ). - Mojsisovics ${ }^{2}$ ) stellt diese wie ich es auch gethan habe, in die rhätische Stufe.

12. Fine Mergelfacies mit Daomella oder Partnachschichten einerseits und eine Kalk- und Mergelfacies mit Konintina oder Cassianer Schichten anderseits, wie sie Fraas in seiner Scenerie der Alpen unterscheidet, ist imnerhalb der Partnachschichten in den nördlichen Ostalpen nicht aufreclit zu halten. Diese Facies sind nirgendswo getremnt entwickelt, sondern überall, wo Partnachschichten vorkommen, wechseln mehr oder weniger sowohl die Tersteinermingen als anch die Gesteinsarten verschiedenartig mit einander. (Vergl. Partnachschichten pag. 153 [im Separatabdruck pag. 9] und meine frühere Arbeit.)

13. Da ich den ganzen Schichtencomplex zwischen Partnachschichten und Hauptdolomit als den Raibler Schichten im weiteren Simue entsprechend nachgewiesen habe, ist nunmehr auch der Name Arlbergkalk aufzugeben.

14. Der Wettersteinkalk fehlt ganz und gar in Vorarlberg und im Fürstenthum Liechtenstein.

15. Es ist möglich, rlass in der Zeit, in welcher der Wettersteinkalk abgelagert wurde, in unserem Gebiete vielleicht der oberste Theil der Partnachschichten und die untersten cavernösen Kalke, welche mit dümnen Mergelschichten wechsellagern und ren Raibler Schichten angehören, zum Absatz kamen. Dahel wäre anch die Grenze zwischen Muschelkalk und Keuper oberhalb dieser cavernösen Raibler Schichten zu ziehen; wemn sich die Vermuthung, dass auch der Wettersteinkalk zur Zeit des ausseralpinen oberen Muschelkalkes abgelagert ist, bestätigt ${ }^{3}$ ).

16. Es unterliegt keinem Zweifel mehr, dass die Partnachschichten zum Muschelkalk gehören. und zwar als ein oberes Glied desselben. Mit den cavernösen untersten Bänken der Raibler Schichten zusammen gehören sie dem ausseralpinen oberen Muschelkalke an (Vergl. Partanosan?us etc.)

1) E. Fraas. Scenerie der Alpen. Tueipzig 1892, pag. 146 n. 147.

$\left.{ }^{2}\right)$ E. v. Mojsisovics. Die Hallstätter Entwicklung der Trias. (Sitzungsbericht d k. Akad. d. Wiss. in Wien. Bd CI. Abth. I, 1892, pag. 775 ff.)

3) Soehen geht mir eine Publication meines Freundes, Herrn Dr. Wilhelm Salom on (Verhandl. d. k. k. geol. Reichsinstalt zn Wien 1893, pag 90) zu, in welcher aut Grund palaeontologischer Untersuchung der Marmolatafanna der Marmolatakalk selbst und ansser diesen der Esinokalk, Schlerndolomit, Wettersteinkalk und das System der Wengener- und Cassianer Schichten mit dem oberen deutschen Muschelkalk parallelisirt werden. 


\section{Tafel I.}

Ueber die systematische Stellung der Trigoniden und die Abstanmung der Nayaden. 


\section{Erklärung der Tafel I.}

Bei beiden Tafeln ist die Bezeichnung der Zähne eine gleiche.

An der linken Klappe:

I. Hauptzahn

a. Vorderzahn.

b. Hinterer äusserer Zahn.

c. Hinterer innerer Zahn bei Unio und Trigonodus.

An der rechten Klappe:

$I^{\prime}$. Hauptzahn

$a^{\prime}$. Vorderzahn der bei Myophoria laeriguta v. Alb., Trigonodus rablensis Gredler sp. fellt, bei Trigonodis problematicus Klipst. sp. nur angedeutet ist.

$b^{\prime}$. Hinterer Zahu.

$c^{c}$. Kleiner Mittelzahn, der bei Crnio decurvatus Rossm. ünd Trigonodus rablensis $\mathrm{Gr}$ rdler $s p$. deutlich zu sehen ist.

Fig. 1. Myophoria fissidentata v. Wö hrm. Schloss der rechten Klappe. Raibler - Schichten vom Haller Anger (Nordtirol), kgl. baier. Staatssammlung.

Fig. 2. Dieselbe. Schloss der linken Klappe.

Fig. 3. Trigonia pectinuta Lam. Schloss der linken Klappe. Lebend aus Australien. Privatsammlung von Prof. v. Zittel.

Fig. 4. Dieselbe. Schloss der rechten Klappe.

Fig. 5. Myophoria laerigata v. Alb. Schloss der linken Klappe. Schaumkalk von Rüdersdorf ; kgl. baier. Staatssammlung.

Fig. 6. Dieselbe. Schloss der rechten Klappe.

Fig. 7. Unio rectus L a m. Schloss der linken Klappe mit getheiltem Hauptzahu Lebend vom Ohio (Nordamerika). Privatsammlung von Prof. v. Zittel.

Fig. 8. Derselbe. Schloss der rechten Krlappe.

Fig. 9. Trigonodus problematicus Klipst. sp. Schloss der linken Klappe. Hilfsnuskeleindrücke sind hier nicht sichthar, da die Eindrïcke ganz mit einer kohligen Substanz ansgefüllt sind

Raibler Schichten. Rio Laváz. Friaul. Sammlung des Istituto tecnico in Udine

Fig. 10. Derselbe. Schloss der rechten Klappe. Vorderer und hinterer Hilfsmuskeleindruck deutlich sichtbar. 
S.Frh.v.Wöhrmanu: Systematische Stellung der Trigoniden etc.

Tat 1.
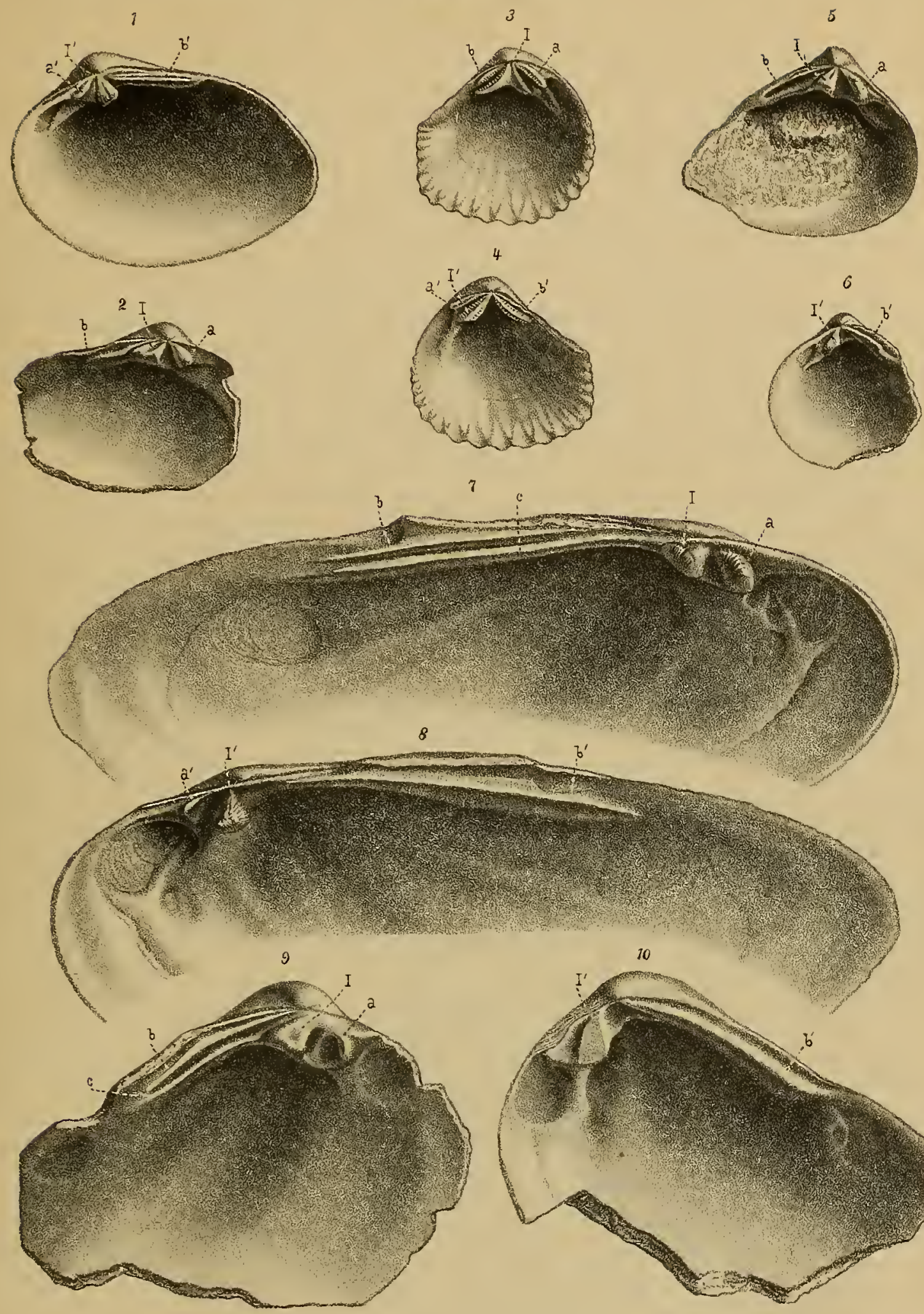

7

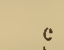





\section{Tafel II.}

Ueber die systematische Stellung der Trigoniden und die Abstammung der Nayaden. 


\section{ErkIärung der TafeI II.}

Fig. 1. Trigonodus rablensis Gredler sp. Schloss der linken Klappe. Raibler Schichten vom Schlern (Südtirol), kgl. baier. Staatssammllung.

Fig. 2. Derselbe. Schloss der rechten Klappe.

Fig. 3. Palaeoneilo constrictus Conrad sp. nach $\mathrm{Ha}$ ll: Palaeontologie Vol. V. part. I. Lamellibranchiata II. Tah. XLVII, Fig. 10. Hamilton group bei Cumberland Md.

Fig. 4. Palaeoneilo (Tellinomya) sinuosus de Ryckhold sp.; um ein Drittel verkleinert nach de Koninck: Faune du Calcaire carbonifére de la Belgique. V. Lamellibranchiata. Tab. XXVI, Fig. 29. Tonrnay (Et. I).

Fig. 5. Palaeomutelo subovalis Amalizky nach Amalizky: Palaeontographica Bd. XXXIX, Tab. XXI, Fig. 3. Sand. Kalkstein bei Nischnj-Nowgorod, Horizont CII.

Fig 6. Palaeoneilo truncatus Hall nach Hall: l. c. Tab. I, Fig. 41. Wawerly group. Bagdad, Ohio.

Fig. 7. Palaeomutela sp. ans den permischen bunten Mergeln bei NischnjNowgorod. Kgl. baier. Staatssammlung.

Fig. 8. Unio decurvatus Rossm. Schloss der rechten Klappe; lebend von Klagenfurt. Privatsammlung von Prof. v. Zittel.

Fig. 9. Derselbe. Schloss der linken Klappe.

Fig. 10. Iridina ovata Swains. Schloss der rechten Klappe mit rudimentären Zähnen. Lebend in Afrika. Privatsammlung von Prof. v. Z it tel.

Fig. 11. Dieselbe. Schloss der linken Klappe, ebenfalls mit rudimentären Zähnen. 

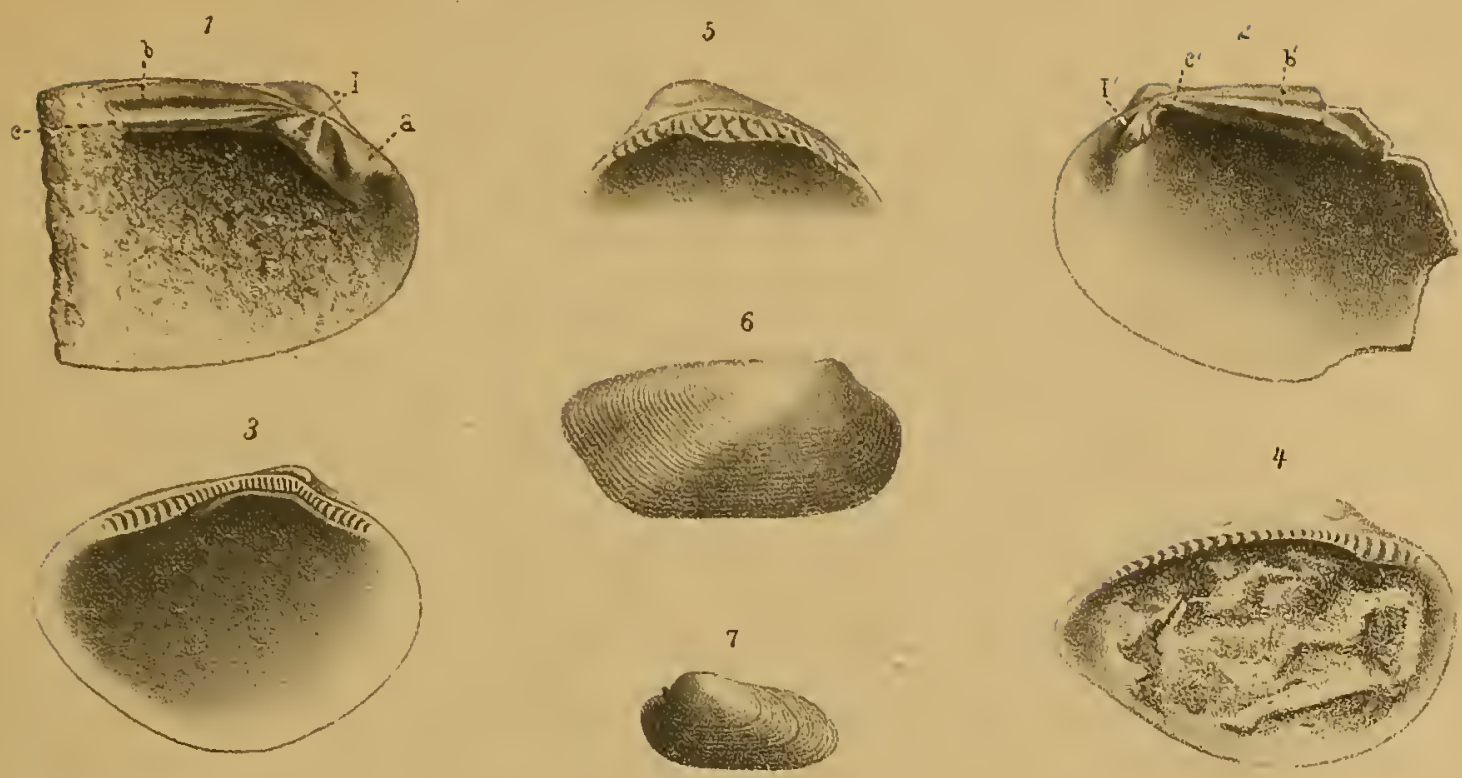

8


d. Birkmaier.n.d.Nat.gez.uz.7ith

Lith.Anst.r. Br: Kellex: Müinchen.

Jahrbuch Re1 k. k. Geologischen Reichsanstalt. Brl.XLIII .1893.

Verlag derk.k.Geologischen Reichsanstalt,Wien, Ill.Rasumoffskygasse 23 

Taf. III.

Horizont

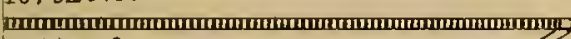

teilauf

,

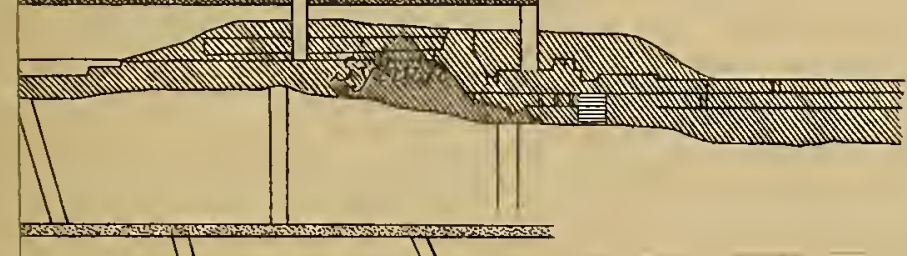



E. Tietze: Die Aussichten des Bergbaues auf Kalisalze in Ostgalizien.

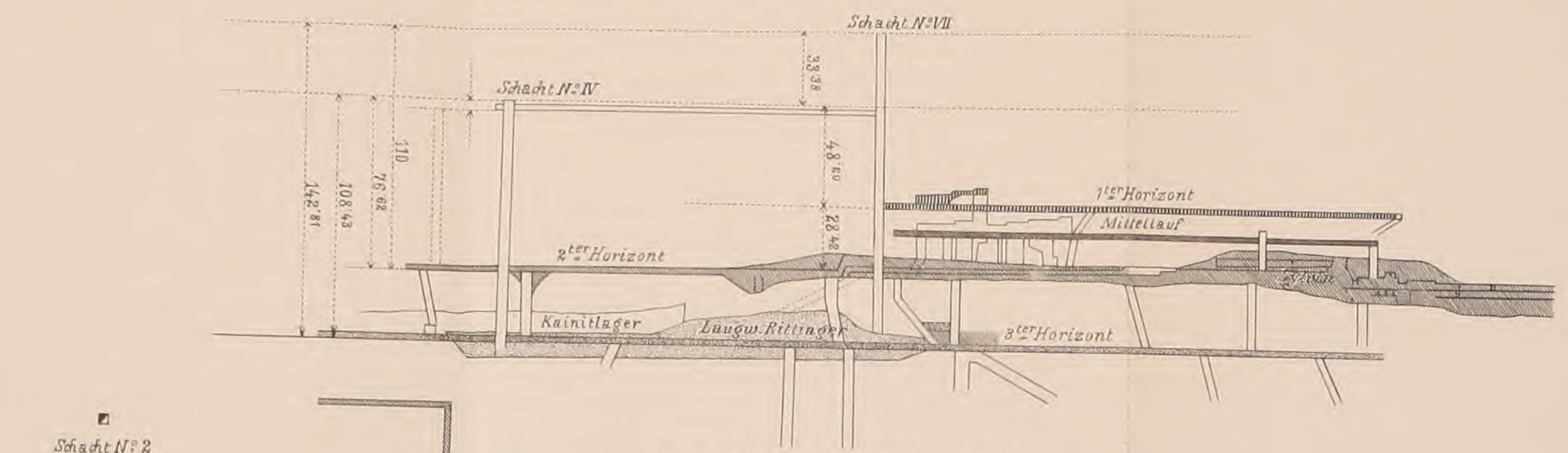

Fig. 2: PROFIL U.AUFRISSnach EF.
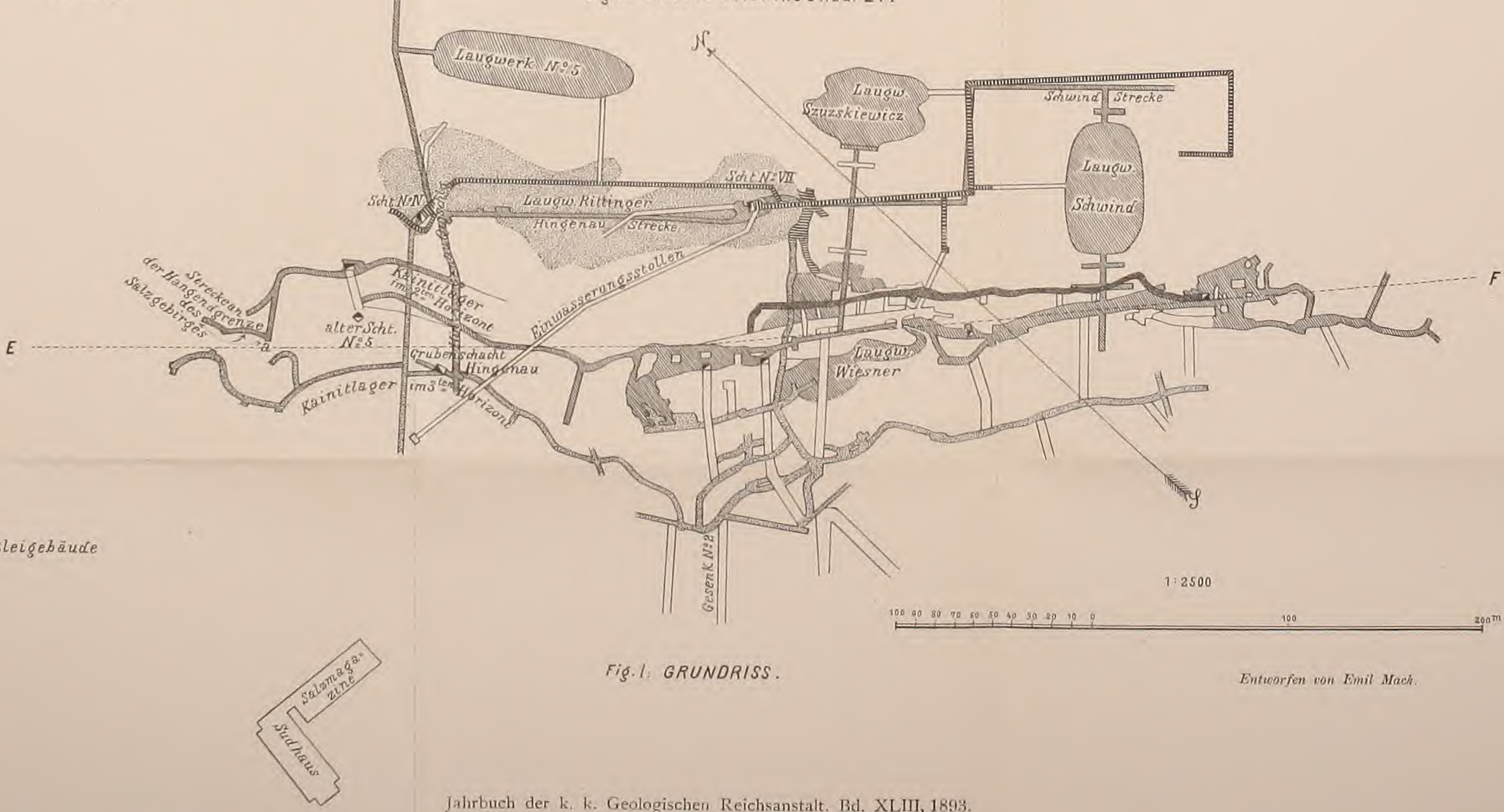

Fig.l: GRUNDRISS. 



\section{Tafel IV.}

Neue Koninckiniden des alpinen Lias. 


\section{Erklärung der Tafel IV.}

Fig. 1. Koninchina (Koninchodonta?) Eberhardi Bittu. Das bereits im Jahrh 1887, Tab. XIV, Fig. 1 abgehildete Exemplar, an welchem nachträglich dic Schlosspartien besser präparirt wurden. In natiirlicher Grösse und in drei Ansichten dopyelt vergrössert. Untersberg hei Salzburg.

Fig. 2. Koninclina (Konincliodonta?) Eberhardi Bittu. Ein Exemplar der breiteren Form vom Ischler Schafberg mit wohlerhaltonem Schlossfelde. In dreifacher Vergrösserung.

Fig. 3. Koninchina (Koninchodonta?) Pichleri nov. spec. In natïrlicher Grösse und in drei doppelt vergrösserten Ansichten. Sonnwendjoch.

Fig. 4. Koninclina (Koninchodonta) Fuggeri nov. spec. In natiulicher Grösse und in zwei doppelt vergrösserten Ansichten. Iscliler Schafberg.

Fig 5. Dieselbe Art. Ein Exemplar mit blossgelegten Armspiralen und Seitenrandverdickungen. In natürlicher und doppelter Grösse. Ischler Schafberg.

Fig. 6. Dieselbe Art. Von der kleinen (concaven) Klappe gesehen, um die Breite des Schlossrandes zu zeigen. In $1 \frac{1}{2}$ facher Vergrösserung. Ischler Schafberg.

Fig. 7. Dieselhe Art. Querschliff durch die Spiralkegel. Dreifach vergrössert. Ischler Schafberg.

Fig. 8. Dieselbe Art. Schliff parallel zur Symmetrieebene knapp neben derselben (Verdickungen des Schlossseitenrandes) und (nntere Figur) in der. Symmetrieebene sellost (Verdickung der Schale unter dem Wirbel der grossen Klappe). Zweifach vergrössert. Ischler Schafberg.

Fig. 9. Dieselbe Art. Fiinf Schliffe durch die Wirbelhälfte des Gehäuses, um die Randverdickungen zu zeigen. Zweifach vergössert. Ischler Schatberg.

Fig. 10. Koninctina (Konincliodonta) Geyeri nov. spec. Einziges bisher vorliegendes Stück dieser Art in natürlicher Grösse und zwei anfs Doppelte vergrösserte Ansichten. Ischler Schafborg.

Fig. 11. Koninckina Wähneri nov. spec. In drei verschiedenen Ansichten, aufs Dreifaclse vergrössert. Sonnwendjoch.

Fig. 12 Amphiclinodonta liasina Bittn. Ischler Schafherg.

Fig 13. Amphiclimodonta (?) adnethica nov. spec. Adneth.

Fig. 14. Koninckina Leopoldi Austriae Bittu. Schlossansicht anfs eineinhalbfache vergrössert. Mïh]thal hei Piesting.

Fig. 15. Koninchina Telleri var. dilatata Bittn. Dieselbe Ansicht eineinhalbfach vergrössert. Raibl.

Fig. 16. Amphiclina amoena Bittn Dieselbe Ansicht zweifach vergrössert. "Stuores" bei St. Cassian.

Die drei letztgenannten Abbildungen $(14,15,16)$ zum Vergleiche der Schlossgegend der verschiedenen Koninckinidentypen miteinander abgebildet und als Extreme der breiten und der schmalen Area. Yon den Auphiclinen wude absichtlich ein breitgeflïgelter Typus gewählt, 1 m den Contrast iı der Arealbreite auffallender zll machen.

Die Mehrzahl der abgebildeten Stiicke liegt in der Sammlıng der k. k. geol. Reichsanstalt, die Originale zu Fig. 3, 11, 15 befiuden sich im k. k. naturhist. Hofinuseum, das Original zu Fig. 16 gehört der palaeoutol. Staatssammlung zu München. 
A. Bittner: Neue Koninckiniden des alpinen Lias.

Taf.IV.
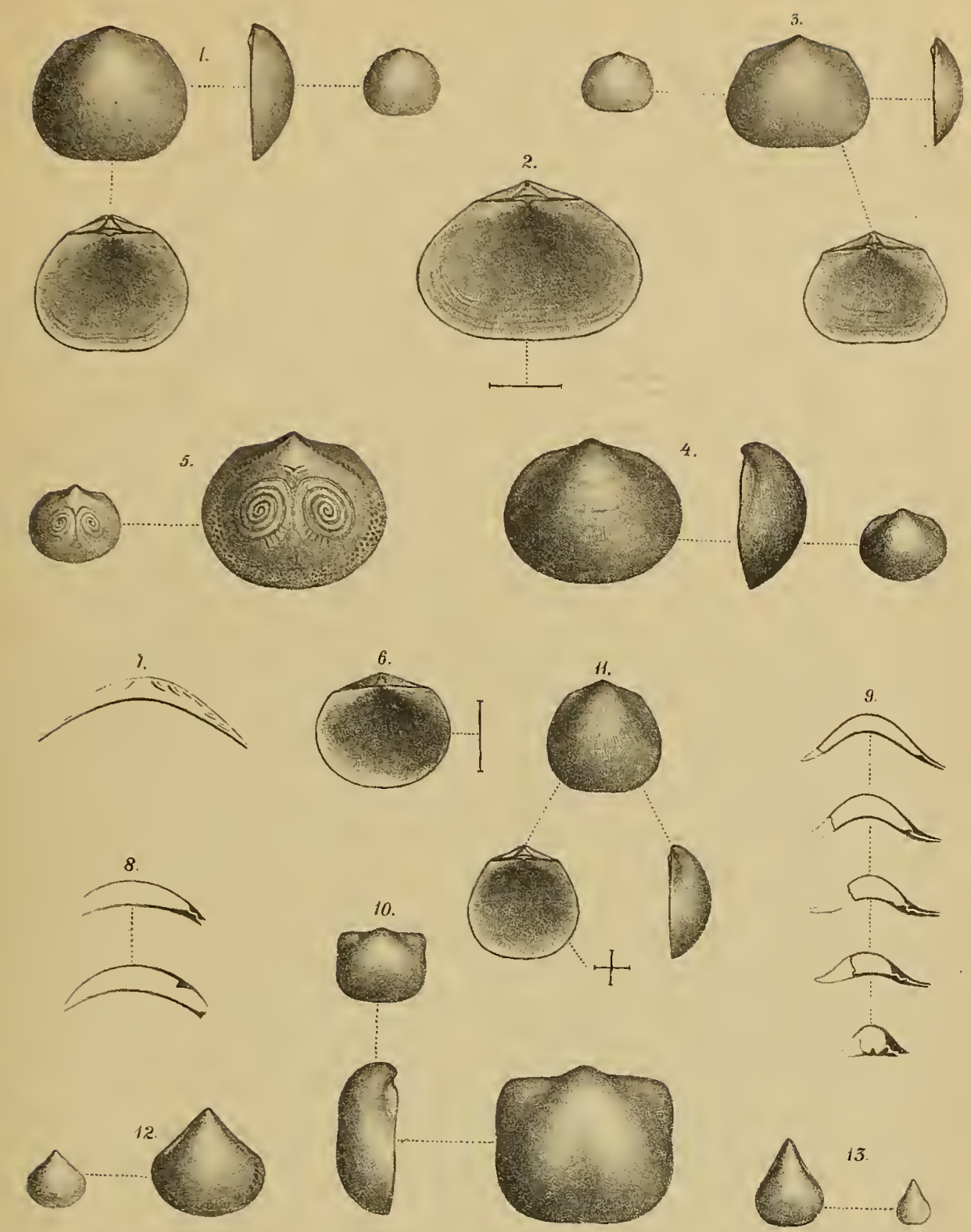

15.
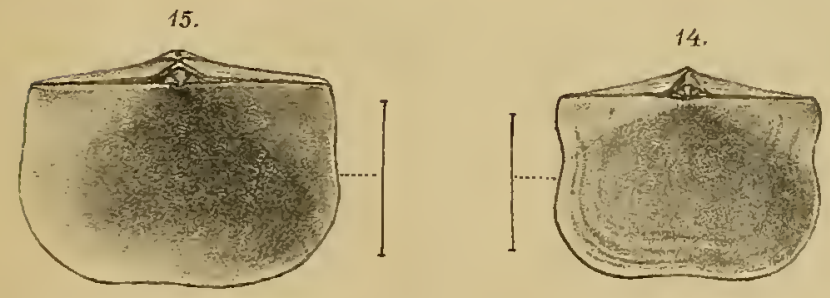

-1. Swobora m.d.Xat.gez.ı.lith.

Jahrbuch der k. k. Geologischen Reichsanstalt. Bd. XLIII.1893.

Verlag der k.k.Geologischen Reichsanstalt,Wien,Ill.Rasumoffskygasse 23. 



\section{Tafel V.}

Ueber die Entwicklung und Verbreitung der Partnachschichten in Vorarlberg und im Fürstenthum Liechtenstein. 


\section{Erklärung zu Tafel V.}

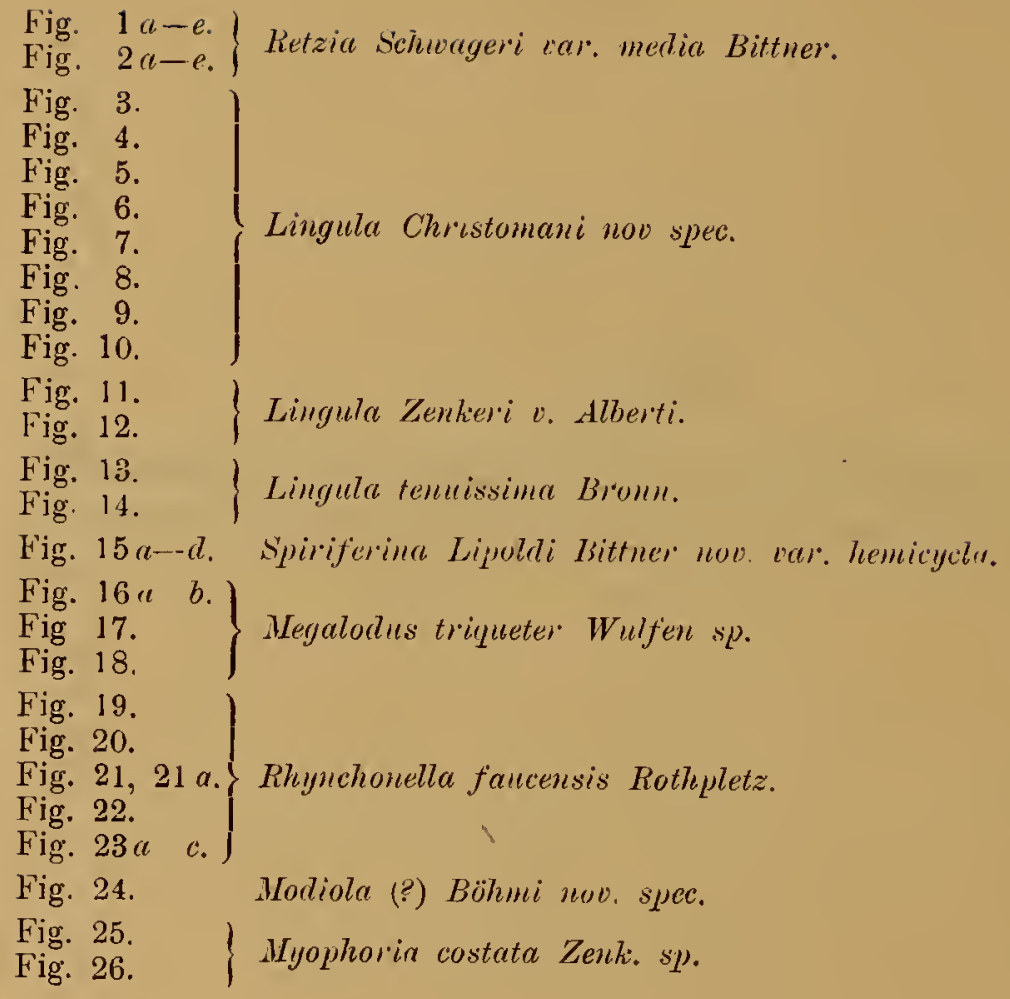




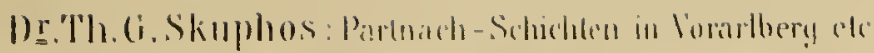

'Tili.
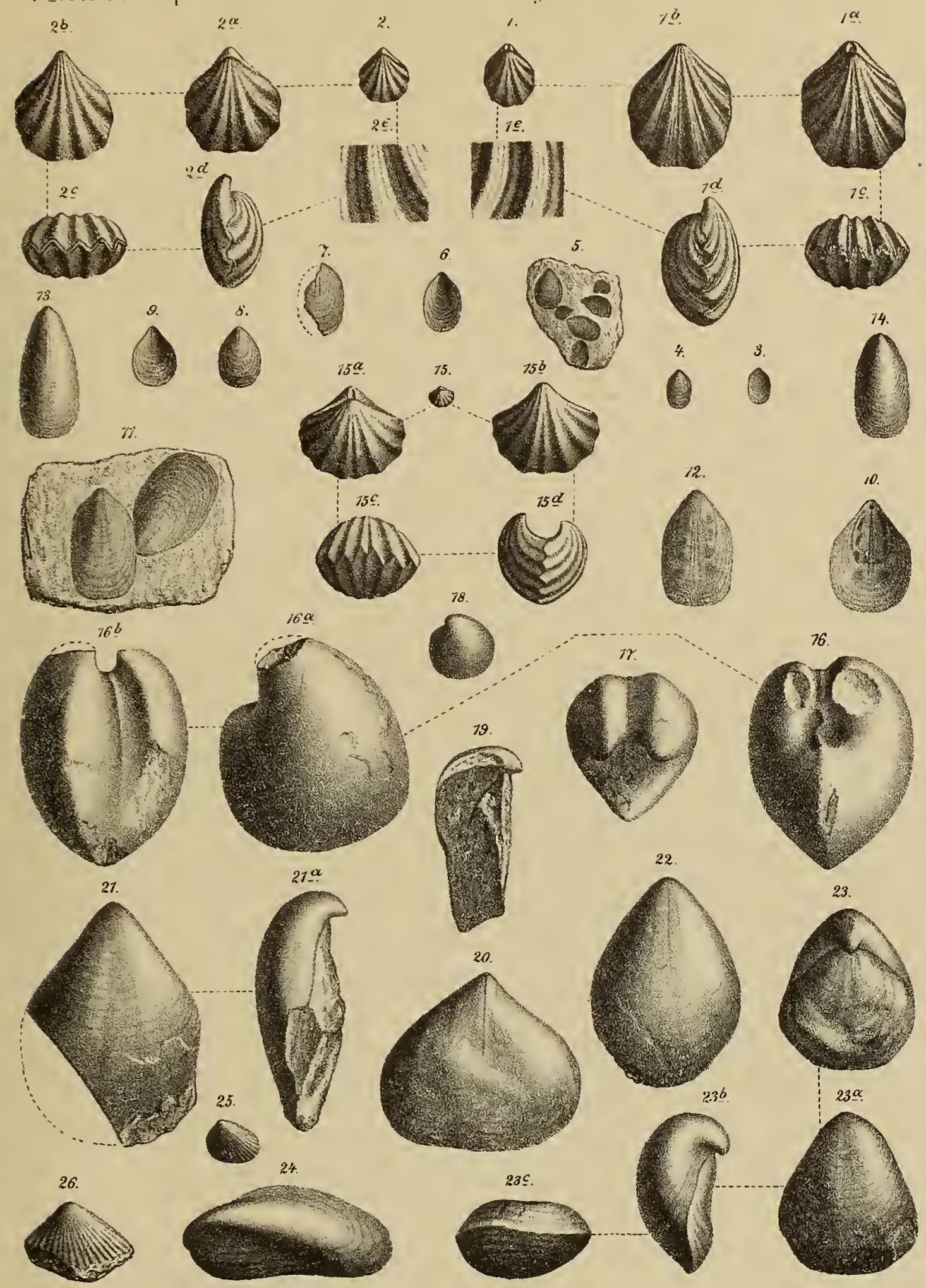

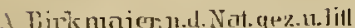

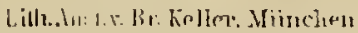

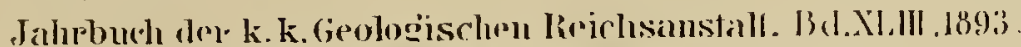

Verlag der k.k.Geologischen Reichsanslall,Wien, Ill.Rasumuffskygasse 23. 





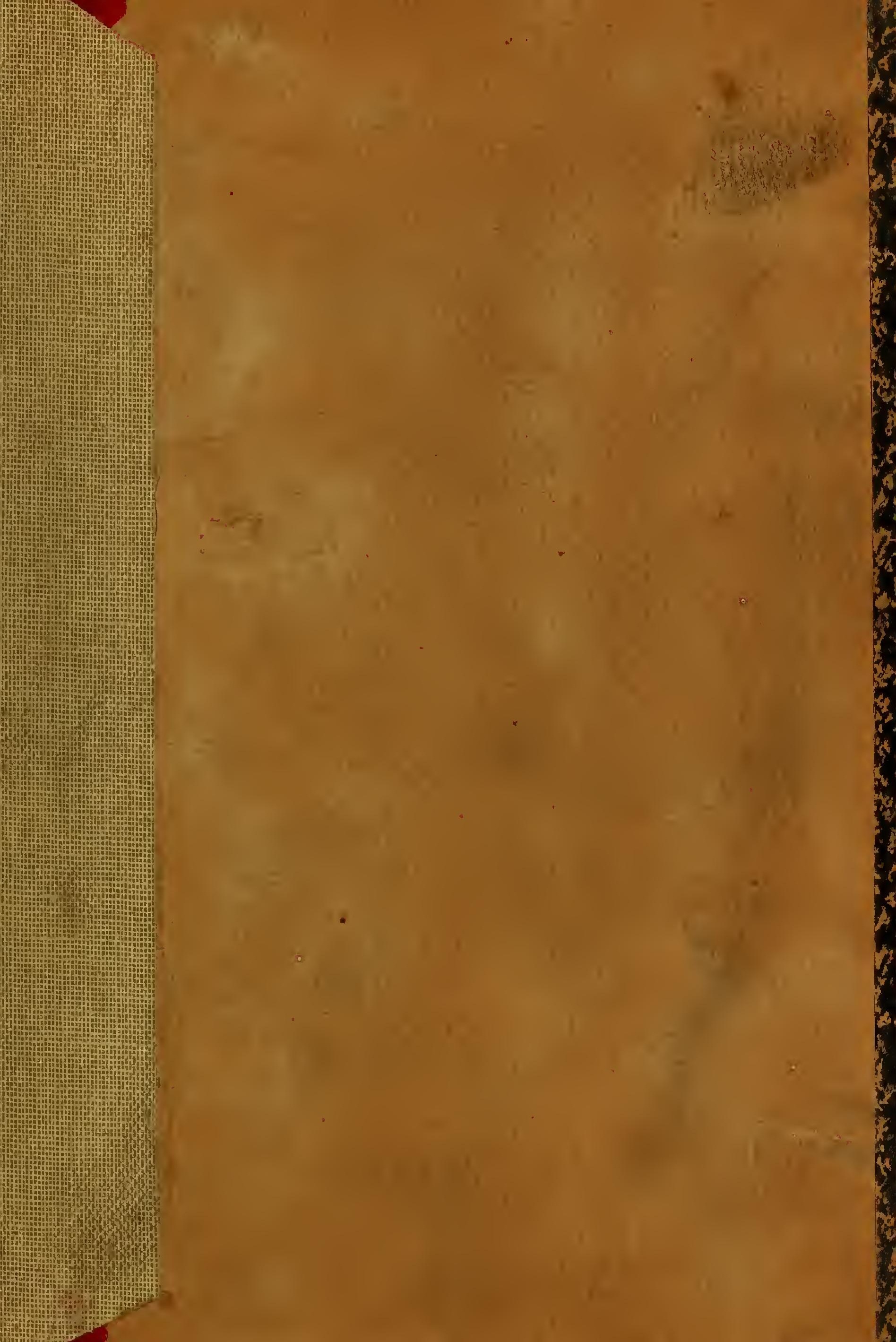


